\author{
Universidade de São Paulo \\ Instituto de Física
}

\title{
Dinâmica de Íons Temporários de Biomoléculas Halogenadas
}

\author{
Fábris Kossoski
}

\begin{abstract}
Orientador: Prof. Dr. Márcio Teixeira do Nascimento Varella
Tese de doutorado apresentada ao Instituto de Física para a obtenção do título de Doutor em Ciências
\end{abstract}

Banca examinadora:

Prof. Dr. Márcio Teixeira do Nascimento Varella (IFUSP)

Prof. Dr. Sylvio Roberto Accioly Canuto (IFUSP)

Prof. Dr. Luis Gregório Godoy de Vasconcellos Dias da Silva (IFUSP)

Prof. Dr. Antonio Carlos Borin (IQUSP)

Prof. Dr. Marco Aurélio Pinheiro Lima (UNICAMP)

São Paulo

2016 


\section{FICHA CATALOGRÁFICA \\ Preparada pelo Serviço de Biblioteca e Informação do Instituto de Física da Universidade de São Paulo}

Kossoski, Fábris

Dinâmica de íons temporários de biomoléculas halogenadas. São Paulo, 2016.

Tese (Doutorado) - Universidade de São Paulo. Instituto de Física. Depto. de Física Geral

Orientador: Prof. Dr. Márcio Teixeira do Nascimento Varella

Área de Concentração: Física Atômica e Molecular.

Unitermos: 1. Física molecular; 2. Física computacional

3. Espalhamento; 4. Compostos halogenados; 5. Radiação ionizante.

USP/IF/SBI-013/2016 


\section{Agradecimentos}

Devo sinceros agradecimentos para quem contribuiu em algum sentido ao longo desses quatro anos de doutorado.

- Agradeço à FAPESP, por fornecer o financiamento necessário para a realização desse trabalho.

- Ao CNPq, pela bolsa nos primeiros meses do doutorado.

- Ao HPC-USP e ao CENAPAD-SP, pelos recursos e suporte computacionais.

- À USP, ao Instituto de Física, e seus funcionários, por fornecer e manter toda a estrutura necessária.

- Agradeço à minha família, especialmente meus pais, João Carlos e Márcia, por sempre me apoiarem e incentivarem.

- À Dávila, pelo carinho, companhia e atenção.

- Aos amigos de São Paulo e de Curitiba, que sempre estiveram presentes.

- Às várias pessoas que passaram pelo Grupo de Física Molecular e Modelagem, pela amizade, discussões e aprendizagem.

- Ao Prof. Márcio Bettega, que me orientou nos tempos de iniciação e mestrado e permaneceu me acompanhando e aconselhando.

- E agradeço ao Prof. Márcio Varella, pelo aprendizado proporcionado, pela confiança em mim depositada, e por servir de inspiração para a carreira científica. 


\section{Resumo}

Apresentamos resultados para o espectro de ânions e para a dinâmica vibracional induzida pela captura eletrônica, para uma série de moléculas halogenadas. Os estados do ânion foram caracterizados por meio de cálculos de espalhamento elástico realizados na aproximação de núcleos fixos, efetuados com o método multicanal de Schwinger com pseudopotenciais. Cálculos de dinâmica quântica do pacote de onda nuclear foram realizados a partir da propagação desse nas superfícies de energia potencial descritas na aproximação local. Foram alvo de estudo clorometano, cloroeteno, uracila, 5-fluorouracila, 5-clorouracila, 5-bromouracila, 5-iodouracila, 6-clorouracila, 2-tiouracila, adenina, 2-cloroadenina e 8-cloroadenina. Para o clorometano, calculamos seções de choque de excitação vibracional do estiramento $\mathrm{C}-\mathrm{Cl}$, e mostramos que esse modo é prontamente ativado pela presença da carga adicional. Para o cloroeteno, demonstramos que o mecanismo direto de dissociação é muito ineficiente, e também revelamos a interessante topologia de suas superfícies de energia potencial complexas. Os derivados de uracila apresentaram ricos espectros aniônicos, contando com três estados delocalizados $\pi^{*}$, um estado $\sigma^{*}$ localizado na ligação do átomo substituído com o anel, além de um estado ligado por dipolo. No geral, as energias obtidas estão em ótimo acordo com os valores experimentais. Análises dos espectros aniônicos e das superfícies de energia potencial indicam mecanismos em que o ânion é formado numa ressonância $\pi^{*}$ de longo tempo de vida, que muda de caráter para o estado dissociativo $\sigma^{*}$. Na 5-clorouracila em particular, esse acoplamento é mediado pelo movimento do cloro para fora do plano molecular. Conforme os estados do ânion progressivamente estabilizam com o aumento do número atômico do halogênio, os acoplamentos tornam-se mais favoráveis, o que responde pelas crescentes seções de choque de dissociação. Nossos resultados explicam muitas das características observadas na captura eletrônica dissociativa de halouracilas, fornecendo uma base teórica para sua habilidade radiossensibilizadora. Nas cloroadeninas, encontramos uma ressonância $\sigma^{*}$ e quatro ressonâncias $\pi^{*}$. Nós sustentamos que elas também poderiam atuar como potenciais radiossensibilizadores. 


\begin{abstract}
We present results on the anion spectrum and on the vibrational dynamics induced by electron capture, for a series of halogenated molecules. The anion states were characterized by means of elastic scattering calculations, in the fixed nuclei approximation, performed with the Schwinger multichannel method with pseudopotentials. Quantum dynamics calculations of the nuclear wavepacket were performed by the propagation on potential energy surfaces described in the local approximation. The target molecules comprise chloromethane, chloroethene, uracil, 5-fluorouracil, 5-chlorouracil, 5-bromouracil, 5-iodouracil, 6-chlorouracil, 2-thiouracil, adenine, 2-chloroadenine and 8-chloroadenine. For chloromethane we computed vibrational excitation cross sections for the $\mathrm{C}-\mathrm{Cl}$ stretching, and showed this mode is promptly activated by the presence of the extra charge. For chloroethene, we demonstrated that the direct mechanism of dissociation is very inefficient, and also revealed the interesting topology of its complex potential energy surfaces. The derivatives of uracil presented rich anionic spectra, as each one has three $\pi^{*}$ delocalized states, a $\sigma^{*}$ state located at the bond between the substituted atom and the ring, and a dipole bound state. Overall, the obtained energetics are in very good agreement with experimental data. Analysis of the anionic spectra and the potential energy surfaces indicate mechanisms in which the anion is formed in a long-lived $\pi^{*}$ resonance and changes its character to the dissociative $\sigma^{*}$ state. For 5 -chlorouracil in particular, this coupling is mediated by an out-of-plane movement of the chlorine atom. As the anion states progressively stabilize as the halogen atomic number increases, the couplings become more favorable, and account for the increasing dissociation cross sections. Our results explain many of the observed features of dissociative electron attachment to halouracils, providing a theoretical basis for its radiosensitizing ability. In chloroadenines, we found a $\sigma^{*}$ resonance and four $\pi^{*}$ resonances. We support they could also act as potential radiosensitizers.
\end{abstract}




\section{Sumário}

Lista de Figuras $\quad$ viii

Lista de Tabelas $\quad$ xiv

1 Introdução 1

1.1 Interação elétron-molécula . . . . . . . . . . . . . . . . . . . . . . 1

1.2 Estados do ânion . . . . . . . . . . . . . . . . . . . . . . 3

1.3 Captura eletrônica dissociativa . . . . . . . . . . . . . . . . 8

1.4 Relevância biológica . . . . . . . . . . . . . . . . . . . . . . 11

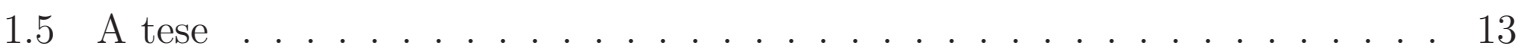

2 Descrição teórica $\quad 16$

2.1 Descrição do espalhamento . . . . . . . . . . . . . . . . . . . . 17

2.1.1 Considerações gerais . . . . . . . . . . . . . . . . . 17 
2.1 .2 O método multicanal de Schwinger . . . . . . . . . . . . . 19

2.1.3 Aspectos numéricos . . . . . . . . . . . . . . . . . . . . 24

2.1.4 Aproximações Estático-Troca e Estático-Troca mais Polarização . . 25

2.1.5 Pseudopotenciais . . . . . . . . . . . . . . . 28

2.1.6 Cálculo das seções de choque . . . . . . . . . . . . . . . . . . . . 29

2.2 Descrição da dinâmica nuclear . . . . . . . . . . . . . . . . . . . . . 32

2.2.1 Formalismo dos operadores de projeção de Feshbach . . . . . . . . . 32

2.2 .2 Aproximação local . . . . . . . . . . . . . . . . . . . 35

2.2 .3 Propagação do pacote de onda . . . . . . . . . . . . . . . 38

3 Pequenas moléculas halogenadas 40

3.1 Introdução . . . . . . . . . . . . . . . . . . . . 40

3.2 Procedimentos computacionais . . . . . . . . . . . . . . . . . 42

3.3 Clorometano . . . . . . . . . . . . . . . . . . . . . . . . 44

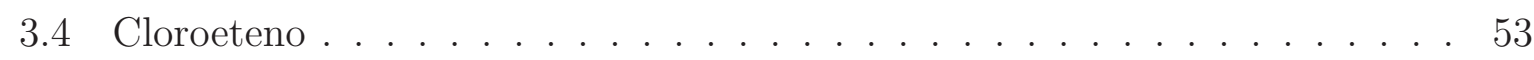

$\begin{array}{lll}4 & \text { Derivados de uracila } & 68\end{array}$

4.1 Introdução . . . . . . . . . . . . . . . . . . . . . 68

4.2 Procedimentos computacionais . . . . . . . . . . . . . 71 
4.3 Uracila . . . . . . . . . . . . . . . . . . . 76

$4.4 \quad 5$-Fluorouracila . . . . . . . . . . . . . . . . . . . . 78

4.5 5-Clorouracila . . . . . . . . . . . . . . . . . . 80

4.6 5-bromouracila . . . . . . . . . . . . . . . . . . . . . . 89

4.7 5-iodouracila . . . . . . . . . . . . . . . . . . . . 97

4.8 6-clorouracila . . . . . . . . . . . . . . . . . . . . . . . . . . . . . 99

4.9 2-tiouracila . . . . . . . . . . . . . . . . . . . . . . 101

4.10 Comparação entre uracila e derivados . . . . . . . . . . . . . . . 106

\section{Cloroadeninas}

5.1 Introdução . . . . . . . . . . . . . . . . . . . . . . . . . 124

5.2 Procedimentos computacionais . . . . . . . . . . . . . 126

5.3 Adenina . . . . . . . . . . . . . . . . . . . . 127

5.4 2-cloroadenina . . . . . . . . . . . . . . . . . . 130

5.58 -cloroadenina . . . . . . . . . . . . . . . . . . 137

5.6 Comparação entre adenina e derivados . . . . . . . . . . . . . . . . . . . . 139

6 Conclusões 143 


\section{Lista de Figuras}

1.1 Esquema representando os tipos de ressonâncias . . . . . . . . . . . . . 5

1.2 Potencial efetivo gerado pela combinação de um potencial tipo caixa de profundidade $U_{0}$ mais a barreira de momento angular para a onda parcial $l \quad 6$

1.3 Curvas de energia potencial esquemáticas para o estado fundamental da molécula neutra e dos estados do ânion $\pi^{*}$ e $\sigma^{*} \ldots$. . . . . . . . . . . . 9

3.1 Estrutura geométrica do clorometano e do cloroeteno . . . . . . . . . . . . 41

3.2 Seção de choque integral das simetrias $A^{\prime}$ e $A^{\prime \prime}$ do clorometano, calculadas nas aproximações SE e SEP . . . . . . . . . . . . . . . . . . . . 45

3.3 Orbital $\sigma_{\mathrm{CCl}}^{*}$ do clorometano ..................... 46

3.4 Seção de choque integral calculada para o clorometano, com e sem a correção de Born, juntamente com os valores experimentais de seção de choque total 47

3.5 Seção de choque integral e soma da autofase da simetria $A^{\prime}$ do clorometano, calculadas para a distância $\mathrm{C}-\mathrm{Cl}$ de equilíbrio e fora do equilíbrio . . . . . 49

3.6 Curvas de energia potencial do clorometano, em função do comprimento

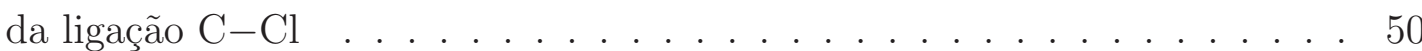


3.7 Curvas de energia potencial do clorometano, em função do comprimento da ligação $\mathrm{C}-\mathrm{Cl}$, obtidas do modelo, e pacote de onda do nível vibracional fundamental da molécula neutra . . . . . . . . . . . . . . . . . 51

3.8 Seções de choque de excitação vibracional do estiramento C-Cl do clorometano, obtidas para os níveis vibracionais excitados $\nu=1,2,3$, juntamente com valores experimentais para o nível $\nu=1 \ldots$. . . . . . . . . . 52

3.9 Seção de choque integral das simetrias $A^{\prime}$ e $A^{\prime \prime}$ do cloroeteno, calculadas nas aproximações SE e SEP . . . . . . . . . . . . . . . . . . 54

3.10 Orbitais $\pi^{*}$ e $\sigma_{\mathrm{CCl}}^{*}$ do cloroeteno . . . . . . . . . . . . . 55

3.11 Curvas de energia potencial para o cloroeteno, em função da distância $\mathrm{C}-\mathrm{Cl} 56$

3.12 Curvas de energia potencial da parte imaginária dos estados do ânion do cloroeteno, em função da distância $\mathrm{C}-\mathrm{Cl}$. . . . . . . . . . . . . . 57

3.13 Seção de choque de dissociação do cloroeteno, a partir do nível vibracional $\nu=0$ e tomando uma média sobre populações a $450 K \ldots$. . . . . . . 58

3.14 Superfícies de energia potencial da componente real dos dois estados do ânion de cloroeteno, em função da distância $\mathrm{C}-\mathrm{Cl} r$ e do ângulo $\theta$. . . . . 60

3.15 Superfícies de energia potencial da componente imaginária dos dois estados do ânion de cloroeteno, em função da distância $\mathrm{C}-\mathrm{Cl} r$ e do ângulo $\theta$. . . 61

3.16 Superfícies de energia potenciais $V_{R}^{a}$ e $V_{I}^{a}$ do cloroeteno, focando na região da interseção cônica . . . . . . . . . . . . . . . . . . . . . . 65 
3.17 Superfícies de energia potencial $V_{R}^{a}, V_{I}^{a}, V_{R}^{d}, V_{I}^{d}, V_{12 R}^{d}$ e $V_{12 I}^{d}$ dos dois estados do ânion de cloroeteno, em função das coordenadas $r$ e $\theta$, conforme obtidas do modelo . . . . . . . . . . . . . . . . . . . . 67

4.1 Estrutura geométrica da timina, uracila, 2-tiouracila, 5-fluorouracila, 5clorouracila, 6-clorouracila, 5-bromouracila e 5-iodouracila . . . . . . . . . 69

4.2 Seção de choque integral das simetrias $A^{\prime}$ e $A^{\prime \prime}$ da uracila, calculadas nas aproximações SE e SEP . . . . . . . . . . . . . . . . . . . 77

4.3 Orbitais $\pi^{*}$ da uracila . . . . . . . . . . . . . . . . . . 77

4.4 Seção de choque integral das simetrias $A^{\prime}$ e $A^{\prime \prime}$ da 5-fluorouracila, calculadas nas aproximações SE e SEP . . . . . . . . . . . . . . . . . . . . . . . 79

4.5 Seção de choque integral das simetrias $A^{\prime}$ e $A^{\prime \prime}$ da 5-clorouracila, calculadas nas aproximações SE e SEP . . . . . . . . . . . . . . . . . . . . . 81

4.6 Curvas de energia potencial para a 5-clorouracila, em função do desvio da posição de equilíbrio $\Delta r \ldots \ldots \ldots$. . . . . . . . . . . . 82

4.7 Seção de choque de dissociação da 5-clorouracila, a partir do nível vibracional $\nu=0$ e tomando uma média sobre populações a $450 K \ldots$. . . . . . 84

4.8 Curvas de energia potencial para a 5-clorouracila, em função do deslocamento cartesiano perpendicular ao plano molecular, para cada átomo . . .

$4.9 \mathrm{LUMO}+1, \mathrm{LUMO}+2$ e LUMO +3 da 5-clorouracila, na geometria de equilíbrio e para deslocamentos cartesianos do cloro na direção perpendicular ao plano

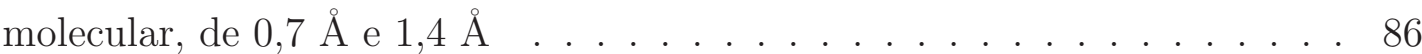


4.10 Superfícies de energia potencial dos três estados do ânion da 5-clorouracila, em função dos deslocamentos radial $\Delta r$ e angular $\theta \ldots$. . . . . . . . 88

4.11 Seção de choque integral das simetrias $A^{\prime}$ e $A^{\prime \prime}$ da 5-bromouracila, calculadas nas aproximações SE e SEP . . . . . . . . . . . . . . . . . . . . 90

4.12 Seção de choque integral da simetria $A^{\prime}$ da 5-bromouracila, calculada na aproximação SE, e de acordo com cálculos SEP progressivamente mais sofisticados. Posição e largura da ressonância $\sigma_{\mathrm{CBr}}^{*}$ de acordo com os cálculos realizados em diferentes níveis de polarização, como função da dimensão do espaço de configurações . . . . . . . . . . . . . . . . . . . . . . . . . 91

4.13 Curvas de energia potencial para a 5-bromouracila, em função do desvio da posição de equilíbrio $\Delta r \ldots \ldots \ldots$. . . . . . . . . . . 93

4.14 Seção de choque de dissociação da 5-bromouracila, a partir do nível vibracional $\nu=0$ e tomando uma média sobre populações a $450 K \ldots$. . . . . 94

4.15 Superfícies de energia potencial dos três estados do ânion da 5-bromouracila, em função dos deslocamentos radial $\Delta r$ e angular $\theta$. . . . . . . . . . . . 96

4.16 Seção de choque integral das simetrias $A^{\prime}$ e $A^{\prime \prime}$ da 5-iodouracila, calculadas nas aproximações SE e SEP . . . . . . . . . . . . . . . . . . . . 98

4.17 Curvas de energia potencial para a 5-iodouracila, em função do desvio da posição de equilíbrio $\Delta r \ldots \ldots \ldots$. . . . . . . . . . . 99

4.18 Seção de choque integral das simetrias $A^{\prime}$ e $A^{\prime \prime}$ da 6-clorouracila, calculadas nas aproximações SE e SEP . . . . . . . . . . . . . . . . . . . . 100

4.19 Seção de choque integral das simetrias $A^{\prime}$ e $A^{\prime \prime}$ da 2-tiouracila, calculadas nas aproximações SE e SEP . . . . . . . . . . . . . . . . . . . . 102 
4.20 Estrutura da 2-tiouracila, os orbitais virtuais $\pi^{*}$ e $\sigma_{\mathrm{CS}}^{*}$, e o orbital unicamente ocupado do estado ligado por dipolo . . . . . . . . . . . . . . . . 103

4.21 Curvas de eficiência para captura eletrônica dissociativa da 2-tiouracila . 105

4.22 Posições dos estados do ânion da série de derivados de uracila, de acordo com os cálculos de espalhamento e segundo as medidas de Scheer et al. . . 108

4.23 Estrutura da 5-bromouracila, orbitais virtuais $\pi^{*}, \sigma_{\mathrm{NH}}^{*}$ e $\sigma_{\mathrm{CBr}}^{*}$, e o SOMO do estado ligado por dipolo . . . . . . . . . . . . . . . . . . 109

4.24 Orbitais $\sigma^{*}$ da 5-fluorouracila, 5-clorouracila, 5-bromouracila e 6-clorouracila111

4.25 Curvas de energia potencial para o estado ligado por dipolo e para o estado $\sigma_{\mathrm{NH}}^{*}$ da série de 5-halouracilas, obtidas ao longo da coordenada de estiramento $\mathrm{N}-\mathrm{H} \ldots \ldots \ldots \ldots 116$

4.26 Curvas de energia potencial para o ânion adiabático das quatro 5-halouracilas, em função da distância C-X . . . . . . . . . . . . . . . . . . . . . . . . . 119

4.27 Estruturas da 5-fluorouracila e 5-clorouracila referentes à curva do ânion adiabático, em distintos comprimentos da ligação C-X . . . . . . . . . . . 121

4.28 Curvas de energia potencial para o ânion adiabático de 6-clorouracila, em função da distância $\mathrm{C}-\mathrm{Cl}$. . . . . . . . . . . . . . . . . . . . . 123

5.1 Estrutura geométrica da adenina, 2-cloroadenina, 8-cloroadenina . . . . . 125

5.2 Seção de choque integral das simetrias $A^{\prime}$ e $A^{\prime \prime}$ da adenina, calculadas nas aproximações SE e SEP . . . . . . . . . . . . . . . . . . . . . 128 
5.3 Seção de choque integral das simetrias $A^{\prime}$ e $A^{\prime \prime}$ da 2-cloroadenina, calculadas nas aproximações SE e SEP . . . . . . . . . . . . . . . . . . . . 131

5.4 Curvas de eficiência para captura eletrônica dissociativa da 2-cloroadenina 133

5.5 Seção de choque integral das simetrias $A^{\prime}$ e $A^{\prime \prime}$ da 8-cloroadenina, calculadas nas aproximações SE e SEP . . . . . . . . . . . . . . . . . . . . . . 138

5.6 Orbitais $\pi^{*}$ da adenina, 2-cloroadenina e 8-cloroadenina . . . . . . . . . . 140

5.7 Orbitais $\sigma^{*}$ de mais baixa energia da 2-cloroadenina e 8-cloroadenina . . . 142 


\section{Lista de Tabelas}

3.1 Exponentes das funções gaussianas-cartesianas do carbono e do cloro . . . 43

3.2 Parâmetros do modelo para as superfícies de energia potencial do cloroeteno 64

4.1 Exponentes das funções gaussianas-cartesianas dos átomos de carbono, nitrogênio, oxigênio e enxofre . . . . . . . . . . . . . . 73

4.2 Exponentes das funções gaussianas-cartesianas dos átomos de flúor, cloro, bromo e iodo . . . . . . . . . . . . . . . . . . . 74

4.3 Posições e larguras dos estados $\pi^{*}$ da uracila . . . . . . . . . . . . . . 78

4.4 Posições e larguras dos estados $\pi^{*}$ e $\sigma_{\mathrm{CX}}^{*}$ da 5-fluorouracila, 5-clorouracila, 5-bromouracila, 5-iodouracila e 6-clorouracila . . . . . . . . . . . 107

4.5 Energias necessárias para a eliminação de $\mathrm{H}, \mathrm{X}^{-}, \mathrm{X}$ e HX, para uracila, 5-fluorouracila, 5-clorouracila, 5-bromouracila e 6-clorouracila . . . . . . . . 114

5.1 Energias necessárias para a eliminação de $\mathrm{H}, \mathrm{Cl}^{-}$e $\mathrm{HCl}$, para 2-cloroadenina, 8-cloroadenina e adenina . . . . . . . . . . . . . . . . . . 134

5.2 Posições dos estados $\pi^{*}$ e $\sigma_{\mathrm{CCl}}^{*}$ da adenina, 2-cloroadenina e 8-cloroadenina 141 


\section{Capítulo 1}

\section{Introdução}

\subsection{Interação elétron-molécula}

A colisão entre um elétron e uma molécula consiste num problema fundamental em física molecular. A interação se dá em diversos ambientes, e compõe um processo de grande relevância nas áreas tecnológica, biológica e de energia. A dinâmica do espalhamento é governada pela energia cinética do elétron incidente e tendo em vista os diferentes processos que podem ocorrer e a natureza da interação entre projétil e alvo, é interessante definir diferentes regimes de energia, embora não exista uma classificação rigorosa. Cada faixa de energia exige diferentes abordagens teóricas e experimentais. Nesse trabalho estamos interessados na região de baixas energias, particularmente entre $0 \mathrm{eV}$ até cerca de $5 \mathrm{eV}$.

A quantidade física central num processo de espalhamento é a seção de choque, definida como a razão entre o fluxo de partículas espalhadas e a densidade de fluxo de partículas incidentes. A grandeza representa uma medida de proporcionalidade entre o número de partículas incidentes e espalhadas, sendo interpretada como uma probabilidade efetiva de que projétil e alvo interajam. A seção de choque pode ser visualizada 
ainda como uma área efetiva do alvo, de modo que apenas o projétil que por ali passar sentirá a ação de seu potencial. Denomina-se canal a configuração do sistema na região assintótica, quando projétil e alvo não mais interagem. Um canal é dito aberto se ele for energeticamente permitido, e fechado caso contrário, de modo que para energias mais elevadas, um maior número de canais se encontra aberto. O espalhamento elástico ocorre quando o elétron não transfere energia para os graus de liberdade internos da molécula, sendo um canal sempre aberto. Quando há transferência de energia, o espalhamento é dito inelástico, podendo haver a excitação rotacional, vibracional ou eletrônica, bem como ionização. Além dos processos de excitação de graus de liberdade internos da molécula, o elétron incidente também pode induzir dissociações. O processo é denominado captura eletrônica dissociativa, e ocorre a partir da formação de um íon transiente, ou ressonância, que desencadeia uma dinâmica nuclear que pode levar à quebra da ligação. A formação da ressonância e o processo dissociativo são discutidos em detalhes nas duas seções seguintes.

Do ponto de vista de aplicações, a principal motivação no estudo da interação elétron-molécula está relacionado ao uso industrial de plasmas de processamento no tratamento de materiais [1-4]. Também denominado plasma frio, ele consiste num gás parcialmente ionizado, fora do equilíbrio termodinâmico, em que os elétrons estão quentes e as espécies pesadas, como moléculas e íons, estão frias. Os elétrons livres interagem com as moléculas neutras e dão origem a íons e radicais, que por sua vez irão atuar sobre a superfície a ser tratada. Diferentes configurações e composições do plasma frio dão origem há uma série de aplicações distintas, onde podemos citar técnicas de corrosão controlada, recobrimento de superfícies, deposição de filmes poliméricos, descontaminação de materiais e nitretação de superfícies. Tais processos possuem aplicação na fabricação de dispositivos semicondutores e circuitos integrados, e na indústria microeletrônica de modo geral. A fim de modelar o comportamento desses plasmas, são necessárias informações sobre os vários processos que ali ocorrem, e a etapa que dá origem às espécies reativas é exatamente a colisão entre um elétron e uma molécula. Portanto, o conhecimento de seções de choque elásticas, inelásticas e de dissociação são fundamentais para a descrição desses plasmas. 
O uso de plasmas de processamento pode ter potencial aplicação na geração de etanol e biogás, sendo empregados no pré-tratamento da biomassa [5]. A ideia consiste em atacar as camadas externas de hemicelulose e lignina da biomassa, expondo as fibras de celulose internas [6]. Como são essas fibras que sofrem a ação convencional da hidrólise, um pré-tratamento eficiente deve gerar um melhor aproveitamento energético no uso da biomassa. Em propostas que se baseiam no uso de plasmas de processamento, a ação de elétrons de baixa energia pode ter um papel importante na quebra molecular. Também em técnicas de irradiação por raios gama ou feixes de elétrons de alta energia [6], as sucessivas ionizações dão origem a elétrons de baixa energia, que podem então atacar o material. Essa potencial aplicação tem motivado o estudo da colisão de elétron com subunidades do material lignocelulósico [7-9].

Até a virada do século, a grande motivação estava relacionada ao uso de plasmas de processamento. A partir do ano 2000, com a descoberta de que elétrons de baixa energia são muito eficazes em danificar o DNA [10], o foco principal passa das moléculas de apelo tecnológico para as biomoléculas. Antes de discutir a relevância biológica da interação elétron-molécula, vamos apresentar dois processos fundamentais que ocorrem no espalhamento em baixa energia: a formação de estados ressonantes e a captura eletrônica dissociativa.

\subsection{Estados do ânion}

Uma ressonância é um estado metaestável do composto projétil+alvo, sendo quase-ligado e portanto com tempo de vida finito. Um estado ressonante é caracterizado por um energia complexa $E=\epsilon-i \Gamma / 2$, onde a parte real $\epsilon$ é chamada de energia da ressonância, enquanto o termo $\Gamma$ denota sua largura. Essa está associada ao seu tempo de vida finito $\tau$ através da relação $\Gamma \tau=\hbar$.

No espalhamento de um elétron por uma molécula, a ressonância é entendida 
como a formação de um ânion transiente, com energia superior àquela da molécula isolada. Nessa situação, o elétron incidente passa a ocupar um orbital molecular virtual, chamado então de orbital ressonante. Desse modo, a captura eletrônica no orbital molecular desocupado de mais baixa energia (LUMO, do inglês lowest unoccupied molecular orbital) dá origem a uma ressonância. Se a energia do elétron incidente for mais elevada, o aprisionamento pode se dar num orbital de mais alta energia, dando origem a um segundo estado ressonante, e assim por diante.

As ressonâncias podem ser classificadas como sendo de uma partícula, ou de muitas partículas. Na ressonância de uma partícula, o elétron é aprisionado pela molécula neutra em seu estado eletrônico fundamental, que é o estado-pai dessa ressonância. Se o aprisionamento do elétron incidente acompanha uma excitação eletrônica, a ressonância é de muitas partículas, e o estado-pai é o estado excitado da molécula neutra. Outra maneira de classificar os estados do ânion consiste em comparar sua energia com aquela de seu estado-pai. Se a ressonância estiver energeticamente acima do estado-pai, temos uma ressonância de forma. Caso o ânion for mais estável, a ressonância é do tipo Feshbach. A partir dos dois critérios, há quatro categorias em que os estados do ânion se enquadram, e a figura 1.1 ilustra o perfil energético de cada uma.

Em mais baixas energias, podemos ter uma ressonância de Feshbach de núcleo excitado, ou ressonância de Feshbach vibracional. Nesse caso, o estado eletrônico do ânion é ligado, estando abaixo da energia da molécula neutra. Mas como o elétron incide com energia cinética positiva, a ressonância é formada em um nível vibracionalmente excitado do estado ligado do ânion. Subindo em energia temos o processo de captura de uma partícula num estado acima do estado neutro fundamental, que gera uma ressonância de forma de uma partícula, ou simplesmente ressonância de forma. Para energias mais altas, processos de duas partículas passam a ocorrer. Se a captura do elétron estabiliza o estado excitado da espécie neutra, há uma ressonância de Feshbach de caroço-excitado, ou simplesmente ressonância de Feshbach. E caso o ânion seja mais energético que o estadopai, temos a ressonância de forma de caroço-excitado, ou simplesmente ressonância de caroço-excitado. Na maior parte das situações, o estado ressonante do ânion é descrito 


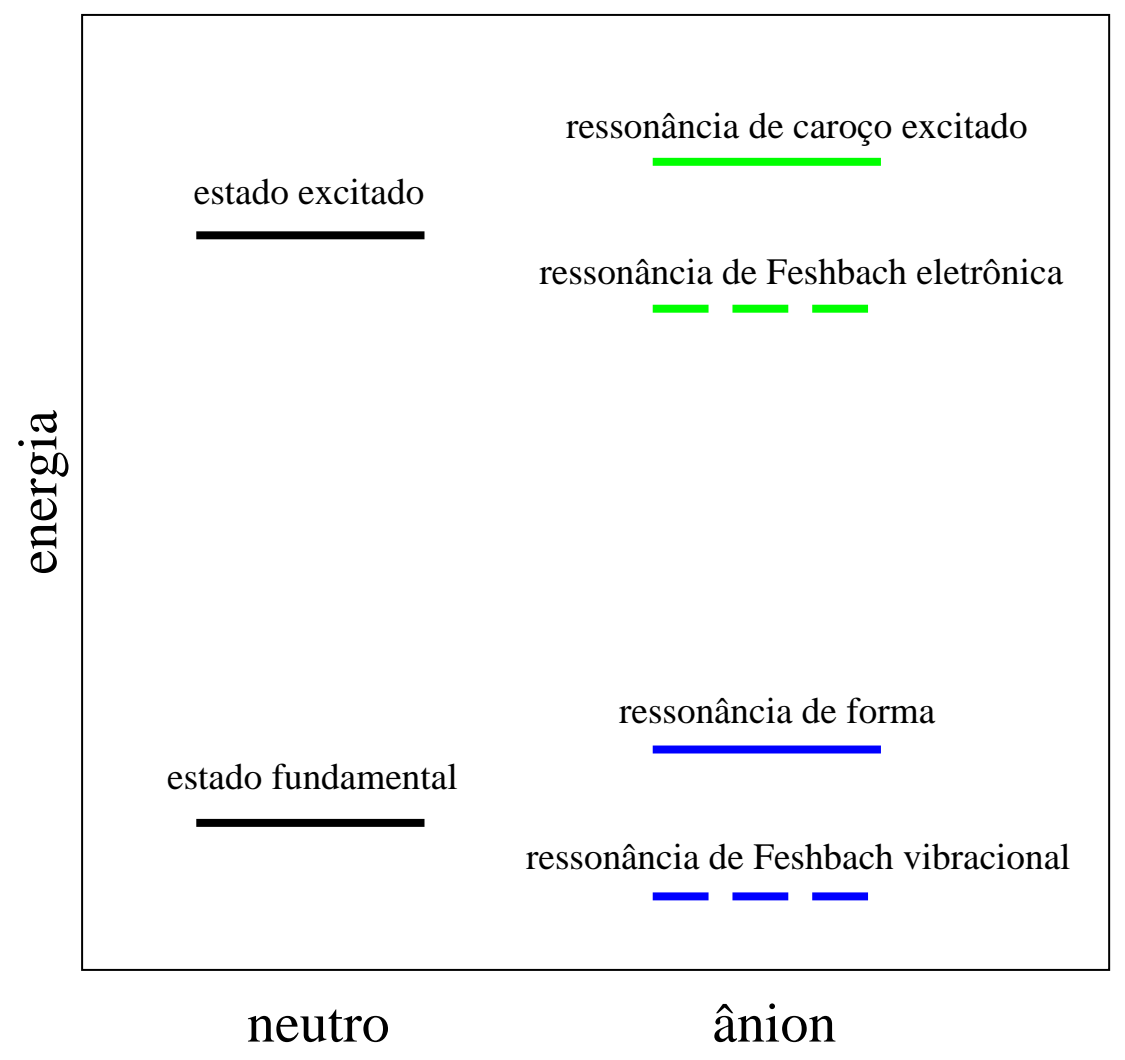

Figura 1.1: Esquema representando os tipos de ressonâncias. À esquerda, estado eletrônico fundamental do neutro e um estado excitado. À direita estão os quatro tipos de estados do ânion, dependendo se o processo for de uma (em azul) ou de duas (em verde) partículas, e se o estado estiver acima (linha cheia) ou abaixo (linha tracejada) do estado pai.

relativamente bem por apenas uma configuração eletrônica, podendo ser caracterizado como um dos tipos de ressonância. Se, no entanto, processos de uma e de duas partículas forem significativos para o caráter da ressonância, essa assume um perfil misto, com características de ressonância de forma e também de caroço excitado.

Uma ressonância de forma apresenta esse nome porque é a forma do potencial que permite a existência de um estado ressonante. O processo pode ser compreendido no contexto do espalhamento por um potencial, sendo válido para qualquer combinação de projétil e alvo. A figura 1.2 ilustra um potencial efetivo para o projétil, sendo dado por um potencial atrativo do tipo caixa mais a contribuição da barreira de momento angular, 


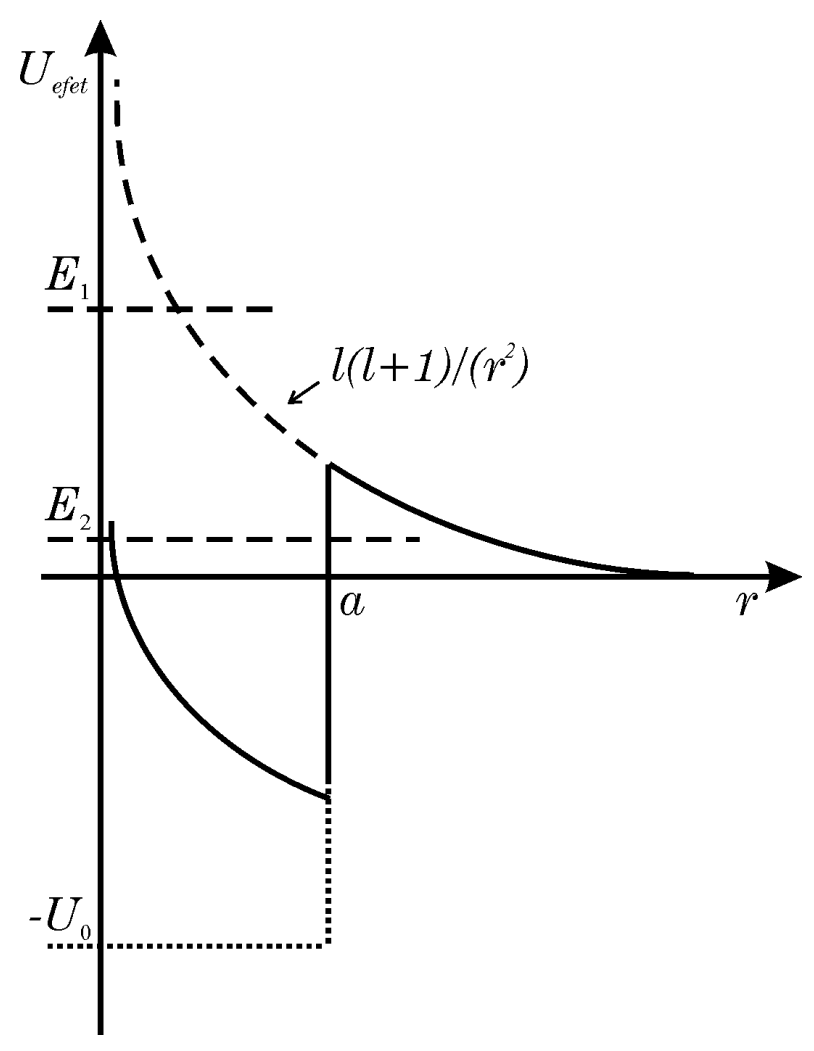

Figura 1.2: Potencial efetivo gerado pela combinação de um potencial tipo caixa de profundidade $U_{0}$ mais a barreira de momento angular para a onda parcial $l$. Em $E=E_{2}$ há a formação da ressonância de forma.

para uma dada onda parcial. A combinação entre as componentes atrativa e repulsiva gera um mínimo na forma do potencial, podendo comportar um estado quase-ligado em uma dada energia. Esse estado não é efetivamente ligado porque está acoplado aos estados do contínuo. Na condição de ressonância, o mínimo do potencial comporta meio comprimento de onda, havendo significativa densidade de probabilidade nessa região e um forte acoplamento entre o estado discreto e os estados do contínuo. Esse acoplamento indica a possibilidade de transição entre eles, o que reflete num tempo de vida finito para o estado ressonante.

A análise também pode ser realizada a partir de uma perspectiva dependente do tempo, em que um pacote de onda com energia mais ou menos definida se aproxima da região de interação do potencial. Se sua energia estiver abaixo da energia da ressonância, 
ele reflete na barreira de potencial sem adentrar na região do mínimo. Caso a energia seja mais elevada do que a da ressonância, ele passa por sobre a barreira e será refletido numa posição mais interior, sem que a estrutura na forma do potencial altere sua dinâmica de maneira significativa. Quando, no entanto, a energia de incidência for intermediária entre as duas situações anteriores, haverá a possibilidade de tunelamento da barreira de potencial. Parte da densidade de probabilidade é refletida, mas uma porção sofre tunelamento e fica aprisionada na região do mínimo, formando assim um estado temporário. Nessa situação, há a formação da ressonância. Eventualmente, a porção aprisionada tunela e retorna para o contínuo completando o processo de espalhamento. O tempo característico da duração do aprisionamento representa o tempo de vida finito do estado.

Como a interação efetiva entre projétil e alvo é mais intensa na condição de ressonância, haverá um aumento na seção de choque nessa energia. Em cálculos teóricos de espalhamento, um pico na curva de seção de choque é a assinatura de uma ressonância. A posição do pico representa a energia da ressonância e sua largura está relacionada ao seu tempo de vida. Usualmente, quanto menor a energia da ressonância, mais fina será seu sinal na seção de choque, indicando um maior tempo de vida. Uma ressonância também pode se apresentar na curva de seção de choque como uma depressão ou uma combinação de uma depressão e um pico. Na soma de autofases sua presença é revelada por um desvio de $\pi$.

Estamos interessados em ressonâncias de uma partícula, onde o estado-pai corresponde ao estado fundamental da molécula neutra. Nessa situação, o orbital desocupado que o elétron incidente passa a ocupar define o caráter da ressonância. Tipicamente, os orbitais virtuais de baixa energia tem caráter $\pi^{*}$ ou $\sigma^{*}$. Ressonâncias $\pi^{*}$ tem um perfil mais delocalizado e se concentram nas ligações insaturadas, e se apresentam com picos mais pronunciados na seção de choque. Por outro lado, nas ressonâncias $\sigma^{*}$ o elétron extra ocupa um orbital anti-ligante ao longo de uma ou mais ligações polares, e a estrutura correspondente na seção de choque é mais larga. Além da possibilidade de ejeção do elétron, o ânion também pode estabilizar estruturalmente. Ressonâncias $\sigma^{*}$ relaxam através do estiramento da ligação em que a carga se concentra, enquanto nos estados $\pi^{*}$ movimentos 
angulares aliviam o caráter anti-ligante do orbital. Diz-se portanto que a ressonância $\sigma^{*}$ é dissociativa, enquanto a ressonância $\pi^{*}$ é não-dissociativa.

Um estado do ânion de diferente natureza é o chamado estado ligado por dipolo, onde o aprisionamento do elétron se dá pelo potencial do dipolo permanente da molécula. O elétron reside então em seu polo positivo, num orbital muito difuso. Diante da classificação de estados do ânion apresentada acima, um estado ligado por dipolo seria formado como uma ressonância de Feshbach vibracional.

\subsection{Captura eletrônica dissociativa}

Uma ressonância é um estado intermediário muito eficiente em transferir a energia do elétron incidente para graus de liberdade dos núcleos. De fato, essa transferência se dá essencialmente de maneira ressonante, enquanto que a excitação direta dos núcleos a partir do elétron incidente é muito pouco provável. Uma vez formado o ânion, os núcleos irão relaxar nesse novo ambiente eletrônico e buscar uma configuração mais estável. Essa dinâmica irá competir com a possibilidade de ejeção do elétron extra, que permanece acoplado ao contínuo enquanto o estado for ressonante. Os tempos característicos desses dois processos irá determinar a probabilidade de cada um. Se o tempo de vida da ressonância for relativamente longo frente ao tempo necessário para que os núcleos estabilizem o ânion, prevalece o fenômeno de captura eletrônica dissociativa. Caso contrário, o estado ressonante é desfeito rapidamente, e os núcleos retornam para o ambiente eletrônico da molécula neutra. Nesse caso, no entanto, eles não mais estarão em sua configuração de equilíbrio, e dizemos que houve excitação vibracional da molécula.

A dinâmica dos núcleos induzida pela formação do ânion também pode ser compreendida a partir da análise de suas curvas de energia potencial. Na figura 1.3 estão representados o estado fundamental da molécula neutra e dois estados ressonantes do ânion, um estado dissociativo $\sigma^{*}$ e um estado não-dissociativo $\pi^{*}$, construídas em função 


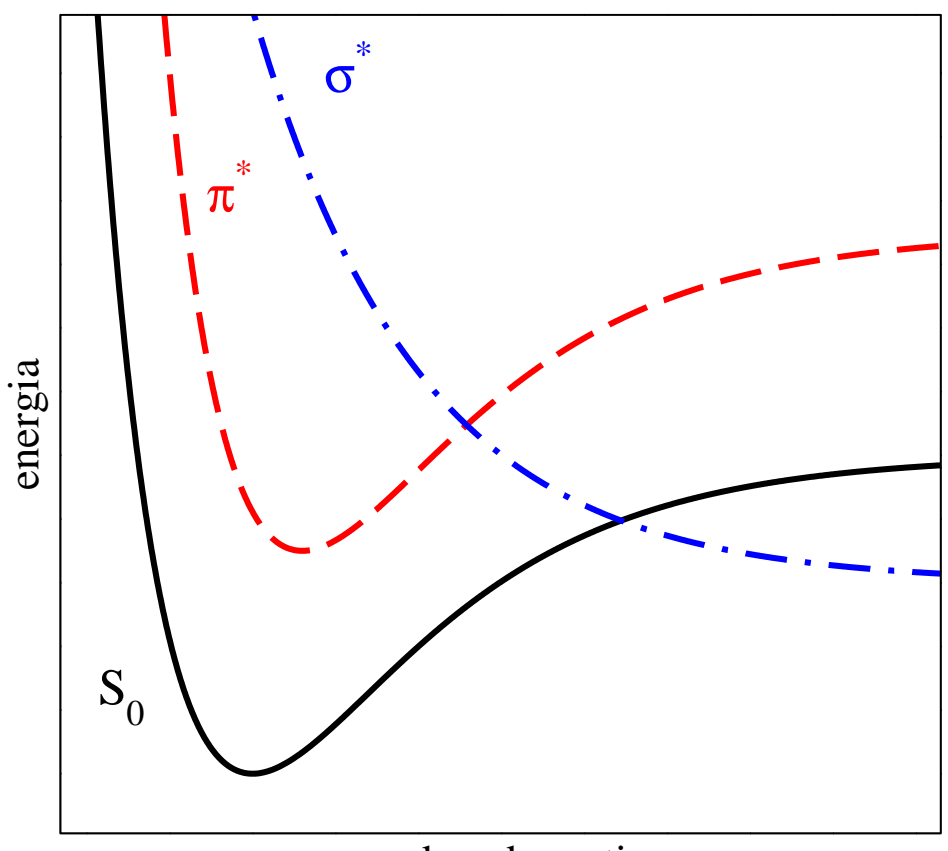

coordenada reativa

Figura 1.3: Curvas de energia potencial esquemáticas para o estado fundamental da molécula neutra e dos estados do ânion $\pi^{*}$ e $\sigma^{*}$.

de alguma coordenada reativa que dê origem à dissociação. Inicialmente, o pacote de onda nuclear se encontra em algum nível vibracional da curva do neutro, e quando há a formação da ressonância, esse passa a ter sua dinâmica governada pela curva de energia potencial correspondente. Nessa nova curva, o pacote de onda não se encontra mais num estado estacionário e irá evoluir dinamicamente. Como o estado do ânion apresenta tempo de vida finito, há uma componente imaginária de sua energia, não mostrada na figura 1.3. A ação dessa componente na propagação do pacote de onda atua como um sumidouro de densidade de probabilidade, representando que o ânion se desfez com o retorno do elétron para o contínuo. A densidade de probabilidade eliminada retorna para a curva do estado neutro, sendo responsável pelo processo de excitação vibracional. A parte que sobrevive à possibilidade de autoionização e atinge a região de estabilidade segue então ao longo da coordenada reativa, indicando a ocorrência de dissociação.

Há dois mecanismos distintos que podem dar origem à dissociação. Se for mediada pela formação da ressonância de caráter dissociativo $\sigma^{*}$, o mecanismo é dito direto. 
Nesse caso, o elétron incidente se localiza numa ligação específica, causando um afastamento entre os átomos que compõe essa ligação até que o ânion seja mais estável que o neutro e o sistema dissocie. O mecanismo indireto envolve a formação da ressonância $\pi^{*}$. Aqui, o elétron se localiza tipicamente numa ligação insaturada e o ânion tende a se dobrar em torno dessa ligação para acomodar a carga extra. Esse movimento, por sua vez, acompanha uma transferência do elétron do orbital $\pi^{*}$ para o orbital $\sigma^{*}$, e partir daí o sistema dissocia. Dizemos que o movimento nuclear gera um acoplamento entre os estados do ânion $\pi^{*}$ e $\sigma^{*}$, possibilitando portanto uma transferência entre suas populações. Podem haver outras situações, envolvendo por exemplo um estado ligado por dipolo. Esse pode acoplar tanto com um estado $\sigma^{*}$, por meio do estiramento de uma ligação, ou com um estado $\pi^{*}$, através de uma vibração que torcione a estrutura da molécula.

A ocorrência de um ou outro mecanismo pode ser avaliado experimentalmente ao se comparar a energia em que se dá a formação de um fragmento com as energias das ressonâncias. Em várias situações, no entanto, essa correspondência não é evidente. Teoricamente, o processo de dissociação geralmente é estudado por cálculos de dinâmica quântica do pacote de onda nuclear, realizados em uma superfície de energia potencial de dimensão reduzida e que seja representativa do processo a ser investigado. A maior parte dos cálculos já realizados considera apenas uma dimensão [11-14], com poucos casos em que uma segunda coordenada foi incluída $[15,16]$. Sistemas pequenos como $\mathrm{H}_{2} \mathrm{O}[17,18]$ e $\mathrm{CO}_{2}$ [19] permitem a inclusão dos três graus de liberdade vibracionais. Para avaliar o mecanismo direto a escolha natural para a coordenada reativa é o comprimento da ligação a ser desfeita, e com apenas uma dimensão o processo pode ser descrito, ao menos qualitativamente. O estudo do mecanismo indireto é mais complicado, uma vez que exige superfícies de energia potencial ao longo de duas coordenadas no mínimo. Uma delas representa a coordenada onde se dará a dissociação, e a outra será responsável por induzir o acoplamento entre os dois estados do ânion. 


\subsection{Relevância biológica}

Diante da descoberta de que elétrons de baixa energia podem provocar quebras de fitas simples e duplas do DNA [10], a comunidade de interação elétron-molécula voltou-se para a área biológica. A presença de elétrons de baixa energia num ambiente biológico se dá a partir da termalização de uma partícula de alta energia que percorre o meio. Quando radiação ionizante incide sobre o material biológico, ocorre uma cascata de colisões inelásticas, gerando ionizações e dissociações ao longo do seu caminho. Boa parte do dano sofrido pelo DNA advém de sua ionização direta e da presença de radicais OH gerados da dissociação da água. No entanto, uma nova rodada de dano terá origem a partir da ação dos elétrons de até $\sim 20 \mathrm{eV}$, que constituem a espécie secundária mais abundante gerada no processo de termalização. Parte desses elétrons também será termalizada e finalmente solvatada por moléculas de água, mas outra porção irá atacar o DNA e induzir processos dissociativos. O DNA, e biomoléculas em geral, são bastante suscetíveis a sofrer dissociação por captura eletrônica, o que contribui de maneira significativa para o cômputo final do dano biológico. Em experimentos em que filmes de DNA eram irradiados diretamente por elétrons de baixa energia, foram observadas quebras de fita simples, quebra de fita dupla, bem como liberação da base nitrogenada [10,20,21]. Embora o DNA seja muito eficaz em se auto-reparar, se houver uma significativa alteração em sua estrutura ou uma quantidade muito grande de erros, é provável que algo deixe de ser corrigido e ocasione um dano permanente. A longo prazo, a mudança sofrida pelo material genético pode levar à morte celular ou prejudicar seu funcionamento, podendo inclusive iniciar a formação de um câncer.

Dado que elétrons de baixa energia podem reagir com moléculas biológicas e alterar decisivamente sua atividade, é fundamental conhecer em detalhes como se dá essa interação. Diversos trabalhos seguiram a partir da descoberta inicial, e hoje se tem uma visão mais clara do que ocorre $[22,23]$. O elétron interage com uma subunidade do DNA, dando origem a um dano local [24], sendo o processo independente da estrutura do DNA. Ele é então capturado e forma-se um estado ressonante do ânion, que por sua vez 
desencadeia uma dinâmica vibracional que dará origem à dissociação. De 0 a $\sim 4 \mathrm{eV}$, os picos observados na contagem de quebras das fitas do DNA [10,25] advém da formação de ressonâncias de forma, enquanto que entre $\sim 4 \mathrm{e} \sim 10 \mathrm{eV}$ são as ressonâncias de Feshbach que devem responder pelas lesões. Estudos teóricos de espalhamento vem contribuído significativamente para o entendimento do problema, onde mencionamos trabalhos sobre as bases do DNA [26-29], açúcares [27,30], aminoácidos [31], e mesmo sistemas maiores como nucleosídeos [32]. Como cálculos de espalhamento de elétrons são relativamente custosos, outra abordagem consiste em investigar pequenas biomoléculas, que apresentem características químicas semelhantes a moléculas maiores, servindo portanto como sistemas modelo. Um melhor entendimento sobre a colisão eletrônica com pequenas biomoléculas pode fornecer importantes informações sobre o processo num ambiente mais complexo, havendo uma série de trabalhos que fazem uso dessa abordagem [33-37].

O ataque dos elétrons de baixa energia ao material genético de células saudáveis é uma consequência indesejada da radiação ionizante. No entanto, o mesmo processo seria bem-vindo caso a ação seja concentrada no DNA de células cancerígenas, o que pode ser arranjado através do uso de drogas radiossensibilizadoras incorporadas ao material genético. Um composto é dito radiossensibilizador se ele aumenta o dano biológico causado pela ação de radiação ionizante, onde se destacam moléculas halogenadas como as halouracilas [38] e moléculas pesadas como a cisplatina [39]. A relação direta que existe entre elevadas seções de choque de dissociação e uma marcante radiossensibilidade [40] indicam que essa propriedade surge devido à tendência dessas moléculas em sofrer captura eletrônica dissociativa. Portanto, uma melhor compreensão sobre sua interação com elétrons de baixa energia é crucial para que um potencial radiossensibilizador possa vir a ter aplicação médica. Uma vez conhecendo os detalhes dos mecanismos que dão origem ao processo dissociativo, poderiam-se desenvolver tratamentos radioterápicos mais eficientes, que elevem a taxa de morte celular e causem menos dano colateral. Essa é a aplicação mais tangível que pode surgir a partir do estudo da interação de elétrons e biomoléculas. 5-halouracilas são reconhecidas por serem uma classe promissora de radiossensibilizadores [38], e sua incorporação em segmentos do DNA já demonstrou sua capacidade 
em gerar dano quando interagindo com elétrons de baixa energia [41,42]. Essa classe é gerada pelo substituição do hidrogênio da uracila na posição 5 do anel por um halogênio. A molécula substitui a timina na cadeia do DNA, mantendo sua expressão gênica, mas aumentando significativamente sua sensibilidade diante de radiação ionizante.

Medidas do espectro de transmissão eletrônica realizadas para as 5-halouracilas apontam para a existência de ressonâncias nesses sistemas [43], enquanto cálculos de estrutura eletrônica mostram para a existência de um estado ligado [44,45]. As seções de choque de dissociação são ordens de grandeza mais elevadas nas 5-halouracilas do que na uracila ou timina, além de apresentar um espectro de fragmentos muito mais rico [46-51]. A reação dominante consiste na formação do ânion de halogênio $\mathrm{X}^{-}$, que deixa o radical complementar XU-X, onde X denota o átomo de halogênio, e XU a molécula neutra original. Também se observa a quebra dessa ligação mas com o elétron residindo no anel, gerando o ânion $[\mathrm{XU}-\mathrm{X}]^{-}$e o radical X. Esses fragmentos, entre outros gerados em menor quantidade, podem reagir com porções da cadeia de DNA e gerar danos biológicos. Em última análise a radiossensibilidade das 5-halouracilas advém de sua interação com elétrons de baixa energia, embora os mecanismos que dão origem à sua tendência em sofrer dissociação a partir da captura eletrônica ainda não são compreendidos. Do lado teórico em particular, os resultados são muito escassos, especialmente sobre seu espectro de ressonâncias e a dinâmica nuclear que tem início a partir de sua formação.

\subsection{A tese}

O objetivo central do nosso trabalho é compreender os mecanismos que geram a dissociação das 5-halouracilas quando essas são expostas a elétrons de baixa energia. Queremos avaliar quais os estados do ânion formados pela captura do elétron, como esses relaxam sua estrutura, e quais as rotas de dissociação mais eficientes. Foram alvo de estudo a 5-fluorouracila, 5-clorouracila, 5-bromouracila e 5-iodouracila, além da própria 
uracila. Investigamos ainda o isômero 6-clorouracila, e a 2-tiouracila, essa também conhecida por seu potencial radiossensibilizador [52]. Em vista das semelhanças esperadas entre os resultados para a família de halouracilas, elegemos a 5-clorouracila como a molécula em que a investigação será realizada em maior profundidade. Conhecendo em maiores detalhes esse caso, poderemos inferir sobre os resultados esperados para o restante das halouracilas. Outra classe de biomoléculas que apresenta potencial radiossensibilizador são os derivados halogenados da adenina $[53,54]$. Por isso incluímos a 2-cloroadenina, 8-cloroadenina e a própria adenina no rol de moléculas estudadas em nosso trabalho. Estudamos ainda as pequenas moléculas halogenadas clorometano e cloroeteno, com o propósito de servir como modelos para investigar em mais detalhes os processos dissociativos. A literatura existente e nossos objetivos específicos para cada sistema serão apresentados na introdução de cada capítulo de resultados.

Os sistemas estudados podem ser agrupadas em três grandes grupos: pequenas moléculas halogenadas, derivados de uracila e derivados de adenina. Para todos os sistemas realizamos cálculos de espalhamento elástico de elétrons, com a molécula em sua geometria de equilíbrio. Os cálculos foram realizados na aproximação de núcleos fixos, com o método método multicanal de Schwinger implementado com pseudopotenciais, nas aproximações estático-troca e estático-troca mais polarização. A partir desses cálculos, caracterizamos os estados do ânion e comparamos nossos resultados com os existentes. Foram realizados uma série de cálculos de espalhamento em geometrias distorcidas das pequenas moléculas halogenadas e das 5-halouracilas. Para todos esses sistemas, construímos curvas de energia potencial ao longo de uma coordenada reativa, e para cloroeteno, 5-clorouracila e 5-bromouracila, superfícies de energia potencial que incorporam uma segunda coordenada também foram realizados. A análise das curvas e superfícies de potencial calculadas sugerem possíveis mecanismos de dissociação, que são discutidos em vista das medidas experimentais existentes. Cálculos de estrutura eletrônica foram efetuados para descrever os estados ligados por dipolo, o ânion adiabático ao longo da coordenada reativa, e para avaliar o caráter dos orbitais ressonantes. Para o clorometano, cloroeteno, 5-clorouracila e 5-bromouracila, foram realizados cálculos quânticos de 
dinâmica nuclear para uma coordenada, dentro do formalismo de operadores de projeção de Feshbach, na aproximação semi-local.

O texto está organizado da seguinte maneira. O capítulo 2 contém a descrição teórica dos cálculos de espalhamento e de dinâmica nuclear. Nos três capítulos seguintes apresentamos e discutimos nossos resultados, sendo o capítulo 3 reservado para as pequenas biomoléculas, o capítulo 4 para os derivados de uracila e o capítulo 5 para as cloroadeninas. Por fim, o capítulo 6 sumariza as principais conclusões da tese. 


\section{Capítulo 2}

\section{Descrição teórica}

Os métodos teóricos empregados nesse trabalho são apresentados nesse capítulo. Na primeira seção do capítulo discutimos o problema do espalhamento eletrônico. Iniciamos introduzido o problema geral do espalhamento, apresentamos então o método multicanal de Schwinger, e na sequência alguns pontos relevantes sobre o método são elaborados. Discutimos alguns aspectos numéricos, o uso de pseudopotenciais, as aproximação estático-troca e estático-troca mais polarização e finalmente como as seções de choque são obtidas.

A segunda seção se concentra na descrição da dinâmica dos núcleos. Apresentamos o formalismo de operadores de projeção de Feshach, que fundamenta nossos cálculos de dinâmica quântica. Em seguida introduzimos a aproximação local e então discutimos alguns aspectos computacionais sobre a propagação do pacote de onda.

Métodos de estrutura eletrônica como o método de Hartree-Fock [55], teoria de perturbação de Møller-Plesset de segunda ordem (MP2) [55] e teoria do funcional da densidade (DFT, do inglês Density Functional Theory) [56,57] são amplamente conhecidos, e por isso não serão descritos em maiores detalhes aqui. 


\subsection{Descrição do espalhamento}

\subsubsection{Considerações gerais}

Nessa seção descrevemos o problema geral do espalhamento de um elétron por um alvo molecular. A situação é definida por um feixe de partículas com energia bem definida, que incide sobre o alvo, sofre a ação do seu potencial e é espalhado em alguma direção, sendo por fim detectado numa região fora do alcance do potencial do alvo.

O problema é geralmente descrito na aproximação de núcleos fixos. Quando há interesse em estudar a dinâmica nuclear no processo de colisão eletrônica, como no caso de excitação vibracional e dissociação, os problemas eletrônico e nuclear são desacoplados, e resolvidos em separado. Para uma dada configuração dos núcleos resolve-se o problema de espalhamento eletrônico, enquanto o problema nuclear é tratado numa próxima etapa.

Durante a colisão a energia total do sistema deve se conservar:

$$
E=\frac{k_{l}^{2}}{2}+E_{l}=\frac{k_{l^{\prime}}^{2}}{2}+E_{l^{\prime}}
$$

onde $E$ é a energia total do sistema, $k_{l}^{2} / 2\left(k_{l^{\prime}}^{2} / 2\right)$ é a energia inicial (final) do elétron e $E_{l}$ $\left(E_{l^{\prime}}\right)$ é energia inicial (final) da molécula.

Quando um dado processo satisfaz a equação 2.1, o canal correspondente é dito aberto, e haverá uma probabilidade de que esse processo ocorra. Se, no entanto, um processo viola a equação 2.1, então o canal é dito fechado, e não haverá possibilidade de que tal processo ocorra. Ainda assim, os canais fechados representam o efeito de polarização do alvo devido a presença da partícula incidente, como será discutido adiante.

Nosso problema de interesse é o espalhamento de um elétron de baixa energia por um alvo molecular neutro. Efeitos relativísticos e interação spin-órbita não são relevantes nesse regime de energia, e o hamiltoniano de espalhamento será:

$$
H_{N+1}=H_{N}+T_{e}+V=H_{0}+V
$$

onde $H_{N}$ é o hamiltoniano da molécula neutra,

$$
T_{e}=-\frac{1}{2} \nabla_{N+1}^{2}
$$


é o operador energia cinética do elétron incidente e

$$
V=\sum_{i=1}^{N} \frac{1}{\left|\vec{r}_{N+1}-\vec{r}_{i}\right|}-\sum_{A=1}^{M} \frac{Z_{A}}{\left|\vec{r}_{N+1}-\vec{r}_{A}\right|}
$$

é o potencial de interação elétron-molécula.

A solução estacionária $\Psi\left(\vec{r}_{1}, \ldots, \vec{r}_{N+1}\right)$ deve satisfazer a equação de Schroedinger:

$$
\hat{H} \Psi\left(\vec{r}_{1}, \ldots, \vec{r}_{N+1}\right)=0
$$

onde

$$
\hat{H}=E-H_{N+1},
$$

O problema de espalhamento se manifesta pela presença de uma condição de contorno para a função de onda, ausente na descrição de estados ligados. Na região assintótica $\left(r_{N+1} \rightarrow \infty\right)$, a função de onda deve assumir o formato:

$$
\Psi_{\vec{k}_{l}}\left(\vec{r}_{1}, \ldots, \vec{r}_{N+1}\right)=S_{\vec{k}_{l}}\left(\vec{r}_{1}, \ldots, \vec{r}_{N+1}\right)+\sum_{l^{\prime}} f_{l, l^{\prime}}\left(\vec{k}_{l^{\prime}}, \vec{k}_{l}\right) \Phi_{l^{\prime}}\left(\vec{r}_{1}, \ldots, \vec{r}_{N}\right) \frac{e^{i \vec{k}_{l^{\prime}} \cdot \vec{r}_{N+1}}}{r_{N+1}}
$$

onde os índices $l$ e $l^{\prime}$ indicam o estado do sistema, lembrando que o estado do alvo e do elétron espalhado estão vinculados pela equação 2.1. O primeiro termo da equação 2.7 é a solução do problema sem interação:

$$
H_{0} S_{\vec{k}_{l}}\left(\vec{r}_{1}, \ldots, \vec{r}_{N+1}\right)=\left(E_{l}+k_{l}^{2} / 2\right) S_{\vec{k}_{l}}\left(\vec{r}_{1}, \ldots, \vec{r}_{N+1}\right)
$$

sendo separável em duas partes:

$$
S_{\vec{k}_{l}}\left(\vec{r}_{1}, \ldots, \vec{r}_{N+1}\right)=\Phi_{l}\left(\vec{r}_{1}, \ldots, \vec{r}_{N}\right) e^{i \vec{k}_{l} \cdot \vec{r}_{N+1}}
$$

onde $\Phi_{l}\left(\vec{r}_{1}, \ldots, \vec{r}_{N}\right)$ é um estado da molécula isolada:

$$
H_{N} \Phi_{l}\left(\vec{r}_{1}, \ldots, \vec{r}_{N}\right)=E_{l} \Phi_{l}\left(\vec{r}_{1}, \ldots, \vec{r}_{N}\right)
$$

enquanto que $e^{i \vec{k}_{l} \cdot \vec{r}_{N+1}}$ é a solução de partícula livre do elétron incidente.

O segundo termo da equação 2.7 incorpora a condição de contorno de espalhamento. Para cada canal aberto $l^{\prime}$, há uma onda esférica divergindo do alvo, modulada 
em magnitude e angularmente pela amplitude de espalhamento $f_{l, l^{\prime}}\left(\vec{k}_{l^{\prime}}, \vec{k}_{l}\right)$. Esse termo contém toda a informação relativa ao processo de espalhamento, sendo o objeto central de qualquer método teórico.

É possível incorporar a condição de contorno diretamente na equação de Schroedinger, fazendo uso da função de Green e escrevendo a equação numa forma integral. Temos assim a equação de Lippmann-Schwinger, na notação de Dirac:

$$
\left|\Psi_{\vec{k}_{i}}^{( \pm)}\right\rangle=\left|S_{\vec{k}_{i}}\right\rangle+G_{0}^{( \pm)} V\left|\Psi_{\vec{k}_{i}}^{( \pm)}\right\rangle
$$

onde $\left|S_{\vec{k}_{i}}\right\rangle$ é a solução do problema homogêneo, conforme a equação 2.9 , e $G_{0}^{( \pm)}$é o operador de Green associado ao operador $\hat{H}=E-H_{0}$ :

$$
G_{0}^{( \pm)}=\lim _{\varepsilon \rightarrow 0} \frac{1}{E-H_{0} \pm i \varepsilon} .
$$

O índice $( \pm)$ está relacionado à forma da função de onda na região assintótica. O sinal $(+)$ está associado a uma onda plana mais uma onda esférica divergente, enquanto o sinal (-) corresponde a uma onda esférica convergente mais uma onda plana. A situação física é aquela do índice $(+)$, embora ambas sejam soluções matematicamente possíveis.

A base de autoestados do operador $H_{0}=H_{N}+T_{e}$ forma uma base interessante para representar o operador de Green:

$$
G_{0}^{( \pm)}=\lim _{\varepsilon \rightarrow 0} \sum_{l} \int d^{3} k \frac{\left|\Phi_{l} \vec{k}\right\rangle\left\langle\Phi_{l} \vec{k}\right|}{E-E_{l}-\frac{k^{2}}{2} \pm i \varepsilon},
$$

onde o símbolo $\mathbb{Z}_{l}$ representa uma soma sobre os estados discretos do alvo e uma integral sobre os estados do contínuo, e a integral em $\vec{k}$ é realizada sobre o momento da partícula livre. Substituindo a relação $E=E_{l}+\frac{k_{l}^{2}}{2}$, da equação 2.1, obtemos a seguinte representação do operador de Green:

$$
G_{0}^{( \pm)}=\lim _{\varepsilon \rightarrow 0} \sum_{l} \int d^{3} k \frac{\left|\Phi_{l} \vec{k}\right\rangle\left\langle\Phi_{l} \vec{k}\right|}{\left(k_{l}^{2}-k^{2}\right) / 2 \pm i \varepsilon} .
$$

\subsubsection{O método multicanal de Schwinger}

Nossos cálculos de espalhamento são realizados com o método multicanal de Schwinger (SMC, do inglês Schwinger multichannel method) [58-60]. O método é uma 
extensão multicanal do princípio variacional de Schwinger [61], tendo sido formulado para o estudo de colisões de elétrons de baixa energia por moléculas. No método SMC, as interações eletrostática, efeitos de troca, correlação, polarização, e acoplamento multicanal são considerados de maneira ab-initio. A principal característica e vantagem do método consiste no uso de funções de quadrado integrável (funções $L^{2}$ ), como será discutido em detalhes adiante. Essa propriedade permite o uso de funções gaussianas-cartesianas, com todas as vantagens que essas funções possuem. A seguir, apresentamos o desenvolvendo teórico do método.

Parte-se da equação de Lippmann-Schwinger (equação 2.11). Multiplicando a equação por $V$, podemos escrever:

$$
A^{( \pm)}\left|\Psi_{\vec{k}_{i}}^{( \pm)}\right\rangle=V\left|S_{\vec{k}_{i}}\right\rangle
$$

onde é introduzido o operador $A^{( \pm)}$:

$$
A^{( \pm)}=V-V G_{0}^{( \pm)} V
$$

Da teoria geral de espalhamento, pode-se escrever a amplitude de espalhamento nas duas formas abaixo:

$$
\begin{aligned}
& f=-\frac{1}{2 \pi}\left\langle S_{\vec{k}_{f}}|V| \Psi_{\vec{k}_{i}}^{(+)}\right\rangle, \\
& f=-\frac{1}{2 \pi}\left\langle\Psi_{\vec{k}_{f}}^{(-)}|V| S_{\vec{k}_{i}}\right\rangle .
\end{aligned}
$$

Cada forma representa uma condição de contorno. A primeira está associada a uma onda plana incidente mais uma onda esférica divergindo, enquanto a segunda expressão corresponde à reversão temporal da primeira.

Substituindo a equação 2.15 na equação 2.18, obtém-se ainda uma terceira expressão para a amplitude de espalhamento:

$$
f=-\frac{1}{2 \pi}\left\langle\Psi_{\vec{k}_{f}}^{(-)}\left|A^{(+)}\right| \Psi_{\vec{k}_{i}}^{(+)}\right\rangle
$$

Finalmente, somando as expressões 2.17 e 2.18 e subtraindo a 2.19, ainda temos a amplitude de espalhamento, agora na chamada forma bilinear:

$$
f=-\frac{1}{2 \pi}\left[\left\langle S_{\vec{k}_{f}}|V| \Psi_{\vec{k}_{i}}^{(+)}\right\rangle+\left\langle\Psi_{\vec{k}_{f}}^{(-)}|V| S_{\vec{k}_{i}}\right\rangle-\left\langle\Psi_{\vec{k}_{f}}^{(-)}\left|A^{(+)}\right| \Psi_{\vec{k}_{i}}^{(+)}\right\rangle\right]
$$


A fim de que as equações 2.15 sejam satisfeitas, a seguinte condição deve ser obedecida:

$$
A^{(-) \dagger}=A^{(+)} .
$$

Nesse ponto, expandimos a função de onda de espalhamento num conjunto de funções de base $\left\{\chi_{\mu}\right\}$ de $(N+1)$ partículas:

$$
\begin{aligned}
\left|\Psi_{\vec{k}_{i}}^{(+)}\right\rangle & =\sum_{\mu} a_{\mu}^{(+)}\left(\vec{k}_{i}\right)\left|\chi_{\mu}\right\rangle, \\
\left\langle\Psi_{\vec{k}_{f}}^{(-)}\right| & =\sum_{\nu} a_{\nu}^{(-) *}\left(\vec{k}_{f}\right)\left\langle\chi_{\nu}\right| .
\end{aligned}
$$

Impomos então o princípio variacional de Schwinger, que estabelece que a amplitude de espalhamento escrita na forma da equação 2.20 deve ser variacionalmente estável sob pequenas variações de $\Psi_{\vec{k}_{i}}^{(+)}$e de $\Psi_{\vec{k}_{f}}^{(-)}$. Essa afirmação equivale às equações de Lippmann-Schwinger, desde que a condição 2.21 seja satisfeita. Tomando a amplitude de espalhamento como um funcional dos coeficientes da expansão, que assumem o papel de parâmetros variacionais, e impondo sua estabilidade frente a variações em primeira ordem nos coeficientes:

$$
\frac{\partial[f]}{\partial a_{\mu}^{(+)}}=\frac{\partial[f]}{\partial a_{\nu}^{(-) *}}=0
$$

obtemos as expressões para os coeficientes e para a função de onda. Com os coeficientes em mãos, obtemos a seguinte expressão para a amplitude de espalhamento:

$$
f_{\vec{k}_{f}, \vec{k}_{i}}=-\frac{1}{2 \pi} \sum_{m, n}\left\langle S_{\vec{k}_{f}}|V| \chi_{m}\right\rangle\left(d^{-1}\right)_{m n}\left\langle\chi_{n}|V| S_{\vec{k}_{i}}\right\rangle,
$$

onde

$$
d_{m n}=\left\langle\chi_{m}\left|A^{(+)}\right| \chi_{n}\right\rangle
$$

e

$$
A^{(+)}=V-V G_{0}^{(+)} V
$$

Aqui notamos que as funções de base $\left\{\chi_{m}\right\}$ sempre aparecem multiplicadas pelo potencial de interação $V$. Como na região assintótica temos $V \rightarrow 0$, o comportamento assintótico das funções de base não é relevante. A função de onda deve ser descrita somente 
na região do alcance do potencial, o que permite o uso de funções de quadrado integrável $\left(L^{2}\right)$ na representação de $\left\{\chi_{m}\right\}$. A expressão para a amplitude de espalhamento 2.25 é correta, e possibilita o uso de funções $L^{2}$, mas ainda não é viável computacionalmente. Isso se dá devido a presença dos estados do contínuo do alvo no operador de Green $G_{0}^{(+)}$, que representam os canais de ionização. Nesse caso, haveria dois ou mais elétrons livres na região assintótica submetidos ao potencial de um cátion. Essa interação é de longo alcance, tornando difícil um tratamento adequado. Para baixas energias do elétron incidente, no entanto, os canais de ionização são pouco relevantes frente aos outros canais, e a componente de ionização pode ser retirada do operador de Green. Isso é feito através de um operador $P$ que projeta sobre os canais abertos do alvo:

$$
P=\sum_{l}^{\text {abertos }}\left|\Phi_{l}\left(\vec{r}_{1}, \ldots, \vec{r}_{N}\right)\right\rangle\left\langle\Phi_{l}\left(\vec{r}_{1}, \ldots, \vec{r}_{N}\right)\right| .
$$

Projetando a equação de Lippmann-Schwinger no espaço definido por $P$, e rearranjando, temos que:

$$
A^{(+)}\left|\Psi_{\vec{k}_{i}}\right\rangle=V\left|S_{\vec{k}_{i}}\right\rangle
$$

com

$$
A^{(+)}=V P-V G_{P}^{(+)} V
$$

onde $G_{P}^{(+)}$é o operador de Green projetado no espaço definido por $P$ :

$$
G_{P}^{(+)}=\lim _{\varepsilon \rightarrow 0} \sum_{l}^{\text {abertos }} \int d^{3} k \frac{\left|\Phi_{l} \vec{k}\right\rangle\left\langle\Phi_{l} \vec{k}\right|}{\left(k_{l}^{2}-k^{2}\right) / 2 \pm i \varepsilon} .
$$

Agora, no entanto, não há mais garantia de estabilidade variacional $\left(A^{(-) \dagger} \neq\right.$ $A^{(+)}$) para a amplitude de espalhamento na forma como o operador $A^{(+)}$está escrito, pois em geral $[V, P] \neq 0$. Para que a garantia volte a ser satisfeita devemos recuperar a informação contida no espaço complementar ao do operador $P$, que contém a contribuição dos canais fechados. O procedimento consiste em decompor a função de onda nos espaços de canais abertos e fechados, e montar a equação de Schroedinger:

$$
\hat{H}\left|\Psi_{\vec{k}_{i}}^{(+)}\right\rangle=\hat{H}\left[a P\left|\Psi_{\vec{k}_{i}}^{(+)}\right\rangle+(1-a P)\left|\Psi_{\vec{k}_{i}}^{(+)}\right\rangle\right]=0 .
$$


onde $a$ é um parâmetro que será calculado logo adiante.

A equação de Lippmann-Schwinger projetada 2.29 é então substituída na expressão acima, e seguindo o desenvolvimento dos cálculos, temos:

$$
A^{(+)}\left|\Psi_{\vec{k}_{i}}\right\rangle=V\left|S_{\vec{k}_{i}}\right\rangle
$$

com uma nova expressão para o operador $A^{(+)}$:

$$
A^{(+)}=\frac{1}{2}(P V+V P)-V G_{P}^{(+)} V+\frac{1}{a}\left[\hat{H}-\frac{a}{2}(\hat{H} P+P \hat{H})\right] .
$$

Escrita nessa forma, o operador $A^{(+)}$satisfaz a condição de estabilidade variacional $A^{(-) \dagger}=A^{(+)}$, para todos os elementos de matriz que envolvem funções $L^{2}$, para qualquer valor do parâmetro $a$. Para elementos de matriz que envolvem funções do contínuo, no entanto, essa condição não é satisfeita. Devemos impor, portanto, que tais elementos de matriz se anulem, sob a escolha apropriada de $a$. Tomando $a=N+1$ essa exigência é satisfeita [62]. Com isso, a condição de estabilidade variacional $A^{(-) \dagger}=A^{(+)}$é válida para todos os elementos de matriz, permitindo então o uso do princípio variacional para o cálculo da amplitude de espalhamento. O procedimento é o mesmo do apresentado anteriormente. Expande-se a função de onda numa base conhecida de funções de quadrado integrável:

$$
\left|\Psi_{\vec{k}_{i}}^{(+)}\right\rangle=\sum_{\mu} a_{\mu}^{(+)}\left(\vec{k}_{i}\right)\left|\chi_{\mu}\right\rangle
$$

e usa-se o princípio variacional para a amplitude de espalhamento escrita na forma bilinear, onde os coeficientes da expansão são tomados como parâmetros variacionais. A expressão de trabalho para a amplitude de espalhamento é dada por:

$$
f_{\vec{k}_{f}, \vec{k}_{i}}=-\frac{1}{2 \pi} \sum_{m, n}\left\langle S_{\vec{k}_{f}}|V| \chi_{m}\right\rangle\left(d^{-1}\right)_{m n}\left\langle\chi_{n}|V| S_{\vec{k}_{i}}\right\rangle
$$

onde

$$
d_{m n}=\left\langle\chi_{m}\left|A^{(+)}\right| \chi_{n}\right\rangle,
$$

$\mathrm{e}$

$$
A^{(+)}=\frac{1}{2}(P V+V P)-V G_{P}^{(+)} V+\frac{1}{N+1}\left[\hat{H}-\frac{N+1}{2}(\hat{H} P+P \hat{H})\right] .
$$




\subsubsection{Aspectos numéricos}

Apresentamos na sequência alguns detalhes sobre o cálculo do elemento de matriz envolvendo o operador de Green. Escrito na forma da equação 2.14, ele pode ser separada em parte real (valor principal de Cauchy) e imaginária (resíduo):

$$
G_{P}^{(+)}=G_{P}^{P r}+G_{P}^{R}
$$

onde

$$
G_{P}^{R}=i \pi \sum_{l}^{\text {abertos }} k_{l} \int d \Omega_{k_{l}}\left|\Phi_{l} \vec{k}\right\rangle\left\langle\Phi_{l} \vec{k}\right|
$$

e

$$
G_{P}^{P r}=\sum_{l}^{\text {abertos }} \mathscr{P} \int_{0}^{\infty} d k \frac{k^{2}}{\left(k_{l}^{2}-k^{2}\right) / 2} \int d \Omega_{k_{l}}\left|\Phi_{l} \vec{k}\right\rangle\left\langle\Phi_{l} \vec{k}\right| .
$$

O elemento de matriz da equação 2.37 que contém o operador de Green também pode ser separado em parte real e imaginária:

$$
\left\langle\chi_{m}\left|V G_{P}^{(+)} V\right| \chi_{n}\right\rangle=\left\langle\chi_{m}\left|V G_{P}^{P r} V\right| \chi_{n}\right\rangle+\left\langle\chi_{m}\left|V G_{P}^{R} V\right| \chi_{n}\right\rangle
$$

onde obtemos o termo on-shell:

$$
\left\langle\chi_{m}\left|V G_{P}^{R} V\right| \chi_{n}\right\rangle=i \pi \sum_{l}^{\text {abertos }} k_{l} g_{m n}^{l}\left(k_{l}\right)
$$

e o termo off-shell:

$$
\left\langle\chi_{m}\left|V G_{P}^{P r} V\right| \chi_{n}\right\rangle=\sum_{l}^{\text {abertos }} \mathscr{P} \int_{0}^{\infty} d k \frac{k^{2}}{\left(k_{l}^{2}-k^{2}\right) / 2} g_{m n}^{l}(k),
$$

onde

$$
g_{m n}^{l}(k)=\int d \Omega_{k_{l}}\left\langle\chi_{m}|V| \Phi_{l} \vec{k}\right\rangle\left\langle\Phi_{l} \vec{k}|V| \chi_{n}\right\rangle .
$$

As integrais angulares em $d \Omega_{k_{l}}$ da equação 2.45 e as integrais radiais em $k$ da equação 2.44 são calculadas numericamente [63], através da quadratura de GaussLegendre.

Como apontado anteriormente, o método SMC permite o uso de funções $L^{2}$. A escolha natural são as funções gaussianas-cartesianas. Desse modo, todas as integrais no 
espaço real $\{\vec{r}\}$ presentes nas equações $2.36,2.37$ e 2.45 podem ser calculadas analiticamente. Teremos as integrais de um elétron entre duas funções gaussianas-cartesianas e as integrais de dois elétrons entre quatro funções gaussianas-cartesianas, essencialmente as mesmas presentes nos cálculos de estado ligado. A novidade está nas integrais envolvendo uma onda plana. Nesse caso, as integrais de um elétron assumem a forma:

$$
(\alpha \mid \vec{k})=\int d \vec{r}_{1} \alpha\left(\vec{r}_{1}\right) \mathscr{O}_{1} e^{i \vec{k} \cdot \vec{r}_{1}}
$$

envolvendo uma função gaussiana-cartesiana $\alpha$, o operador de um elétron $\mathscr{O}_{1}$ (energia cinética ou interação elétron-núcleo) e uma onda plana. Enquanto que as integrais de dois elétrons serão:

$$
(\alpha \beta \mid \gamma \vec{k})=\int d \vec{r}_{1} \int d \vec{r}_{2} \alpha\left(\vec{r}_{1}\right) \beta\left(\vec{r}_{1}\right) \frac{1}{\left|\vec{r}_{1}-\vec{r}_{2}\right|} \gamma\left(\vec{r}_{2}\right) e^{i \vec{k} \cdot \vec{r}_{2}}
$$

envolvendo três funções gaussianas-cartesianas $\alpha, \beta$ e $\gamma$, o operador de dois elétrons (interação elétron-elétron) e uma onda plana.

\subsubsection{Aproximações Estático-Troca e Estático-Troca mais Pola- rização}

A função de onda de espalhamento é representada numa base de $(\mathrm{N}+1)$ partículas, onde cada função $\chi_{m}$ é denominada configuração, e o conjunto de funções $\left\{\chi_{m}\right\}$ é chamado de espaço de configurações (CSFs, do inglês configuration space functions). Como o método SMC faz uso do princípio variacional, um maior espaço de configurações gera maior flexibilidade na função de onda, e portanto a qualidade da descrição do processo de espalhamento está definida pelo espaço de configurações. Cada configuração é tomada como um produto antissimetrizado de uma função de N partículas representando o alvo, e uma função de uma partícula que descreve o elétron incidente na vizinhança do alvo, denominado orbital de espalhamento. Há dois níveis de aproximação em que os cálculos são realizados, a aproximação estático-troca (SE, do inglês static-exchange) e a aproximação 
estático-troca mais polarização (SEP, do inglês static-exchange plus polarization).

Dentro da aproximação estático-troca (SE), o espaço de configurações é gerado como:

$$
\left|\chi_{m}\right\rangle=A_{N+1}\left|\Phi_{0}\right\rangle \otimes\left|\phi_{m}\right\rangle
$$

onde $\left|\Phi_{0}\right\rangle$ é o estado fundamental da molécula, $\left|\phi_{m}\right\rangle$ é um orbital de espalhamento e $A_{N+1}$ é o antissimetrizador de $\mathrm{N}+1$ partículas. O alvo é descrito na aproximação Hartree-Fock e portanto $\left|\Phi_{0}\right\rangle$ é representado por um determinante de Slater de N elétrons.

Nesse nível de aproximação há flexibilidade apenas na descrição do elétron incidente, por meio do orbital de espalhamento, enquanto $\mathrm{N}$ elétrons estão restritos a ocupar os orbitais ocupados do alvo. Isso significa que a nuvem eletrônica da molécula permanece congelada no decorrer da colisão, não reagindo dinamicamente à presença do elétron extra. Para colisões com energia superior a $\sim 20 \mathrm{eV}$, os elétrons do alvo não têm tempo para se acomodar sob a ação do elétron incidente, e a aproximação SE é adequada. Para energias inferiores, no entanto, o elétron incide mais lentamente, permitindo uma distorção mais significativa da nuvem eletrônica, e é necessário ir além da aproximação SE.

$\mathrm{Na}$ aproximação estático-troca mais polarização (SEP), o espaço de configurações é aumentado, e passa a contar com configurações do tipo:

$$
\left|\chi_{i m}\right\rangle=A_{N+1}\left|\Phi_{i}\right\rangle \otimes\left|\phi_{m}\right\rangle
$$

onde $\left|\Phi_{i}\right\rangle$ representa uma excitação virtual da molécula, $\left|\phi_{m}\right\rangle$ é um orbital de espalhamento e $A_{N+1}$ é o antissimetrizador.

Nesse nível de aproximação os elétrons do alvo passam a ocupar orbitais usualmente desocupados, o que é permitido pela presença de $\left|\Phi_{i}\right\rangle$. Isso representa a possibilidade de deformação da nuvem eletrônica do alvo sob a ação do campo do elétron incidente, e portanto essa interação de polarização de longo alcance passa a ser contemplada. As novas configurações são geradas no espírito de expansão CI (configuration interaction), de modo que efeitos de correlação eletrônica de curto alcance também são incorporados na descrição da função de onda. Portanto, a interação estática, e efeitos de troca, polarização e correlação são levados em consideração nesse nível de cálculo. 
Os estados $\left|\Phi_{i}\right\rangle$ são gerados a partir de excitações virtuais simples do alvo, onde um elétron é retirado de um orbital ocupado, chamado de orbital de buraco, e promovido para um orbital vazio, chamado orbital de partícula. Para cada excitação virtual, os elétrons de buraco e de partícula podem apresentar acoplamento de spin singleto ou tripleto. Por fim, o produto antissimetrizado de um estado excitado por um orbital de espalhamento $\left|\phi_{m}\right\rangle$ dá origem a uma configuração. Cada configuração, portanto, é definida pelo conjunto orbital de buraco + orbital de partícula + acoplamento singleto ou tripleto + orbital de espalhamento. Como o programa atual está limitado a alvos com camada fechada, a adição do elétron adicional impõe que o spin global seja dubleto, e portanto apenas configurações dessa multiplicidade de spin são mantidas no espaço CSF.

Os orbitais virtuais canônicos (VOs, do inglês virtual orbitals) obtidos na descrição Hartree-Fock do alvo molecular formam um conjunto natural para representar os orbitais de partícula e de espalhamento. Esses orbitais, no entanto, geralmente apresentam uma performance inferior do que outros conjuntos de orbitais, e não costumam ser utilizados. Isso significa que para outros tipos de orbitais um pequeno número de configurações oferece a mesma qualidade na descrição do espalhamento que um espaço de configurações mais expressivo gerado a partir dos orbitais virtuais canônicos. Os VOs são pouco eficientes por dois motivos. Primeiro, não descrevem bem o estado excitado da molécula, já que foram gerados no campo de $\mathrm{N}$ elétrons, enquanto um elétron promovido a um orbital de mais alta energia sente a ação N-1 elétrons. Essa deficiência pode ser contornada com o uso dos orbitais virtuais melhorados (IVOs, do inglês improved virtual orbitals) [64]. Os IVOs são simplesmente os orbitais obtidos no campo do cátion de carga +1 , gerado pela remoção do elétron do último orbital ocupado, e tomando um dado acoplamento de spin, singleto ou tripleto. O segundo problema no uso dos VOs, e que atinge em certa medida os IVOs, está no fato de que muitos deles são difusos, se estendendo para além da região da molécula. Embora sejam importantes por exemplo para a interação de longo alcance da polarização, o uso de muitos orbitais com esse perfil pouco acrescenta na descrição de curto alcance da correlação. O mais interessante, portanto, é que se adote orbitais relativamente compactos, localizados na região do alvo. Os orbitais virtuais mo- 
dificados (MVOs, do inglês modified virtual orbitals) [65] atendem a esse requisito, e tem sido amplamente utilizados em aplicações do método SMC. São retirados elétrons dos n/2 orbitais ocupados de mais alta energia, e a diagonalização do operador de Fock no campo do cátion de carga $+\mathrm{n}$ dá origem aos MVOs. A retirada de um número par de elétrons elimina a questão da escolha do acoplamento de spin, presente no caso dos IVOs.

\subsubsection{Pseudopotenciais}

Boa parte do custo computacional, tanto nos cálculos de estado ligado quanto nos cálculos de espalhamento, está nas integrais de dois elétrons, que devem ser calculadas para todas as combinações possíveis de funções de base. O número de integrais cresce portanto com a quarta potência do número de funções. Por isso, cálculos que envolvam átomos pesados se tornam muito caros, ou mesmo inviáveis, pois é necessário um conjunto muito grande de funções a fim de representar todos os seus elétrons. Certamente, os elétrons de valência devem ser tratados explicitamente, já que interagem fortemente com o elétron incidente. Os elétrons de caroço, por outro lado, não devem exercer tanta influência, já que permanecem essencialmente ligados ao núcleo. Esse fato permite o uso de pseudopotenciais para representar conjuntamente o núcleo e seus elétrons de caroço. Logo, apenas os elétrons de valência serão representados por orbitais moleculares, o que diminui consideravelmente o número de funções de base necessárias. O uso de pseudopotenciais representa um grande ganho computacional para sistemas com núcleos mais pesados, o que permite que esses casos possam ser efetivamente tratados.

São empregados pseudopotenciais de Bachelet, Hamann e Schlüter (BHS), nos cálculos de estado ligados e de espalhamento. Esses pseudopotenciais foram gerados para quase todos os átomos da tabela periódica, sendo encontrados na referência [66]. Os pseudopotenciais de BHS assumem a forma:

$$
\hat{V}_{P P}=\hat{V}_{\text {core }}+\hat{V}_{\text {ion }}
$$


onde

$$
\hat{V}_{\text {core }}=-\frac{Z v}{r} \sum_{i=1}^{2} c_{i} \operatorname{erf}\left[\left(\rho_{i}\right)^{1 / 2} r\right]
$$

e

$$
\hat{V}_{i o n}=\sum_{n=0}^{1} \sum_{j=1}^{3} \sum_{l=0}^{2} A_{n j l} r^{2 n} e^{-\sigma_{j l} r^{2}} \sum_{m=-l}^{l}|l m\rangle\langle l m|
$$

Os parâmetros $A_{n j l}, \sigma_{j l}, c_{i}$ e $\rho_{i}$ definem a forma do pseudopotencial, e erf denota a função erro.

Nos cálculos de estrutura eletrônica e de espalhamento, cada termo do potencial nuclear $-Z_{C} / r$ é substituído pelo pseudopotencial correspondente $\hat{V}_{P P}$, e todas as integrais envolvendo o termo $\hat{V}_{P P}$ continuam sendo resolvidas analiticamente. A implementação dos pseudopotenciais de BHS no método SMC foi realizada por Bettega et. al. [67], e essa versão do método também é denominado método multicanal de Schwinger implementado com pseudopotenciais (SMCPP). Todos os cálculos de espalhamento efetuados nesse trabalho foram realizados com o método SMCPP.

O uso dos pseudopotenciais de BHS impõe a construção de funções de base apropriadas para representar os elétrons de valência, que sejam adaptadas à presença do potencial efetivo do caroço. As funções de base empregadas aqui foram geradas de acordo com o a referência [68].

\subsubsection{Cálculo das seções de choque}

A amplitude de espalhamento $f^{s m c}$ foi obtida no referencial fixo da molécula. Isso permite que as simetrias do sistema sejam exploradas, diminuindo o custo computacional. Contudo, é necessário obter a amplitude de espalhamento no referencial do laboratório, para então efetuar o cálculo das seções de choque [69].

Inicialmente a amplitude de espalhamento calculada na equação 2.36 é expan- 
dida em harmônicos esféricos:

$$
f^{s m c}\left(\vec{k}_{f}, \vec{k}_{i}\right)=\sum_{l=0}^{l_{\max }} \sum_{m=-l}^{+l} f_{l, m}\left(k_{f}, \vec{k}_{i}\right) Y_{l}^{m}\left(\hat{k}_{f}\right),
$$

onde

$$
f_{l, m}\left(k_{f}, \vec{k}_{i}\right)=\int d \hat{k}_{f} Y_{l}^{m *}\left(\hat{k}_{f}\right) f^{s m c}\left(\vec{k}_{f}, \vec{k}_{i}\right)
$$

No referencial do laboratório, tomamos a direção do feixe incidente $\hat{k}_{i}$ coincidente ao eixo z. O referencial da molécula, de coordenadas $(x, y, z)$ é então rotacionado para o referencial do laboratório, de coordenadas $\left(x^{\prime}, y^{\prime}, z^{\prime}\right)$. Para tal são utilizadas as matrizes de Wigner $D_{m, m^{\prime}}^{(l)}\left(\varphi_{i}, \theta_{i}, 0\right)$, onde $\varphi_{i}$ e $\theta_{i}$ são os ângulos azimutal e polar associados ao eixo z. No novo referencial, os harmônicos esféricos assumem a forma:

$$
Y_{l}^{m}\left(\hat{k}_{f}^{\prime}\right)=\sum_{\mu} D_{\mu, m}^{(l)}\left(\varphi_{i}, \theta_{i}, 0\right) Y_{l}^{\mu}\left(\hat{k}_{f}\right)
$$

Invertendo essa relação e substituindo na equação 2.53 obtemos a expressão para a amplitude de espalhamento no referencial do laboratório:

$$
f^{L}\left(\vec{k}_{f}^{\prime}, \vec{k}_{i}\right)=\sum_{l, m, \mu} f_{l, m}\left(k_{f}, \vec{k}_{i}\right) D_{m, \mu}^{(l) *}\left(\varphi_{i}, \theta, 0\right) Y_{l}^{\mu}\left(\hat{k}_{f}^{\prime}\right)
$$

Nesse ponto podemos calcular efetivamente as seções de choque, que constituem o objeto central numa situação de espalhamento, sendo a quantidade física medida experimentalmente. A seção de choque diferencial $(d \sigma / d \Omega)^{L}$ é definida como a razão entre o fluxo de partículas espalhadas numa direção $\left(\theta_{f}, \phi_{f}\right)$ e a densidade de fluxo de partículas incidentes. Ela fornece uma medida das direções preferenciais para onde o projétil é espalhado. Pode ser obtida da amplitude de espalhamento através da expressão:

$$
\frac{d \sigma^{L}}{d \Omega}\left(\theta_{f}, \phi_{f}, k_{i}, k_{f}\right)=\frac{k_{f}}{4 \pi k_{i}} \int d \hat{k}_{i}\left|f^{L}\left(\vec{k}_{f}, \vec{k}_{i}\right)\right|^{2} .
$$

A integral em $d \hat{k}_{i}$ representa uma média sobre todas as direções do elétron incidente. Ou, de forma equivalente, uma média sobre as orientações espaciais da molécula. Isso é feito porque num experimento envolvendo colisão de elétrons por moléculas em fase gasosa, as moléculas estão orientadas aleatoriamente. A quadratura de Gauss-Legendre é utilizada novamente no cálculo da integral em $d \hat{k}_{f}$, na equação 2.54 , e da integral em $d \hat{k}_{i}$, 
na equação 2.57. Por fim, a seção de choque diferencial usualmente apresentada $d \sigma / d \Omega$ é obtida ao realizar uma média sobre a direção azimutal $\phi_{f}$, uma média sobre os estados iniciais do spin e uma soma sobre os estados finais do spin, passando a depender apenas da direção $\theta_{f}$ e das energias inicial e final do projétil.

Integrando essa seção de choque diferencial ao longo da direção $\theta_{f}$, obtemos a seção de choque integral:

$$
\sigma\left(k_{i}, k_{f}\right)=\int_{0}^{\pi} d \theta_{f} \operatorname{sen}\left(\theta_{f}\right) \frac{d \sigma}{d \Omega}
$$

a qual depende apenas das energias inicial e final da partícula incidente. A seção de choque integral dá uma medida da probabilidade de que projétil e alvo interajam, havendo então uma transição do canal inicial $i$ para o canal final $f$.

Nesse trabalho nos concentramos em colisões elétron-molécula eletronicamente elásticas. Nesse caso, $\left|\vec{k}_{i}\right|=\left|\vec{k}_{f}\right|$, o operador $P$ projeta apenas no estado fundamental da molécula:

$$
P=\left|\Phi_{0}\right\rangle\left\langle\Phi_{0}\right|
$$

e as seções de choque calculadas são ditas elásticas.

Todas as curvas de seção de choque elásticas aqui apresentadas passaram por um tratamento numérico a fim de se eliminar estruturas espúrias, tipicamente advindas de problemas de dependência linear da base atômica. Isso foi realizado através da decomposição em valores singulares (SVD, do inglês, singular value decomposition) da matriz $A^{(+)}$(equações 2.37 e 2.38). No momento da inversão da matriz, foram eliminados os vetores singulares associados aos menores valores singulares, até que a seção de choque se torne numericamente estável. Usualmente, é necessário eliminar entre zero e cinco vetores singulares. 


\subsection{Descrição da dinâmica nuclear}

\subsubsection{Formalismo dos operadores de projeção de Feshbach}

Uma vez tendo descrito o processo do espalhamento eletrônico, passamos ao problema da dinâmica dos núcleos, que será realizada por meio do formalismo de operadores de projeção de Feshbach [70]. O formalismo é uma poderosa ferramenta para a descrição da dinâmica nuclear de estados ressonantes de moléculas [71-73], embora o formalismo seja geral, podendo ser aplicado para estados virtuais ou ligados e para colisões envolvendo outras partículas [74]. A ideia central do formalismo de Feshbach consiste em decompor o espaço de Hilbert eletrônico em duas componentes, um estado discreto $\left|\phi_{d}\right\rangle$ e um contínuo de estados $\left|\phi_{\vec{k}}\right\rangle$ :

$$
\begin{gathered}
\mathfrak{Q}=\left|\phi_{d}\right\rangle\left\langle\phi_{d}\right|, \\
\mathfrak{P}=\int d k k d \Omega_{\vec{k}}\left|\phi_{\vec{k}}\right\rangle\left\langle\phi_{\vec{k}}\right|,
\end{gathered}
$$

de modo que $\mathfrak{P}+\mathfrak{Q}=1$ e $\mathfrak{P Q}=0$. Por simplicidade, a descrição realizada considera a existência de apenas um estado discreto, mas o resultado é geral e válido para um maior número de estados.

O formalismo de operadores de Feshbach pode ser desenvolvido na representação independente do tempo ou dependente do tempo. As abordagens são equivalentes, embora cada uma ofereça visões distintas sobre a dinâmica e dê origem a diferentes implementações computacionais. Iremos apresentar o formalismo dependente do tempo, embora façamos um conexão com as equações independentes do tempo mais adiante.

O hamiltoniano da colisão elétron-molécula é dado por:

$$
H=T_{n}+T_{e}+H_{n}+V \equiv T_{n}+H_{e l e}
$$

onde $T_{n}$ e $T_{e}$ indicam respectivamente a energia cinética dos núcleos e do elétron incidente, $H_{n}$ é o hamiltoniano eletrônico da molécula isolada e $V$ é a interação elétron-molécula. $H_{\text {ele }}$ define portanto o hamiltoniano total menos a energia cinética nuclear. 
A função de onda eletrônico-nuclear $|\Psi(t)\rangle$ pode ser projetada nos espaços $P$ e $Q$, dando origem às funções de onda nucleares:

$$
\begin{aligned}
\left|\psi_{d}(t)\right\rangle & =\left\langle\phi_{d} \mid \Psi(t)\right\rangle, \\
\left|\psi_{\vec{k}}(t)\right\rangle & =\left\langle\phi_{\vec{k}} \mid \Psi(t)\right\rangle .
\end{aligned}
$$

Substituindo na equação de Schroedinger dependente do tempo para o hamiltoniano dado acima, podemos obter a solução geral do problema. Impomos então a condição inicial:

$$
\begin{gathered}
\left|\psi_{d}(t=0)\right\rangle=V_{d \vec{k}_{i}}|\nu\rangle, \\
\left|\psi_{\vec{k}}(t=0)\right\rangle=0
\end{gathered}
$$

onde $\vec{k}_{i}$ é o momento do elétron incidente e $|\nu\rangle$ representa o estado vibracional inicial da molécula. O acoplamento discreto-contínuo é dado pela amplitude de entrada $V_{d \vec{k}_{i}}$. Já escrevendo na representação das posições dos núcleos (indicada aqui por $R$ ), o pacote de onda nuclear no estado discreto do ânion será regido por uma equação de Schroedinger dependente do tempo efetiva:

$$
i \frac{\partial}{\partial t} \psi_{d}(R, t)=\left[T_{n}+V_{d}(R)\right] \psi_{d}(R, t)+\frac{1}{i} \int_{0}^{t} d t^{\prime} \int d R^{\prime} F\left(R, R^{\prime} ; t-t^{\prime}\right) \psi_{d}\left(R^{\prime}, t^{\prime}\right),
$$

onde o chamado kernel de memória é dado por:

$$
F\left(R, R^{\prime} ; t\right)=\int d k k d \Omega_{\vec{k}} V_{d \vec{k}}(R) e^{i t \vec{k}^{2} / 2} K_{0}\left(R, R^{\prime} ; t\right) V_{\vec{k} d}\left(R^{\prime}\right)
$$

e

$$
K_{0}\left(R, R^{\prime} ; t\right)=\left\langle R\left|e^{-i\left[T_{n}+V_{0}\right] t}\right| R^{\prime}\right\rangle
$$

é o propagador de Feynmann para o movimento nuclear da molécula isolada, sendo $V_{0}(R)$ sua superfície de energia potencial. $V_{d}(R)$ representa a superfície de energia potencial do estado do ânion.

O potencial $V_{d}(R)$, juntamente com o operador complexo e não-local no tempo e na posição, definem um potencial efetivo para o movimento nuclear. Portanto, a evolução do pacote de onda depende de seu estado em todos os tempos passados, bem como em 
todas as posições, de modo que há um efeito de memória na sua evolução. Sua dinâmica é governada portanto por um processo não-Markoviano.

Como estamos interessados na dinâmica nuclear induzida pela formação de um estado do ânion, a condição inicial do pacote de onda deve ser:

$$
\psi_{d}(R, t=0)=V_{d \vec{k}_{i}}(R) \chi_{\nu}(R)
$$

onde $\chi_{\nu}(R)$ representa a função de onda vibracional inicial da molécula isolada.

Uma vez resolvido o problema para $\psi_{d}(R, t)$, podemos calcular a matriz $T$, que é essencialmente igual à amplitude de espalhamento, a menos de um fator de normalização. Para espalhamento vibracionalmente elástico ou inelástico, onde há uma transição do estado inicial $\nu$ para o estado final $\nu^{\prime}$, a matriz $T$ é calculada como:

$$
T_{\nu^{\prime} \nu}(E)=\frac{1}{i} \int_{0}^{\infty} d t e^{i E t} \int d R \chi_{\nu^{\prime}}^{*} V_{d \vec{k}_{f}}^{*}(R) \psi_{d}(R, t)
$$

onde $\vec{k}_{f}$ representa o vetor de onda do elétron espalhado. Para a captura eletrônica dissociativa, a expressão é:

$$
T_{\mathrm{DEA}}(E)=\left[\frac{K}{2 \pi \mu}\right]^{1 / 2} \lim _{R \rightarrow \infty} e^{-i K R} \int_{0}^{\infty} d t \psi_{d}(R, t) e^{i E t}
$$

onde $K$ é momento relativo dos fragmentos gerados na dissociação. As seções de choque dos dois processos são dadas por:

$$
\sigma_{\nu^{\prime} \nu}(E)=\frac{4 \pi^{3}}{k_{i}^{2}}\left|\overline{T_{\nu^{\prime} \nu}(E)}\right|^{2}
$$

e

$$
\sigma_{\mathrm{DEA}}(E)=\frac{4 \pi^{3}}{k_{i}^{2}}\left|\overline{T_{D E A}(E)}\right|^{2},
$$

onde a barra sobre a matriz $T$ indica uma média sobre as orientações da molécula.

Nesse ponto vamos apresentar os resultados obtidos da formulação independente do tempo e indicar as conexões com a formulação dependente. A função de onda, nesse caso dependente na energia, será solução de uma equação de Schroedinger independente do tempo efetiva:

$$
\left[T_{n}+V_{d}(R)-E\right] \psi_{d}(R, E)+\int_{0}^{\infty} d R^{\prime} F\left(R, R^{\prime} ; E-H_{0}\right) \psi_{d}\left(R^{\prime}, E\right)=V_{d \vec{k}_{i}}(R) \psi_{d}(R, E),
$$


onde agora temos um termo não-local na posição e na energia, que pode ser decomposto em parte real e imaginária:

$$
F\left(R, E-H_{0}\right)=\Delta\left(R, E-H_{0}\right)-\frac{i}{2} \Gamma\left(R, E-H_{0}\right) .
$$

O termo $\Gamma$ representa a largura do estado discreto, e está associado ao tempo de vida finito desse estado, sendo dado por:

$$
\Gamma(R, E)=2 \pi \int d \Omega_{k}\left|V_{d \vec{k}}(R)\right|^{2}
$$

A contribuição real $\Delta$ é denominada level-shift, e representa um deslocamento na energia do estado discreto devido ao acoplamento com o contínuo, tendo a expressão:

$$
\Delta(R, E)=\mathscr{P} \int \frac{d E^{\prime}}{2 \pi} \frac{\Gamma\left(R, E^{\prime}\right)}{E-E^{\prime}}
$$

onde $\mathscr{P}$ denota o valor principal de Cauchy.

A conexão entre as descrições dependente e independente do tempo é feita através da transformada de Laplace. A função de onda independente do tempo e o operador não-local na energia definido acima estão relacionados com seus análogos dependentes do tempo por:

$$
\psi_{d}(R, E)=\frac{1}{i} \int_{0}^{\infty} d t e^{i E t} \psi_{d}(R, t)
$$

e

$$
F\left(R, R^{\prime} ; E\right)=\frac{1}{i} \int_{0}^{\infty} d t e^{i E t} F\left(R, R^{\prime} ; t\right)
$$

respectivamente.

\subsubsection{Aproximação local}

As equações 2.67 e 2.75 para a função de onda dependente ou independente do tempo são formalmente exatas, mas muito complicadas de serem tratadas computacionalmente, devido a efeitos de memória na primeira e ao caráter não-local da energia 
na segunda, além do caráter não-local da posição em ambas. Nesse ponto o problema passa a ser tratado na chamada aproximação local [75], que consiste em ignorar efeitos de memória e não-locais, aproximando o kernel $F$ por:

$$
F\left(R, R^{\prime} ; t-t^{\prime}\right)=i\left[\Delta_{L}(R)-\frac{i}{2} \Gamma_{L}(R)\right] \delta\left(R-R^{\prime}\right) \delta\left(t-t^{\prime}\right)
$$

onde $\Gamma_{L}$ e $\Delta_{L}$ correspondem à largura e ao level-shift locais:

$$
\begin{gathered}
\Gamma_{L}(R)=\Gamma\left(R, \epsilon_{d}(R)\right), \\
\Delta_{L}(R)=\Delta\left(R, \epsilon_{d}(R)\right),
\end{gathered}
$$

onde $\epsilon_{d}$ é a energia real da ressonância, dada implicitamente por:

$$
\epsilon_{d}(R)=V_{d}(R)-V_{0}(R)+\Delta\left(R, \epsilon_{d}(R)\right)
$$

Com essa aproximação, a equação 2.75 para a evolução temporal da função de onda assume um formato mais familiar:

$$
i \frac{\partial}{\partial t} \psi_{d}(R, t)=\left[T_{n}+V_{o p t}\right] \psi_{d}(R, t)
$$

onde o potencial efetivo, ou potencial ótico $V_{\text {opt }}$ é dado por:

$$
V_{\text {opt }}(R)=V_{d}(R)+\Delta_{L}(R)-\frac{i}{2} \Gamma_{L}(R)
$$

Com a aproximação local, portanto, passamos da equação integro-diferencial 2.75 para uma equação diferencial parcial, que é muito mais simples de se implementar computacionalmente.

Embora a aproximação local despreze a dependência energética de $\Gamma$ e $\Delta$ na dinâmica do pacote de onda, as amplitudes de entrada $V_{d \vec{k}_{i}}$ e saída $V_{\vec{k}_{f} d}$ ainda mantém essa dependência. Se a dependência na energia for mantida nas amplitudes, temos a chamada aproximação semi-local [76], mas caso ela seja ignorada também nesses termos, a aproximação é dita totalmente local. No nosso caso, a dinâmica é descrita na aproximação semi-local.

Embora consideremos a dependência explícita de $\Gamma$ na energia e na posição, 
uma importante simplificação que facilita a propagação temporal do pacote de onda consiste em desacoplar a função em duas componentes:

$$
\Gamma(E, R)=\Gamma(E) g(R)^{2}
$$

Considerando a condição inicial 2.70, podemos definir uma função de onda modificada:

$$
\tilde{\psi}_{d}(R, t)=\left(\frac{2 \pi}{\Gamma\left(E_{i}\right)}\right)^{1 / 2} \psi_{d}(R, t),
$$

com a condição inicial

$$
\tilde{\psi}_{d}(R, 0)=g(R) \chi_{\nu}(R)
$$

A grande vantagem em separar as dependências em energia e posição é que tendo realizado a propagação de uma única função $\tilde{\psi}_{d}(R, t)$, as amplitudes de espalhamento podem ser calculadas para qualquer energia. As expressões para a matriz $T$ ficam então:

$$
\begin{gathered}
T_{\nu^{\prime} \nu}(E)=\frac{1}{2 \pi i}\left[\Gamma\left(E_{f}\right) \Gamma\left(E_{i}\right)\right]^{1 / 2} \int_{0}^{\infty} d t \int d R \chi_{\nu^{\prime}}^{*}(R) g(R) \tilde{\psi}_{d}(R, t) e^{i E t}, \\
T_{\mathrm{DEA}}(E)=\left[\frac{K \Gamma\left(E_{i}\right)}{4 \pi^{2} \mu}\right]^{1 / 2} \lim _{R \rightarrow \infty} e^{-i K R} \int_{0}^{\infty} d t \tilde{\psi}_{d}(R, t) e^{i E t} .
\end{gathered}
$$

Em nosso caso, o estado discreto representa uma ressonância de baixa energia do ânion. Na geometria de equilíbrio da molécula neutra, mantém-se o caráter não-local nas amplitudes de entrada e saída. A autofase obtida dos cálculos de espalhamento é modelada por:

$$
\delta(E)=\delta_{b g}(E)+\delta_{d}(E)
$$

onde a componente de background é dada por:

$$
\delta_{b g}(E)=a E^{1 / 2}
$$

enquanto a componente ressonante é escrita como:

$$
\delta_{d}(E)=-\tan ^{-1}\left(\frac{\Gamma(E) / 2}{E-\epsilon_{d}-\Delta(E)}\right) .
$$

A dependência da largura com a energia é representada por:

$$
\Gamma(E)=A E^{l+1 / 2} e^{-b E},
$$


que respeita a lei de threshold de Wigner [77]:

$$
\Gamma(E \rightarrow 0) \propto E^{l+1 / 2},
$$

onde $l$ indica a menor onda parcial que compõe o estado da ressonância. Além disso, essa função tem a grande vantagem de fornecer uma expressão analítica para o level-shift [78], obtida através da equação 2.78 .

\subsubsection{Propagação do pacote de onda}

Uma vez resolvido o problema do espalhamento eletrônico numa dada configuração dos núcleos $R$, a energia complexa da ressonância (parte real $\epsilon_{d}$ e parte imaginária $\Gamma_{L}$ ) pode ser obtida a partir da soma de autofases. Em torno da região da ressonância, essa é ajustada por:

$$
\delta(E)=\tan ^{-1}\left[\frac{\Gamma_{L} / 2}{E-\epsilon_{d}}\right]+\left[a_{0}+a_{1} E+a_{2} E^{2}\right]
$$

onde o termo de Breit-Wigner captura o comportamento da ressonância, enquanto o termo polinomial descreve a contribuição de background. O problema de espalhamento é resolvido para uma série de configurações $R$ distintas, de onde se obtém o comportamento da ressonância em função da posição, $\epsilon_{d}(R)$ e $\Gamma_{L}(R)$.

Cálculos usuais de estrutura eletrônica, realizados preferencialmente com o mesmo método e base adotado na otimização de sua geometria, fornecem a superfície de energia potencial do estado neutro da molécula isolada $V_{0}(R)$. Finalmente, a superfície de energia potencial real do estado discreto do ânion é obtida por $V_{d}(R)=V_{0}(R)+\epsilon_{d}(R)$, enquanto sua componente imaginária é simplesmente $\Gamma_{L}(R)$.

Após a obtenção de alguns pontos representativos, esses são ajustados a alguma forma funcional, que irá representar as superfícies de energia potencial nos cálculos de dinâmica. Para cada dimensão em que a superfície foi construída, empregamos uma rede espacial de $2^{N}$ pontos, com $N$ inteiro. Isso garante que a técnica FFT (do inglês 
fast Fourier transform) [79] seja aplicada para facililtar os cálculos de propagação. O espectro vibracional da superfície do estado neutro é obtido de acordo com a técnica energy-screening [80].

A propagação do pacote de onda $\Psi$ segue a equação de Schroedinger dependente do tempo:

$$
\psi(t)=\hat{U}(t, 0) \psi(0)
$$

onde o operador de evolução temporal é dado por:

$$
\hat{U}(t, 0)=e^{-i \hat{H} t}
$$

No cálculo computacional, a propagação é realizada em pequenos intervalos de tempo $\Delta t$, de modo que:

$$
\hat{U}(t, 0)=\prod_{n=0}^{N_{t}-1} \hat{U}[(n+1) \Delta t, n \Delta t],
$$

onde $N_{t}$ é o número total de passos, também escrito como uma potência de 2 , e o intervalo de tempo é determinado por $\Delta t=t / N_{t}$.

Como os operadores de energia cinética $\hat{T}$ e energia potencial $\hat{V}$ não comutam, a propagação do operador de evolução temporal introduz um erro de segunda ordem no intervalo de tempo. Através da técnica Split-Operator [81], esse erro é reduzido para terceira ordem. A ideia consiste em separar de modo simétrico uma das componentes do hamiltoniano (cinética ou potencial). Para um esquema em que o termo potencial permanece no centro do operador, a evolução temporal assume a forma:

$$
\psi(t+\Delta t)=e^{-i \hat{T} \Delta t / 2} e^{-i \hat{V} \Delta t} e^{-i \hat{T} \Delta t / 2} \psi(t)
$$

A fim de evitar reflexões espúrias do pacote de onda no extremo da grade numérica, adota-se uma função de amortecimento [82], que atua sobre a função de onda a partir de uma certa distância, atenuando-a continuamente até zero. 


\section{Capítulo 3}

\section{Pequenas moléculas halogenadas}

\subsection{Introdução}

A investigação teórica da dinâmica das halouracilas exige várias aproximações e uma série de cálculos dispendiosos. A fim de compreender melhor como obter uma descrição que ofereça um bom compromisso entre acurácia e custo computacional, é interessante que moléculas menores sejam alvo inicial de estudo. Desse modo, o conhecimento adquirido para sistemas mais simples será fundamental para que se faça boas escolhas na descrição de biomoléculas mais complexas. Como a dinâmica de dissociação da 5-clorouracila se dá na ligação $\mathrm{C}-\mathrm{Cl}$, elegemos como modelo a molécula mais simples que apresente essa ligação, o clorometano. Consideramos ainda o cloroeteno, que servirá de modelo para avaliar o mecanismo indireto de dissociação que envolve o acoplamento entre os estados $\pi^{*}$ e $\sigma_{\mathrm{CCl}}^{*}$, que também deve estar presente na 5-clorouracila. Na figura 3.1 as estruturas geométricas do clorometano e do cloroeteno são apresentadas.

O clorometano possui uma ressonância de forma $\sigma_{\mathrm{CCl}}^{*}$ bem conhecida [83-87], cujo curto tempo de vida não permite que a molécula dissocie. Por outro lado, a formação do ânion induz forte excitação vibracional, em especial do modo dominado pelo estira- 


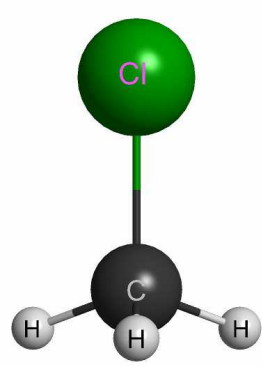

(a) Clorometano

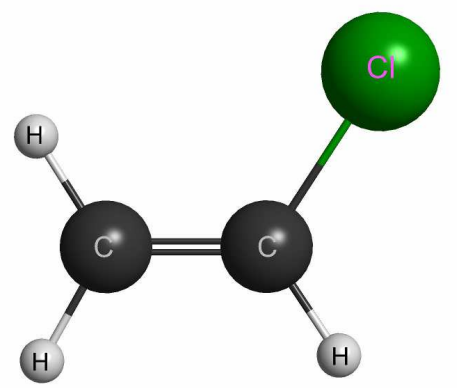

(b) Cloroeteno

Figura 3.1: Estrutura geométrica do clorometano e do cloroeteno.

mento $\mathrm{C}-\mathrm{Cl}$. A molécula de cloroeteno apresenta duas ressonâncias, uma $\pi^{*}$ e uma $\sigma^{*}[88,89]$. Medidas do espectro de fragmentos gerados por colisão com elétrons aponta um pico na formação do fragmento $\mathrm{Cl}^{-}$exatamente na posição da ressonância $\pi^{*}$, sugerindo a existência de um mecanismo indireto de dissociação $[88,89]$. No entanto, não há qualquer trabalho teórico que busque descrever a dissociação do ânion de cloroeteno.

A principal motivação em estudar o clorometano e o cloroeteno é de que sirvam como sistemas modelo das halouracilas. Poderemos avaliar aspectos como a construção a partir de cálculos de espalhamento de curvas e superfícies de energia potencial dos estados do ânion, a escolha das coordenadas reativas, modelos para os potenciais diabáticos, além da dinâmica do pacote de onda. Além disso, resultados teóricos para esses sistemas ainda são escassos, o que os torna interessantes em si. Para o clorometano, queremos fornecer uma descrição teórica do processo de excitação vibracional, comparando as seções de choque com os dados experimentais. Quanto ao cloroeteno, buscamos avaliar a relevância do mecanismo direto de dissociação para o pico experimental observado na formação do fragmento $\mathrm{Cl}^{-}$. Realizamos cálculos de espalhamento elástico de elétrons na geometria de equilíbrio da molécula neutra, através do método multicanal de Schwinger implementado com pseudopotenciais, nas aproximações estático-troca e estático-troca mais polarização. As energias dos estados do ânion são comparados com os valores experimentais existentes [83-86,88-90]. Também comparamos a seção de choque integral elástica do clorometano com dois trabalhos experimentais $[91,92]$. Para ambas as moléculas construímos 
curvas de energia potencial ao longo do estiramento $\mathrm{C}-\mathrm{Cl}$, e para o cloroeteno geramos ainda superfícies de energia potencial em que o ângulo que move o cloro para fora do plano entra como a segunda coordenada. Realizamos a propagação do pacote de onda nuclear nas curvas de energia potencial, de onde calculamos seções de choque de excitação vibracional para o clorometano, e seções de choque de dissociação para o cloroeteno, que são comparadas com os resultados experimentais disponíveis [87-89,93].

\subsection{Procedimentos computacionais}

A descrição do espalhamento foi realizada na geometria de equilíbrio do estado eletrônico fundamental da molécula neutra. Para a otimização do clorometano empregamos o método DFT, enquanto que para o cloroeteno a otimização foi realizada com o método MP2. Os cálculos de otimização foram realizados com o programa Gaussian09 [94], com uso da base aug-cc-pVTZ. Em todos os cálculos realizados com o método DFT adotamos o funcional híbrido Becke, 3-parameter, Lee-Yang-Parr (B3LYP) [95], que é amplamente utilizado para tratar sistemas moleculares e reconhecido por oferecer uma boa descrição de várias grandezas. Em particular, o funcional é adequado para cálculos de otimizações de geometria e de curvas de energia potencial de estados fundamentais ligados, que são as situações em que o método é aqui empregado.

Tendo obtido as geometrias de equilíbrio o alvo isolado foi descrito por meio do método Hartree-Fock restrito. Pseudopotenciais de norma conservada de BHS [66] foram empregados para substituir os núcleos e os elétrons de caroço dos átomos de carbono e de cloro. Utilizamos um conjunto de funções gaussianas-cartesianas geradas de acordo com Bettega et al. [68], sendo essas funções adaptas ao uso dos pseudopotenciais de BHS. Adotamos uma base $5 s 5 p 2 d$ para os átomos de carbono e uma base $6 s 5 p 2 d$ para o átomo de cloro, cujos expoentes estão apresentados na tabela 3.1. A base 3s de Dunning [96] foi utilizada para os hidrogênios. Tanto na descrição do alvo como nos cálculos de espalha- 
Tabela 3.1: Exponentes das funções gaussianas-cartesianas do carbono e do cloro (em unidades atômicas).

\begin{tabular}{crr}
\hline Tipo & Cloro & Carbono \\
\hline \hline$s$ & 10,490650 & 12,496280 \\
$s$ & 6,836599 & 2,470286 \\
$s$ & 2,420592 & 0,614028 \\
$s$ & 0,513579 & 0,184028 \\
$s$ & 0,188863 & 0,039982 \\
$s$ & 0,062954 & \\
\hline$p$ & 6,037205 & 5,228869 \\
$p$ & 2,012401 & 1,592058 \\
$p$ & 0,686842 & 0,568612 \\
$p$ & 0,218056 & 0,210326 \\
$p$ & 0,071193 & 0,072250 \\
\hline$d$ & 1,611766 & 0,603592 \\
$d$ & 0,328314 & 0,156753 \\
\hline \hline
\end{tabular}

mento foram utilizados pseudopotenciais de BHS e o conjunto de funções de base acima mencionado. Obtivemos um total de 70 funções para representar os elétrons de valência do clorometano, e 109 para o cloroeteno. A descrição do estado eletrônico do alvo foi realizado com o pacote GAMESS [97].

MVOs [65] foram utilizados para representar os orbitais de partícula e de espalhamento. Esses orbitais foram gerados no campo do cátion de carga +6 para o caso do clorometano, e de carga +8 nos cálculos do cloroeteno. Embora a clorometano pertença ao grupo pontual $C_{3 v}$, ele foi tratado no grupo pontual $C_{s}$, o que facilita que exploremos as operações de simetria na realização dos cálculos. Portanto, clorometano e cloroeteno foram descritos no grupo pontual $C_{s}$, de modo que as seções de choque foram calculadas em separado para cada representação irredutível do grupo, as compo- 
nentes $A^{\prime}$ e $A^{\prime \prime}$. As configurações foram obtidas de acordo com o critério de energia [37] $\varepsilon_{\text {espa }}+\varepsilon_{\text {part }}-\varepsilon_{\text {bura }}<\varepsilon_{\text {cut }}$, onde $\varepsilon_{\text {espa }}$, $\varepsilon_{\text {part }}$ e $\varepsilon_{\text {bura }}$ representam a energia dos orbitais de espalhamento, partícula e buraco, respectivamente. Adotamos $\varepsilon_{\text {cut }}=-2,20$ hartree para clorometano e $\varepsilon_{\text {cut }}=-2,60$ hartree para cloroeteno, de modo que as configurações que satisfazem o critério de energia acima foram incluídas no espaço de configurações, onde excitações virtuais de acoplamento singleto e tripleto foram consideradas. Para o clorometano os cálculos de espalhamento envolveram 1212 configurações, sendo 641 na simetria $A^{\prime}$ e 571 na $A^{\prime \prime}$. E para o cloroeteno, obtivemos um total de 4450 configurações, sendo 2342 na simetria $A^{\prime}$ e 2108 na $A^{\prime \prime}$.

\subsection{Clorometano}

Na figura 3.2 é apresentada a seção de choque integral elástica do clorometano, calculada nas representações irredutível $A^{\prime}$ e $A^{\prime \prime}$ e nos dois níveis de aproximação, SE e SEP. A estrutura presente em torno de 6,9 eV na aproximação SE é a assinatura de uma ressonância de forma. A fim de melhor inspecionar o caráter das ressonâncias, foram calculados os orbitais virtuais a partir de uma base compacta, precedimento rotineiramente adotado na interpretação do espectro de transmissão de elétrons e de cálculos de espalhamento. Num cálculo com base compacta os orbitais virtuais apresentam caráter de valência, estando localizados na região da molécula, e por isso representam qualitativamente bem o perfil do orbital ressonante. Todos os orbitais virtuais que serão aqui apresentados com o intuito de mostrar o caráter das ressonâncias foram obtidos de cálculos efetuados para a molécula neutra, com o método Hartree-Fock e base 6-31G(d), onde o valor de 0,04 unidades atômicas foi adotado para a geração das superfícies de isoprobabilidade, salvo quando indicado o contrário. O LUMO do clorometano, mostrado na figura 3.3, é fortemente anti-ligante na ligação $\mathrm{C}-\mathrm{Cl}$, e por isso a estrutura da seção de choque é caracterizada como uma ressonância $\sigma_{\mathrm{CCl}}^{*}$. 


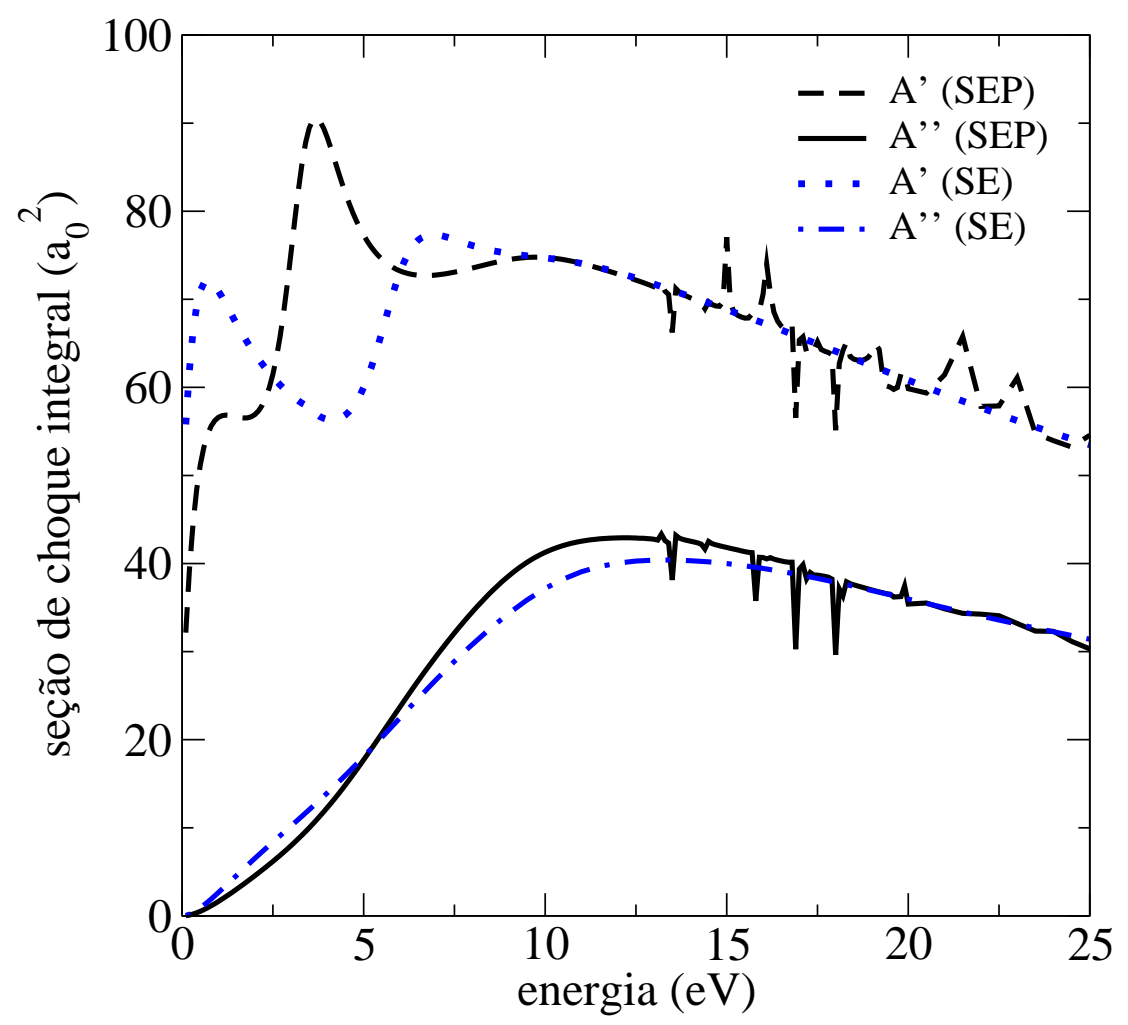

Figura 3.2: Seção de choque integral das simetrias $A^{\prime}$ e $A^{\prime \prime}$ do clorometano, calculadas nas aproximações SE e SEP.

Com a inclusão de efeitos de polarização, a estrutura ressonante se move para menores energias e torna-se mais pronunciada. Nesse nível de cálculo ela se situa em 3,46 eV, com uma largura de 1,90 eV. Experimentos de espectroscopia de transmissão de elétrons [83-86] revelam a ressonância $\sigma_{\mathrm{CCl}}^{*}$ em torno de $3,45 \mathrm{eV}$, em ótimo acordo com nosso resultado. Esse tipo de experimento fornece ainda uma estimativa da largura da ressonância, obtida da diferença em energia entre as posições do mínimo e do máximo no sinal da corrente transmitida. Seu valor foi estimado em 3,05 eV [83,84], acima do valor obtido pelo nosso cálculo de espalhamento, de 1,90 eV. Essa diferença é esperada, tendo em vista que o cálculo é realizado na aproximação de núcleos fixos, e portanto a presença de diferentes níveis vibracionais é ignorada. No experimento, a captura e a ejeção eletrônica são processos vibrônicos e portanto a largura observada deve ser maior do que a obtida de um cálculo com núcleos fixos. Nosso resultado está em acordo ainda com o 


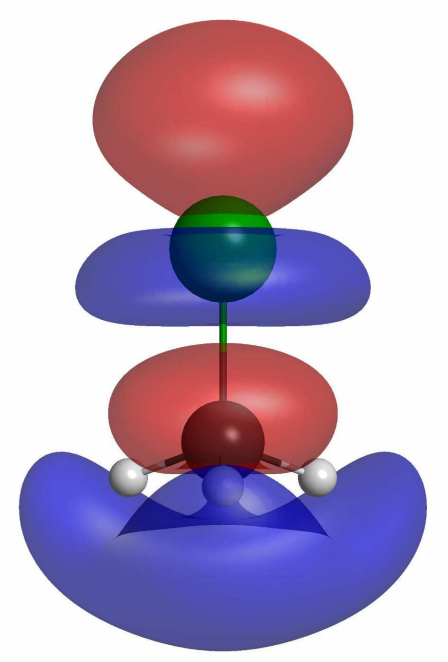

Figura 3.3: Orbital $\sigma_{\mathrm{CCl}}^{*}$ do clorometano.

cálculo de espalhamento realizado com o método de Kohn [90], que reporta a ressonância em 3,5 eV. Mach et al., adotando o método de estabilização de cálculos de estado ligado, reporta a energia da ressonância em 2,46 eV, com uma largura ao redor em 4 eV [98]. Esse resultado subestima a energia da ressonância, enquanto superestima sua largura.

A componente $A^{\prime}$ apresenta ainda uma estrutura larga em torno de $10 \mathrm{eV}$ segundo o cálculo SEP, pouco clara na aproximação SE. Na simetria $A^{\prime \prime}$ há uma estrutura larga ao redor de $12 \mathrm{eV}$, sofrendo um pequeno deslocamento a partir do resultado SE. O clorometano apresenta ainda uma ressonância de forma de simetria $E$, cuja existência foi inferida em experimentos de excitação vibracional [87], e que deve contribuir para a estrutura em torno de $10 \mathrm{eV}$. Porém, tal ressonância possui largura considerável e sua presença na seção de choque calculada se sobrepõe ao espalhamento de background e às ressonâncias de forma de mais alta energia. As curvas de seção de choque foram calculadas com uma maior resolução em energia a partir de $12 \mathrm{eV}$, a fim de evidenciar as instabilidades presentes em mais altas energias, chamadas de pseudoressonâncias. Essas são estruturas não-físicas que surgem nas seções de choque calculadas quando estados excitados do alvo, que estão abertos, não são incluídos no operador de projeção $P$. Nessa situação, o elétron incidente teria energia suficiente para excitar o alvo, mas não pode 


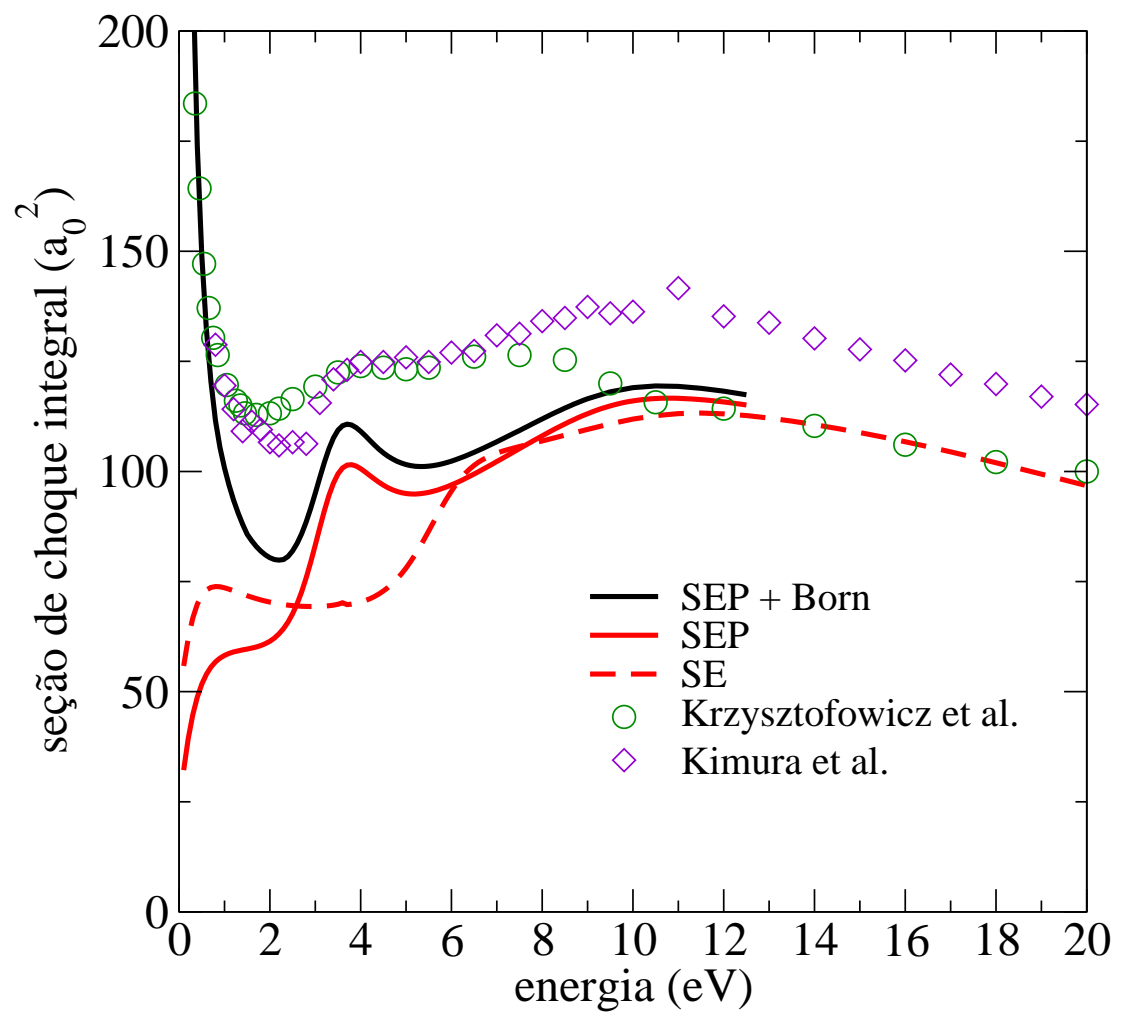

Figura 3.4: Seção de choque integral calculada para o clorometano, com e sem a correção de Born, juntamente com os valores experimentais de seção de choque total de Krzysztofowicz et al. [91] e de Kimura et al. [92].

fazê-lo porque o canal é mantido fechado no cálculo. O sistema inevitavelmente terá de retornar para o canal elástico, o que dá origem a estados do ânion com tempos de vida artificialmente longos, explicando as pseudorressonâncias da seção de choque. Em cálculos que permitam o acoplamento multicanal, as curvas de seção de choque elásticas adquirem um comportamento suave $[99,100]$.

A seção de choque integral somada, obtida a partir da soma direta das componentes $A^{\prime}$ e $A^{\prime \prime}$ está apresentada na figura 3.4. O resultado obtido do cálculo SEP é apresentado até $12,5 \mathrm{eV}$, pois para energias mais altas efeitos de polarização não são importantes e a aproximação SE é suficiente. De fato, as curvas de seção de choque obtidas nos dois níveis de cálculo são muito semelhantes a partir dessa energia. A figura apresenta ainda a seção de choque calculada a partir do procedimento Born-closure [9], que 
incorpora o potencial de longo alcance do momento de dipolo permanente, ignorado no cálculo de espalhamento. Medidas da seção de choque total de Krzysztofowicz et al. [91] e de Kimura et al. [92] também estão presentes na figura 3.4. A inclusão do efeito do momento dipolar causa um aumento na magnitude da seção de choque, sobretudo abaixo de $\sim 2 \mathrm{eV}$, sendo fundamental para descrever a acentuada subida em menores energias. Ambos os resultados experimentais observam a ressonância $\sigma_{\mathrm{CCl}}^{*}$ na região de $3-4 \mathrm{eV}$, com uma largura consideravelmente maior que a obtida em nosso cálculo, como já discutido. A estrutura na seção de choque calculada em torno de $10 \mathrm{eV}$ pode corresponder àquela observada em $10 \mathrm{eV}$ por Kimura et al. e em $7 \mathrm{eV}$ por Krzysztofowicz et al. A seção de choque calculada corresponde apenas ao canal elástico, e por isso deve ser inferior às medidas de seção de choque total, onde excitações ro-vibracionais, eletrônicas e ionização também podem contribuir. Como esses canais passam a ser relevantes acima de $\sim 10 \mathrm{eV}$, nosso resultado sugere que a medida de Krzysztofowicz et al. tenha subestimado a seção de choque total.

A fim de investigar a excitação vibracional do clorometano, foram realizados uma série de cálculos de espalhamento para a molécula em geometrias distorcidas. Foram considerados estiramentos da ligação $\mathrm{C}-\mathrm{Cl}$ de $-0,2,+0,2,+0,4,+0,6$ e $+0,8 a_{0}$, enquanto o restante da geometria foi mantida fixa. Na figura 3.5 apresentamos as seções de choque e a soma da autofases da simetria $A^{\prime}$. A ressonância $\sigma_{\mathrm{CCl}}^{*}$ se desloca para menores energia e fica mais fina a medida que a ligação é estirada, o que confirma o caráter anti-ligante na ligação $\mathrm{C}-\mathrm{Cl}$. No cálculo com estiramento de $+0.8 a_{0}$ não há assinatura da ressonância na seção de choque, indicando que o ânion virou um estado ligado. A autofase correspondente tende a $\pi$ quando a energia vai a $0 \mathrm{eV}$, indicando a presença desse estado ligado. Sua energia pode ser obtida da diagonalização do hamiltoniano de N+1 partículas na base de configurações utilizada no cálculo de espalhamento.

Em todas as curvas e superfícies de energia potencial aqui apresentadas, as curvas do ânion foram obtidas somando a energia da ressonância à energia do estado fundamental da molécula neutra, calculada no mesmo nível de cálculo em que foi realizada a otimização da geometria. As curvas de energia potencial do estado fundamental 

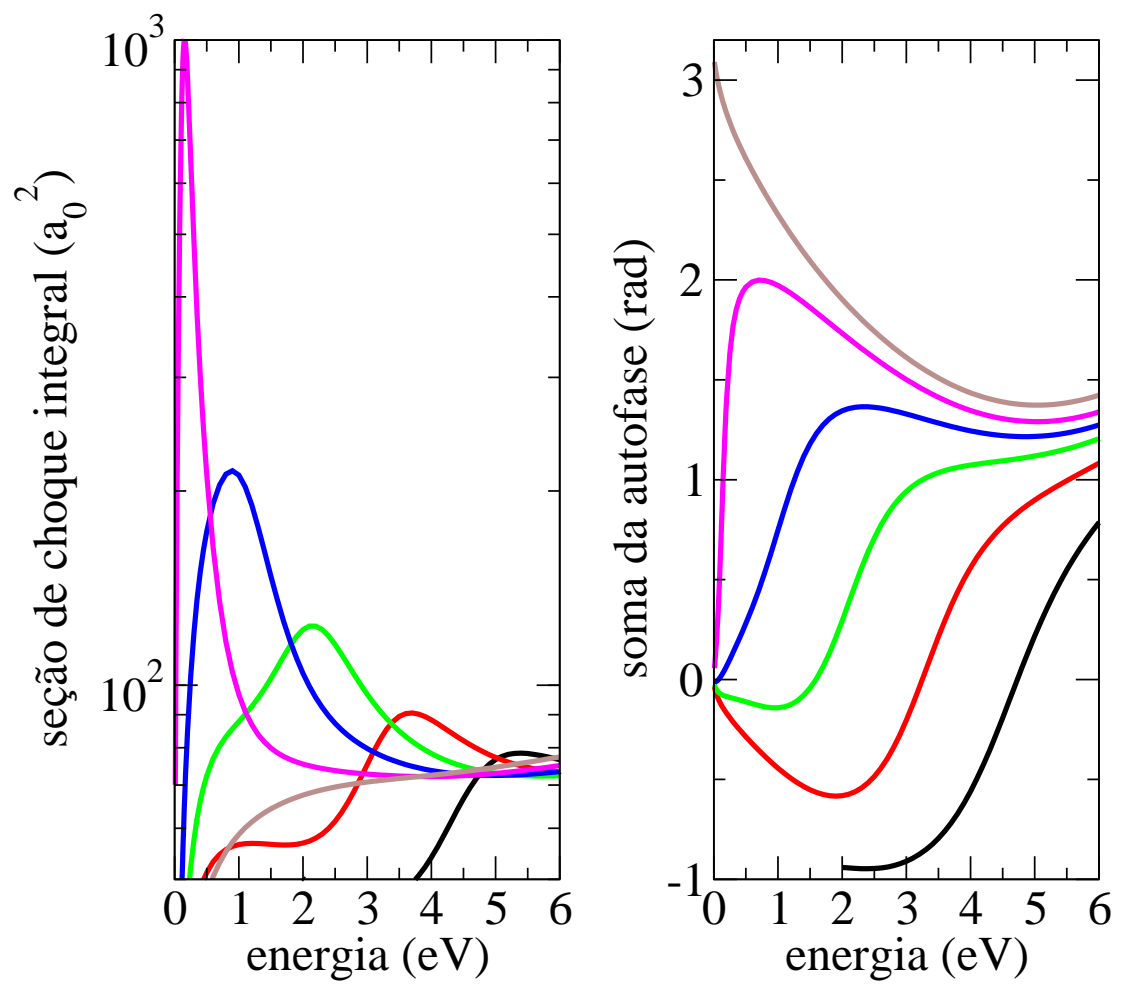

Figura 3.5: Seção de choque integral e soma da autofase da simetria $A^{\prime}$ do clorometano, calculadas para a distância $\mathrm{C}-\mathrm{Cl}$ de equilíbrio (preto) e para deslocamentos de $-0,2$ (vermelho), +0,2 (verde), $+0,4$ (azul), $+0,6$ (magenta) e $+0,8$ (marrom) $a_{0}$.

do neutro, e as componentes real e imaginária da ressonância $\sigma_{\mathrm{CCl}}^{*}$ do clorometano estão apresentados na figura 3.6. Condizente com o caráter dissociativo dessa ressonância, a curva do ânion estabiliza com o estiramento da ligação $\mathrm{C}-\mathrm{Cl}$ e cruza a curva do neutro, indicando que o estado deixa de ser ressonante e passa a ser um estado ligado. A partir desse ponto, o ânion pode ser descrito por meio de cálculos de estrutura eletrônica, usualmente mais baratos computacionalmente do que cálculos de espalhamento. A figura 3.6 também ilustra a curva do ânion nessa região, conforme obtida de cálculos no nível B3LYP/aug-cc-pVTZ, o mesmo empregado para construir a curva do estado neutro. A similaridade com resultados obtidos com método MP2 indicam que o funcional também é adequado para o nosso propósito. As curvas obtidas dos cálculos de espalhamento e de estado ligado se conectam de maneira relativamente suave, indicando que a descrição do 


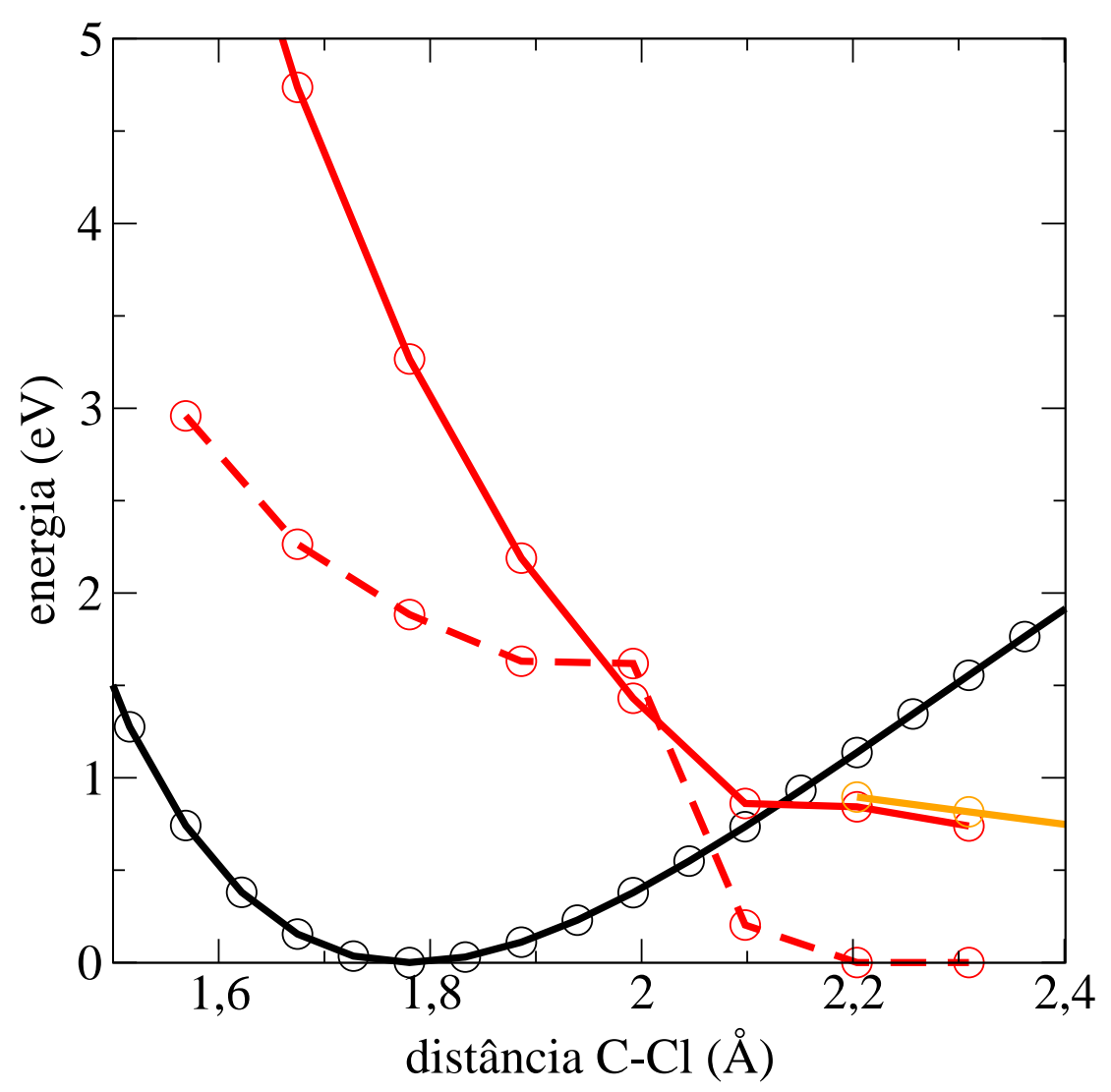

Figura 3.6: Curvas de energia potencial do clorometano, em função do comprimento da ligação $\mathrm{C}-\mathrm{Cl}$. Estão representadas as componentes real (vermelho, linha cheia) e imaginária (vermelho, linha tracejada) do estado $\sigma_{\mathrm{CCl}}^{*}$ do ânion, obtidas dos cálculos de espalhamento, bem como o estado da molécula neutra (preto) e o ânion na região em que esse é ligado (em laranja), obtidos por cálculos de estado ligado.

ânion está balanceada nos dois tipos de cálculo. A componente imaginária da ressonância também decresce a medida que o ânion é estabilizado. Nos dois últimos pontos da curva obtida do cálculo de espalhamento, o ânion é estável, não havendo possibilidade de ejeção do elétron, e portanto a componente imaginária deve ser nula desse ponto em diante.

As curvas empregadas nos cálculos de dinâmica estão apresentadas na figura 3.7. Elas foram obtidas pelo do ajuste dos pontos obtidos dos cálculos de espalhamento 


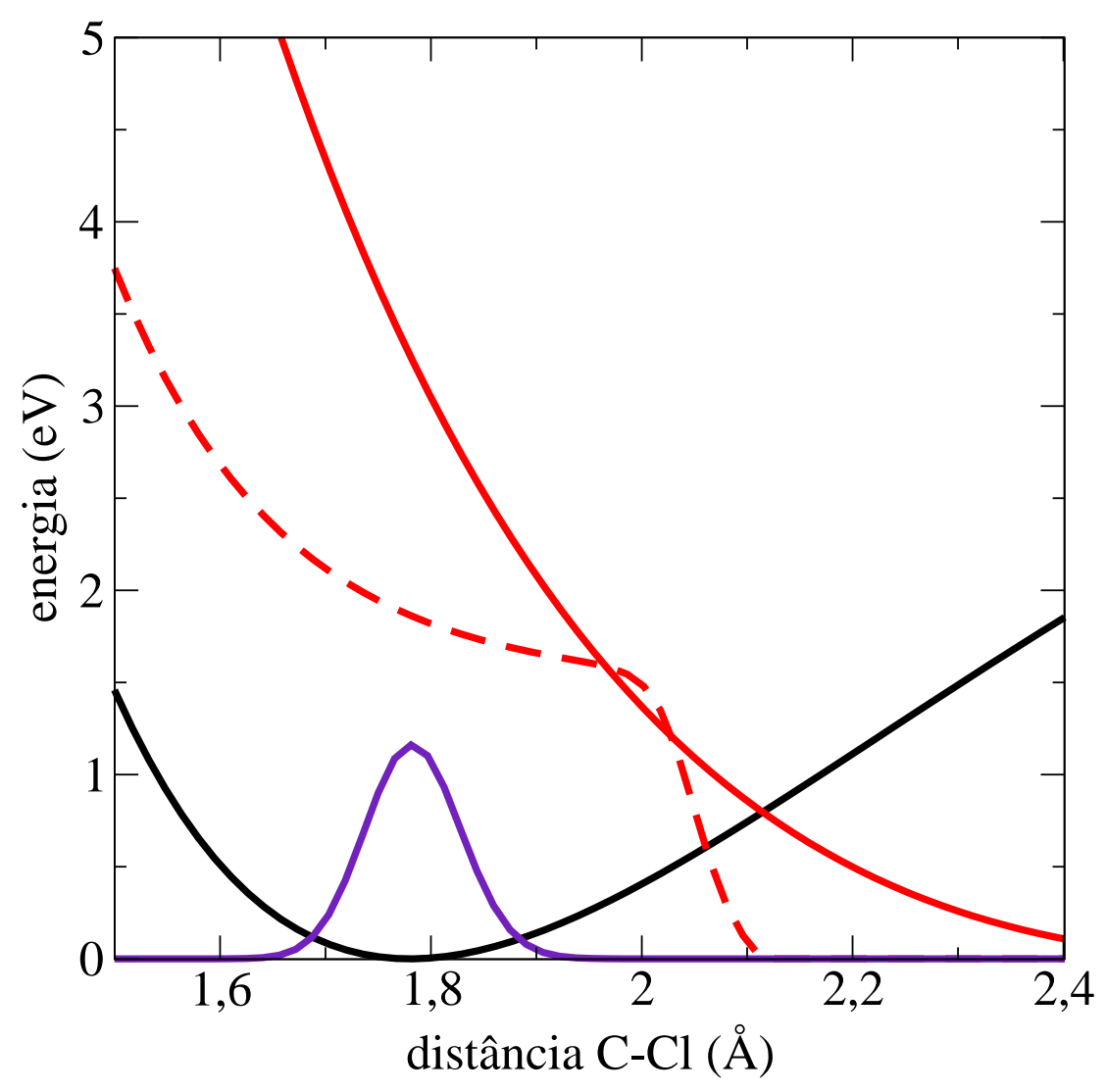

Figura 3.7: Curvas de energia potencial do clorometano, em função do comprimento da ligação $\mathrm{C}-\mathrm{Cl}$. Estão representados o estado da molécula neutra (preto), as componentes real (vermelho, linha cheia) e imaginária (vermelho, linha tracejada) do estado $\sigma_{\mathrm{CCl}}^{*}$ do ânion. O pacote de onda do nível vibracional fundamental da molécula neutra também está representado pela curva violeta.

às seguintes expressões analíticas:

$$
\begin{aligned}
& V_{0}=N_{1}\left(1-e^{-n_{2} x}\right)^{2} \\
& V_{R}=A_{1}\left(1-e^{-a_{2}\left(x-a_{3}\right)}\right)^{2} \\
& V_{I}=\frac{B_{1}}{\left(1+e^{b_{2}\left(x-b_{3}\right)}\right)^{1 / 2}}+B_{4} e^{-b_{5} x}-\frac{B_{1}}{\left(1+e^{b_{2}\left(x_{c}-b_{3}\right)}\right)^{1 / 2}}-B_{4} e^{-b_{5} x_{c}}
\end{aligned}
$$

O ajuste para os potenciais do estado neutro $V_{0}$ e da parte real do ânion $V_{R}$ definem o ponto de cruzamento entre as duas curvas $x_{c}$, de tal modo que $V_{I}$ se anula exatamente nesse ponto. A partir daí o ânion torna-se ligado e portanto $V_{I}$ assume valor nulo. A 


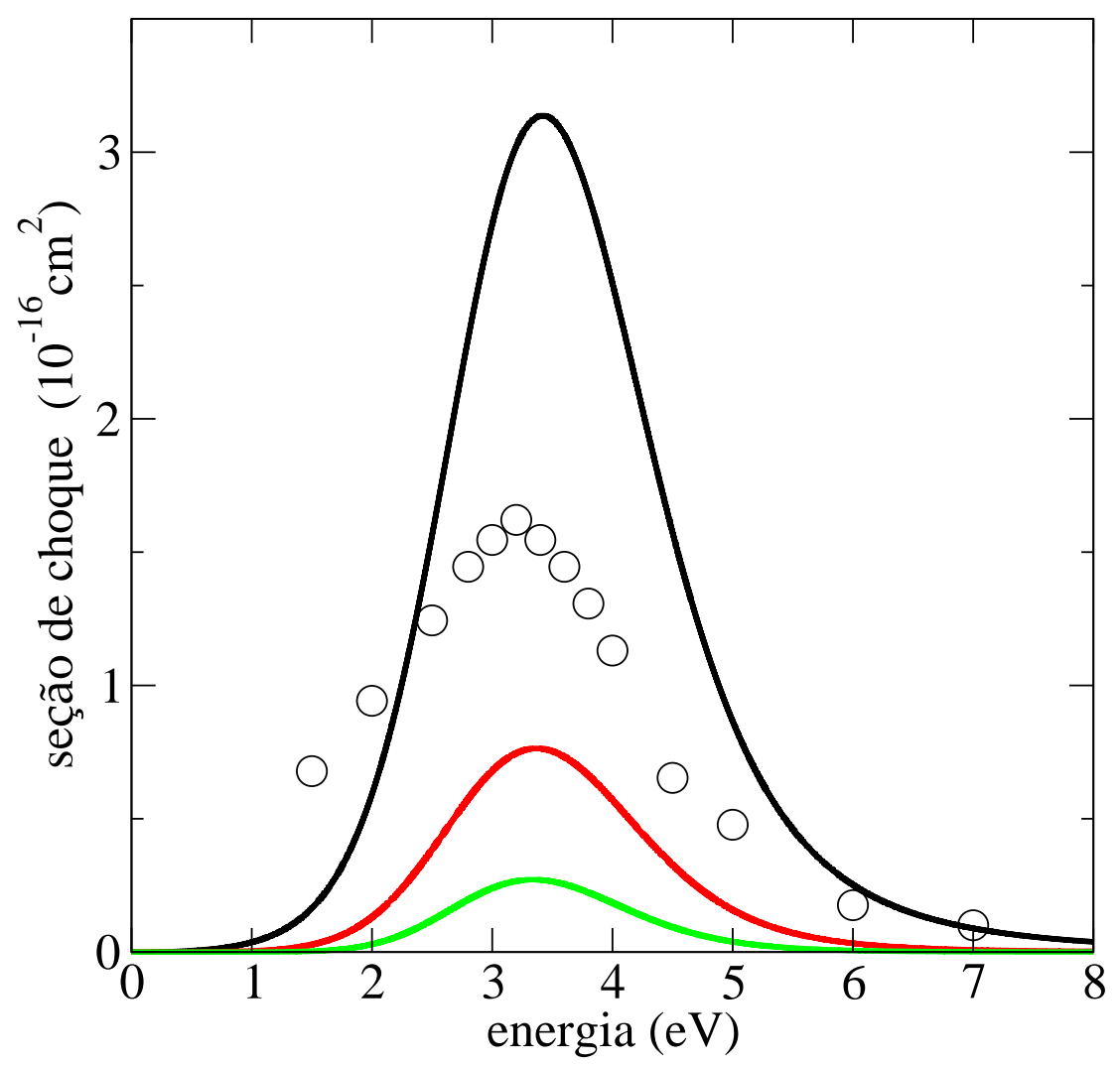

Figura 3.8: Seções de choque de excitação vibracional do estiramento $\mathrm{C}-\mathrm{Cl}$ do clorometano, obtidas para os níveis vibracionais excitados $\nu=1$ (preto), $\nu=2$ (vermelho) e $\nu=3$ (verde). Os pontos são valores experimentais para o nível $\nu=1$ [93].

figura 3.7 também mostra o pacote de onda do nível vibracional fundamental da molécula neutra, que consiste na função de onda inicial para a dinâmica na curva do ânion, a partir da captura eletrônica. Para o cálculo de dinâmica nuclear, utilizamos uma grade de 512 pontos para representar as curvas de energia potencial, se estendendo de distâncias $\mathrm{C}-\mathrm{Cl}$ de $1 \AA$ até $9 \AA$. O tempo total da propagação foi de $10 p s$, em $2^{16}$ passos, de modo que o intervalo de tempo de cada passo foi de aproximadamente $0,015 f s$. O cálculo do fluxo de probabilidade foi efetuado em 5,0 $\AA$.

A figura 3.8 ilustra as seções de choque de excitação vibracional do estiramento $\mathrm{C}-\mathrm{Cl}$, nos três primeiros níveis vibracionais excitados $\nu=1,2,3$. Shi et al. [93] mediu a seção de choque diferencial a $100^{\circ}$, para a excitação do nível $\nu=1$ do modo vibraci- 
onal associado ao estiramento $\mathrm{C}-\mathrm{Cl}$. Para uma energia incidente de $3,2 \mathrm{eV}$ os autores observaram uma seção de choque razoavelmente isotrópica, e assumindo que o mesmo se aplica em outras energias, a seção de choque integral pode ser estimada multiplicando os resultados diferenciais por $4 \pi$. O resultado dessa estimativa também é mostrada na figura 3.8. Há bom acordo no perfil das curvas de seção de choque calculadas e medidas, estando ambas centradas em torno de $3,2 \mathrm{eV}$. No entanto, nosso resultado superestima o valor medido em $\sim 1,8$ vezes na posição do pico, além de apresentar uma largura mais fina. Essa discrepância pode decorrer do modelo unidimensional adotado, que ignora a possibilidade de decaimento nos demais modos vibracionais. A magnitude das seções de choque avaliadas em 3,3 eV assumem uma proporção de 1,00 : 0,23: 0,069 para a excitação dos níveis $\nu=1,2,3$, respectivamente, em excelente concordância com a observação experimental, de 1,00 : 0,20 : 0,06 [93]. Cálculos teóricos anteriores haviam apontado para uma proporção de 1,00 : 0,57 : 0,072 [101]. Nosso resultado indica que a captura eletrônica prontamente excita o modo vibracional do estiramento $\mathrm{C}-\mathrm{Cl}$, sem que haja significativos acoplamentos com outros modos vibracionais.

\subsection{Cloroeteno}

A figura 3.9 ilustra a contribuição das simetrias $A^{\prime}$ e $A^{\prime \prime}$ para a seção de choque integral do cloroeteno, calculadas nas aproximações SE e SEP. Há uma ressonância $\pi^{*}$ na simetria $A^{\prime \prime}$ e uma ressonância $\sigma_{\mathrm{CCl}}^{*}$ na simetria $A^{\prime}$. Na figura 3.10 estão representados os orbitais $\pi^{*}(\mathrm{LUMO})$, que se localiza na dupla ligação $\mathrm{C}=\mathrm{C}$, e $\sigma_{\mathrm{CCl}}^{*}(\mathrm{LUMO}+1)$, que é antiligante na ligação C-Cl. Na aproximação SE as ressonâncias surgem em 3,3 e em 6,3 eV. Com a inclusão de efeitos de polarização, a ressonância $\pi^{*}$ fica centrada em 1,31 $\mathrm{eV}$ (com largura de 0,28 eV), enquanto a $\sigma_{\mathrm{CCl}}^{*}$ se localiza em 2,20 eV (largura de 0,95 eV). Há bom acordo com a medida de espectroscopia de transmissão de elétrons [89], que situam as ressonâncias em 1,28 e 2,84 eV. Como o sinal da ressonância $\sigma_{\mathrm{CCl}}^{*}$ é mais fraco, e apresenta uma sobreposição razoável com o sinal mais forte do estado $\pi^{*}$, o valor 


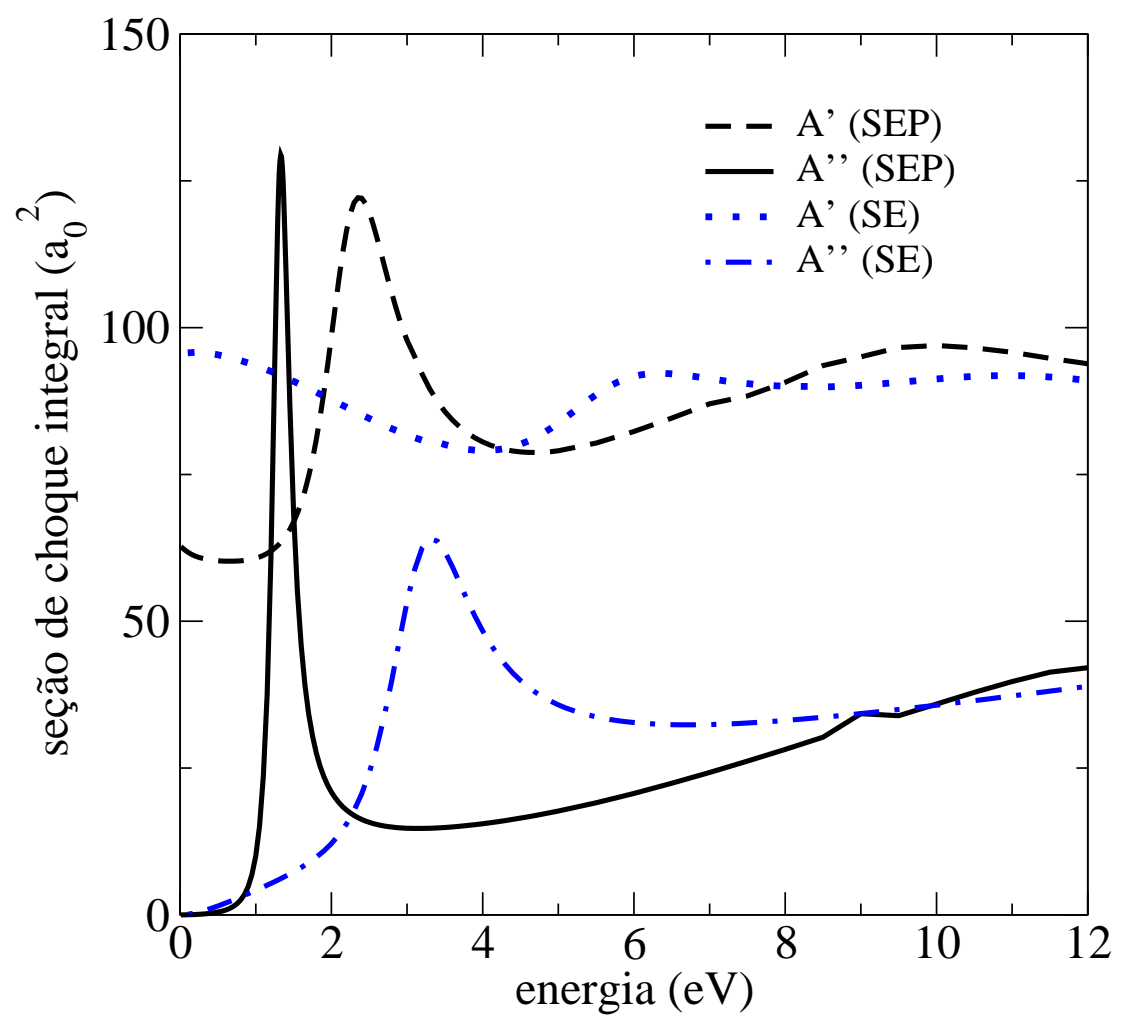

Figura 3.9: Seção de choque integral das simetrias $A^{\prime}$ e $A^{\prime \prime}$ do cloroeteno, calculadas nas aproximações SE e SEP.

reportado de 2,84 eV consiste num limite superior para a energia desse estado [89]. Desse modo, a real energia da ressonância pode estar um pouco abaixo disso e mais próximo do valor obtido em nosso cálculo, de 2,20 eV. Também há bom acordo com os valores obtidos por cálculos de estado ligado com técnicas de estabilização, de 1,59 e 2,36 eV [102].

Com o intuito de avaliar os mecanismos de dissociação do cloroeteno, foram realizados cálculos de espalhamento para geometrias distorcidas da molécula. A partir da geometria de equilíbrio, consideramos deslocamentos da ligação $\mathrm{C}-\mathrm{Cl}$ de $-0,6$ até $+1,0 a_{0}$, em passos de $0,2 a_{0}$, enquanto o restante da geometria foi mantida fixa. Para cada um dos 9 cálculos, posições e larguras das duas ressonâncias foram obtidas, o que permitiu a construção das curvas de energia potencial adiabáticas desses ânions, que estão apresentadas na figura 3.11. É mostrado ainda a curva para o estado fundamental da molécula neutra, obtida de cálculos B3LYP/aug-cc-pVTZ. A curva da ressonância 


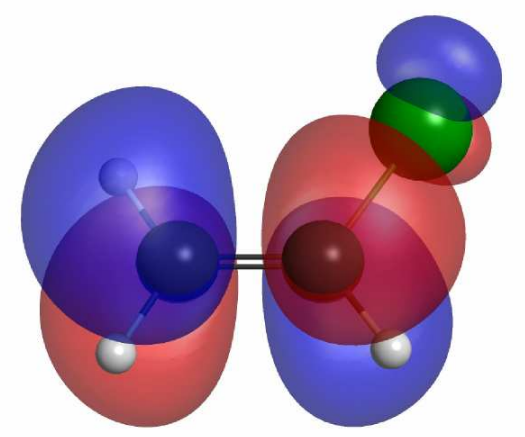

(a) Orbital $\pi^{*}$ do cloroeteno

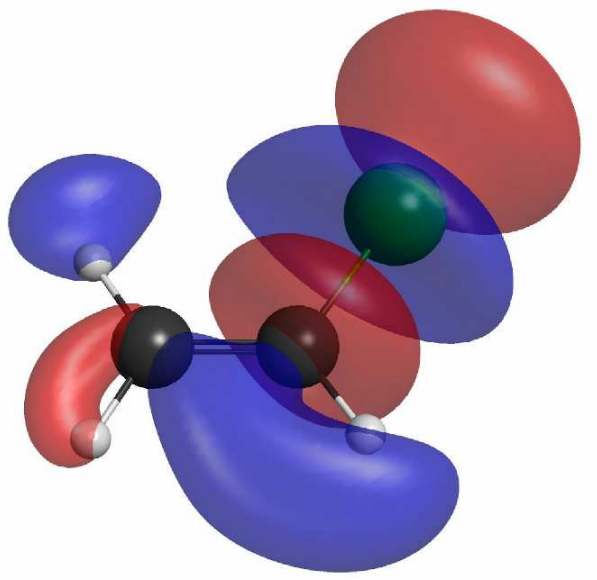

(b) Orbital $\sigma_{\mathrm{CCl}}^{*}$ do cloroeteno

Figura 3.10: Orbitais $\pi^{*}$ e $\sigma_{\mathrm{CCl}}^{*}$ do cloroeteno.

$\pi^{*}$ segue praticamente paralela à curva do neutro, refletindo a pequena probabilidade de que o elétron adicional se localize na ligação $\mathrm{C}-\mathrm{Cl}$. $\mathrm{O}$ minimo da ressonância $\pi^{*}$ coincide aproximadamente com o da molécula neutra, embora a concavidade da curva do ânion seja um pouco maior. Se a captura do elétron ocorrer no orbital $\sigma_{\mathrm{CCl}}^{*}$, a carga extra será acomodada mediante o estiramento da ligação $\mathrm{C}-\mathrm{Cl}$, de modo que a curva dessa ressonância decresce rapidamente. Para maiores estiramentos o ânion torna-se mais estável que a molécula neutra, o elétron fica definitivamente ligado a um dos fragmentos e a dissociação se completa. A carga tende a se localizar no fragmento com maior afinidade eletrônica, no presente caso o cloro, formando assim o ânion $\mathrm{Cl}^{-}$.

Além da parte real da energia da ressonância (identificada como a posição do pico na seção de choque), o cálculo de espalhamento também provê a parte imaginária (que corresponde à largura do pico). A figura 3.12 mostra a componente imaginária das ressonâncias $\pi^{*}$ e $\sigma_{\mathrm{CCl}}^{*}$ do cloroeteno, em função da distância $\mathrm{C}-\mathrm{Cl}$. A ressonância $\pi^{*}$ tem largura de 0,28 eV na geometria de equilíbrio, apresentando uma leve diminuição com o estiramentos da ligação $\mathrm{C}-\mathrm{Cl}$, e aumento quando essa é comprimida. Na ressonância $\sigma_{\mathrm{CCl}}^{*}$, o estiramento gera um aumento do tempo de vida muito mais expressivo. Como o estado passa a ser ligado a partir de uma certa distância, a largura associada deve ir a 


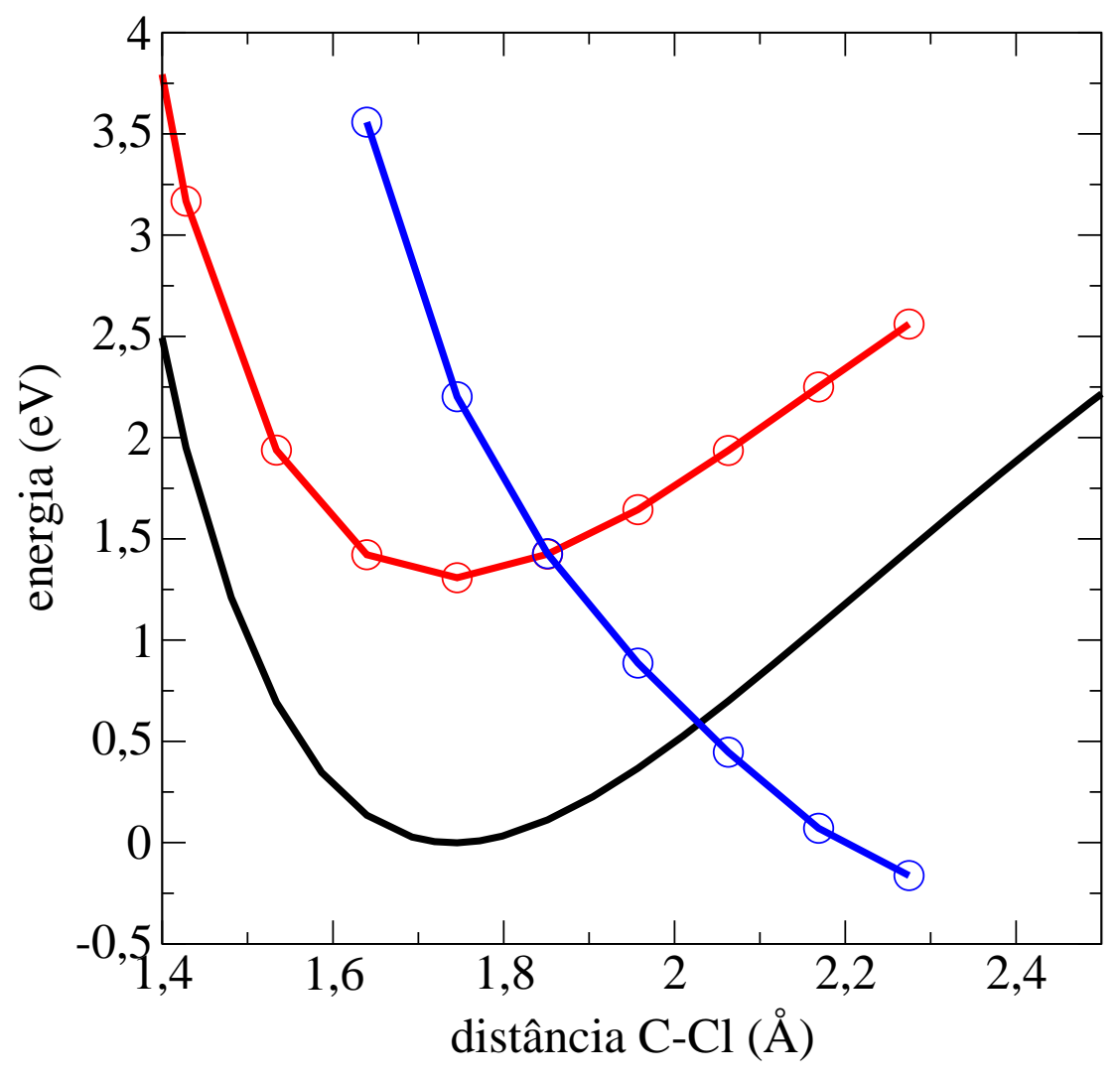

Figura 3.11: Curvas de energia potencial para o cloroeteno, em função da distância C-Cl. Estão representados o estado fundamental da molécula neutra (preto), e os estados $\pi^{*}$ (vermelho) e $\sigma_{\mathrm{CCl}}^{*}($ azul).

zero, valor atribuído aos três últimos pontos da figura 3.12 .

Cálculos de dinâmica quântica do pacote de onda nuclear foram realizados na curva de energia potencial complexa do estado $\sigma_{\mathrm{CCl}}^{*}$, o que permite avaliar a relevância do mecanismo direto no processo dissociativo. Empregamos uma grade de 512 pontos para representar as curvas de energia potencial do neutro e do ânion, se estendendo da distância da ligação $\mathrm{C}-\mathrm{Cl}$ comprimida de $1 a_{0}$ até a configuração em que ela é estirada de $7 a_{0}$, tomando a posição de equilíbrio como referência. A grade temporal foi a mesma que a utilizada para a dinâmica do clorometano. O fluxo de probabilidade foi calculado para uma distância estirada de $4 a_{0}$. Os potenciais da molécula neutra $V_{0}$ e da componente real $V_{R}$ da ressonância $\sigma_{\mathrm{CCl}}^{*}$ foram modelados por potenciais de Morse, tal como nas equações 


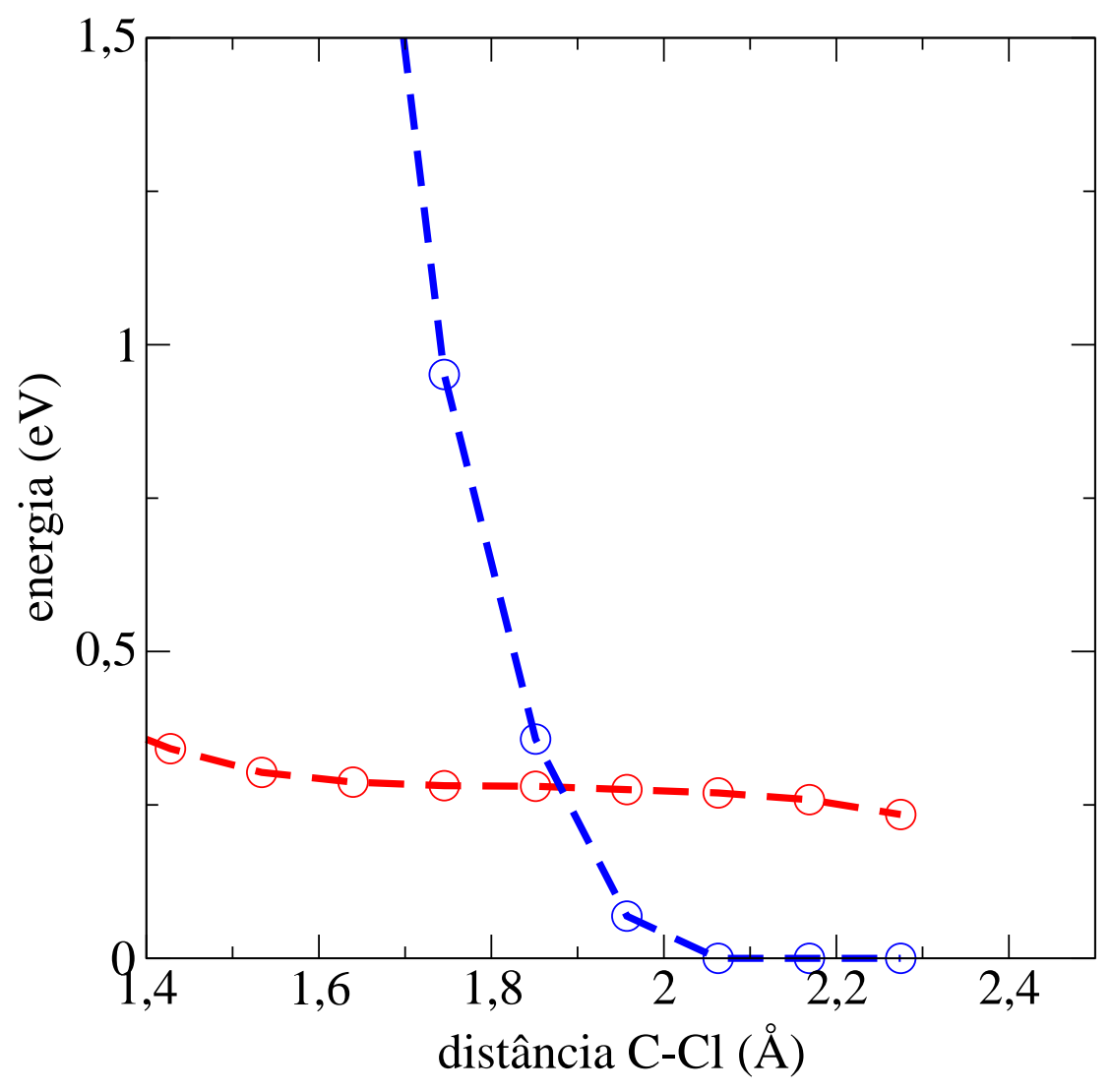

Figura 3.12: Curvas de energia potencial da parte imaginária dos estados do ânion do cloroeteno, em função da distância $\mathrm{C}-\mathrm{Cl}$. Estão representados os estados $\pi^{*}$ (vermelho) e $\sigma_{\mathrm{CCl}}^{*}(\mathrm{azul})$.

3.2 e 3.3. Para a componente imaginária $V_{I}$ adotamos a seguintes função:

$$
V_{I}=\frac{B_{0}}{\left(1+e^{b_{1}\left(x-b_{2}\right)}\right)^{1 / 2}}-\frac{B_{0}}{\left(1+e^{b_{1}\left(x_{c}-b_{2}\right)}\right)^{1 / 2}},
$$

onde $x_{c}$ é o ponto em que as curvas $V_{0}$ e $V_{R}$ se cruzam.

Na figura 3.13 apresentamos a seção de choque para a eliminação de $\mathrm{Cl}^{-}$. A curva preta da figura corresponde à situação em que a molécula neutra está inicialmente em seu nível vibracional fundamental. A curva se estrutura em um pico centrado em 1,77 $\mathrm{eV}$, abaixo portanto da posição em que a ressonância $\sigma_{\mathrm{CCl}}^{*}$ foi encontrada, de $2,20 \mathrm{eV}$. Esse deslocamento para menores energias ocorre porque a largura da ressonância é maior na região de comprimentos da ligação $\mathrm{C}-\mathrm{Cl}$ contraídas, enquanto é menor para distâncias 


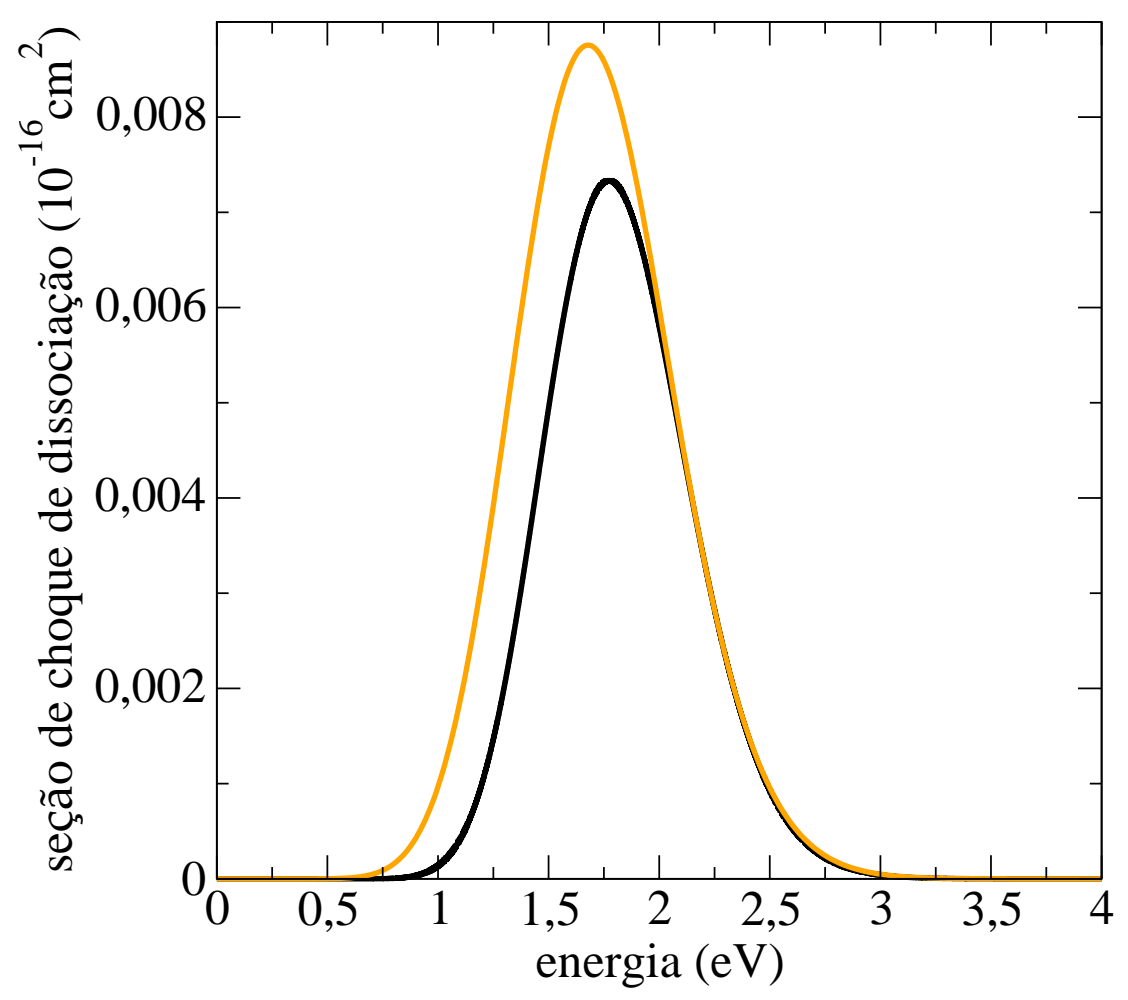

Figura 3.13: Seção de choque de dissociação do cloroeteno, a partir do nível vibracional $\nu=0$ (preto) e tomando uma média sobre populações a $450 K$ (laranja).

estiradas. Desse modo, para energias de impacto mais elevadas a probabilidade de ejeção do elétron cresce e a seção de choque de dissociação se atenua, o que causa o deslocamento do pico de dissociação para menores energias. Realizamos ainda cálculos de dinâmica nuclear tomando níveis vibracionais até $\nu=8$, e tomando uma distribuição de Boltzmann para a ocupação de cada nível calculamos a seção de choque de dissociação a uma temperatura de $450 \mathrm{~K}$, condição aproximada em que medidas do espectro de fragmentação costumam ser realizadas. Nesse caso, o pico é levemente deslocado para menores energias, e fica centrado em 1,68 eV. A magnitude da seção de choque também cresce em certa medida, especialmente para menores energias, devido à captura eletrônica a partir de níveis vibracionalmente excitados.

Contudo, essa estrutura não deve responder pelo pico proeminente observado experimentalmente em 1,31 eV [88,89], em vista da diferença entre a seção de choque 
calculada $\left(\sim 9 \times 10^{-19} \mathrm{~cm}^{2}\right)$ e a medida $\left(\sim 3 \times 10^{-17} \mathrm{~cm}^{2}\right)$ [88]. Apesar da forte estabilização que o estado $\sigma_{\mathrm{CCl}}^{*}$ sofre com o estiramento, nas partes real e imaginária, o curto tempo de vida na geometria de equilíbrio $(0,69 f s)$ impede que uma porção apreciável do pacote de onda atinja a região em que o ânion é estável. Portanto, nossos resultados apontam que o mecanismo direto de dissociação do cloroeteno é inviável. Por outro lado, a captura do elétron no orbital $\pi^{*}$ deve ser mais favorável para a quebra da ligação $\mathrm{C}-\mathrm{Cl}$. O estado é formado com um tempo de vida mais expressivo $(2,35 \mathrm{fs})$, o que permite uma maior relaxação da geometria. Pode ocorrer um acoplamento com o estado dissociativo $\sigma_{\mathrm{CCl}}^{*}$ numa configuração em que esse possua tempo de vida mais elevado, efetivando assim a dissociação. Vale notar, no entanto, que a curva de seção de choque experimental [88,89] apresenta uma leve assimetria em torno da posição do pico, tendo maior magnitude à direita desse. Esse efeito pode ter como origem o mecanismo direto, em vista da diferença de duas ordens de magnitude entre as seções de choque calculadas e medidas.

Como os estados possuem simetrias distintas, sendo o primeiro $A^{\prime \prime}$ e o segundo $A^{\prime}$, o acoplamento será nulo se a estrutura for mantida planar. Uma segunda coordenada deve ser incorporada no problema, a fim de construir superfícies de energia potencial ao longo de duas dimensões. Essa coordenada deve quebrar a simetria planar, permitindo que os estados ressonantes efetivamente acoplem. Diferentes coordenadas foram testadas, e a avaliação dos orbitais virtuais apontou que o deslocamento do átomo de cloro para fora do plano molecular gera uma forte mistura entre os orbitais $\pi^{*}$ e $\sigma_{\mathrm{CCl}}^{*}$. Portanto, o ângulo $\theta$ formado entre o átomo de cloro, o carbono ao qual ele se liga e a posição do cloro na geometria de equilíbrio foi tomada como segunda coordena do problema. O procedimento para a escolha dessa coordenada será discutida em detalhes mais adiante, para o caso da 5-clorouracila.

Tomamos então as coordenadas $\theta$, acima definida, e $r$, que representa o comprimento da ligação $\mathrm{C}-\mathrm{Cl}$. Realizamos cálculos de espalhamento tomando 7 pontos na coordenada $r$, de $-0,4$ até $+0,8 a_{0}$, em passos de $0,2 a_{0}$, e 10 pontos na coordenada $\theta$, de 0 até $30^{\circ}$, em passos de $5^{\circ}$, além dos pontos a $40^{\circ}, 50^{\circ}$ e $60^{\circ}$. Considerando que as superfícies devem ser simétricas em relação a $\theta$, foram realizados cálculos de espalhamento em um to- 


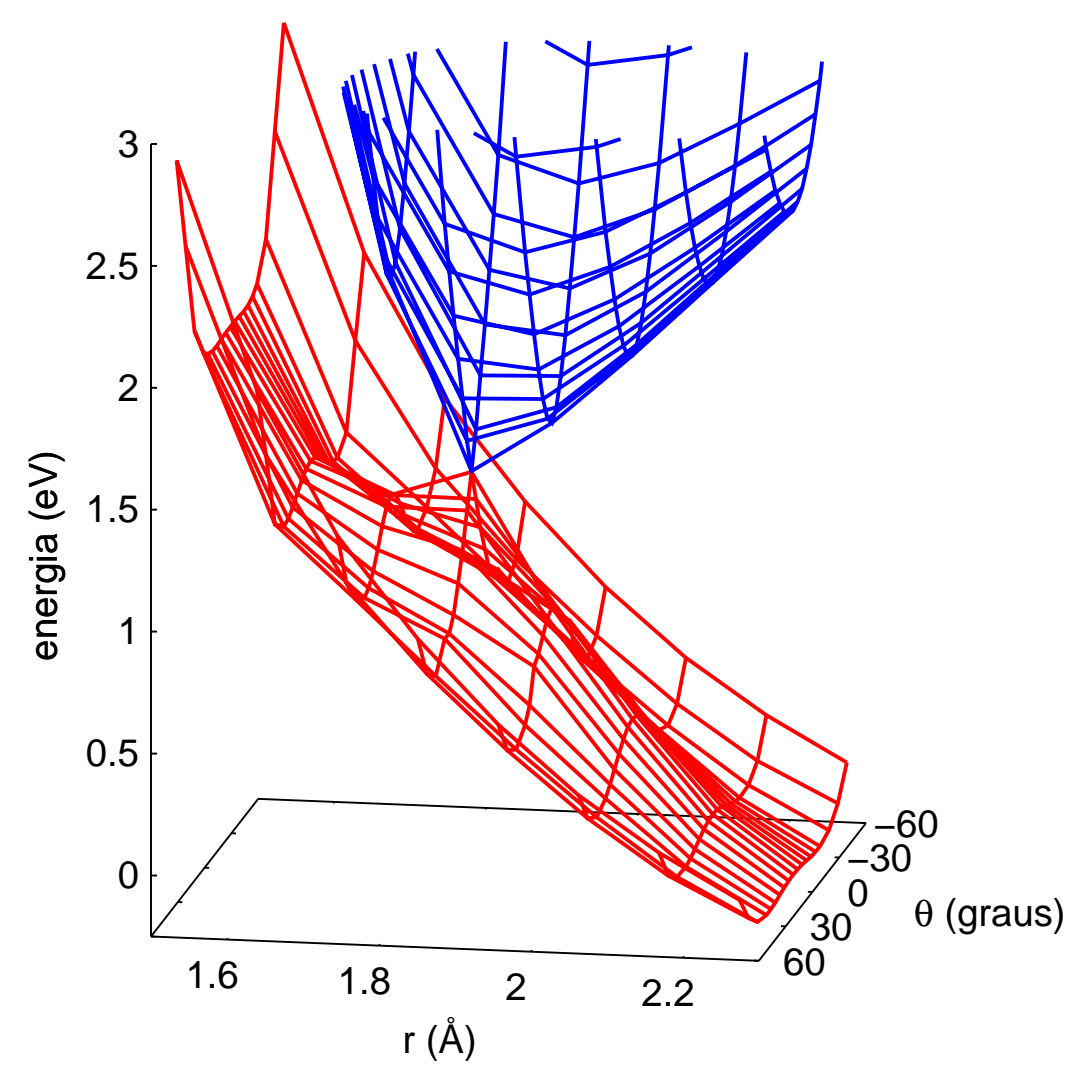

Figura 3.14: Superfícies de energia potencial da componente real dos dois estados do ânion de cloroeteno, em função da distância $\mathrm{C}-\mathrm{Cl} r$ e do ângulo $\theta$.

tal de 70 configurações distintas, gerando 133 pontos nas superfícies de energia potencial. Para cada cálculo posições e larguras dos dois estados do ânion foram obtidas. A figura 3.14 ilustra as superfícies de energia potencial reais, para os dois estados do ânion. A superfície do estado neutro não é apresentada para não atrapalhar a visualização. Nessa situação não faz mais sentido caracterizar os estados como $\pi^{*}$ ou $\sigma_{\mathrm{CCl}}^{*}$, já que ambos manifestam os dois caráteres, em maior ou menor grau dependendo da geometria. Vamos nos referir portanto, aos estados do ânion inferior (que corresponde à superfície vermelha da figura 3.14) e superior (representado pela superfície azul). Os cálculos de espalhamento fornecem ainda as larguras das duas ressonâncias, que são apresentadas na figura 3.15.

O estado inferior é estabilizado no sentido de deslocamentos positivos de $r$, salvo na região da interseção com o estado superior, onde há uma certa elevação na ener- 


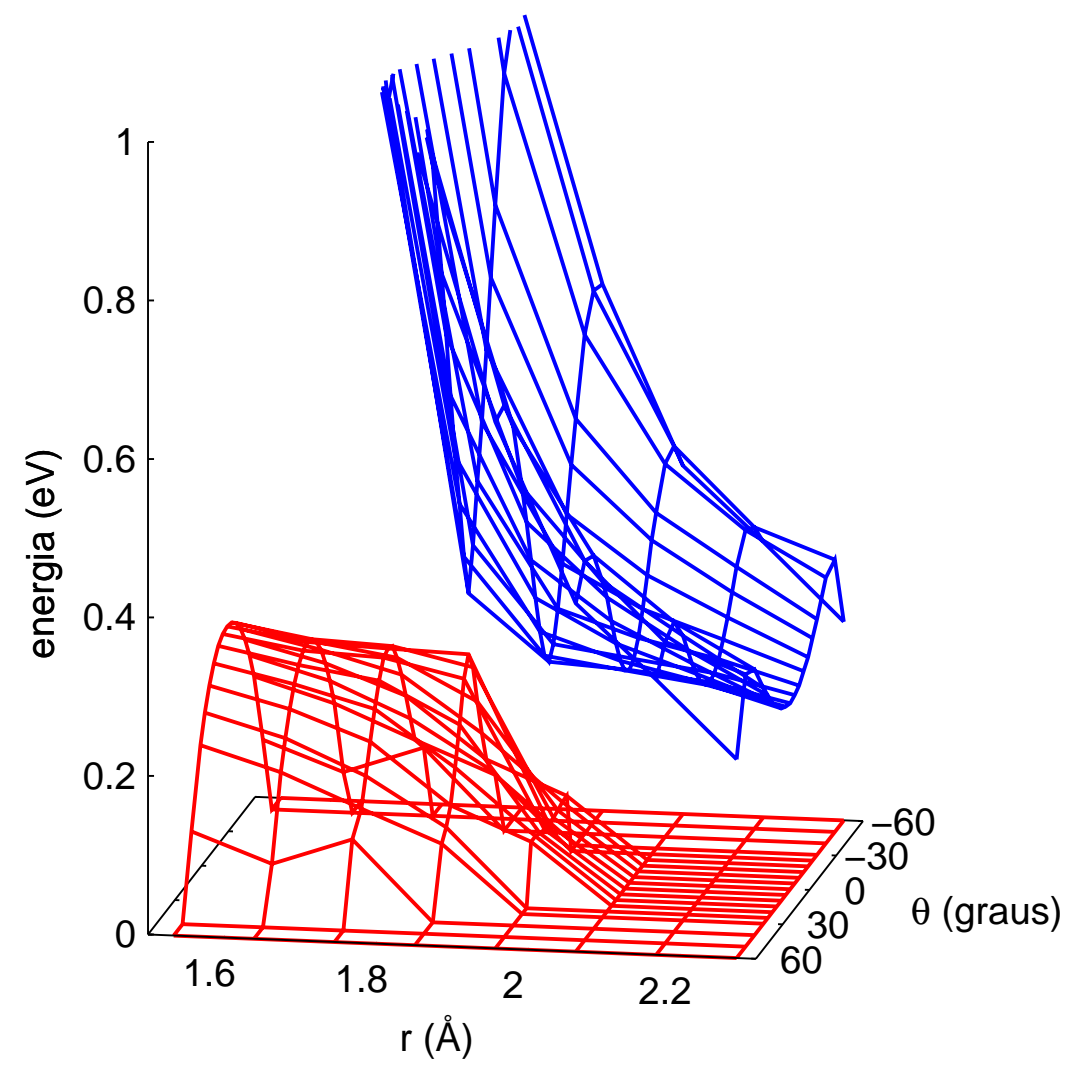

Figura 3.15: Superfícies de energia potencial da componente imaginária dos dois estados do ânion de cloroeteno, em função da distância $\mathrm{C}-\mathrm{Cl} r$ e do ângulo $\theta$.

gia. No estado superior há um íngreme afunilamento da superfície em direção à interseção, especialmente a partir da região em que $r$ é menor do que o valor de equilíbrio. Desvios em $\theta$ estabilizam o estado inferior, para qualquer deslocamento $r$. Tal efeito já é presente em torno da região de equilíbrio, cresce próximo da interseção, e se atenua para maiores distâncias. Havendo a formação da ressonância $\pi^{*}$, que corresponde ao estado inferior na geometria de equilíbrio do neutro, o pacote de onda deve se movimentar na direção de maiores $r$ e $\theta$ crescentes em módulo, permitindo uma rota eficiente rumo à região de estabilidade, onde a componente imaginária se anula. Segundo essa dinâmica, a componente imaginária também decresce fortemente, o que aumenta a probabilidade de que o pacote de onda alcance a região de estabilidade. A análise das superfícies indica que o ânion $\pi^{*}$ estabiliza mediante a dobra da estrutura molecular, juntamente com o estiramento 
da ligação $\mathrm{C}-\mathrm{Cl}$. A medida que essa reestruturação ocorre o estado do ânion muda de caráter, de $\pi^{*}$ para $\sigma_{\mathrm{CCl}}^{*}$, o que representa uma migração da densidade de carga da região da dupla ligação $\mathrm{C}=\mathrm{C}$ para a ligação $\mathrm{C}-\mathrm{Cl}$, e por fim para o fragmento $\mathrm{Cl}^{-}$.

Nas superfícies reais, há a indicação de uma interseção cônica conectando as superfícies dos dois estados, na região de $r=1,85 \AA$ e $\theta=0$. Essas estruturas são frequentemente encontradas em superfícies de estados excitados de moléculas neutras, e costumam desempenhar papéis fundamentais na dinâmica desses estados, fornecendo rotas eficientes para processos de conversão interna [103]. As superfícies imaginárias também apresentam uma interseção cônica, que parece coincidir aproximadamente com a posição em que ela ocorre na componente real. Uma discussão mais detalhada sobre o perfil dessa estrutura no caso de superfícies complexas será dado mais adiante, através dos modelos utilizados.

Uma vez obtidos os potenciais adiabáticos, é possível em princípio realizar os cálculos de dinâmica nuclear. Havendo mais de uma superfície, essas estarão acopladas por termos não-diagonais do operador de energia cinética nuclear [102,104]. A obtenção desse termo é muito dispendioso em cálculos de estrutura eletrônica, por envolver gradientes nucleares da função de onda eletrônica, e seria inviável obtê-lo através de cálculos de espalhamento. Além disso, há uma divergência na interseção cônica, quando dois estados tornam-se degenerados [104]. Dada a dificuldade no cálculo desse elemento e as complicações de ordem numérica introduzidas pela singularidade, a propagação da dinâmica não costuma ser realizada na representação adiabática. O problema é contornado por meio de uma transformação diabática, que modifica a base eletrônica do problema para a chamada representação diabática. Com essa transformação a equação de Schroedinger assume um formato mais simples, em que os termos não-diagonais do operador de energia cinética são substituídos por termos não-diagonais do potencial diabático, mais fáceis de serem estimados.

Portanto, a propagação do pacote de onda em superfícies bidimensionais requer a obtenção dos potenciais diabáticos $V^{d}$, bem como dos termos não-diagonais do potencial diabático $V_{12}^{d}$. Quando há dois estados do ânion relevantes, como no caso do cloroeteno, a diagonalização da matriz construída a partir dos potenciais diabáticos pode ser realizada 
sem grandes dificuldades. Os potenciais adiabáticos das superfícies inferior $V_{1}^{a}$ e superior $V_{2}^{a}$ são obtidas da seguinte transformação $[102,105]$ :

$$
\begin{aligned}
& V_{1 R}^{a}(r, \theta)=\frac{V_{1 R}^{d}+V_{2 R}^{d}}{2}-\frac{1}{2} \sqrt{\frac{\sqrt{\alpha^{2}+\beta^{2}}+\alpha}{2}} \\
& V_{2 R}^{a}(r, \theta)=\frac{V_{1 R}^{d}+V_{2 R}^{d}}{2}+\frac{1}{2} \sqrt{\frac{\sqrt{\alpha^{2}+\beta^{2}}+\alpha}{2}} \\
& V_{1 I}^{a}(r, \theta)=\frac{V_{1 I}^{d}+V_{2 I}^{d}}{2}-\frac{1}{2} \sqrt{\frac{\sqrt{\alpha^{2}+\beta^{2}}-\alpha}{2}} \\
& V_{2 I}^{a}(r, \theta)=\frac{V_{1 I}^{d}+V_{2 I}^{d}}{2}+\frac{1}{2} \sqrt{\frac{\sqrt{\alpha^{2}+\beta^{2}}-\alpha}{2}}
\end{aligned}
$$

onde os índices $R$ e $I$ indicam as componentes real e imaginária do potencial, e

$$
\begin{aligned}
\alpha & =\mathfrak{R e}\left\{\left(V_{1}^{d}-V_{2}^{d}\right)^{2}+4\left(V_{12}^{d}\right)^{2}\right\} \\
\beta & =\mathfrak{I m}\left\{\left(V_{1}^{d}-V_{2}^{d}\right)^{2}+4\left(V_{12}^{d}\right)^{2}\right\},
\end{aligned}
$$

onde $\mathfrak{R e}$ e $\mathfrak{I m}$ denotam a parte real e imaginária, respectivamente. A presença da componente imaginária dos potenciais complexos torna a transformação um tanto mais complicada do que no caso de superfícies puramente reais.

O procedimento aqui adotado para a obtenção dos potenciais diabáticos consistiu na construção de modelos [106]. Inicialmente, uma série de cálculos de espalhamento fornecem pontos representativos das superfícies de energia potencial adiabáticas, tal como apresentado nas figuras 3.14 e 3.15. Os potenciais diabáticos $V_{1}^{d}, V_{2}^{d}$ e $V_{12}^{d}$ são então modelados por funções analíticas, com um conjunto de parâmetros a serem determinados. Por fim, a equação 3.5 fornece o modelo para os potenciais adiabáticos, e os parâmetros são obtidos a partir de uma regressão não-linear às superfícies calculadas. Obtemos por fim expressões analíticas para os potenciais adiabáticos $V^{a}$ e diabáticos $V^{d}$, e para os acoplamentos $V_{12}^{d}$. O seguinte conjunto de funções foi adotado para representar os potenciais 
Tabela 3.2: Parâmetros do modelo para as superfícies de energia potencial do cloroeteno, definidas em unidades de eV, $\AA$ e graus.

\begin{tabular}{ccll}
\hline \hline$V_{1 R}^{d}$ & \multicolumn{1}{c}{$V_{2 R}^{d}$} & \multicolumn{1}{c}{$V_{1 I}^{d}$} & \multicolumn{1}{c}{$V_{2 I}^{d}$} \\
\hline$A_{1}=0.79824$ & $B_{1}=3.01148$ & $D_{1}=488.74911$ & $E_{1}=-0.01721$ \\
$a_{2}=1.15330$ & $b_{2}=1.99690$ & $d_{2}=3.11342$ & $E_{2}=0.33667$ \\
$a_{3}=2.65387$ & $b_{3}=1.72941$ & $D_{3}=-1.03793$ & $E_{3}=-0.00204$ \\
$A_{4}=0.01471$ & $B_{4}=0.00155$ & $D_{4}=0.00750$ & $e_{4}=1.44815$ \\
$a_{5}=2.21926$ & $b_{5}=0.68800$ & $d_{5}=1.95998$ & \\
$A_{6}=-0.40552$ & $B_{6}=1.24337$ & & \\
\hline \hline & $V_{12 R}^{d}$ & $V_{12 I}^{d}$ & \\
\hline$C_{1}=0.03180$ & $F_{1}=0.00726$ & $N_{1}=4.06077$ & $N_{4}=0.00336$ \\
$c_{2}=1.79647$ & $f_{2}=2.59772$ & $n_{2}=1.66966$ & $n_{5}=1.05352$ \\
$c_{3}=0.92060$ & $f_{3}=1.04966$ & $n_{3}=1.74550$ & \\
\hline \hline
\end{tabular}

diabáticos do cloroeteno:

$$
\begin{aligned}
& V_{0}(r, \theta)=N_{1}\left[1-e^{-n_{2}\left(r-n_{3}\right)}\right]^{2}+N_{4} \theta^{2} e^{-n_{5} r} \\
& V_{1 R}^{d}(r, \theta)=A_{1}\left[1-e^{-a_{2}\left(r-a_{3}\right)}\right]^{2}+A_{4} \theta^{2} e^{-a_{5} r}+A_{6} \\
& V_{2 R}^{d}(r, \theta)=B_{1}\left[1-e^{-b_{2}\left(r-b_{3}\right)}\right]^{2}+B_{4} \theta^{2} e^{-b_{5} r}+B_{6} \\
& V_{12 R}^{d}(r, \theta)=C_{1} \theta\left[1+\tanh \left(\left(c_{2}-r\right) / c_{3}\right)\right] \\
& V_{1 I}^{d}(r, \theta)=D_{1} e^{-d_{2} r}+D_{3}+D_{4} \theta^{2} e^{-d_{5} r} \\
& V_{2 I}^{d}(r, \theta)=E_{1} r+E_{2}+E_{3} \theta^{2} e^{-e_{4} r} \\
& V_{12 I}^{d}(r, \theta)=F_{1} \theta\left[1+\tanh \left(\left(f_{2}-r\right) / f_{3}\right)\right],
\end{aligned}
$$

onde $V_{0}$ denota o potencial do estado fundamental da molécula neutra. Os parâmetros otimizados estão contidos na tabela 3.2.

Discutimos inicialmente a questão da topologia das superfícies de energia potencial complexas, que tem sido relativamente pouco discutido na literatura. Em estados excitados de moléculas neutras, é comum a presença de interseções cônicas, quando 

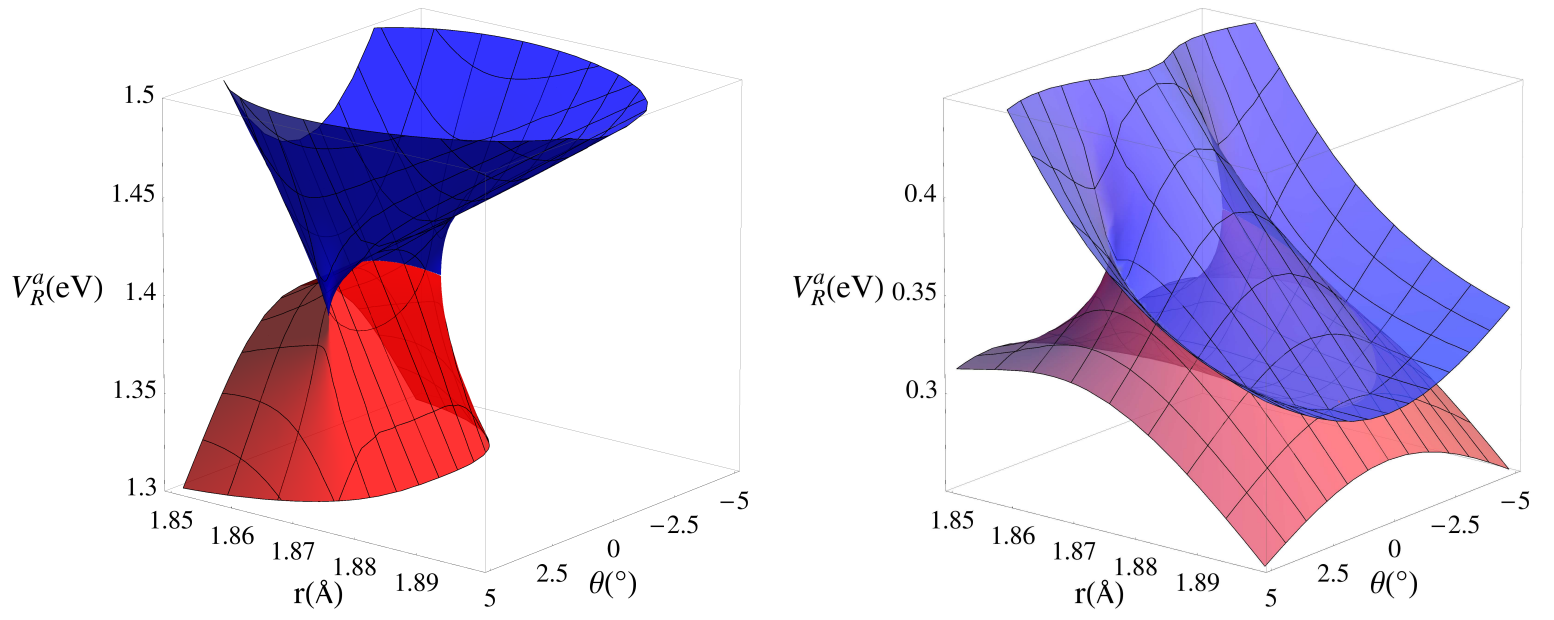

Figura 3.16: Superfícies de energia potenciais $V_{R}^{a}$ e $V_{I}^{a}$ do cloroeteno, focando na região da interseção cônica.

as superfícies adiabáticas tocam em um único ponto, formando a figura de um cone duplo [103]. Em contraste, modelos mínimos para superfícies complexas [102, 105, 107] apontam que a degenerescência se dá ao longo de uma linha. Essa linha seria distinta para as componentes reais e imaginárias, mas poderiam haveriam um ou dois pontos em que elas coincidiriam. Nesse ponto, haveria a chamada interseção cônica complexa [102], onde as superfícies adiabáticas dos dois estados coincidem em ambas as suas componentes. Na figura 3.16 apresentamos os potenciais do cloroeteno, segundo o modelo definido pelas equações 3.7 e os parâmetros da tabela 3.2, focando na região da interseção cônica complexa. Os elementos na topologia das superfícies complexas são contemplados dentro de nosso modelo. A interseção entre as superfícies inferior e superior está limitada à região $-3^{\circ}<\theta<3^{\circ}$ e $1,858 \AA<r<1,894 \AA$. Ambas as superfícies se tocam ao longo de um arco, sendo esse maior para a componente imaginária. Projetando as curvas real e imaginária no plano $(r, \theta)$, e conectando as duas curvas de degenerescência, passamos a ter uma única curva fechada. Os dois pontos de contato correspondem às interseções cônicas complexas, dispostas simetricamente em $\theta= \pm 2,4^{\circ}$ e para $r=1,864 \AA$. Vale notar que os trabalhos existentes fazem uso de modelos mínimos para avaliar o caráter dessas estruturas $[102,105,107]$, enquanto em nosso trabalho os potenciais são modelados por 
funções mais sofisticadas, visando uma descrição equilibrada numa região muito mais extensa de configurações nucleares. Feuerbacher et al. [102], em particular, realizou cálculos de estado ligado com técnicas de estabilização para o cloroeteno, tomando as mesmas duas coordenas. Os autores focaram apenas na região da interseção cônica complexa, e a identificaram em $\theta= \pm 0,88^{\circ}$, para uma estiramento da posição de equilíbrio de $0,307 a_{0}$, que equivale a uma distância $\mathrm{C}-\mathrm{Cl}$ de 1,908 $\AA$, assumindo o nosso valor de equilíbrio (1,746 Å). Uma diferença importante entre nossos cálculos e os de Feuerbacher et al. é que nós encontramos a interseção cônica como uma consequência do modelo adotado para os potenciais complexos, enquanto eles já identificam a formação dessa estrutura a partir de uma série de cálculos que cobrem essa região. Em vista da quase-degenerescência em torno da interseção cônica e das dificuldades inerentes relacionadas ao ajuste da soma de autofases, antecipamos que seria muito árduo obter os parâmetros das ressonâncias através de cálculos de espalhamento. De todo modo, é notável que métodos distintos, aplicados em regiões mais extensas ou mais restritas, forneçam interseções cônicas complexas em posições relativamente próximas. O real impacto da forma particular dessa interseção cônica para a dinâmica vibracional é uma questão em aberto.

Na figura 3.17 estão apresentadas as superfícies de energia potencial complexas, adiabáticas e diabáticas, cobrindo toda a região relevante para o processo dissociativo. Considerando a formação da ressonância $\pi^{*}$ na geometria de equilíbrio, dentro da representação adiabática, o pacote de onda deve percorrer essencialmente a superfície inferior (vermelha na figura 3.17), relaxando para regiões de menor energia, em que ocorre a dissociação. Ao longo da dinâmica, o caráter do ânion se modifica adiabaticamente, de $\pi^{*}$ para $\sigma_{\mathrm{CCl}}^{*}$. O perfil da superfície indica que a função de onda circunda e evita a região da interseção cônica, sugerindo que o acoplamento não-adiabático entre os dois estados pode ser pouco atuante durante a propagação. Na representação diabática, a interpretação da dinâmica é distinta. O caráter do ânion é mais ou menos definido para cada superfície, sendo esse $\pi^{*}$ para a superfície violeta e $\sigma_{\mathrm{CCl}}^{*}$ para a laranja. Nesse caso, a mudança de perfil se dá pelo acoplamento eletrônico entre estados diabáticos $V_{12}^{d}$, que responde pela transição de uma superfície para a outra. 

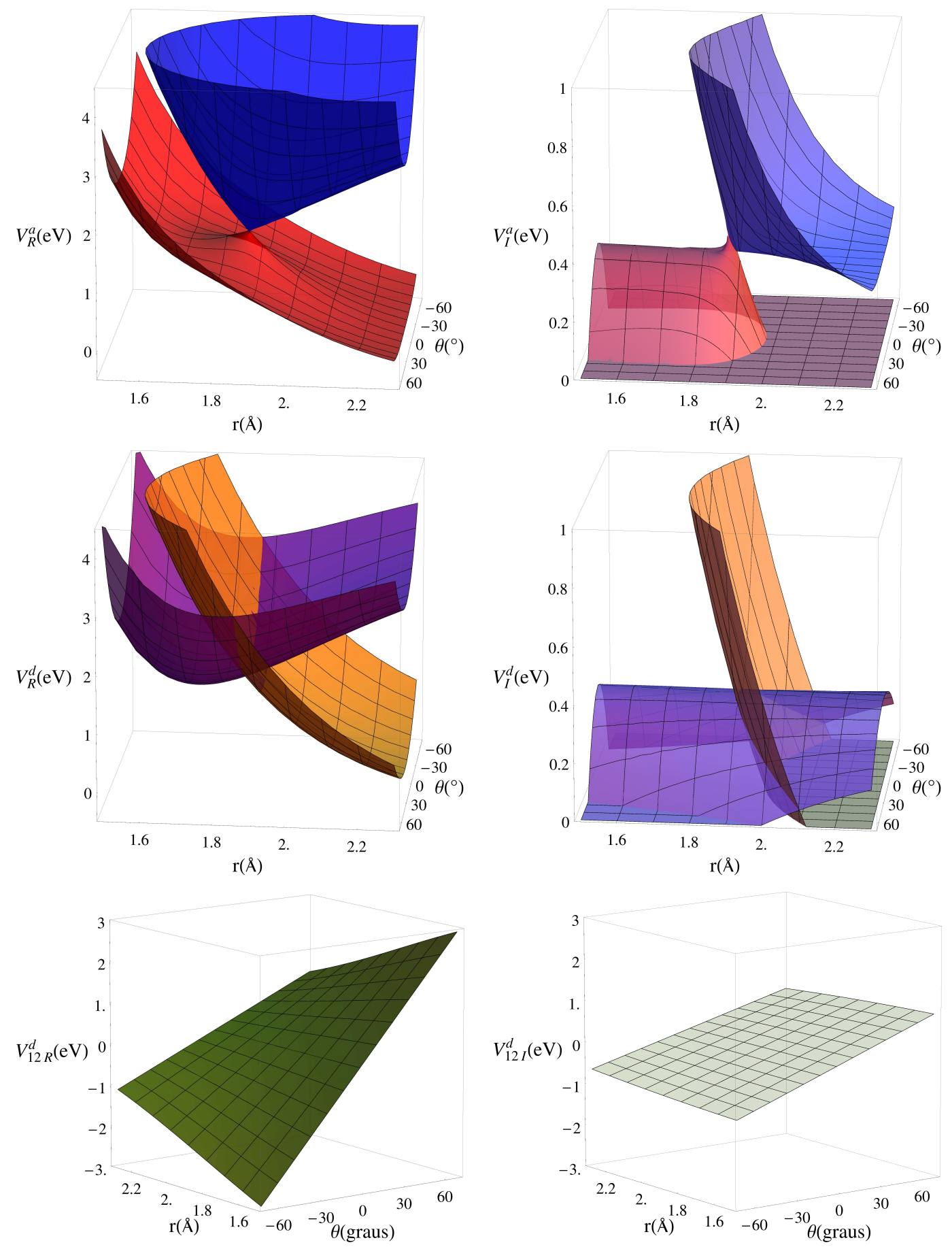

Figura 3.17: Superfícies de energia potencial $V_{R}^{a}, V_{I}^{a}, V_{R}^{d}, V_{I}^{d}, V_{12 R}^{d}$ e $V_{12 I}^{d}$ dos dois estados do ânion de cloroeteno, em função das coordenadas $r$ e $\theta$, conforme obtidas do modelo. 


\section{Capítulo 4}

\section{Derivados de uracila}

\subsection{Introdução}

As halouracilas consistem numa importante classe de biomoléculas com potencial radiossensibilizador [38]. Essa propriedade emerge de sua susceptibilidade frente à ação de elétrons de baixa energia, que são gerados em grande quantidade no caminho traçado pela radiação ionizante. Para que essas moléculas venham a ter seu potencial explorado em tratamentos radioterápicos mais eficientes, é fundamental compreender em detalhes como se dá sua interação com elétrons de baixa energia. A halogenação pode ocorrer nas posições 5 ou 6 do anel da uracila, sendo que as 5-halouracilas tem apresentado maior interesse. A 2-tiouracila é outra molécula derivada da uracila, também apresentando habilidade radiossensibilizadora [52], sendo gerada a partir da uracila pela substituição do oxigênio da posição 2 por um enxofre. Foram estudadas nesse trabalho as moléculas de uracila, 5-fluorouracila, 5-clorouracila, 5-bromouracila, 5-iodouracila, 6clorouracila e 2-tiouracila, cujas estruturas geométricas estão apresentadas na figura 4.1. O derivado de uracila substitui a timina no DNA, que também está mostrada na figura 4.1. 


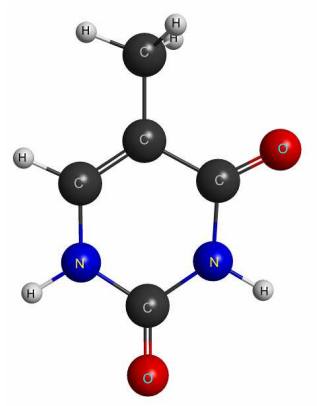

(a) Timina

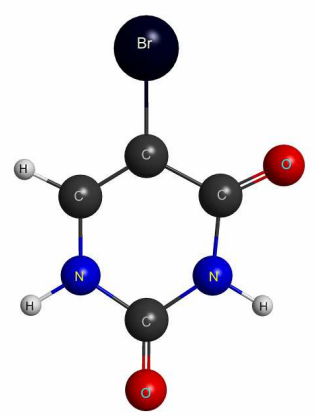

(e) 5-bromouracila

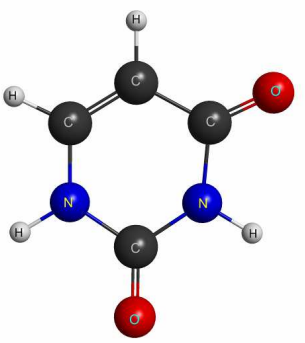

(b) Uracila

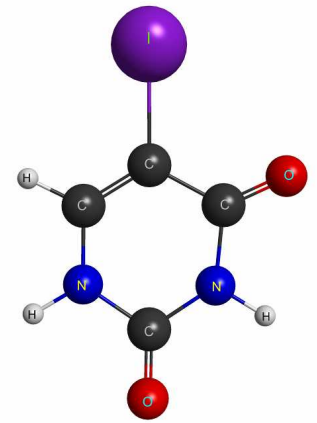

(f) 5-iodouracila

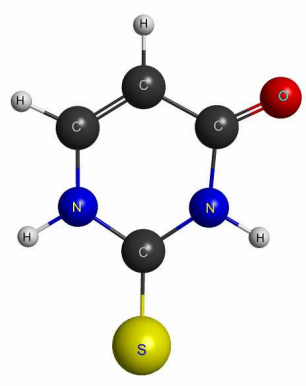

(c) 2-tiouracila

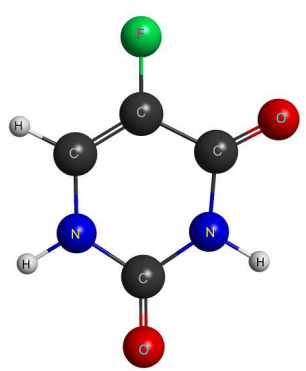

(g) 5-fluorouracila

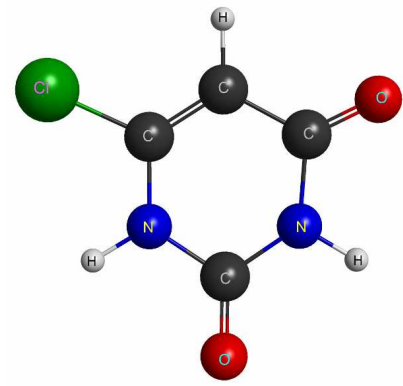

(d) 6-clorouracila

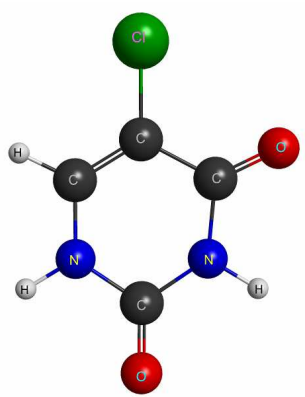

(h) 5-clorouracila

Figura 4.1: Estrutura geométrica da timina, uracila e derivados de uracila.

A uracila possui três ressonâncias de forma $\pi^{*}$ conhecidas, determinadas através do espectro de transmissão eletrônica [83] e por meio de cálculos teóricos [26,28, 32,108-110]. O mesmo tipo de experimento, realizado para a série de 5-halouracilas, com exceção da 5-iodouracila, também revelam a existência de ressonâncias $\pi^{*}$, além de uma ressonância $\sigma^{*}$ na 5-clorouracila e uma de mesmo caráter na 5-bromouracila [43]. Há cálculos $[44,45]$ para os estados $\pi^{*}$ ligados da série, que reportam afinidades eletrônicas verticais e adiabáticas. Curvas de energia potencial ao longo da coordenada de estiramento do halogênio apontam a transição entre o estado $\pi^{*}$ ligado e o estado dissociativo $\sigma^{*}$ [45]. Não há cálculos teóricos para o espectro de ressonâncias desses sistemas, com exceção de um trabalho para a 5-clorouracila que em muito superestima suas energias [111].

Medidas do espectro de dissociação das 5-halouracilas revelam a existência de uma série de fragmentos, com seções de choque de dissociação ordens de grandeza acima do observado na uracila [46-51]. Há uma série de semelhanças e algumas marcantes dife- 
renças no perfil da seção de choque de dissociação ao longo das 5-halouracilas. Em todos os sistemas há a formação do ânion de halogênio $\mathrm{X}^{-}$, com exceção da 5-fluorouracila. Esse é o fragmento mais abundante nas duas halouracilas mais pesadas, embora também apresente intensidade comparável para a 5-clorouracila. Nessa, no entanto, o fragmento mais abundante corresponde à molécula de $\mathrm{HCl}$. Similarmente, na 5-fluorouracila a espécie neutra HF é dominante. O ânion não dissociado $\mathrm{XU}^{-}$também é observado para todas as moléculas, novamente com exceção da 5-fluorouracila. O fragmento $[\mathrm{XU}-\mathrm{X}]^{-}$é gerado pela quebra da ligação $\mathrm{C}-\mathrm{X}$ enquanto a carga reside no anel, e é observado somente para 5-bromouracila e 5-iodouracila. Somente nas duas halouracilas mais leves e na uracila ocorre a eliminação do átomo de hidrogênio. Em energias mais altas ocorrem reações mais complexas, e destacam-se em todas as 5-halouracilas os ânions $\mathrm{OCN}^{-} \mathrm{e}_{2} \mathrm{C}_{3} \mathrm{NO}^{-}$. O sinal mais intenso surge próximo de $0 \mathrm{eV}$, seguido de uma estrutura também intensa em torno de $\sim 1,4 \mathrm{eV}$, e outras estruturas de menor intensidade em maiores energias. A 5-fluorouracila, no entanto, não apresenta sinal algum na região de $0 \mathrm{eV}$. O espectro de fragmentos da 6-clorouracila é similar ao do seu isômero, com algumas importantes diferenças. Na 6-clorouracila a formação de $\mathrm{HCl}$ e de $\mathrm{H}$ apresenta seções de choque mais elevadas, enquanto que para o fragmento $\mathrm{Cl}^{-}$ela é menor. Além disso, as estruturas finas observadas próximas de 0 eV ocorrem em posições distintas. Medidas de seções de choque elásticas são limitadas à uracila, que teve a seção de choque diferencial medida a $90^{\circ}$, para energias de até $1,5 \mathrm{eV}[46]$.

Cálculos teóricos que tentem descrever o processo de dissociação ainda são muito limitados. Há um cálculo para a uracila [14], que sugere a existência de um mecanismo de dissociação envolvendo a captura eletrônica num estado vibracionalmente excitado do estado ligado por dipolo, que acoplaria com um estado dissociativo de valência, induzindo a eliminação do hidrogênio. O cálculo reproduz de maneira razoável o espectro desse ânion até cerca de 1,5 eV. A estrutura observada acima disso na uracila, bem como os picos na formação dos halogênios em $\sim 1,4$ eV são atribuídos a um mecanismo indireto que envolve uma ressonância $\pi^{*}$ existente nessa energia, embora não existam trabalhos teóricos que descrevam e confirmem esse processo. 
Muito mais importante no contexto da motivação biológica, os mecanismos responsáveis pela ruptura da ligação $\mathrm{C}-\mathrm{X}$ ainda são pouco compreendidos. Em particular, as magnitudes das seções de choque para o fragmento $\mathrm{X}^{-}$crescem com o aumento do número atômico do halogênio, mas essa é uma das únicas tendências evidentes a partir dos experimentos. Há uma série de particularidades com relação à presença ou ausência de certos fragmentos, e às energias e intensidades que eles apresentam, que ainda não são compreendidas. A própria natureza dos estados do ânion e os detalhes dos processos dissociativos que eles inciam não se tornam disponíveis a partir das medidas do espectro de dissociação das halouracilas.

Em vista da importância dessa classe de biomoléculas e da escassez de resultados teóricos que tratem do espectro de ressonâncias e dos mecanismos de dissociação, nosso trabalho visa fornecer uma descrição teórica desses fenômenos. O espectro de ânions é obtido por meio de cálculos de espalhamento elástico, realizados com o método multicanal de Schwinger implementado com pseudopotenciais, nas aproximações estáticotroca e estático-troca mais polarização. A fim de avaliar possíveis mecanismos de dissociação, construímos curvas de energia potencial para a 5-clorouracila, 5-bromouracila e 5-iodouracila, bem como superfícies de energia potencial para as duas primeiras, todas construídas através de uma série de cálculos de espalhamento. Cálculos de dinâmica nuclear nas curvas de energia potencial também foram efetuados. Realizamos ainda cálculos de estrutura eletrônica para descrever o estado ligado por dipolo, o perfil dos orbitais ressonantes, as energias de dissociação, e as curvas de energia potenciais dos ânions adiabáticos.

\subsection{Procedimentos computacionais}

Os cálculos de espalhamento foram realizados com a molécula neutra em sua geometria de equilíbrio, no estado eletrônico fundamental. Para todos os sistemas a otimização da geometria foi realizada com o método DFT, e funcional B3LYP. Empregamos a base 6-311++G $(2 d, 1 p)$ para uracila, 5-fluorouracila, 5-clorouracila e 6-clorouracila. 
Para 5-bromouracila adotamos a base $6-31++\mathrm{G}(2 d, 1 p)$, para a 5 -iodouracila empregamos a base descrita nas referências [112,113], que são de qualidade 6-311G $(d, p)$, e para a 2-tiouracila a base $\mathrm{DZP}++(2 d, p)$ foi utilizada. Tanto na descrição do alvo como nos cálculos de espalhamento, pseudopotenciais de BHS [66] foram empregados para substituir os núcleos e os elétrons de caroço dos átomos pesados (todos com exceção do hidrogênio). O estado eletrônico fundamental da molécula neutra foi descrito no nível Hartree-Fock restrito, com um conjunto de funções gaussianas-cartesianas adaptas ao uso dos pseudopotenciais de BHS, construídas de acordo com Bettega et al. [68]. Adotamos uma base $5 s 5 p 2 d$ para os átomos de carbono, nitrogênio, oxigênio e enxofre (cujos expoentes são mostrados na tabela 4.1) e uma base $6 s 5 p 2 d$ para flúor, cloro, bromo e iodo (cujos expoentes se encontram na tabela 4.2). Para os átomos de hidrogênio adotamos a base $3 s$ reportada por Dunning [96]. Obtivemos um total de 252 funções de base para a uracila e 2-tiouracila, e 280 para cada halouracila. As otimizações de geometria e a descrição do estado eletrônico do alvo foram realizadas com o pacote GAMESS [97].

MVOs [65] foram utilizados para representar os orbitais de partícula e de espalhamento. Para todos os sistemas utilizamos MVOs gerados no campo do cátion de carga +12 , com exceção da uracila e 2-tiouracila, onde os orbitais foram gerados no campo do cátion de carga +6 . Todas as moléculas alvo de estudo pertencem ao grupo pontual $C_{s}$, de modo que as seções de choque foram calculadas em separado para as componentes $A^{\prime}$ e $A^{\prime \prime}$. Em todos os sistemas, o critério $\varepsilon_{\text {espa }}+\varepsilon_{\text {part }}-\varepsilon_{\text {bura }}<\varepsilon_{\text {cut }}$ [37] foi adotado em ambas as simetrias, onde $\varepsilon$ é a energia do orbital correspondente, de espalhamento, partícula e buraco. Empregamos $\varepsilon_{\text {cut }}=-1,19$ hartree para a uracila, $\varepsilon_{\text {cut }}=-4,20$ hartree para a 5-fluorouracila, $\varepsilon_{\text {cut }}=-3,65$ hartree para a 5-clorouracila e 6-clorouracila, $\varepsilon_{\text {cut }}=-3,40$ hartree para a 5 -bromouracila, $\varepsilon_{\text {cut }}=-3,30$ hartree para a 5 -iodouracila, e $\varepsilon_{\text {cut }}=-1,05$ hartree para a 2-tiouracila. Para todos os sistemas e simetrias, foram permitidos acoplamentos de spin singleto e tripleto. Ao final, obtivemos 14136 configurações para uracila (7110 na simetria $A^{\prime}$ e 7026 na $A^{\prime \prime}$ ), 9474 para a 5-fluorouracila (4884 na $A^{\prime}$ e 4590 na $A^{\prime \prime}$ ), 13272 para a 5-clorouracila (6790 na $A^{\prime}$ e 6482 na $A^{\prime \prime}$ ), 18903 para a 5-bromouracila (9653 na $A^{\prime}$ e 9250 na $A^{\prime \prime}$ ), 18586 para a 5-iodouracila (9488 na $A^{\prime}$ e 9098 na $A^{\prime \prime}$ ), 11704 
Tabela 4.1: Exponentes das funções gaussianas-cartesianas dos átomos de carbono, nitrogênio, oxigênio e enxofre (em unidades atômicas).

\begin{tabular}{crrrr}
\hline Tipo & Carbono & Nitrogênio & Oxigênio & Enxofre \\
\hline \hline$s$ & 12,496280 & 17,567340 & 16,058780 & 7,649093 \\
$s$ & 2,470286 & 3,423615 & 5,920242 & 1,743283 \\
$s$ & 0,614028 & 0,884301 & 1,034907 & 0,789128 \\
$s$ & 0,184028 & 0,259045 & 0,316843 & 0,302805 \\
$s$ & 0,039982 & 0,055708 & 0,065203 & 0,063479 \\
\hline$p$ & 5,228869 & 7,050692 & 10,141200 & 7,203417 \\
$p$ & 1,592058 & 1,910543 & 2,783023 & 3,134723 \\
$p$ & 0,568612 & 0,579261 & 0,841010 & 0,529380 \\
$p$ & 0,210326 & 0,165395 & 0,232940 & 0,154155 \\
$p$ & 0,072250 & 0,037192 & 0,052211 & 0,035523 \\
\hline$d$ & 0,603592 & 0,403039 & 0,756793 & 1,163168 \\
$d$ & 0,156753 & 0,091192 & 0,180759 & 0,240526 \\
\hline \hline
\end{tabular}

para a 6-clorouracila (5985 na $A^{\prime}$ e 5719 na $A^{\prime \prime}$ ) e 18256 para a 2-tiouracila (9235 na $A^{\prime}$ e 9021 na $A^{\prime \prime}$ ). Para uracila, 5-fluorouracila e 5-clorouracila, o espaço de configurações foi gerado de maneira distinta do que foi empregado no artigo publicado que discute esses sistemas [110]. Lá, foram utilizados MVOs no campo do cátion de carga +6, e o critério na seleção das configurações da simetria $A^{\prime \prime}$ envolveu apenas a diferença entre as energias dos orbitais de partícula e de buraco. Como será discutido adiante, a concordância com as observações experimentais é melhor com o procedimento aqui adotado do que com o utilizado anteriormente [110]. Para os demais sistemas, o procedimento é o mesmo dos artigos publicados $[114,115]$.

Uma vez que o principal interesse está na obtenção do espectro de ressonâncias, a discussão será baseada na decomposição por simetrias da seção de choque, sem a inclusão de correções que levem em conta o efeito de longo alcance do potencial do dipolo. Esse 
Tabela 4.2: Exponentes das funções gaussianas-cartesianas dos átomos de flúor, cloro, bromo e iodo (em unidades atômicas).

\begin{tabular}{crrrr}
\hline Tipo & Flúor & Cloro & Bromo & Iodo \\
\hline \hline$s$ & 12,545580 & 10,490650 & 6,779740 & 4,497056 \\
$s$ & 6,272790 & 6,836599 & 1,071059 & 1,034061 \\
$s$ & 1,576479 & 2,420592 & 0,748707 & 0,586050 \\
$s$ & 0,499283 & 0,513579 & 0,202254 & 0,229555 \\
$s$ & 0,150680 & 0,188863 & 0,036220 & 0,071496 \\
$s$ & 0,077101 & 0,062954 & 0,009055 & 0,036150 \\
\hline$p$ & 9,852550 & 6,037205 & 4,789276 & 4,343653 \\
$p$ & 2,330403 & 2,012401 & 1,856547 & 1,065825 \\
$p$ & 0,462593 & 0,686842 & 0,664700 & 0,365993 \\
$p$ & 0,154197 & 0,218056 & 0,265909 & 0,118764 \\
$p$ & 0,051399 & 0,071193 & 0,098552 & 0,028456 \\
\hline$d$ & 0,790820 & 1,611766 & 0,477153 & 0,267526 \\
$d$ & 0,181887 & 0,328314 & 0,139024 & 0,093270 \\
\hline \hline
\end{tabular}

potencial exerce grande impacto na seção de choque de background, embora o espectro de ressonâncias permaneça praticamente inalterado. As assinaturas dos estados do ânion se tornam muito menos evidentes diante da dominância do espalhamento de background [9]. Portanto, quando a correção do momento de dipolo é ignorada, as assinaturas das ressonâncias se tornam mais claras, embora deva ser lembrado que as seções de choque estão subestimadas, especialmente em mais baixas energias.

Orbitais virtuais obtidos de cálculos de estrutura eletrônica com base compacta são adequados para representar o caráter qualitativo das ressonâncias. Além disso, esse tipo de cálculo ainda fornece uma estimativa de suas energias através de relações empíricas entre o valor calculado para a energia do orbital virtual (VOE's, do inglês virtual orbital energies) e a energia de aprisionamento vertical (VAE's, do inglês vertical 
attachment energies), que é o mesmo que a energia da ressonância. A relação aproximadamente linear observada entre as duas quantidades deu origem a diferentes relações de escala, dependendo do método usado no cálculos dos VOEs [111,116-118]. O uso de tais relações empíricas costuma fornecer boas estimativas para as energias de estados $\pi^{*}$, com desvios dentro de $\sim 0,4 \mathrm{eV}$, enquanto as estimativas para estados $\sigma^{*}$ usualmente são um pouco inferiores, apresentando erros maiores. Seguimos o procedimento de Staley e Strnad [116], no qual a geometria é otimizada no nível MP2/6-31G(d), os orbitais virtuais Hartree-Fock canônicos são obtidos na geometria otimizada, com a mesma base, e as energias dos estados $\pi^{*}$ são estimadas de acordo com a relação VAE $=0.64795 \times \mathrm{VOE}-1.4298$, em unidades de eV. Para todos os sistemas aqui apresentados essa foi a relação empírica empregada.

Além dos estados de valência, o ânion pode existir no chamado estado ligado por dipolo. Nesse tipo de estado, a captura não se dá por interações de valência de curto alcance, mas pelo potencial de longo alcance, que é dominado pela interação dipolar. O elétron adicional passa a residir num orbital molecular muito mais difuso que os orbitais de valência típicos, situado no polo positivo da molécula. Formalmente, o potencial dipolar é capaz de formar estados de dipolo desde que esse tenha magnitude acima do valor crítico de 1,5 D [119]. Para sistemas moleculares reais, tal estado passa a existir quando o momento de dipolo for superior a 2,4 D [119]. A descrição teórica desse tipo de estado requer o uso de bases ainda mais difusas do que as funções difusas usuais de Dunning e de Pople. Para todos os sistemas em que descrevemos o estado de dipolo, adotamos a base aug-cc-pVDZ aumentada com um conjunto de funções difusas 6s6p, construídas segundo o procedimento de Skurski et al. [120]. As funções da base extra são centradas no átomo que se situa mais próximo do polo positivo do momento de dipolo, enquanto que os expoentes são gerados a partir de sucessivas divisões por 4, partindo do expoente mais difuso da base aug-cc-pVDZ. Esse procedimento é realizado em separado para as funções tipo-s e tipo-p. Todos os cálculos envolvendo o estado de dipolo foram realizados com o programa Gaussian09 [94]. 


\subsection{Uracila}

Na figura 4.2 apresentamos a decomposição por simetrias da seção de choque integral elástica da uracila, calculadas nas aproximações SE e SEP. No cálculo SE, obtivemos três ressonâncias de forma $\pi^{*}$ na simetria $A^{\prime \prime}$, localizadas em 2,27 eV, 4,05 eV e 8,0 eV, em bom acordo com os resultados obtidos no mesmo nível de aproximação por Winstead e McKoy [121] e por Dora et al. [28]. Na figura 4.3 são mostrados os orbitais virtuais que capturam o elétron incidente e dão origem às ressonâncias $\pi^{*}$. Quando efeitos de polarização são incluídos nos cálculos, os estados do ânion são deslocados para menores energias, e surgem em 0,15 eV, 1,82 eV e 4,81 eV. Esses resultados estão em ótimo acordo com os dados do espectro de transmissão eletrônica de Aflatooni et. al. [122] $(0,22 \mathrm{eV}$, 1,58 eV e 3,83 eV), com o cálculo SMC de Winstead e McKoy [121] (0,32 eV, 1,91 eV e 5,08 eV), e com o cálculo da matriz R de Dora et. al. [28] (0,13 eV, 1,94 eV e 4,95 eV). Outros estudos teóricos baseados no uso de potenciais efetivos para descrever a interação entre elétron e molécula $[26,109,123]$ também sustentam a existência de três ressonâncias de forma $\pi^{*}$, embora eles superestimem suas energias em torno de 2 a $4 \mathrm{eV}$. Gianturco et. al. [123] sugeriu a existência de uma quarta ressonância $\pi^{*}$, mas esse possibilidade foi refutada [124]. Por fim, o resultado presente é muito semelhante ao nosso cálculo anterior [110], em que as ressonâncias foram obtidas em 0,14, 1,76 e 4,83 eV. A tabela 4.3 contém as posições e larguras das ressonâncias $\pi^{*}$ da uracila, segundo a medida experimental e os cálculos existentes. Dentre os resultados teóricos, o nosso é o que apresenta melhor acordo com as medidas experimentais.

Estudos anteriores para a uracila $[28,108,109,121,123]$ reportam ressonâncias na simetria $A^{\prime}$. A obtenção de assinaturas desses estados do ânion nas seções de choque calculadas não é imediata. Ressonâncias de caráter $\sigma_{\mathrm{OH}}^{*}[31]$ e $\sigma_{\mathrm{NH}}^{*}[34]$ geralmente apresentam curto tempo de vida, correspondendo a estruturas muito largas na seção de choque. Além disso, elas estariam imersas na contribuição dominante do potencial de dipolo, e dificilmente seriam identificados na seção de choque ou soma de autofases calculadas. Em vista dessas dificuldades, não identificamos ressonâncias $\sigma_{\mathrm{NH}}^{*}$, na uracila ou 


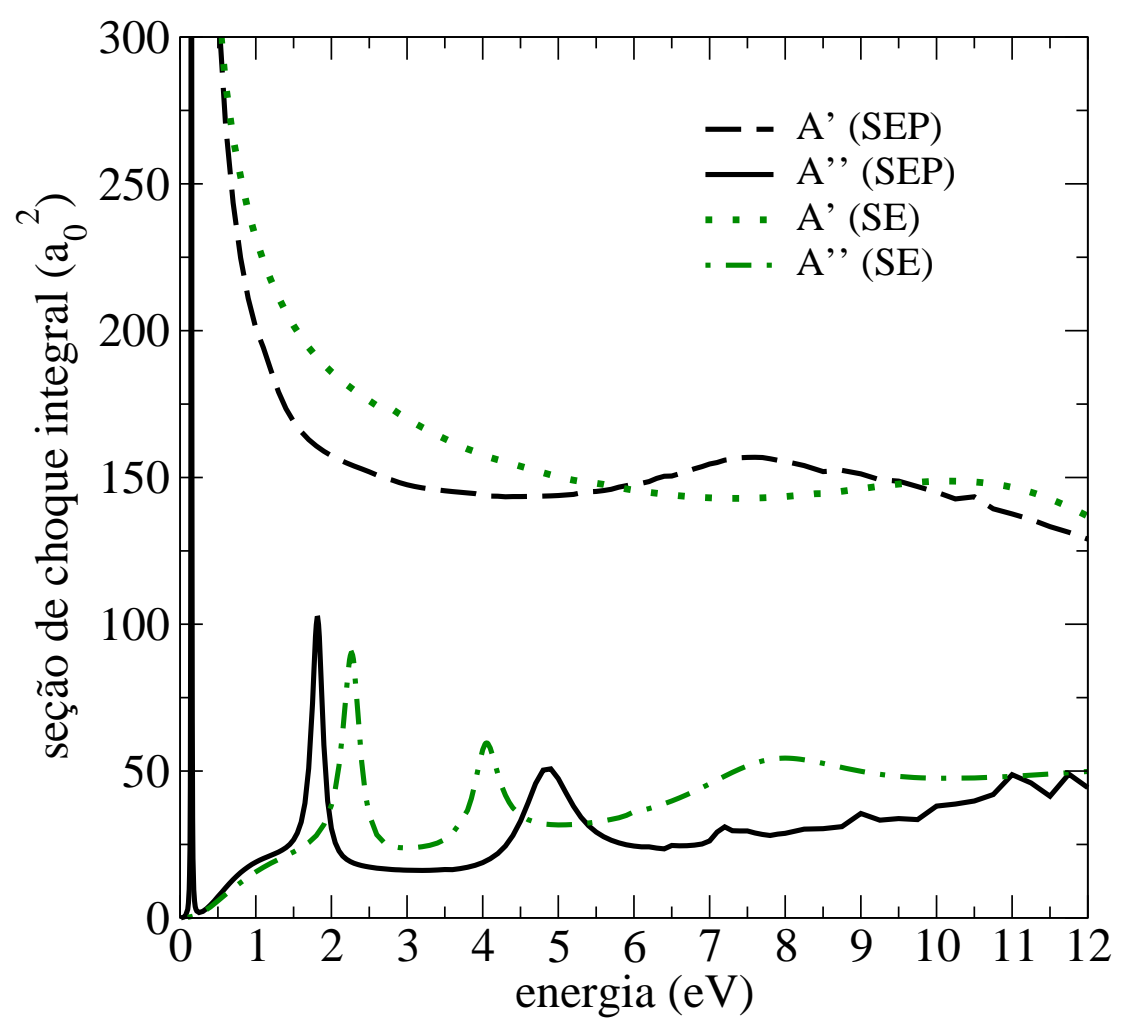

Figura 4.2: Seção de choque integral das simetrias $A^{\prime}$ e $A^{\prime \prime}$ da uracila, calculadas nas aproximações SE e SEP.

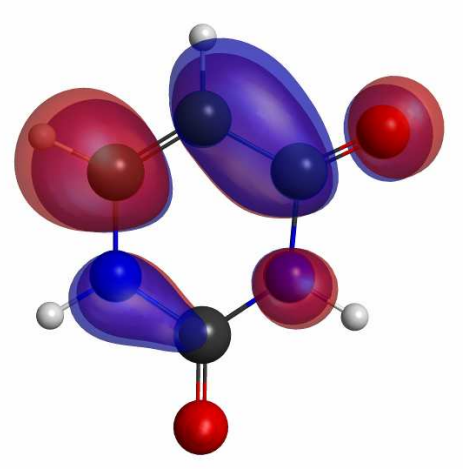

(a) $\pi_{1}^{*}$ da uracila

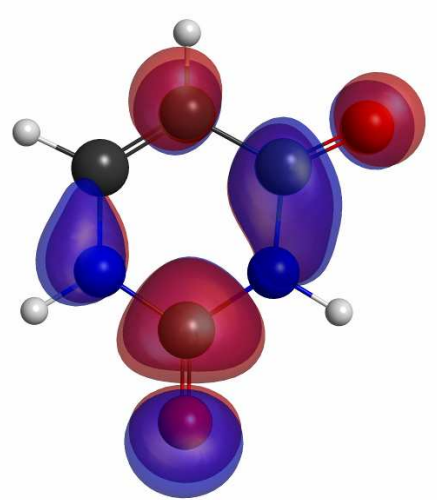

(b) $\pi_{2}^{*}$ da uracila

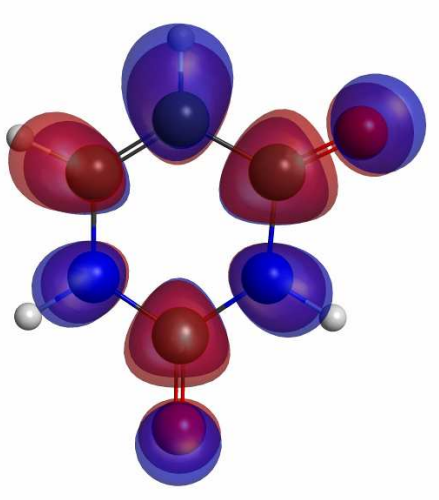

(c) $\pi_{3}^{*}$ da uracila

Figura 4.3: Orbitais $\pi^{*}$ da uracila.

halouracilas. Por outro lado, há estruturas largas presentes na seção de choque da simetria $A^{\prime}$, em torno de $10 \mathrm{eV}$ no cálculo SE, e em 7,5 eV no cálculo SEP. Tais estruturas apa- 
Tabela 4.3: Posições e larguras (essa apresentada entre parênteses) dos estados $\pi^{*}$ da uracila (em unidades de eV).

\begin{tabular}{llll}
\hline \hline & $\pi_{1}^{*}$ & $\pi_{2}^{*}$ & $\pi_{3}^{*}$ \\
\hline Nosso resultado & $0,15(0,0056)$ & $1,82(0,17)$ & $4,81(0,78)$ \\
Relação de escala & 0,32 & 1,62 & 4,16 \\
Scheer et al. $[122]$ & 0,22 & 1,58 & 3,83 \\
Winstead e McKoy [121] & $0,32(0,018)$ & $1,91(0,16)$ & $5,08(0,40)$ \\
Dora et al. $[28]$ & $0,13(0,0034)$ & $1,94(0,168)$ & $4,95(0,38)$ \\
Gianturco e Lucchese [108] & $2,27(0,21)$ & $3,51(0,38)$ & $6,50(1,03)$ \\
Tonzani e Greene [26] & $2,16(0,2)$ & $5,16(0,6)$ & $7,8(0,9)$ \\
Yalunin e Leble $[109]$ & $1,9(4,4)$ & 5,6 & 6,1 \\
\hline \hline
\end{tabular}

recem de maneira sistemática em todas as biomoléculas a serem discutidas na sequência. Uma vez que elas ocorrem em energias mais altas, não tentamos inferir os orbitais ressonantes correspondes. Estruturas semelhantes na simetria $A^{\prime}$ da uracila foram obtidas em cálculos de espalhamento elásticos anteriores, de Winstead e McKoy [121] (8,5 eV), Gianturco et. al. [123] (8,4 eV) e Gianturco e Lucchese [108] (10,4 eV). Dora et. al. [28] obteve ainda ressonâncias de Feshbach em 6,17 eV, 7,62 eV e 8,12 eV em cálculos que permitem acoplamento multicanal.

\subsection{5-Fluorouracila}

A figura 4.4 mostra a decomposição por simetrias da seção de choque integral da 5-fluorouracila. Na aproximação SE há a indicação de três ressonâncias de forma $\pi^{*}$, em 1,82, 4,02 e 8,2 eV, enquanto que no nível SEP elas se deslocam para 0,14, 1,64 e 5,50 $\mathrm{eV}$. As duas primeiras ressonâncias estão em excelente acordo com os valores reportados experimentalmente, de $0,17 \mathrm{eV}$ para a ressonância $\pi_{1}^{*}$ e de $1,5 \mathrm{eV}$ para a $\pi_{2}^{*}$ [43]. A 


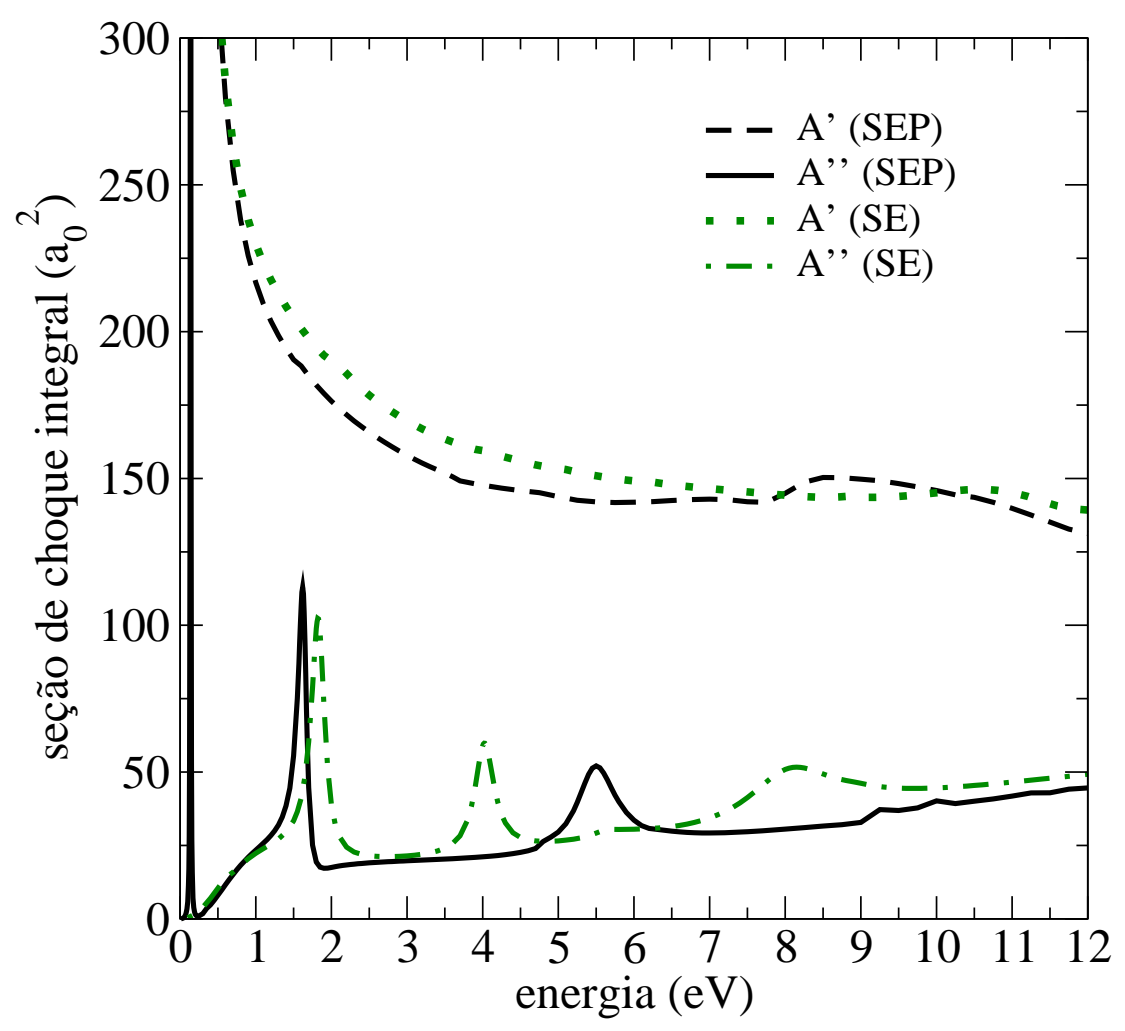

Figura 4.4: Seção de choque integral das simetrias $A^{\prime}$ e $A^{\prime \prime}$ da 5-fluorouracila, calculadas nas aproximações SE e SEP.

energia calculada para o estado $\pi_{1}^{*}$ também se compara de modo favorável aos resultados obtidos por cálculos de estrutura eletrônica de Wetmore et. al. [44], no nível B3LYP/6311G++(2df,p) (0,03 eV) e de Li et. al. [45], no nível B3LYP/6-31+G(d) $(0,15 \mathrm{eV})$. No entanto, a energia da ressonância $\pi_{3}^{*}(5,50 \mathrm{eV})$ fica consideravelmente superestimada em relação ao valor medido de 4,1 eV [43]. No trabalho anterior [37], os estados $\pi^{*}$ da 5-fluorouracila haviam se mostrado em -0,09, 1,70 e 4,97 eV, e a comparação com o experimento era apenas razoável. O estado $\pi^{*}$ se mostrava ligado, e não ressonante, enquanto a energia da ressonância $\pi_{2}^{*}$ era superestimada.

Embora esperássemos a assinatura de uma ressonância $\sigma_{\mathrm{CF}}^{*}$ na seção de choque da simetria $A^{\prime}$, os cálculos não revelaram a presença de tal estado. No entanto, uma estrutura de mais alta energia é observada na simetria $A^{\prime}$, em torno de $10 \mathrm{eV}$ segundo a aproximação $\mathrm{SE}$, e em 8,5 eV com a inclusão de efeitos de polarização. Realizamos 
cálculos de espalhamento em uma configuração em que a distância C-F era estirada, e como essa estrutura permaneceu praticamente inalterada, podemos descartá-la como sendo a ressonância $\sigma_{\mathrm{CF}}^{*}$.

\subsection{5-Clorouracila}

As componentes da seção de choque integral da 5-clorouracila são apresentadas na figura 4.5. Os resultados na aproximação SE indicam três ressonâncias de forma $\pi^{*}$, em 1,69, 3,97 e 7,5 eV. No cálculo SEP apenas os estados $\pi_{2}^{*}$ e $\pi_{3}^{*}$ estão presentes na seção de choque, localizados respectivamente em 1,57 e 4,70 eV. Da diagonalização da hamiltoniana de espalhamento na base CSF, obtivemos o valor de $-0,11 \mathrm{eV}$ para a energia do estado $\pi_{1}^{*}$, em muito bom acordo com os cálculos de estrutura eletrônica de Wetmore et. al. [44] $(-0,14 \mathrm{eV})$ e de Li et. al. [45] (-0,06 eV). As posições obtidas para as ressonâncias $\pi_{2}^{*}$ e $\pi_{3}^{*}$ também estão em bom acordo com as medidas de Scheer et. al. [43], que observaram as ressonâncias $\pi^{*}$ em cerca de 1,3 eV e 3,6 eV. Sommerfeld [111], usando um método com potencial com componente imaginária, obteve os três estados $\pi^{*}$ em cerca de 2, 4,5 e 8 eV, em razoável acordo com nossos resultados SE. Aqui também, o resultado presente é superior ao nosso resultado anterior [110], em que os estados $\pi^{*}$ se localizavam em -0,23, 1,63 e 4,59 eV.

Um pico proeminente é identificado na seção de choque da simetria $A^{\prime}$, em cerca de 4,8 eV e 1,96 eV nos cálculos SE e SEP, respectivamente, com uma largura de 1,03 $\mathrm{eV}$ no último caso. Atribuímos essa estrutura a uma ressonância de forma $\sigma_{\mathrm{CCl}}^{*}$, em consistência com os dados de Scheer et al. [43]. Esses autores atribuíram a uma ressonância $\sigma_{\mathrm{CCl}}^{*}$ a estrutura por eles encontrada em torno de 1,8 eV, estando sobreposta a ressonância $\pi_{2}^{*}$. Nosso valor $(1,96 \mathrm{eV})$ está em ótima concordância com o observado, e mais uma vez o presente cálculo se mostrou superior ao anterior [110], onde esse estado era encontrado em 2,54 eV. Sommerfeld [111] também identificou um estado $\sigma_{\mathrm{CCl}}^{*}$ na 5-clorouracila, ao redor de $6 \mathrm{eV}$, em razoável acordo com nosso resultado SE. Ele obteve 1,65 eV para sua 


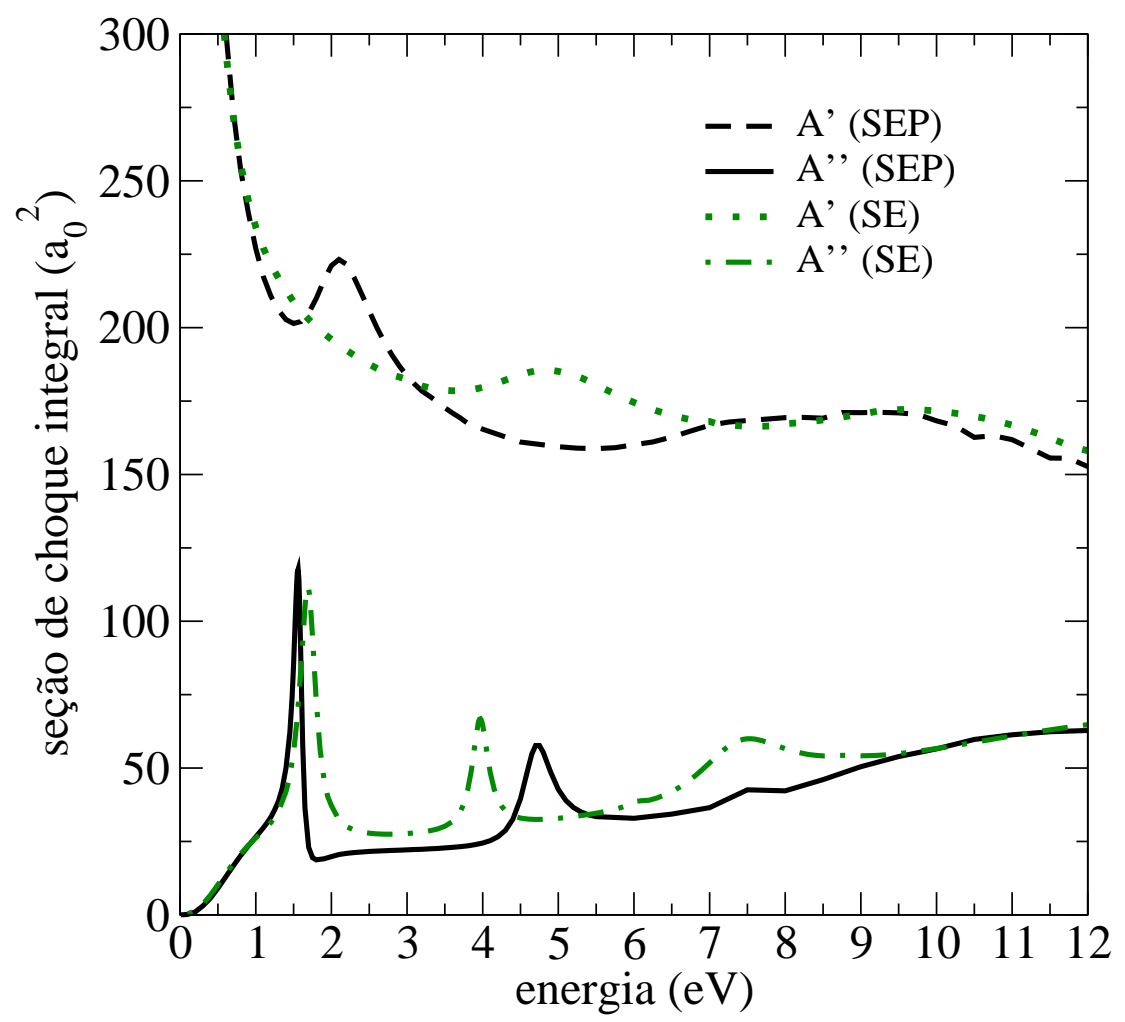

Figura 4.5: Seção de choque integral das simetrias $A^{\prime}$ e $A^{\prime \prime}$ da 5-clorouracila, calculadas nas aproximações SE e SEP.

largura, acima do valor obtido em nosso cálculo SEP, de 1,03 eV. A simetria $A^{\prime}$ apresenta ainda uma estrutura em torno de $10 \mathrm{eV}$ na aproximação SE, que se desloca para $8 \mathrm{eV}$ no cálculo SEP.

Na figura 4.6 são apresentadas as curvas de energia potencial da 5-clorouracila, ao longo da distância $\mathrm{C}-\mathrm{Cl}$. As curvas do estado ligado $\pi_{1}^{*}$ e do estado ressonante $\pi_{2}^{*}$ seguem praticamente paralelas à curva do estado neutro, indicando que são estados nãodissociativos. A pequena densidade de probabilidade na vizinhança do halogênio se manifesta para maiores deslocamentos, quando a energia dos estados $\pi^{*}$ se estabiliza levemente. A ressonância $\sigma_{\mathrm{CCl}}^{*}$, por outro lado, é rapidamente estabilizada frente ao estiramento da ligação $\mathrm{C}-\mathrm{Cl}$, confirmando seu caráter dissociativo. Os cruzamentos entre os estados $\pi^{*}$ e $\sigma_{\mathrm{CCl}}^{*}$ já sugerem possíveis acoplamentos não-adiabáticos entre eles, permitindo que os estados $\pi^{*}$ possam induzir a eliminação do halogênio por meio de um mecanismo indireto 


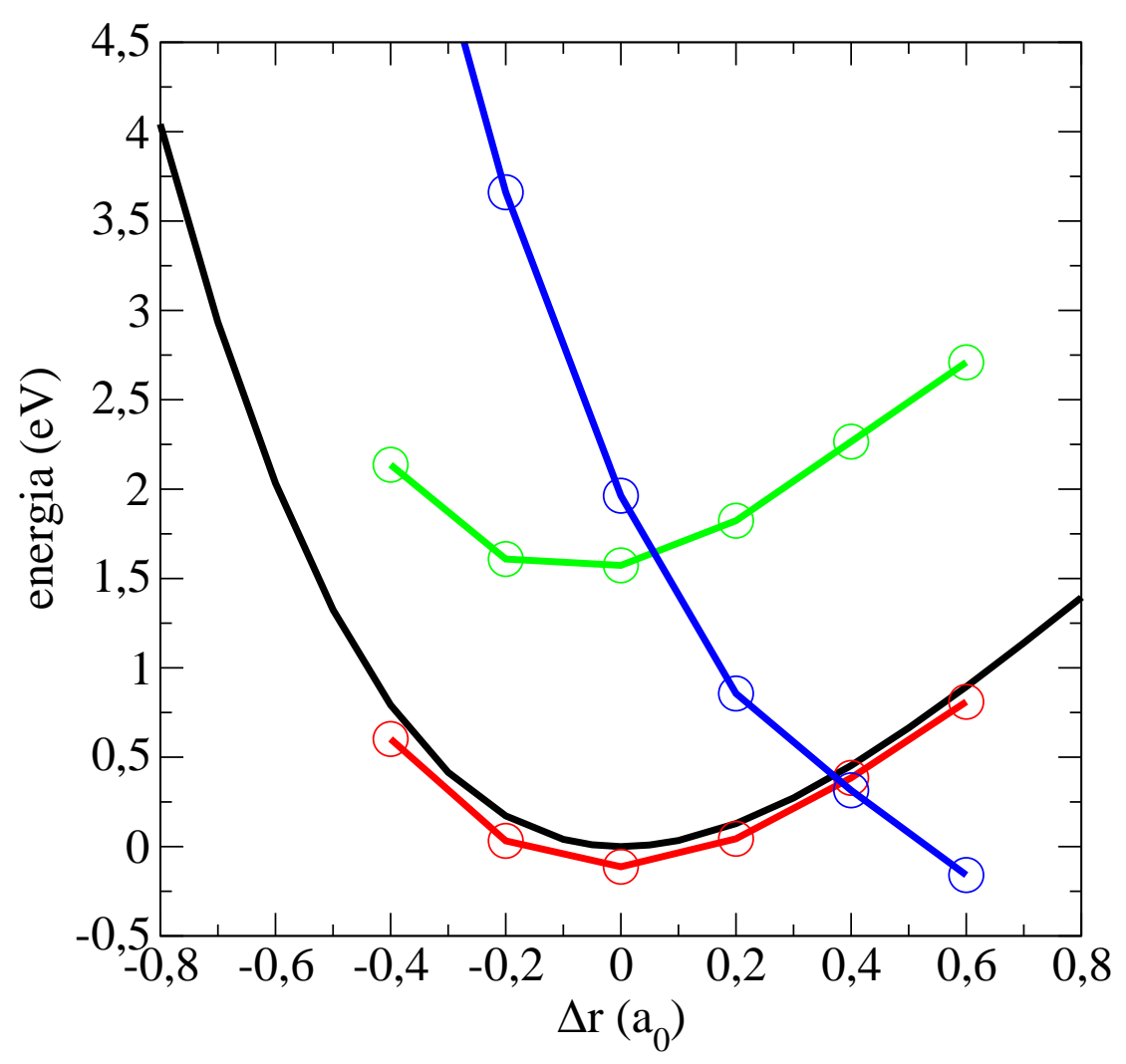

Figura 4.6: Curvas de energia potencial para a 5-clorouracila, em função do desvio da posição de equilíbrio $\Delta r$. Estão representados o estado fundamental da molécula neutra (preto), e os estados do ânion $\pi_{1}^{*}$ (vermelho), $\pi_{2}^{*}$ (verde) e $\sigma_{\mathrm{CCl}}^{*}$ (azul).

de dissociação.

Realizamos cálculos de dinâmica do pacote de onda tomando a distância $\mathrm{C}-\mathrm{Cl}$ como coordenada reativa, assumindo que a captura eletrônica se dê no orbital dissociativo $\sigma_{\mathrm{CCl}}^{*}$. As curvas do neutro e da componente real do ânion foram descritas por potenciais de Morse, (equações 3.2 e 3.3), sendo que para a espécie carregada o limite assintótico foi obtido através dos valores calculados para os fragmentos individualmente, com o mesmo nível de cálculo em em que a otimização de geometria foi realizada. Para a componente imaginária utilizamos a equação 3.4. Parâmetros relacionados à dinâmica, como a grade de pontos e o tempo de propagação são exatamente os mesmos que os adotados no caso do cloroeteno. 
A curva de seção de choque de dissociação do fragmento $\mathrm{Cl}^{-}$é ilustrada na figura 4.7. Há um pico em torno de $0,93 \mathrm{eV}$, deslocado em relação à posição da ressonância $\sigma_{\mathrm{CCl}}^{*}$, encontrada em 1,96 eV, devido à assimetria dos tempos de vida em torno da energia da ressonância. Considerando um ensemble de níveis vibracionais com uma temperatura de $450 \mathrm{~K}$, condição aproximada em que as medidas experimentais foram realizadas $[40,48]$, e somando até o oitavo nível vibracional, temos a seção de choque de dissociação para essa temperatura, também apresentada na figura 4.7. Há contribuições significativas dos quatro primeiros níveis vibracionais, causando um deslocamento do pico para 0,68 eV e um aumento na magnitude da seção de choque de cerca quatro vezes. Os valores máximos da seção de choque calculada, de $\sim 5 \times 10^{-19} \mathrm{~cm}^{2}$ para o nível vibracional fundamental, ou de $\sim 2 \times 10^{-18} \mathrm{~cm}^{2}$ para a média térmica, estão muito abaixo dos valores $\sim 3 \times 10^{-14} \mathrm{~cm}^{2}$ e $\sim 2 \times 10^{-15} \mathrm{~cm}^{2}$, medidos nos picos mais pronunciados do espectro de dissociação, em 0,23 e $\sim 1,4 \mathrm{eV}$, respectivamente [48]. Esse resultado descarta o mecanismo direto como candidato a explicar a quebra da ligação $\mathrm{C}-\mathrm{Cl}$ do ânion de 5-clorouracila, sugerindo que os estados $\pi^{*}$ são os reais precursores do processo dissociativo.

Como um primeiro passo na investigação da dissociação do ânion de 5clorouracila mediada pelo acoplamento entre estados $\pi^{*}$ e $\sigma_{\mathrm{CCl}}^{*}$, é necessário considerar uma coordenada que quebre a simetria planar, tornando desse modo os acoplamentos nãonulos. Essa segunda coordenada, juntamente com a coordenada reativa representada pelo comprimento da ligação $\mathrm{C}-\mathrm{Cl}$ compõe as duas dimensões em que as superfícies de energia potencial são construídas. No caso do cloroeteno tomamos como segunda coordenada o ângulo formado entre o cloro, o carbono ao qual ele se liga e a posição original do cloro. Para a 5-clorouracila adotamos o mesmo ângulo, e a seguir esclarecemos o motivo dessa escolha.

A segunda coordenada deve relaxar os estados não dissociativos $\pi^{*}$, além de induzir um forte acoplamento com a ressonância $\sigma_{\mathrm{CCl}}^{*}$. Foram testados modos normais de simetria $A^{\prime \prime}$, embora nenhum tenha atendido esses critérios. Avaliamos então, para cada núcleo, o deslocamento cartesiano que o move para fora do plano molecular. A energia das ressonâncias foi estimada de acordo com a relação de escala de Staley et al. [116], que 


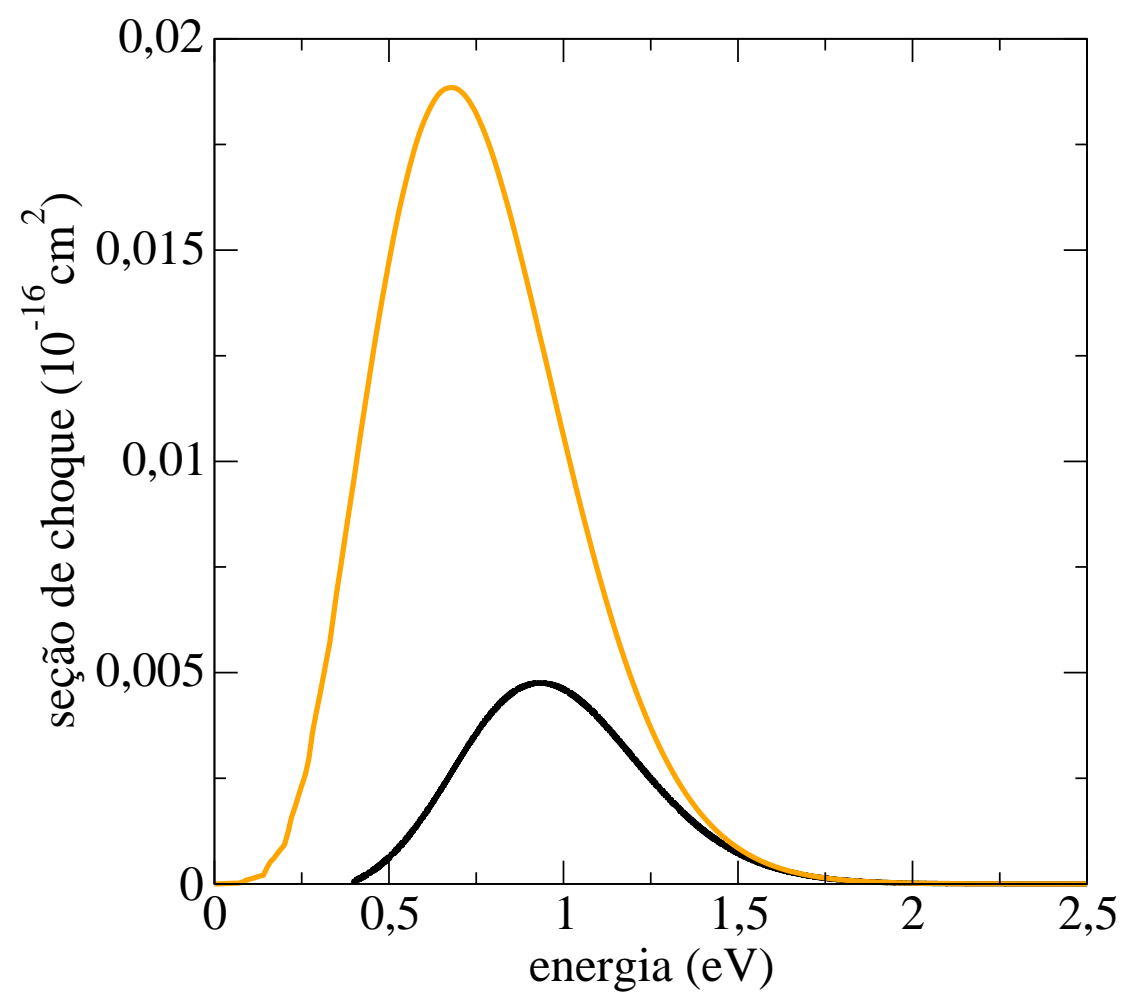

Figura 4.7: Seção de choque de dissociação da 5-clorouracila, a partir do nível vibracional $\nu=0$ (preto) e tomando uma média sobre populações a $450 K$ (laranja).

deve servir ao propósito de descrever o perfil qualitativo das curvas. A energia do ânion é obtida somando a energia da ressonância e a energia do estado neutro obtido de cálculos B3LYP/aug-cc-pVTZ. As curvas de energia potencial dos dois estados aniônicos de mais baixa energia, bem como a curva do neutro, estão apresentadas na figura 4.8. A curva vermelha sempre representa o estado $\pi_{1}^{*}$, enquanto a curva verde denota o segundo estado do ânion, que pode assumir caráter predominante $\pi_{2}^{*}$ ou $\sigma_{\mathrm{CCl}}^{*}$, a depender da geometria. Ambos os estados estão em pontos de equilíbrio na geometria planar, e para alguns deslocamentos cartesianos o equilíbrio é estável, e o átomo tende a permanecer na condição planar. Em outros casos esse equilíbrio é instável, e o ânion deve relaxar para um mínimo que se encontra numa posição deslocada do plano. A estrutura da ressonância $\pi_{2}^{*}$ deve relaxar mediante deslocamentos do carbono e do oxigênio localizados na posição 2 do anel, e em menor medida com movimentos do nitrogênio da posição 1 e do oxigênio da posição 


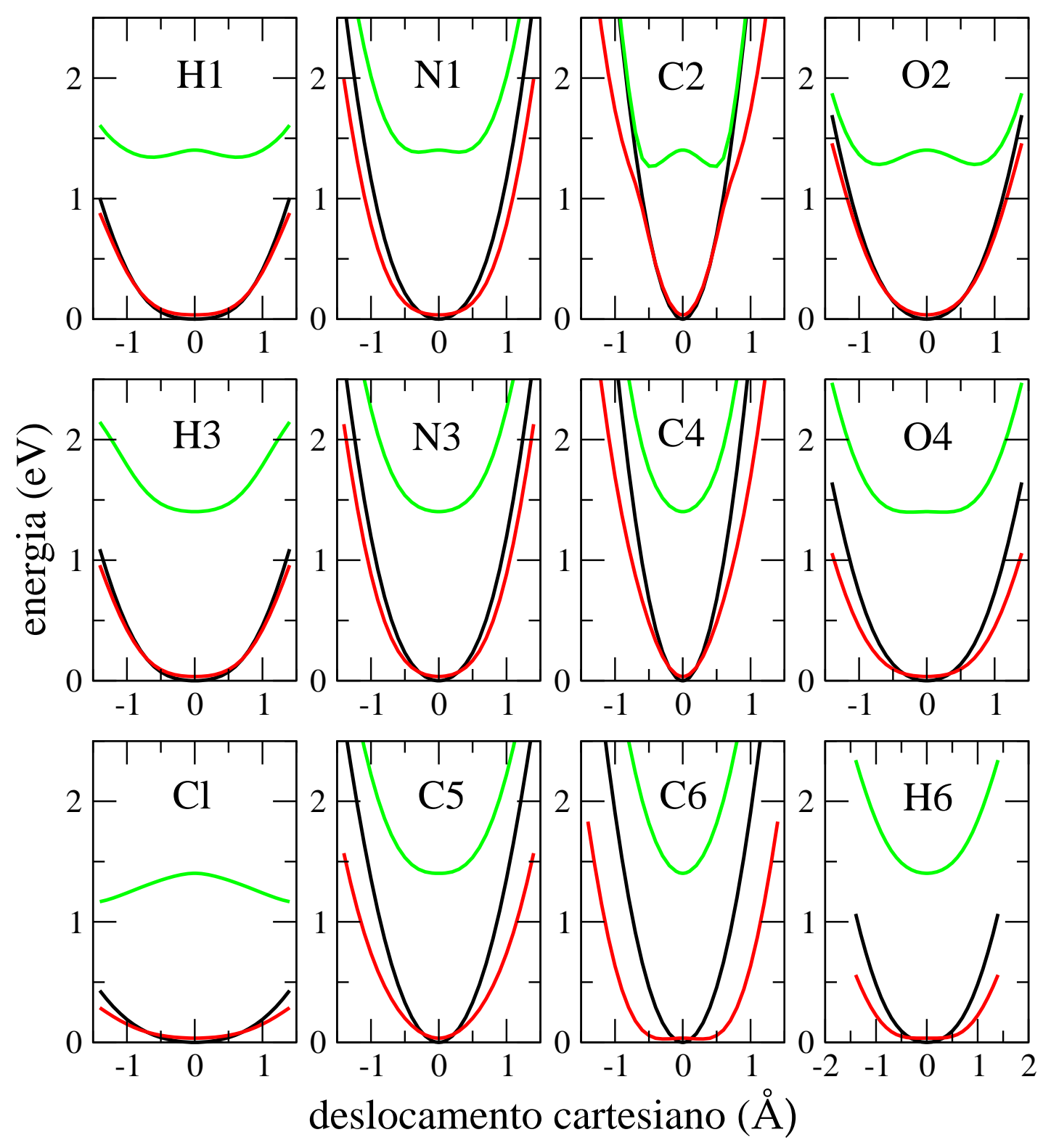

Figura 4.8: Curvas de energia potencial para a 5-clorouracila, em função do deslocamento cartesiano perpendicular ao plano molecular, para cada átomo. Estão representados o estado fundamental da molécula neutra (preto), e os dois primeiros estados do ânion (vermelho e verde).

4. Esses átomos se localizam onde há grande densidade de probabilidade do orbital ressonante, e portanto espera-se que esses deslocamentos estabilizem o ânion. No entanto, nosso cálculo sugere que é o movimento do cloro que mais estabiliza o estado, o que não 


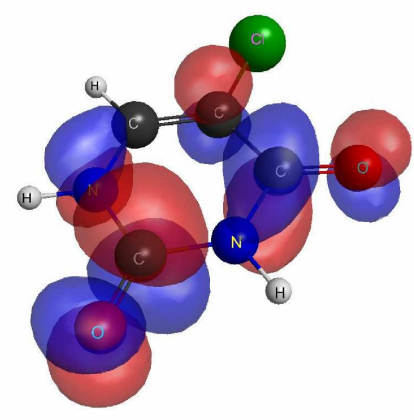

(a) $\mathrm{LUMO}+1$ em $d=0$

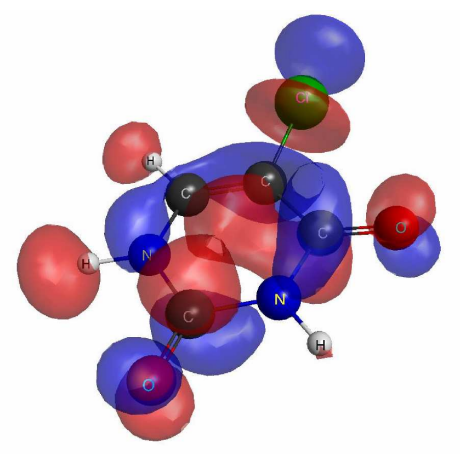

(d) $\mathrm{LUMO}+1$ em $d=0,7 \AA$

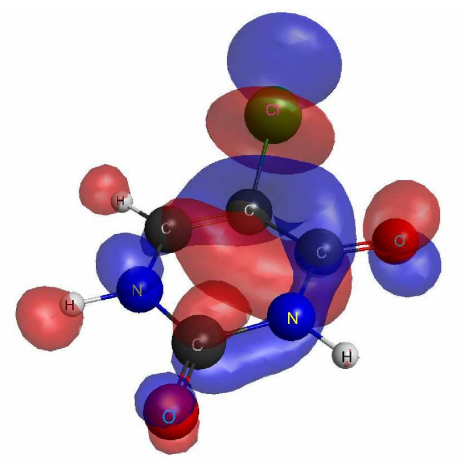

(g) LUMO+1 em $d=1,4 \AA$

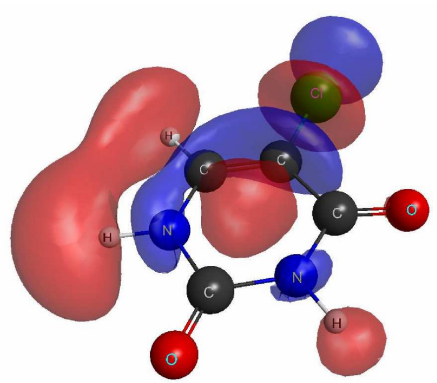

(b) $\mathrm{LUMO}+2$ em $d=0$

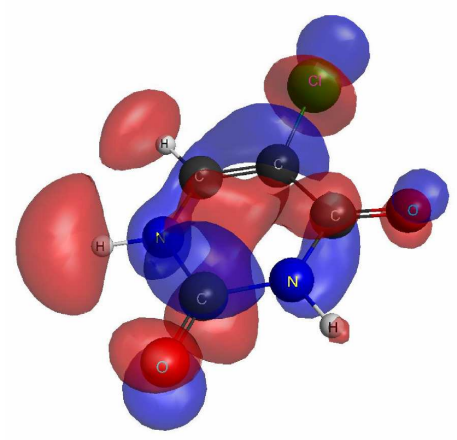

(e) $\mathrm{LUMO}+2$ em $d=0,7 \AA$

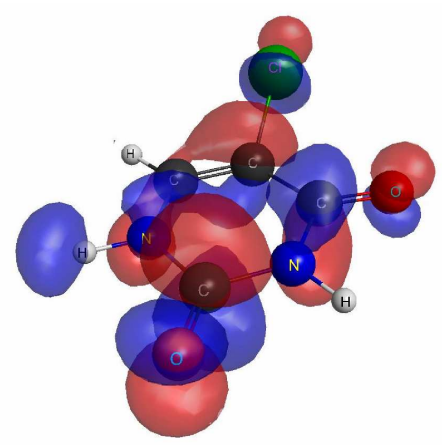

(h) $\mathrm{LUMO}+2$ em $d=1,4 \AA$

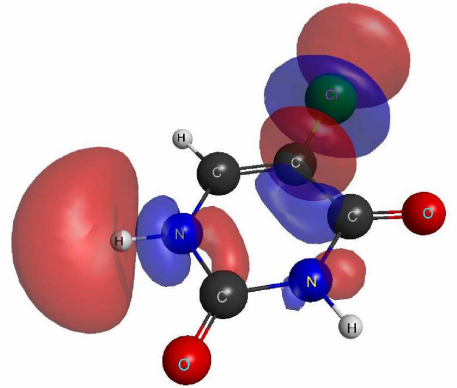

(c) $\mathrm{LUMO}+3$ em $d=0$

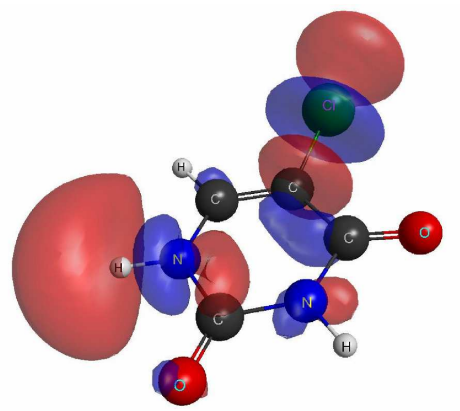

(f) $\mathrm{LUMO}+3$ em $d=0,7 \AA$

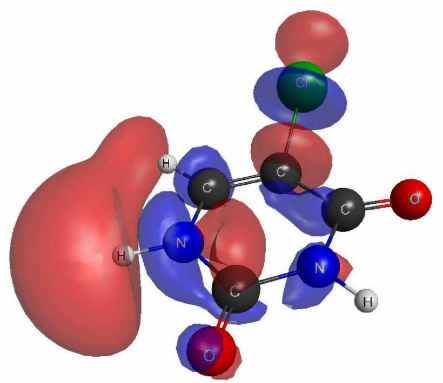

(i) $\mathrm{LUMO}+3$ em $d=1,4 \AA$

Figura 4.9: LUMO+1, LUMO+2 e LUMO+3 da 5-clorouracila, na geometria de equilíbrio e para deslocamentos cartesianos do cloro $d$ na direção perpendicular ao plano molecular, de $d=0,7 \AA$ e $d=1,4 \AA$.

seria esperado com base na análise do orbital $\pi_{2}^{*}$. Além dessa estabilização, é necessário que haja uma mistura entre os orbitais $\pi_{2}^{*}$ e $\sigma_{\mathrm{CCl}}^{*}$ ao longo dessa coordenada. A figura 4.9 ilustra o $\mathrm{LUMO}+1, \mathrm{LUMO}+2$ e $\mathrm{LUMO}+3$ da 5-clorouracila, obtidos na geometria de 
equilíbrio e em geometrias com deslocamentos cartesianos do átomo de cloro de $d=0,7 \AA$ e $d=1,4 \AA$. Na geometria de equilíbrio a ocupação do LUMO+1 dá origem à ressonância $\pi_{2}^{*}$, enquanto o LUMO+2 e o LUMO+3 estão associados às ressonâncias $\sigma_{\mathrm{NH}}^{*}$ e $\sigma_{\mathrm{CCl}}^{*}$. Com $d=0,7 \AA$ o LUMO +1 e o LUMO +2 tornam-se muito parecidos, apresentando um caráter misto entre $\pi_{2}^{*}$ e $\sigma_{\mathrm{CCl}}^{*}$. E para $d=1,4 \AA$ o perfil dos orbitais se inverte, sendo o LUMO +1 predominantemente $\sigma_{\mathrm{CCl}}^{*}$ e o LUMO+2 assumindo o caráter $\pi_{2}^{*}$. Embora ainda reste certa densidade na ligação $\mathrm{C}-\mathrm{Cl}$ no $\mathrm{LUMO}+3$, o caráter $\sigma_{\mathrm{NH}}^{*}$ torna-se mais evidente nesse caso. Portanto, o deslocamento do cloro estabiliza o estado $\pi_{2}^{*}$ e induz um acoplamento com a ressonância dissociativa $\sigma_{\mathrm{CCl}}^{*}$, o que justifica como segunda coordenada o ângulo $\theta$ formado entre o cloro, o carbono ao qual ele se liga e sua a posição original, na geometria de equilíbrio.

O estado $\pi_{1}^{*}$, por sua vez, relaxa a partir de deslocamentos do carbono da posição 6 e do hidrogênio ligado a ele, o que é compatível com a geometria de equilíbrio do ânion, onde esse hidrogênio encontra-se deslocado para fora do plano. O acoplamento $\pi_{1}^{*} / \sigma_{\mathrm{CCl}}^{*}$ deve ocorrer apenas para um maior estiramento da ligação $\mathrm{C}-\mathrm{Cl}$, como apontam as curvas de energia potencial unidimensionais da figura 4.6.

Cálculos de espalhamento foram realizados ao longo dos deslocamentos radial $\Delta r$ e angular $\theta$ do átomo de cloro, onde o procedimento adotado na construção do espaço CSF para a geometria de equilíbrio foi mantido em todas as configurações. O deslocamento radial $\Delta r$ corresponde à variação do comprimento da ligação $\mathrm{C}-\mathrm{Cl}$ a partir da posição de equilíbrio da molécula neutra. A figura 4.10 ilustra as superfícies de energia potencial dos três estados aniônicos da 5-clorouracila. Na geometria de equilíbrio eles correspondem aos estados $\pi_{1}^{*}, \pi_{2}^{*}$ e $\sigma_{\mathrm{CCl}}^{*}$, que mudam de caráter e se acoplam com o movimento do cloro. Identificamos dois pontos de interseção entre as superfícies. O encontro entre as superfícies azul e verde da figura 4.10 indica a transição entre os estados $\pi_{2}^{*}$ e $\sigma_{\mathrm{CCl}}^{*}$, enquanto o acoplamento $\pi_{1}^{*} / \sigma_{\mathrm{CCl}}^{*}$ se dá na conexão das superfícies azul e verde.

Na região de equilíbrio do estado neutro, a superfície da ressonância $\pi_{2}^{*}$ estabiliza na direção da coordenada $\theta$, o que indica que a dinâmica vibracional deve iniciar nessa direção. O deslocamento do pacote de onda para maiores valores de $\theta$ passa a facilitar a 


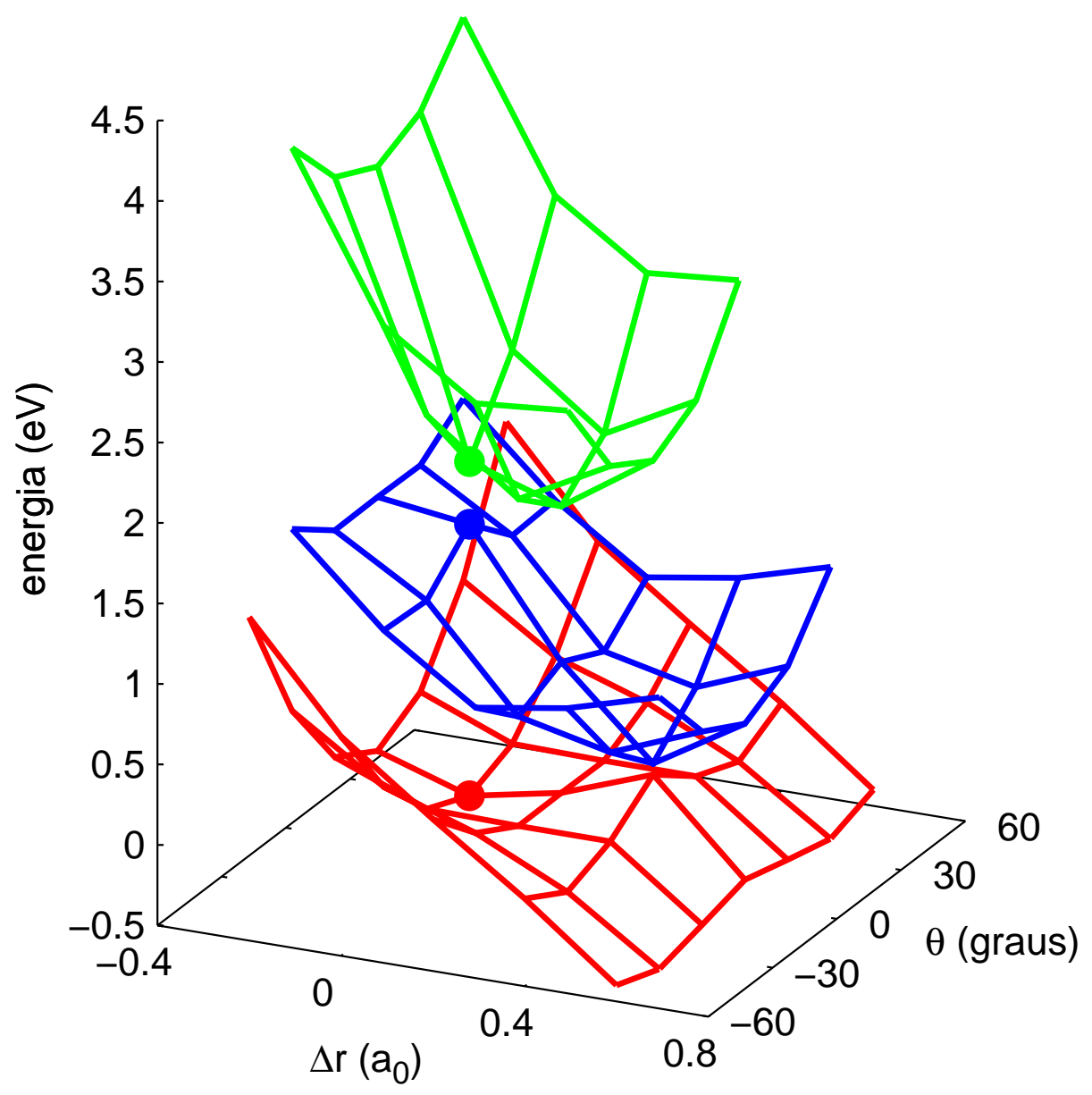

Figura 4.10: Superfícies de energia potencial dos três estados do ânion da 5-clorouracila, em função dos deslocamentos radial $\Delta r$ e angular $\theta$. Os pontos destacam a configuração da geometria de equilíbrio.

estabilização ao longo da coordenada reativa $\Delta r$, que agora não enfrenta a barreira presente na geometria de equilíbrio. O pacote de onda eventualmente deve atingir a região da interseção cônica $\pi_{1}^{*} / \sigma_{\mathrm{CCl}}^{*}$, sofrer uma transição não-adiabática para a superfície inferior e seguir para maiores valores de $\Delta r$. O perfil do estado do ânion também se altera durante a dinâmica, sendo inicialmente do tipo $\pi_{2}^{*}$ e mudando para $\sigma_{\mathrm{CCl}}^{*}$. Ou seja, a partir da formação da ressonância $\pi_{2}^{*}$, o ânion relaxa com o movimento do cloro, acompanhando uma migração da carga do anel para a ligação $\mathrm{C}-\mathrm{Cl}$, que por sua vez induz a dissociação da 5-clorouracila. Esse mecanismo indireto $\pi_{2}^{*} / \sigma_{\mathrm{CCl}}^{*}$ deve ser responsável pela quebra da 
ligação $\mathrm{C}-\mathrm{Cl}$ e formação dos fragmentos $\mathrm{Cl}^{-}$e $[\mathrm{ClU}-\mathrm{HCl}]^{-}$, observados em torno de 1,4 $\mathrm{eV}[46,48,125]$.

Por outro lado, o estado $\pi_{1}^{*}$ não é estabilizado ao longo da coordenada $\theta$, uma vez que a escolha dessa coordenada teve como motivação o acoplamento envolvendo a ressonância $\pi_{2}^{*}$. Em todo caso, como esse é um estado ligado, a dinâmica poderia ser propagada por muito mais tempo até que a dissociação ocorra. Essa poderia ocorrer por meio de uma rota que não encontre barreiras, havendo a ativação de outros modos vibracionais, ou poderia proceder pelo tunelamento através da barreira de potencial formado entre a componente $\pi_{1}^{*}$ interna e a componente $\sigma_{\mathrm{CCl}}^{*}$ externa. Os fragmentos $\mathrm{Cl}^{-}$e $\mathrm{HCl}$ são observados com elevadas seções de choque na região $0-0,5$ eV, e devem ter como origem esse mecanismo $\pi_{1}^{*} / \sigma_{\mathrm{CCl}}^{*}$. Outra possibilidade é que o estado ligado por dipolo acople com a ressonância $\sigma_{\mathrm{CCl}}^{*}$, embora o caráter dos orbitais não suporte esse mecanismo. A natureza do estado de dipolo será discutido em detalhes mais adiante.

Com menor intensidade ainda são observados fragmentos que exigem reações mais complexas do ânion $[48,50]$. Há picos em torno de $1,5 \mathrm{eV}$, sugerindo que a ressonância $\pi_{2}^{*}$ pode sofrer uma série de decaimentos alternativos, de menor probabilidade. Fragmentações também ocorrem ao redor de $3,5 \mathrm{eV}$, que podem ter origem na formação da ressonância $\pi_{3}^{*}$. Em mais altas energias há a ocorrência de outros picos, provavelmente associados à ressonâncias de Feshbach ou de caroço excitados, não caracterizadas em nossos cálculos de espalhamento.

\section{6-bromouracila}

As seções de choque integrais obtidas para a 5-bromouracila estão apresentadas na figura 4.11. Dentro da aproximação SE, três ressonâncias $\pi^{*}$ são encontradas, em 1,74, 3,92 e 7,4 eV. A inclusão de efeitos de polarização move esses estados para mais baixas energias, com os picos correspondentes aos estados $\pi_{2}^{*}$ e $\pi_{3}^{*}$ centrados em 1,50 e 4,45 eV. Nossas energias se comparam de maneira favorável aos valores reportados de 1,3 e 3,6 eV 


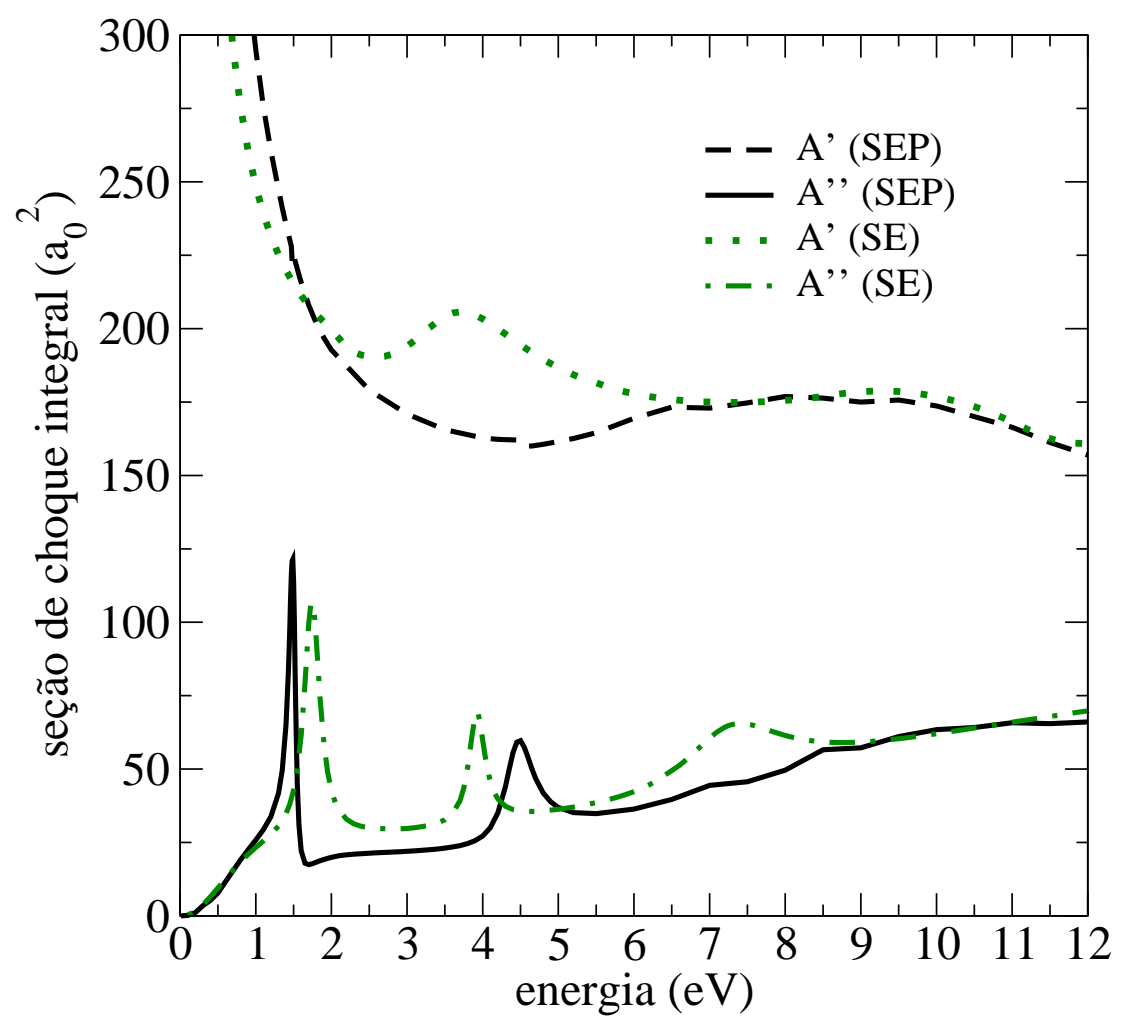

Figura 4.11: Seção de choque integral das simetrias $A^{\prime}$ e $A^{\prime \prime}$ da 5-bromouracila, calculadas nas aproximações SE e SEP.

a partir do espectro de transmissão de elétrons de Scheer et al. [43] A maior discrepância para o estado $\pi_{3}^{*}$ é esperada, tendo em vista o caráter misto de ressonância de forma e ressonância de caroço excitado. Na aproximação SEP, o estado $\pi_{1}^{*}$ não apresenta assinatura na seção de choque, sugerindo que se trata de um estado ligado. De fato, a diagonalização da hamiltoniana na base CSF provê esse estado em $-0,30 \mathrm{eV}$ relativo ao neutro. Esse resultado está em bom acordo com cálculos de estrutura eletrônica anteriores, embora nosso valor seja um tanto mais negativo $(-0,30 \mathrm{eV})$ do que os reportados por Wetmore et al. [44] $(-0,17 \mathrm{eV})$ e por Li et al. $[45](-0,11 \mathrm{eV})$.

A componente $A^{\prime}$ aponta a existência de uma ressonância de forma de caráter $\sigma_{\mathrm{CBr}}^{*}$. Enquanto na aproximação SE a ressonância surge em 3,7 eV, no cálculo com polarização tal estrutura parece desaparecer. Entretanto, nenhum estado ligado foi encontrado a partir da diagonalização da hamiltoniana de espalhamento na base CSF, o que indica 

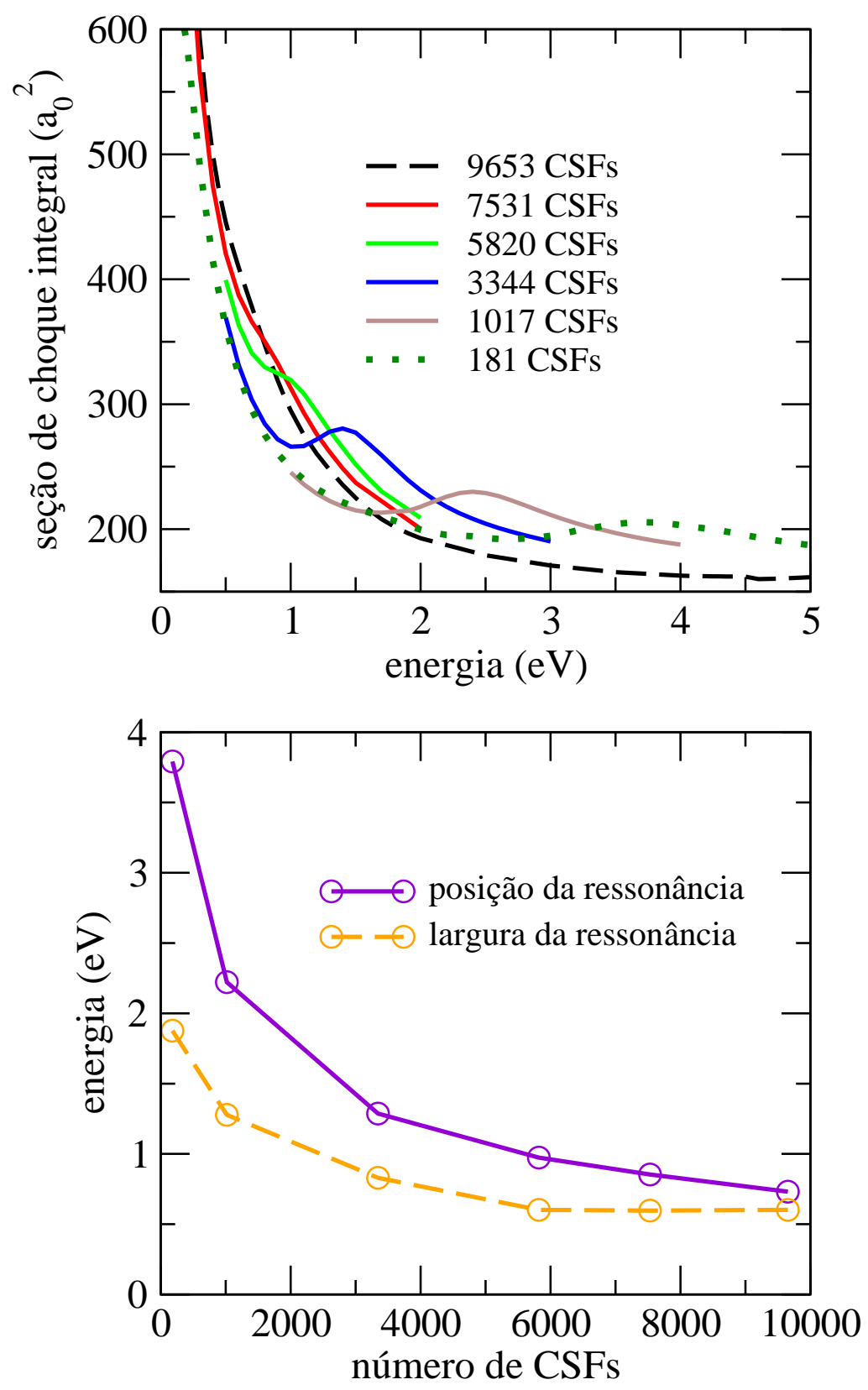

Figura 4.12: Painel superior: seção de choque integral da simetria $A^{\prime}$ da 5-bromouracila, calculada na aproximação SE (181 CSFs), e de acordo com cálculos SEP progressivamente mais sofisticados, até o resultado final com 9653 CSFs. Painel inferior: posição e largura da ressonância $\sigma_{\mathrm{CBr}}^{*}$ de acordo com os cálculos realizados em diferentes níveis de polarização, como função da dimensão do espaço de configurações (número de CSFs). 
que o estado $\sigma_{\mathrm{CBr}}^{*}$ é de fato uma ressonância, com energia acima do neutro. No espectro de transmissão eletrônica de Scheer et al. [43] a presença dessa ressonância não é clara, embora os autores infiram sua existência com base numa análise dos orbitais virtuais. Eles argumentam que a assinatura do ânion $\sigma_{\mathrm{CBr}}^{*}$ estaria camuflada pelo sinal mais intenso da ressonância $\pi_{2}^{*}$, e que portanto ambos os estados teriam aproximadamente a mesma energia, cerca de 1,3 eV. Nossos cálculos são realizados em separado para cada simetria, e a ressonância $\sigma_{\mathrm{CBr}}^{*}$ já não é evidente no cálculo SEP para a simetria $A^{\prime}$, para a qual a ressonância $\pi_{2}^{*}$ não contribui. Portanto, o estado deve estar encoberto pela seção de choque de background (não-ressonante), particularmente devido ao potencial do momento de dipolo, que responde pelo forte aumento da seção de choque em baixas energias. Com o intuito de aprofundar essa explicação, foram realizados cálculos de espalhamento adicionais, com espaços CSF intermediários entre a aproximação SE (181 CSFs) e o resultado SEP (9563 CSFs) apresentado na figura 4.11, sendo esse nosso resultado mais acurado. As curvas de seção de choque são apresentadas no painel superior da figura 4.12, onde a descrição dos efeitos de polarização foi melhorada gradativamente com valores de corte $\varepsilon_{\text {cut }}$ de $-4,2,-3,8,-3,6,-3,5$ hartree, dando origem a 1017, 3344, 5820 e 7531 configurações, respectivamente. A medida que a ressonância $\sigma_{\mathrm{CBr}}^{*}$ se desloca para menores energias, sua assinatura vai se tornando menos clara, sendo quase imperceptível abaixo de $1 \mathrm{eV}$, onde o espalhamento pelo potencial do momento de dipolo se torna mais preponderante. As posições e larguras do ânion $\sigma_{\mathrm{CBr}}^{*}$, obtidos do ajuste da soma de autofase, são mostrados no painel inferior da figura 4.12, em função do número de configurações do espaço CSF. De acordo com o cálculo SEP final (9563 CSFs), a ressonância apresenta energia de 0,73 eV, com uma largura de 0,60 eV. Esse resultado também é apoiado a partir da diagonalização do hamiltoniano de espalhamento na base CSF, que aponta para um pseudo-autoestado com caráter $\sigma_{\mathrm{CBr}}^{*}$ em 0,61 eV. Portanto, nossos cálculos indicam que a presença do ânion $\pi_{2}^{*}$ não deve mascarar o sinal da ressonância $\sigma_{\mathrm{CBr}}^{*}$, uma vez que os estados estariam espaçados por $0,8 \mathrm{eV}$. Atribuímos a ausência de sinal na medida de Scheer et al. [43] à significativa largura $(0,60 \mathrm{eV})$ do estado, juntamente com o forte aumento da seção de choque de background em baixas energias. Por fim, ainda são observadas duas 


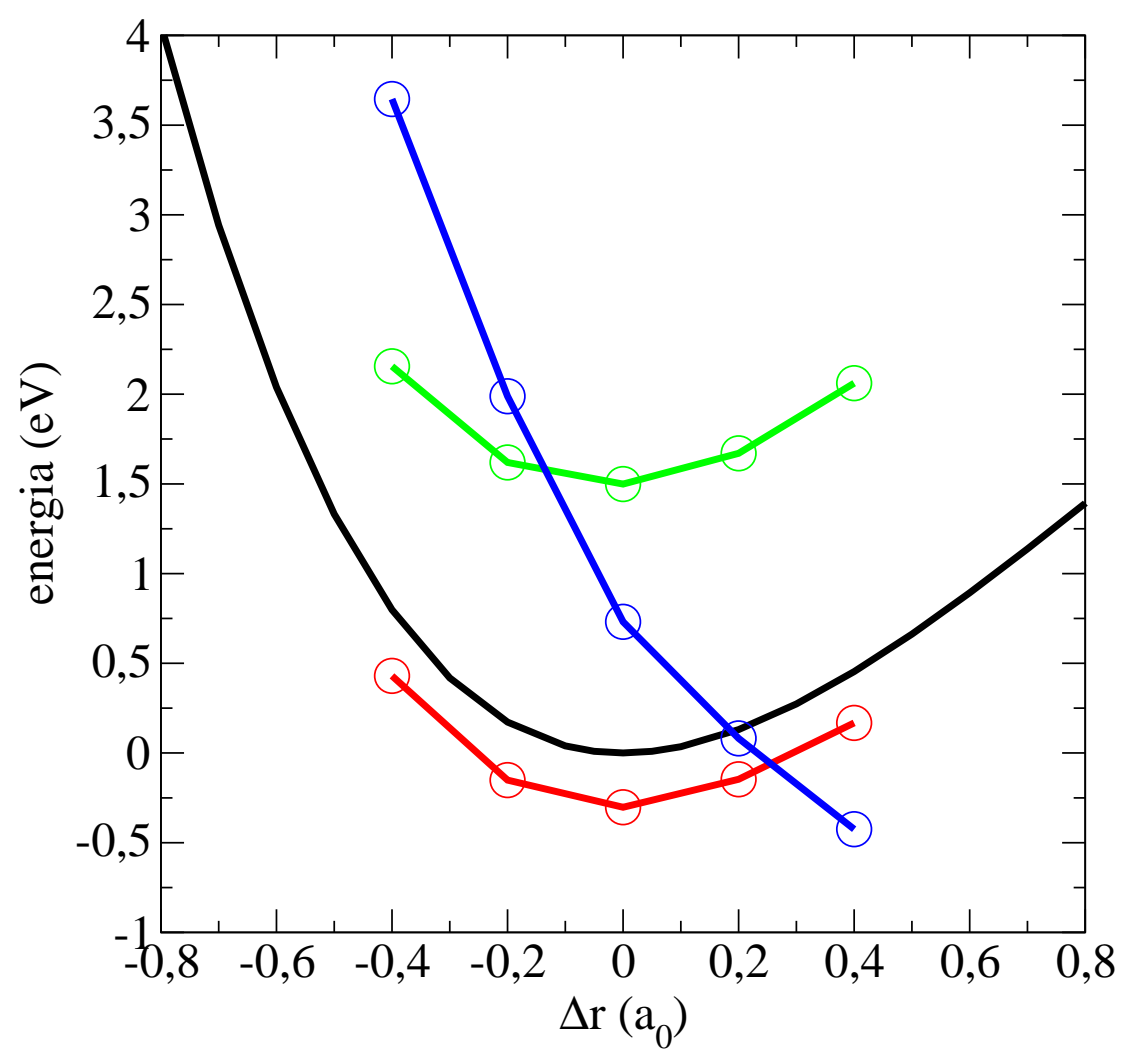

Figura 4.13: Curvas de energia potencial para a 5-bromouracila, em função do desvio da posição de equilíbrio $\Delta r$. Estão representados o estado fundamental da molécula neutra (preto), e os estados do ânion $\pi_{1}^{*}$ (vermelho), $\pi_{2}^{*}$ (verde) e $\sigma_{\mathrm{CBr}}^{*}$ (azul).

estruturas na simetria $A^{\prime}$, em 9 e $12 \mathrm{eV}$, dentro do cálculo SE. Com a inclusão de efeitos de polarização apenas uma estrutura larga permanece discernível, ao redor de $8 \mathrm{eV}$.

A partir de cálculos de espalhamentos realizados para geometrias em que a ligação C-Br era contraída e estirada, construímos curvas de energia potencial para os estados do ânion da 5-bromouracila, que são apresentados na figura 4.13. Os resultados são semelhantes àqueles obtidos para a 5-clorouracila. As curvas dos estados $\pi_{1}^{*}$ e $\pi_{2}^{*}$ seguem paralelas à curva do neutro, enquanto a ressonância $\sigma_{\mathrm{CBr}}^{*}$ é rapidamente estabilizada com o estiramento $\mathrm{C}-\mathrm{Br}$.

Com o intuito de avaliar a relevância do mecanismo direto, envolvendo a formação da ressonância $\sigma_{\mathrm{CBr}}^{*}$, foram realizados cálculos de dinâmica vibracional. Os 


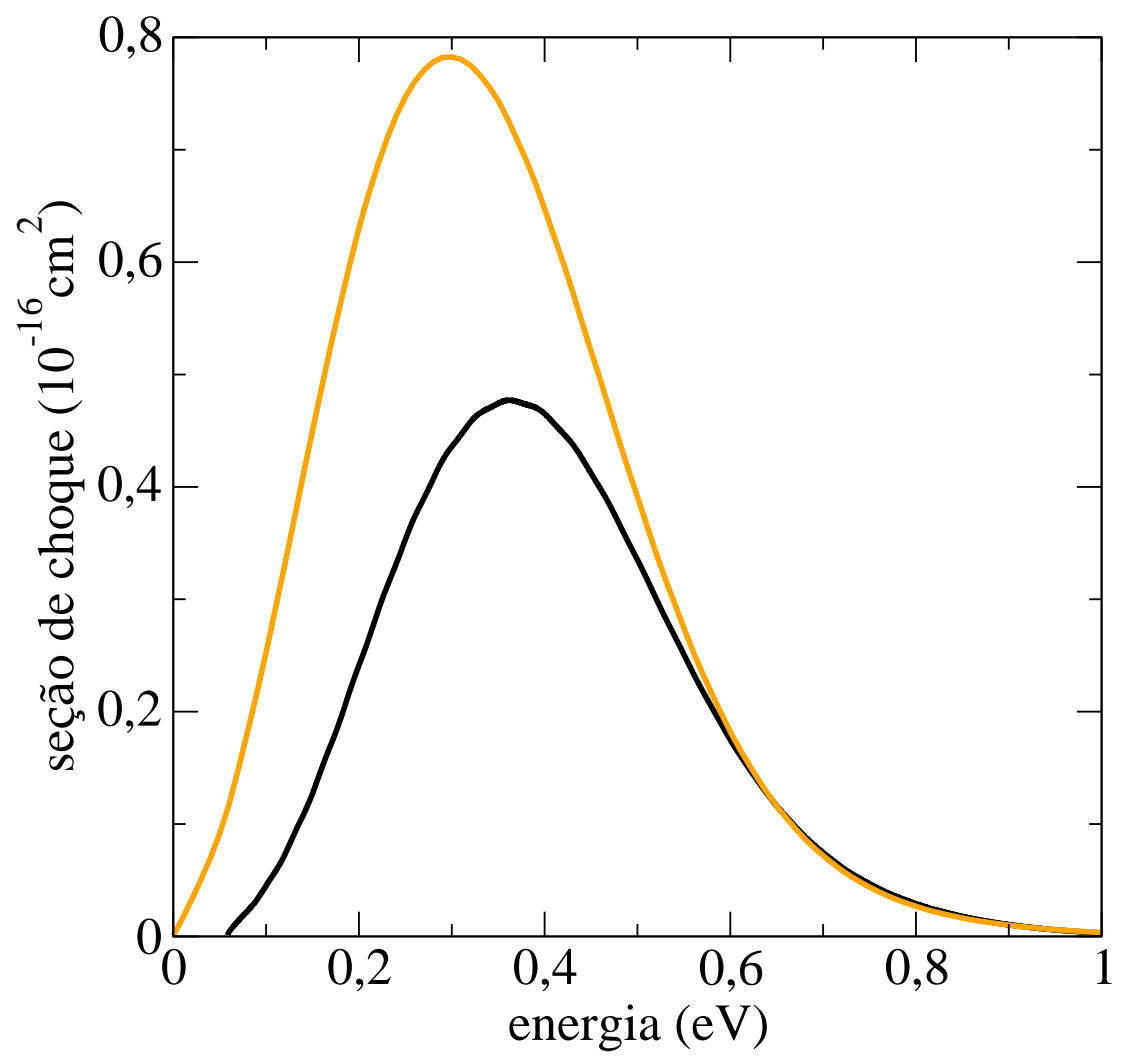

Figura 4.14: Seção de choque de dissociação da 5-bromouracila, a partir do nível vibracional $\nu=0$ (preto) e tomando uma média sobre populações a $450 K$ (laranja).

parâmetros relativos à dinâmica e as expressões analíticas para os potenciais são as mesmas do caso da 5-clorouracila. A figura 4.14 ilustra a curva de seção de choque associada à eliminação do ânion $\mathrm{Br}^{-}$, calculada a partir do nível vibracional fundamental e para um ensemble dos oito primeiros níveis vibracionais em uma temperatura de $450 \mathrm{~K}$, condição aproximada em que as medidas experimentais foram realizadas [40,48]. Em relação à posição da ressonância $\sigma_{\mathrm{CBr}}^{*}$, encontrada em $0,73 \mathrm{eV}$, o pico da seção de choque é pouco afetado, surgindo em 0,36 eV no cálculo a partir do nível fundamental e em 0,30 eV com a inclusão de efeitos térmicos. O máximo da seção de choque apresenta, respectivamente, valores de $\sim 5 \times 10^{-17} \mathrm{~cm}^{2}$ e $\sim 8 \times 10^{-17} \mathrm{~cm}^{2}$. Essa magnitude ainda está três ordens de grandeza abaixo do valor medido na região de $0 \mathrm{eV}\left(\sim 4 \times 10^{-14} \mathrm{~cm}^{2}\right)$ [50], o que aponta que a ocupação direta do orbital $\sigma_{\mathrm{CBr}}^{*}$ é ineficaz para a ruptura da ligação $\mathrm{C}-\mathrm{Br}$, apesar da 
energia relativamente baixa em que a ressonância foi obtida $(0,73 \mathrm{eV})$. Esse resultado sugere que as elevadas seções de choque da 5-bromouracila também devem ter como origem mecanismos indiretos iniciados pela formação de estados $\pi^{*}$. O cálculo aponta para seções de choque até duas ordens de grandeza superiores na 5-bromouracila, em relação à 5-clorouracila, o que tem como causa a menor energia e maior tempo de vida do estado ressonante $\sigma_{\mathrm{CBr}}^{*}$. Embora para esses sistemas o mecanismo direto não dê conta das observações experimentais, a significativa diferença obtida pode ser determinante para outras moléculas halogenados.

Para a 5-bromouracila, também foram realizados cálculos de espalhamento em que o bromo se afasta do anel e se move para fora do plano molecular, o que define as coordenadas $\Delta r$ e $\theta$, em analogia aos casos da 5-clorouracila e cloroeteno. As superfícies de energia potencial real dos três estados aniônicos estão apresentadas na figura 4.15. Da mesma forma como na 5-clorouracila, há duas interseções cônicas, representando os acoplamentos que conectam o estado $\sigma_{\mathrm{CBr}}^{*}$ com os dois estados $\pi^{*}$. As superfícies calculadas sugerem que os mecanismos de dissociação discutidos para a 5-clorouracila também devem ser operantes aqui. Em $0-0,5 \mathrm{eV}$ um mecanismo indireto $\pi_{1}^{*} / \sigma_{\mathrm{CBr}}^{*}$ deve responder pelos picos mais proeminentes associados à eliminação de $\mathrm{Br}^{-}$e seu ânion complementar $[\mathrm{BrU}-\mathrm{Br}]^{-}[46,47,49,50]$. O estado ligado por dipolo poderia em princípio desempenhar um papel, servindo como um estado inicial para a captura do elétron, que acoplaria então com a ressonância dissociativa $\sigma_{\mathrm{CBr}}^{*}$. A ressonância $\pi_{2}^{*}$, que se encontra em 1,50 eV segundo o cálculo de espalhamento realizado na geometria de equilíbrio, deve dar origem ao pico observado em 1,4 eV na formação dos ânions $\mathrm{Br}^{-}$e [BrU-Br] $]^{-}[46,47,49,50]$, através de um mecanismo $\pi_{2}^{*} / \sigma_{\mathrm{CBr}}^{*}$. Entretanto, as superfícies calculadas para a 5-bromouracila apontam que o ânion $\pi_{2}^{*}$ não relaxa através do movimento angular do bromo, em oposição ao caso da 5-clorouracila, e esse acoplamento deve ser mediado pela ativação de outro movimento vibracional.

Fragmentos que envolvem uma maior reestruturação da molécula também devem ser gerados a partir dos estados $\pi^{*}$, embora com probabilidades muito menores. Os fragmentos $\mathrm{OCN}^{-}$e $\mathrm{H}_{2} \mathrm{C}_{3} \mathrm{NO}^{-}$são observados em 1,6, 3,5, 5,0 e 6,5 eV [47,50]. O pico 


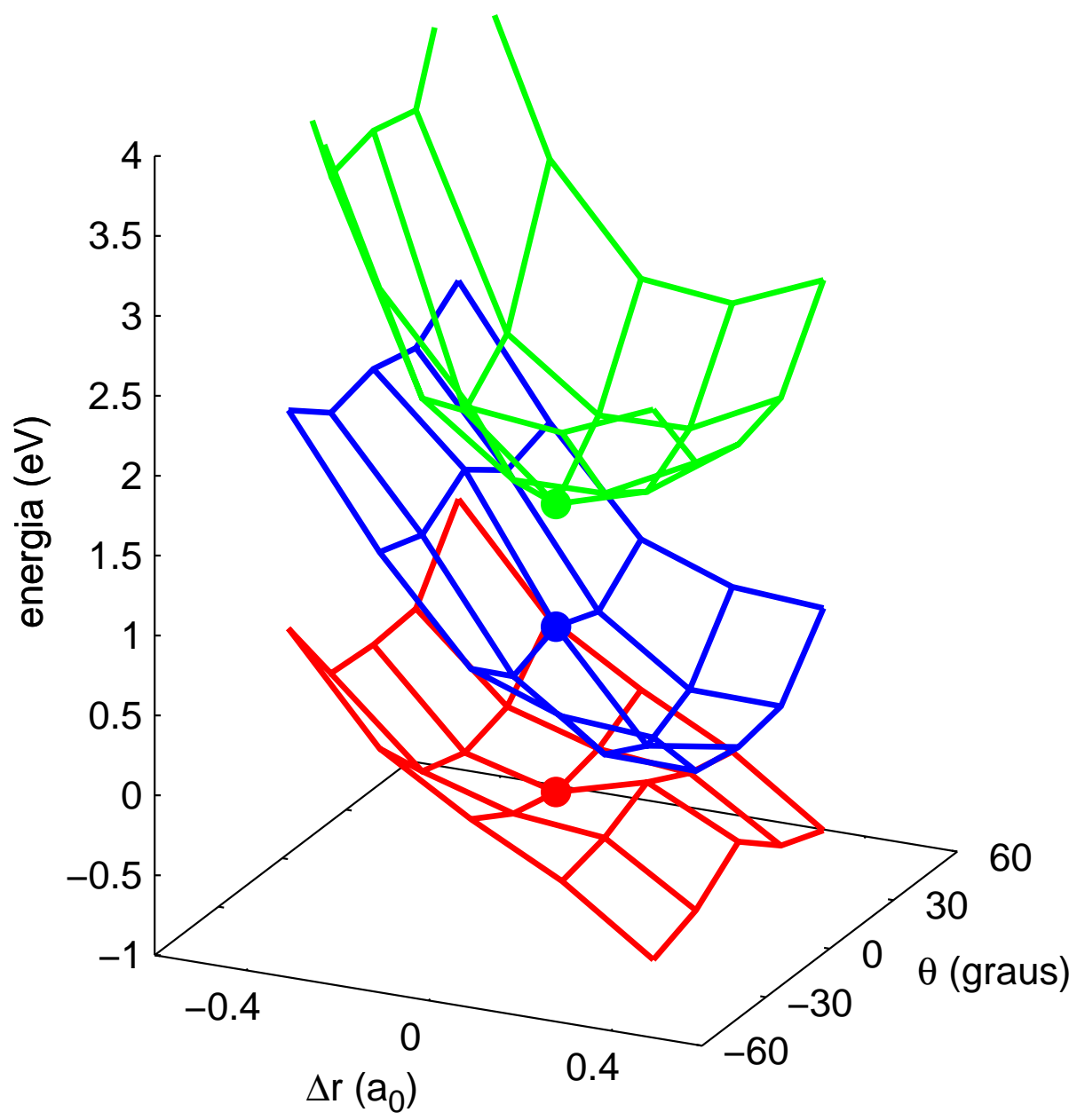

Figura 4.15: Superfícies de energia potencial dos três estados do ânion da 5-bromouracila, em função dos deslocamentos radial $\Delta r$ e angular $\theta$.

de mais baixa energia deve ter o envolvimento da ressonância $\pi_{2}^{*}$, enquanto a estrutura em $3,5 \mathrm{eV}$ pode estar associada à ressonância $\pi_{3}^{*}$. A estrutura que encontramos em 6,5 eV na componente $A^{\prime}$ da seção de choque pode indicar que essa ressonância de forma dê início a formação desses fragmentos na mesma energia. 


\subsection{5-iodouracila}

Na figura 4.16 estão apresentadas as seções de choque integrais da 5-iodouracila. Na aproximação SE, há três picos distintos na simetria $A^{\prime \prime}$, em 1,78, 3,86 e 7,2 eV, que são assinaturas de estados $\pi^{*}$. A componente $A^{\prime}$ apresenta uma estrutura em 2,1 eV, atribuída à ocupação do orbital $\sigma_{\mathrm{CI}}^{*}$ pelo elétron incidente. No cálculo SEP, o estado $\pi_{1}^{*}$ é ligado, surgindo em $-0,35 \mathrm{eV}$ em relação ao estado neutro, enquanto as ressonâncias de forma $\pi_{2}^{*}$ e $\pi_{3}^{*}$ estão centradas em 1,54 e 4,34 eV. O ânion $\sigma_{\mathrm{CI}}^{*}$ se mostra ligado, em $-0,10 \mathrm{eV}$, o que representa uma novidade em relação à série de 5-halouracilas, onde os estados análogos $\sigma_{\mathrm{CX}}^{*}$ são todos ressonantes. Estruturas em mais alta energia também foram encontradas na simetria $A^{\prime}$, em torno de 8 e $12 \mathrm{eV}$ na aproximação SE. No cálculo SEP há uma estrutura ao redor de $10 \mathrm{eV}$, não muito evidente devido à presença de pseudo-ressonâncias, e um pico relativamente bem definido em 5,8 eV. Embora não existam resultados experimentais sobre a energética dos ânions de 5-iodouracila, há medidas do espectro de dissociação, que serão discutidas mais adiante.

As curvas de energia potencial para os estados do ânion de 5-iodouracila estão apresentados na figura 4.17, conforme obtidos de cálculos de espalhamento para deslocamentos da ligação C-I. Mais uma vez, o comportamento dos estados $\pi^{*}$ é semelhante ao observado na 5-clorouracila e 5-bromouracila. O estado $\sigma_{\mathrm{CI}}^{*}$ é fortemente estabilizado diante do elongamento da ligação $\mathrm{C}-\mathrm{I}$, enquanto que para distâncias menores que a de equilíbrio ele surge como uma ressonância na seção de choque. Para essa molécula há dois estados ligados de valência, $\pi_{1}^{*}$ e $\sigma_{\mathrm{CI}}^{*}$, além do estado ligado por dipolo. Os três podem ser acessados por elétrons com energias próximas de 0 eV, e uma vez que são estados ligados, não há a possibilidade de ejeção do elétron capturado. Caso a captura se dê no orbital $\sigma_{\mathrm{CI}}^{*}$, a geometria será prontamente relaxada através da quebra da ligação C-I. Se o estado formado for o $\pi_{1}^{*}$, esse eventualmente irá acoplar com o estado dissociativo e sofrerá o mesmo destino. A existência de mais de um estado ligado e de distintos mecanismos de dissociação possíveis deve implicar em rotas eficientes para o processo dissociativo. De fato, o fragmento $\mathrm{I}^{-}$é observado num intenso pico em $0 \mathrm{eV}$ [50], e apresenta as mais 


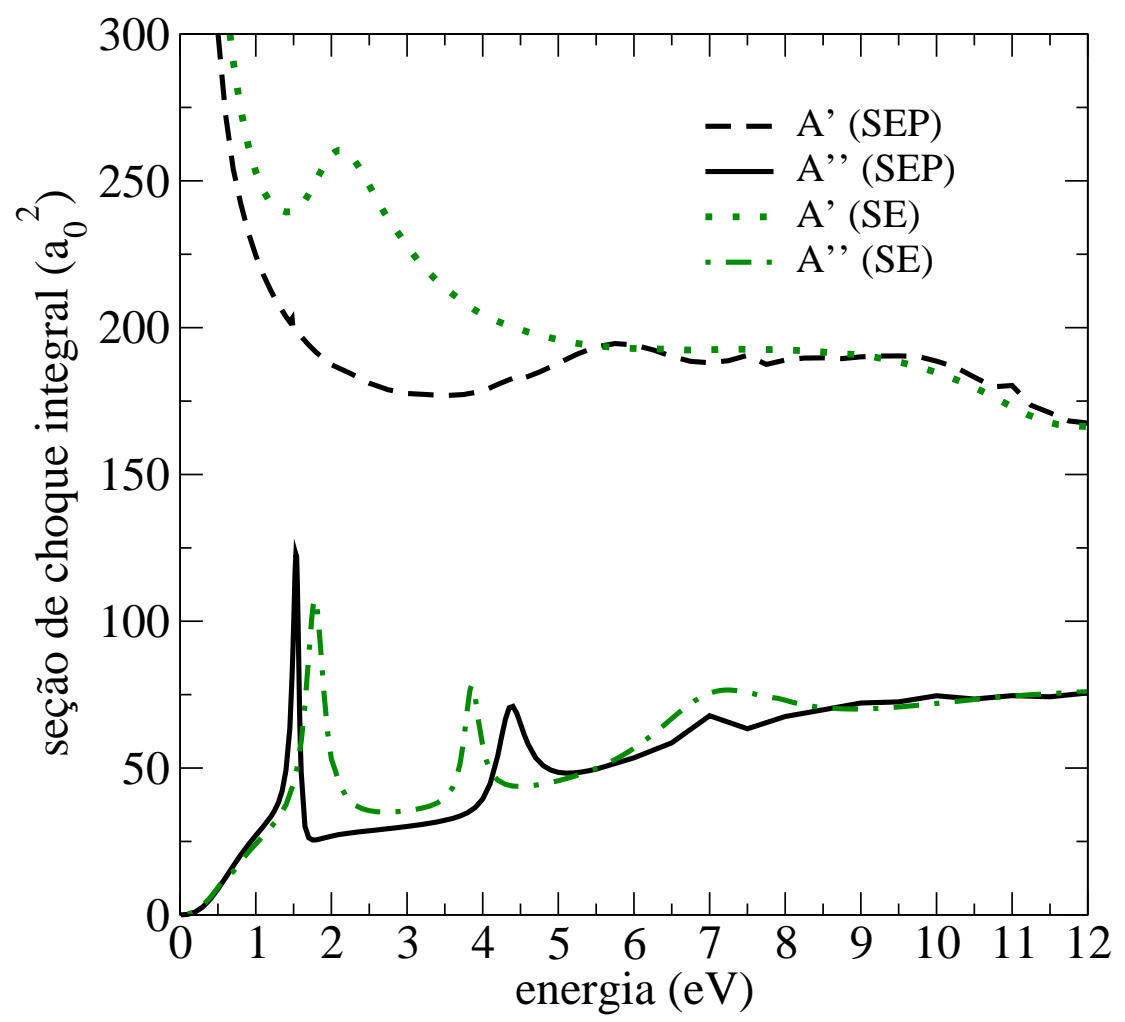

Figura 4.16: Seção de choque integral das simetrias $A^{\prime}$ e $A^{\prime \prime}$ da 5-iodouracila, calculadas nas aproximações SE e SEP.

elevadas seções de choque dentre todos os fragmentos da série de 5-halouracilas.

Em torno de 1,4 eV há a formação do fragmento $\mathrm{I}^{-}$e de seu ânion complementar $[\mathrm{IU}-\mathrm{I}]^{-}[50]$, que devem ser formados a partir de um mecanismo indireto $\pi_{2}^{*} / \sigma_{\mathrm{CI}}^{*}$. Lembrando que não há para a 5-iodouracila resultados experimentais que caracterizem seus estados ressonantes, a medida do espectro de fragmentação por impacto de elétron consiste no único trabalho disponível [50]. O bom acordo entre a posição da ressonância $\pi_{2}^{*}$ obtida do cálculo de espalhamento $(1,54 \mathrm{eV})$ e a posição do pico associado ao fragmento $\mathrm{I}^{-}$e seu ânion complementar, em $\sim 1,4 \mathrm{eV}$ [50], indica que nosso cálculo de fato oferece uma boa descrição do processo de espalhamento.

Os experimentais ainda observam os fragmentos $\mathrm{OCN}^{-}$e $\mathrm{H}_{2} \mathrm{C}_{3} \mathrm{NO}^{-}$[50], assim como nas outras duas halouracilas. O primeiro fragmento apresenta um pico em 1,3 eV, enquanto o segundo em 1,7 eV, que devem ter como origem a formação da ressonância 


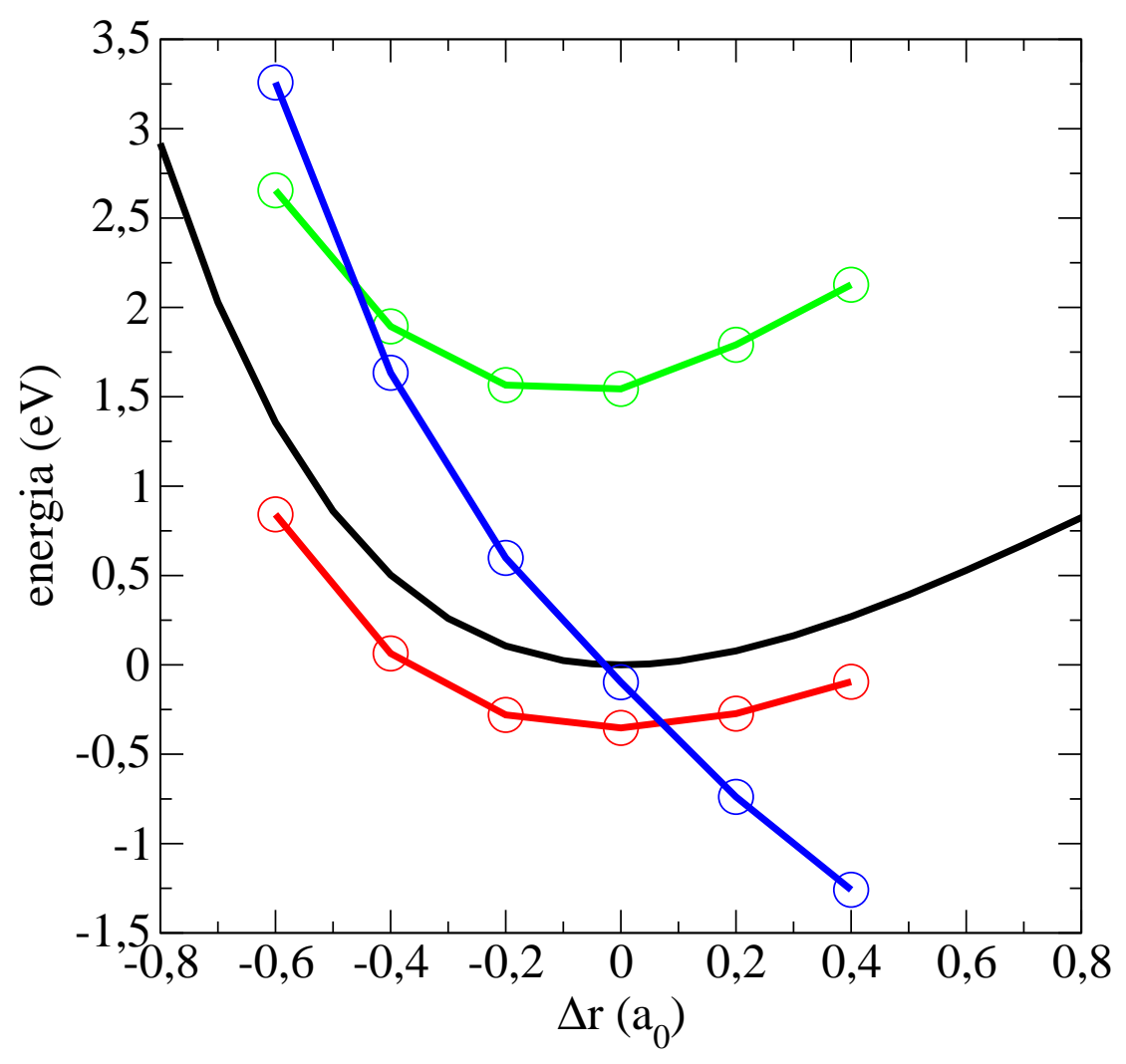

Figura 4.17: Curvas de energia potencial para a 5-iodouracila, em função do desvio da posição de equilíbrio $\Delta r$. Estão representados o estado fundamental da molécula neutra (preto), e os estados do ânion $\pi_{1}^{*}$ (vermelho), $\pi_{2}^{*}$ (verde) e $\sigma_{\mathrm{CI}}^{*}$ (azul).

$\pi_{2}^{*}$. Ambos possuem uma estrutura em 4,0 eV, possivelmente devido à ressonância $\pi_{3}^{*}$, enquanto o fragmento $\mathrm{OCN}^{-}$ainda possui um leve ombro em $6,2 \mathrm{eV}$, que pode estar correlacionado com o pico observado em 5,8 eV na seção de choque da simetria $A^{\prime}$.

\subsection{6-clorouracila}

As componentes $A^{\prime}$ e $A^{\prime \prime}$ da seção de choque integral da 6-clorouracila são apresentadas na figura 4.18, conforme calculadas nas aproximações SE e SEP. Há assinaturas de três ressonâncias de forma $\pi^{*}$ no resultado SE, em 1,96, 3,84 e 8,1 eV. Com 


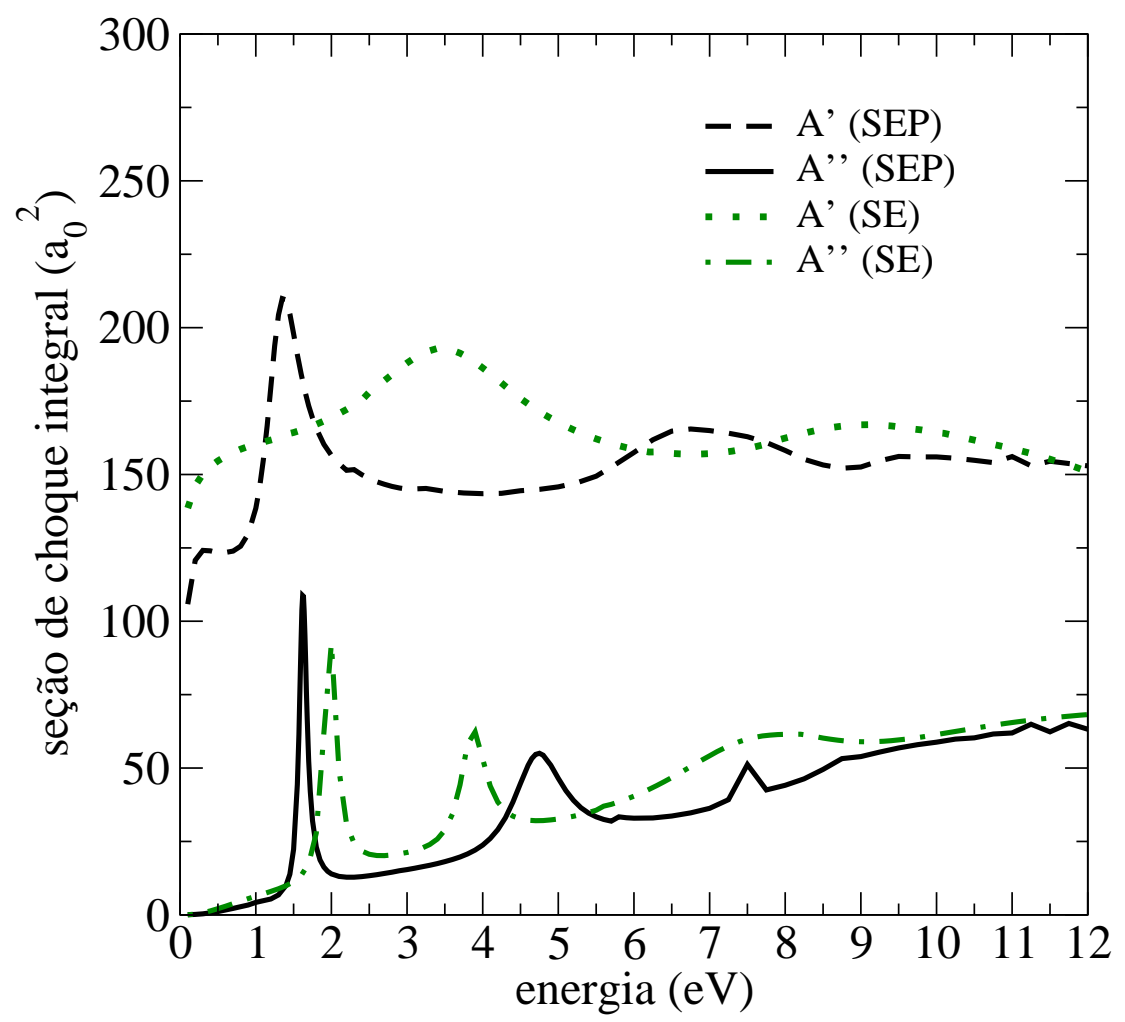

Figura 4.18: Seção de choque integral das simetrias $A^{\prime}$ e $A^{\prime \prime}$ da 6-clorouracila, calculadas nas aproximações SE e SEP.

a inclusão de efeitos de polarização, o estado $\pi_{1}^{*}$ torna-se ligado e surge em $-0,14 \mathrm{eV}$, enquanto as ressonâncias $\pi_{2}^{*}$ e $\pi_{3}^{*}$ de deslocam para 1,62 e 4,70 eV. Identificamos ainda uma ressonância de forma $\sigma_{\mathrm{CCl}}^{*}$ na simetria $A^{\prime}$, centrada em $3,44 \mathrm{eV}$ na aproximação $\mathrm{SE}$ e em torno de 1,31 eV no cálculo SEP, nesse caso com largura de 0,30 eV. Na simetria $A^{\prime}$ há ainda um pico razoavelmente pronunciado em torno de $6,5 \mathrm{eV}$, dentro do cálculo SEP, que corresponde à estrutura em $9 \mathrm{eV}$ da aproximação SE. Não há qualquer trabalho na literatura a respeito dos ânions ressonantes da 6-clorouracila. Mais adiante os resultados serão comparados com os obtidos para a 5-clorouracila.

Embora os cálculos de espalhamento tenham como principal objetivo a caracterização do espectro de estados aniônicos, vale notar a diferença nas magnitudes da seção de choque integral entre a 6-clorouracila e seu isômero (ver figuras 4.18 e 4.5). Particularmente, não há a subida característica da seção de choque em menores ener- 
gias, observada em todos os sistemas discutidos até aqui. Esse comportamento se dá pelo menor momento de dipolo que a molécula apresenta, de 3,50 D, comparado ao valor de 4,53 D da 5-clorouracila, ambos obtidos no nível Hartree-Fock em que o alvo é descrito.

\subsection{2-tiouracila}

As contribuições das simetrias $A^{\prime}$ e $A^{\prime \prime}$ para a seção de choque integral da 2tiouracila são apresentadas na figura 4.19. No cálculo SE, encontramos três ressonâncias de forma $\pi^{*}$, localizadas em 1,60, 2,39 e 7,5 eV. Quando efeitos de polarização são considerados, as ressonâncias se deslocam para menores energias. O estado $\pi_{1}^{*}$ se torna ligado, surgindo em $-0,22 \mathrm{eV}$, enquanto os estados ressonantes $\pi_{2}^{*}$ e $\pi_{3}^{*}$ aparecem em 0,56 e 4,9 eV. A substituição de um oxigênio pelo enxofre na posição 2 da uracila dá origem à 2-tiouracila, que tem seu espectro de ressonâncias $\pi^{*}$ modificado apreciavelmente. Na uracila, nosso cálculo aponta os estados $\pi^{*}$ em $0,15,1,82$ e 4,81 eV. A substituição tem seu efeito maximizado na ressonância $\pi_{2}^{*}$, que é estabilizada em $\sim 1,3 \mathrm{eV}$. O estado $\pi_{1}^{*}$ desce em $\sim 0,4 \mathrm{eV}$, mudando seu caráter de ressonância na uracila para estado ligado na 2-tiouracila, enquanto que a ressonância $\pi_{3}^{*}$ desestabiliza em $\sim 0,1 \mathrm{eV}$. A avaliação dos orbitais ressonantes $\pi^{*}$ permite compreender as tendências de estabilização, e por isso são apresentados na figura 4.20. O deslocamento para menores energias das ressonâncias da 2-tiouracila é atribuído à combinação da maior afinidade eletrônica e polarizabilidade do enxofre, quando comparado ao caso do oxigênio, já tendo sido observado em outros sistemas $[37,126,127]$. A ressonância $\pi_{2}^{*}$ é a mais afetada, devido a uma maior densidade de probabilidade do orbital ressonante próximo do enxofre. Pelo mesmo motivo, a substituição tem um efeito intermediário no orbital $\pi_{1}^{*}$ (densidade se distribui mais uniformemente pelo anel), e mínima no orbital $\pi_{3}^{*}$ (densidade mais afastada da posição do átomo substituído). Uma maior discrepância é esperada na posição da ressonância $\pi_{3}^{*}$, dado seu caráter misto entre ressonância de forma e de caroço excitado, e seu valor real 


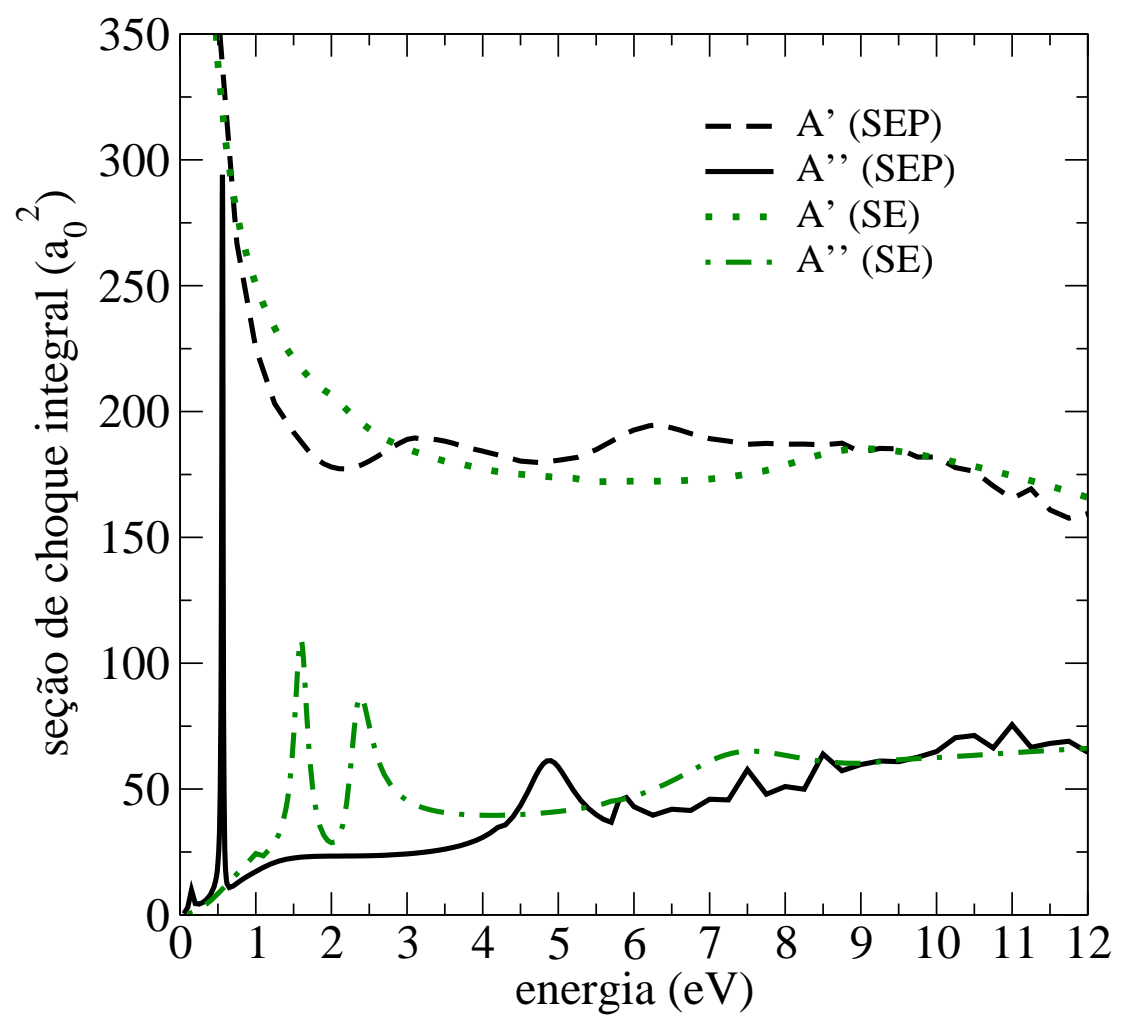

Figura 4.19: Seção de choque integral das simetrias $A^{\prime}$ e $A^{\prime \prime}$ da 2-tiouracila, calculadas nas aproximações SE e SEP.

deve se aproximar de $\sim 4 \mathrm{eV}$.

O uso da relação de escala [116] aponta as energias 0,00, 0,48 e 3,68 eV para os estados $\pi^{*}$, comparáveis aos valores obtidos através dos cálculos de espalhamento, de -0,22, 0,56 e 4,9 eV. Nosso cálculo indica que o estado $\pi_{1}^{*}$ se apresenta como um estado ligado, localizado em -0,22 em relação ao neutro, em contraste o valor positivo de 0,17 eV reportado por cálculos de estado ligado no nível coupled-cluster com excitações simples e duplas, e triplas perturbativas $(\operatorname{CCSD}(\mathrm{T}))$ de Dolgounitcheva et al. [128]. Essa diferença pode indicar que nosso cálculo de espalhamento esteja supercorrelacionado, o que ocorre quando a descrição da função de onda de espalhamento é de melhor qualidade do que a descrição Hartree-Fock do alvo. Sendo esse o caso, o real espectro do ânion de 2-tiouracila deveria se apresentar poucos décimos de eV acima do obtido em nossos cálculos.

A componente $A^{\prime}$ apresenta uma estrutura ao redor de $9 \mathrm{eV}$ na aproximação 

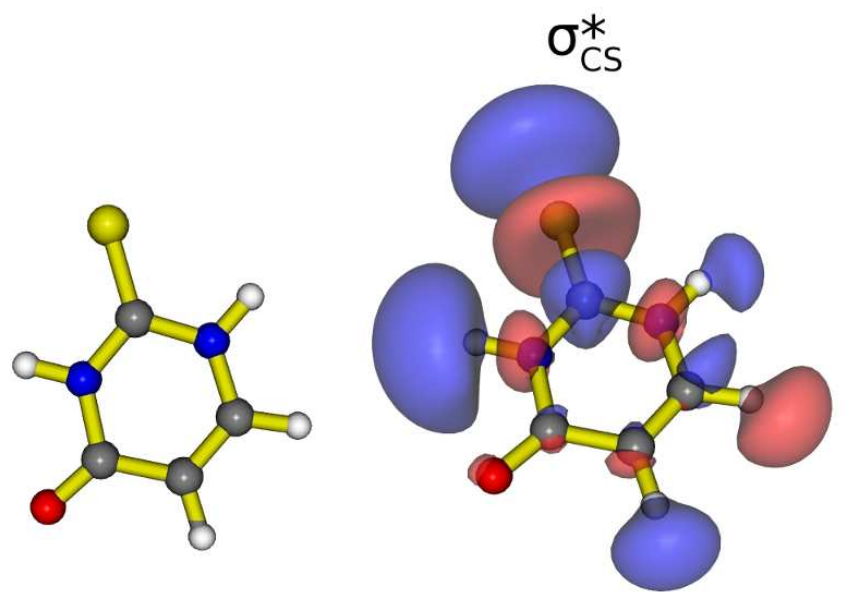

DBS
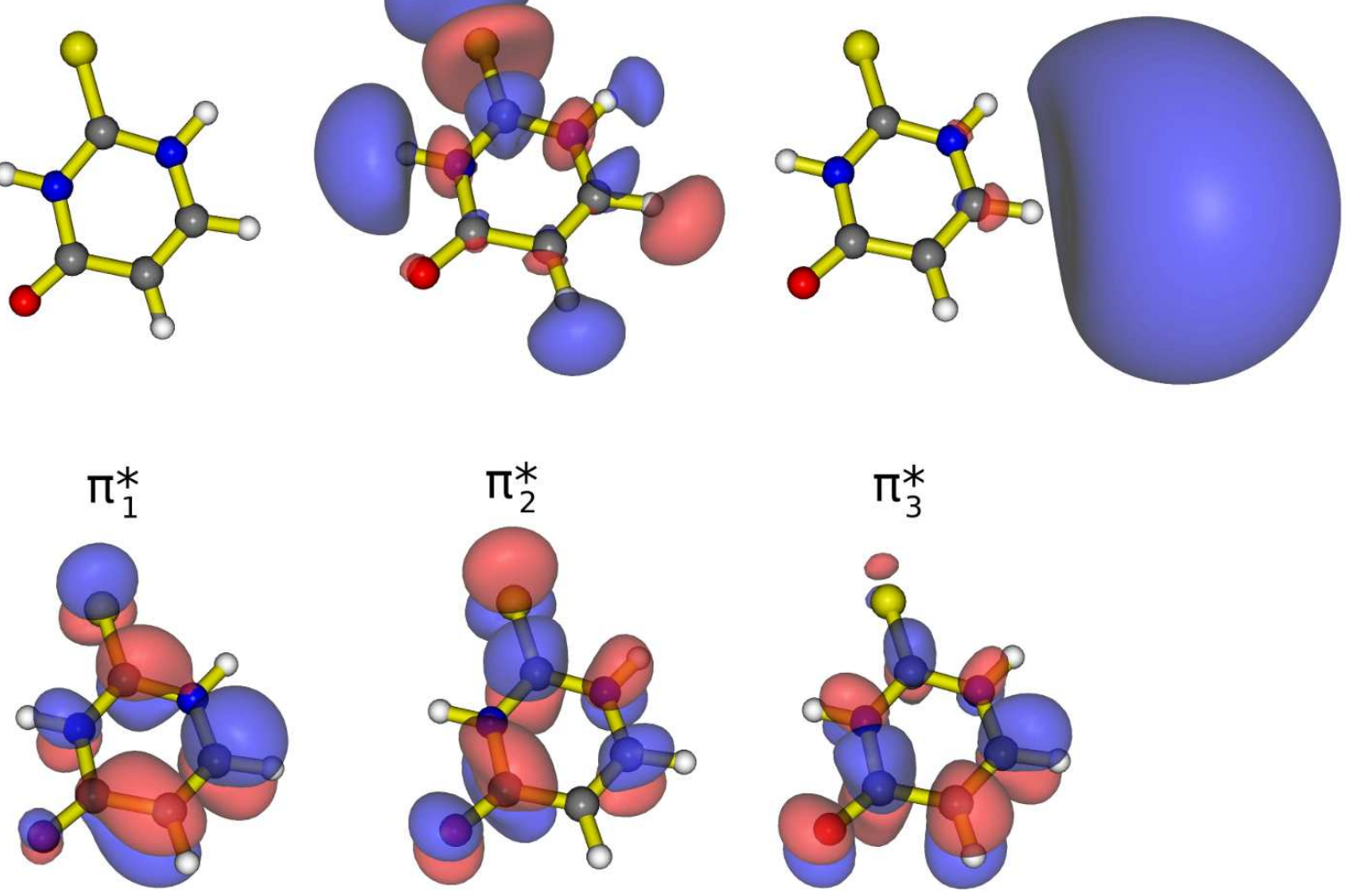

Figura 4.20: Estrutura da 2-tiouracila (acima, à esquerda), os orbitais virtuais $\pi^{*}$ (abaixo), e $\sigma_{\mathrm{CS}}^{*}$ (acima, no meio), e o orbital unicamente ocupado do estado ligado por dipolo (acima, à direita). Os orbitais de valência e do estado de dipolo foram geradas para valores de isoprobabilidade de 0,04 e 0,01 unidades atômicas, respectivamente.

SE. No cálculo SEP, ela se move para $6,3 \mathrm{eV}$ e uma estrutura mais larga fica aparente ao redor de $10 \mathrm{eV}$. A principal característica da simetria $A^{\prime}$, no entanto, é o pico localizado em 3,2 eV, revelado apenas com a inclusão de efeitos de polarização. Atribuímos esse sinal a uma ressonância de forma $\sigma_{\mathrm{CS}}^{*}$, onde o elétron é aprisionado no orbital anti-ligante da ligação $\mathrm{C}=\mathrm{S}$. Tal ressonância não apresenta análogo na uracila, e ela representa a principal novidade no espectro aniônico causado pela presença do enxofre. A figura 4.20 ilustra o LUMO+5 da 2-tiouracila, responsável pela ressonância $\sigma_{\mathrm{CS}}^{*}$. O LUMO+2, de simetria 
$A^{\prime}$, deve dar origem a uma ressonância de baixa energia de caráter $\sigma_{\mathrm{NH}}^{*}$, embora seu curto tempo de vida não gere uma assinatura discernível na curva de seção de choque.

Além dos estados aniônicos de valência, o momento de dipolo de 3,0 D da 2tiouracila é capaz de capturar o elétron num orbital difuso, formando um estado ligado por dipolo. Empregamos a base aug-cc-pVDZ+6s6p descrita anteriormente, onde as funções adicionais mais difusas foram centradas no hidrogênio da posição 6. A energia de ligação desse estado foi calculada como a diferença entre as energias do ânion e do neutro, obtidas no nível MP2. O estado de dipolo se apresenta fracamente ligado, $-64 \mathrm{meV}$ relativo ao estado neutro. O orbital molecular unicamente ocupado (SOMO, do inglês singly occupied molecular orbital), cobre uma extensa região na vizinhança da posição 6 do anel, como pode ser visto na figura 4.20 .

A fim de melhor discutir os mecanismos de dissociação da 2-tiouracila, apresentamos na figura 4.21 o espectro de fragmentação gerado por colisões de elétrons de baixa energia, adaptada da referência [129]. Na uracila, o estado ligado por dipolo é formado em uma ressonância de Feshbach vibracional, que acopla à ressonância dissociativa $\sigma_{\mathrm{NH}}^{*}$, dando origem a estruturas que refletem os estados vibracionalmente excitados $\nu(\mathrm{NH})=2$ e $\nu(\mathrm{NH})=3$ [43]. O mesmo mecanismo pode ser evocado para explicar a formação do fragmento $[\mathrm{TU}-\mathrm{H}]^{-}$, onde TU denota a 2-tiouracila neutra. Considerando que a curva de energia potencial do estado de dipolo ao longo da coordenada de estiramento $\mathrm{N} 1-\mathrm{H}$ seja obtida por meio de um deslocamento vertical de $-64 \mathrm{meV}$ a partir da curva do estado neutro descrita na aproximação harmônica, obtemos as ressonâncias de Feshbach vibracionais em 0,39 eV $(\nu(\mathrm{NH})=1), 0,84 \mathrm{eV}(\nu(\mathrm{NH})=2)$ e 1,29 eV $(\nu(\mathrm{NH})=3)$. Cálculos G4(MP2) apontam que a eliminação do hidrogênio da posição 1 necessita de 0,55 eV (já considerando a energia de ponto zero), de modo que a dissociação é um canal fechado no nível $\nu(\mathrm{NH})=1$. As estimativas para as energias dos níveis $\nu(\mathrm{NH})=2$ e $\nu(\mathrm{NH})=3$ estão em bom acordo com os picos experimentais para a eliminação de $[\mathrm{TU}-\mathrm{H}]^{-}$, em torno de 0,7 e 1,0 eV. Vale notar que a inclusão de efeitos anarmônicos melhoraria a concordância. Em vista da estrutura em $0,7 \mathrm{eV}$ de intensidade muito mais expressiva na 2-tiouracila do que na uracila $[43,46,51,115]$, deve haver um mecanismo distinto nessa região, que com- 

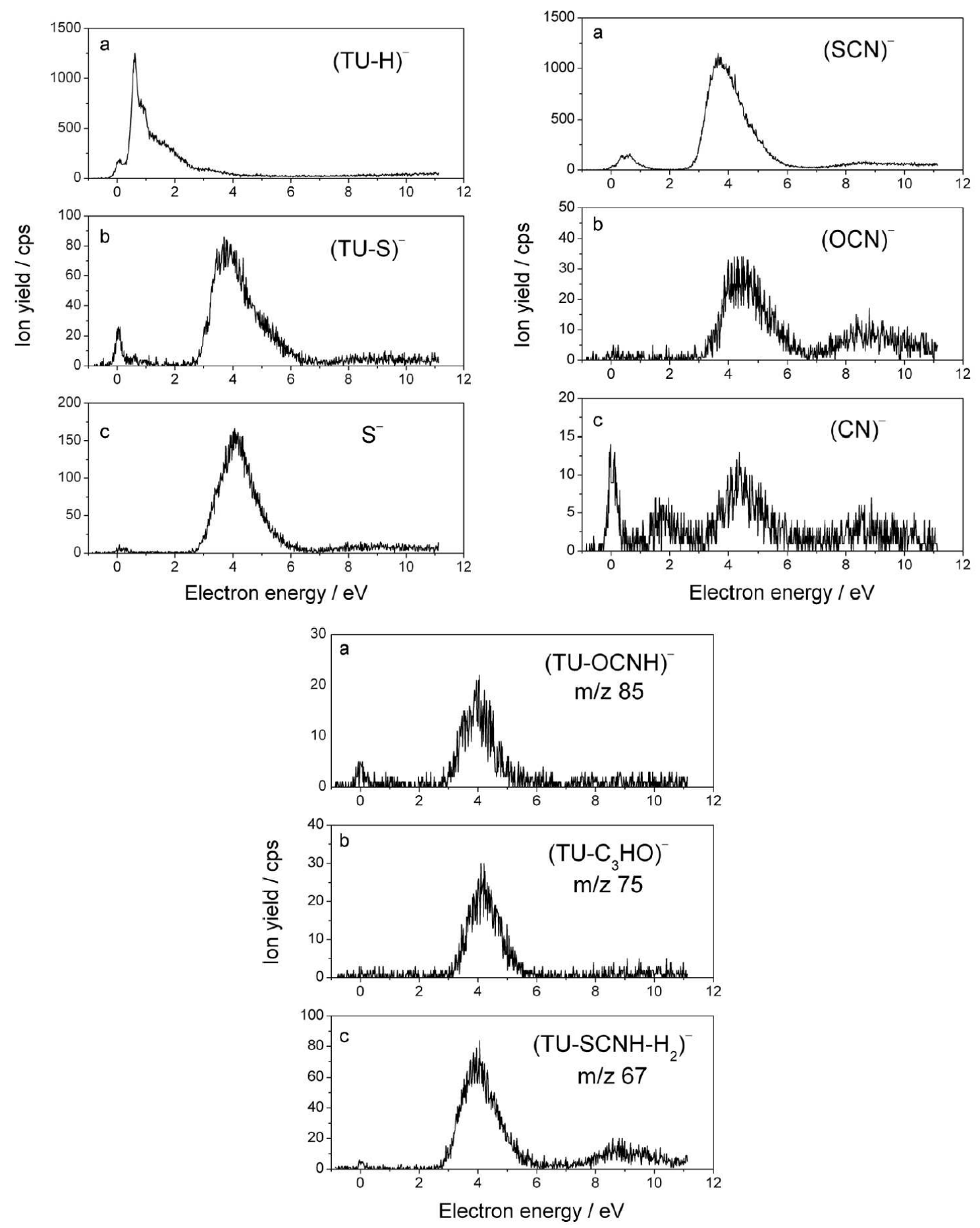

Figura 4.21: Curvas de eficiência para captura eletrônica dissociativa da 2-tiouracila, resultando nos fragmentos $(\mathrm{TU}-\mathrm{H})^{-},(\mathrm{TU}-\mathrm{S})^{-}, \mathrm{S}^{-}, \mathrm{SCN}^{-}, \mathrm{OCN}^{-}, \mathrm{CN}^{-},(\mathrm{TU}-\mathrm{OCNH})^{-}$, $\left(\mathrm{TU}-\mathrm{C}_{3} \mathrm{HO}\right)^{-}$e $\left(\mathrm{TU}-\mathrm{SCNH}-\mathrm{H}_{2}\right)^{-}$. Figura adaptada da referência [115]. 
pete com aquele envolvendo o estado de dipolo. Considerando a ressonância encontrada em 0,56 eV nos cálculos de espalhamento, a captura eletrônica no orbital $\pi_{2}^{*}$ pode responder por esse pico mais intenso, através de um mecanismo indireto $\pi_{2}^{*} / \sigma_{\mathrm{NH}}^{*}$. O longo tempo de vida das ressonâncias de caráter $\pi^{*}$ permite uma considerável deformação estrutural de modo a acomodar a carga extra, favorecendo um acoplamento desses estados com as ressonâncias dissociativas $\sigma_{\mathrm{NH}}^{*}$ e $\sigma_{\mathrm{CS}}^{*}$. O ânion $[\mathrm{TU}-\mathrm{H}]^{-}$é observado próximo de $0 \mathrm{eV}$ na 2-tiouracila [115], bem como na 2-tiotimina [129], mas mal é visível na uracila [43,46,51]. Isso se dá pela maior estabilidade do estado $\pi_{1}^{*}$ nas duas primeiras moléculas, sendo ressonante na uracila e ligado na 2-tiouracila, segundo nossos cálculos. Um acoplamento $\pi_{1}^{*} / \sigma_{\mathrm{NH}}$ deve ser responsável por essa estrutura em torno de $0 \mathrm{eV}$. Uma estrutura larga ainda pode ser observada ao redor de $3 \mathrm{eV}$, que pode advir de um mecanismo indireto envolvendo a ressonância $\pi_{3}^{*}$.

Os intensos picos observados em torno de $4 \mathrm{eV}$ para uma série de fragmentos deve surgir a partir da formação da ressonância de caráter misto $\pi_{3}^{*}$, que deve se localizar na região de $4 \mathrm{eV}$, como já discutido. Esse estado do ânion pode acoplar com a ressonância $\sigma_{\mathrm{CS}}^{*}$, podendo gerar os fragmentos $\mathrm{S}^{-},(\mathrm{TU}-\mathrm{S})^{-}$e $\mathrm{SCN}^{-}$, embora uma significativa reorganização seja necessária no último caso. Dado o caráter de caroço excitado, o elétron também pode ser ejetado da ressonância $\pi_{3}^{*}$ e deixar a molécula neutra em um estado eletronicamente excitado e dissociativo. Os fragmentos $\mathrm{S}^{-}$e $(\mathrm{TU}-\mathrm{S})^{-}$observados próximo de $0 \mathrm{eV}$ devem advir de um mecanismo $\pi_{1}^{*} / \sigma_{\mathrm{CS}}^{*}$. Por fim, o ânion $\mathrm{SCN}^{-}$apresenta uma estrutura ao redor de $0,5 \mathrm{eV}$, próximo da posição calculada para a ressonância $\pi_{2}^{*}$.

\subsection{Comparação entre uracila e derivados}

A tabela 4.4 sumariza as posições e larguras dos estados $\pi^{*}$ da 5 -fluorouracila, 5-clorouracila, 5-bromouracila, 5-iodouracila e 6-clorouracila, conforme obtidas de nossos cálculos de espalhamento e de estudos anteriores. Os mesmos dados são apresentados na figura 4.22, para que as tendências sejam mais facilmente identificadas. De modo geral, 
Tabela 4.4: Posições e larguras (entre parênteses) dos estados $\pi^{*}$ e $\sigma_{\mathrm{CX}}^{*}$ da 5 -fluorouracila, 5-clorouracila, 5-bromouracila, 5-iodouracila e 6-clorouracila (em unidades de eV).

\begin{tabular}{|c|c|c|c|c|}
\hline 5-fluorouracila & $\pi_{1}^{*}$ & $\pi_{2}^{*}$ & $\pi_{3}^{*}$ & $\sigma_{\mathrm{CF}}^{*}$ \\
\hline Nosso resultado & $0,14(0,0053)$ & $1,64(0,13)$ & $5,50(0,62)$ & \\
\hline Scheer et al. [43] & 0,17 & 1,5 & 4,1 & \\
\hline Wetmore et. al. [44] & 0,33 & & & \\
\hline Li et. al. [45] & 0,15 & & & \\
\hline 5-clorouracila & $\pi_{1}^{*}$ & $\pi_{2}^{*}$ & $\pi_{3}^{*}$ & $\sigma_{\mathrm{CCl}}^{*}$ \\
\hline Nosso resultado & $-0,11$ & $1,57(0,13)$ & $4,70(0,45)$ & $1,96(1,03)$ \\
\hline Scheer et. al. [43] & & 1,3 & 3,6 & 1,8 \\
\hline Wetmore et. al. [44] & $-0,14$ & & & \\
\hline Li et. al. $[45]$ & $-0,06$ & & & \\
\hline Sommerfeld [111] & $2(0,25)$ & $4,5(0,37)$ & $8(1,32)$ & $6(1,65)$ \\
\hline 5-bromouracila & $\pi_{1}^{*}$ & $\pi_{2}^{*}$ & $\pi_{3}^{*}$ & $\sigma_{\mathrm{CBr}}^{*}$ \\
\hline Nosso resultado [114] & $-0,30$ & $1,50(0,10)$ & $4,45(0,46)$ & $0,73(0,60)$ \\
\hline Scheer et. al. [43] & & 1,3 & 3,6 & $\sim 1,3$ \\
\hline Wetmore et al. [44] & $-0,17$ & & & \\
\hline Li et al. [45] & $-0,11$ & & & \\
\hline 5-iodouracila & $\pi_{1}^{*}$ & $\pi_{2}^{*}$ & $\pi_{3}^{*}$ & $\sigma_{\mathrm{CI}}^{*}$ \\
\hline Nosso resultado [114] & $-0,35$ & $1,54(0,10)$ & $4,34(0,45)$ & $-0,10$ \\
\hline 6-clorouracila & $\pi_{1}^{*}$ & $\pi_{2}^{*}$ & $\pi_{3}^{*}$ & $\sigma_{\mathrm{CCl}}^{*}$ \\
\hline Nosso resultado & $-0,14$ & $1,62(0,12)$ & $4,70(0,80)$ & $1,31(0,30)$ \\
\hline
\end{tabular}

há muito bom acordo entre nossos resultados e o espectro de transmissão de elétrons de Scheer et. al. [43] para os estados $\pi_{1}^{*}$ e $\pi_{2}^{*}$, sendo que o desvio médio fica em 0,18 eV. Por outro lado, nossos cálculos sistematicamente superestimam as posições da ressonância $\pi_{3}^{*}$, com desvio médio de $1,1 \mathrm{eV}$. Esses estados $\pi^{*}$ de mais alta energia apresentam um 


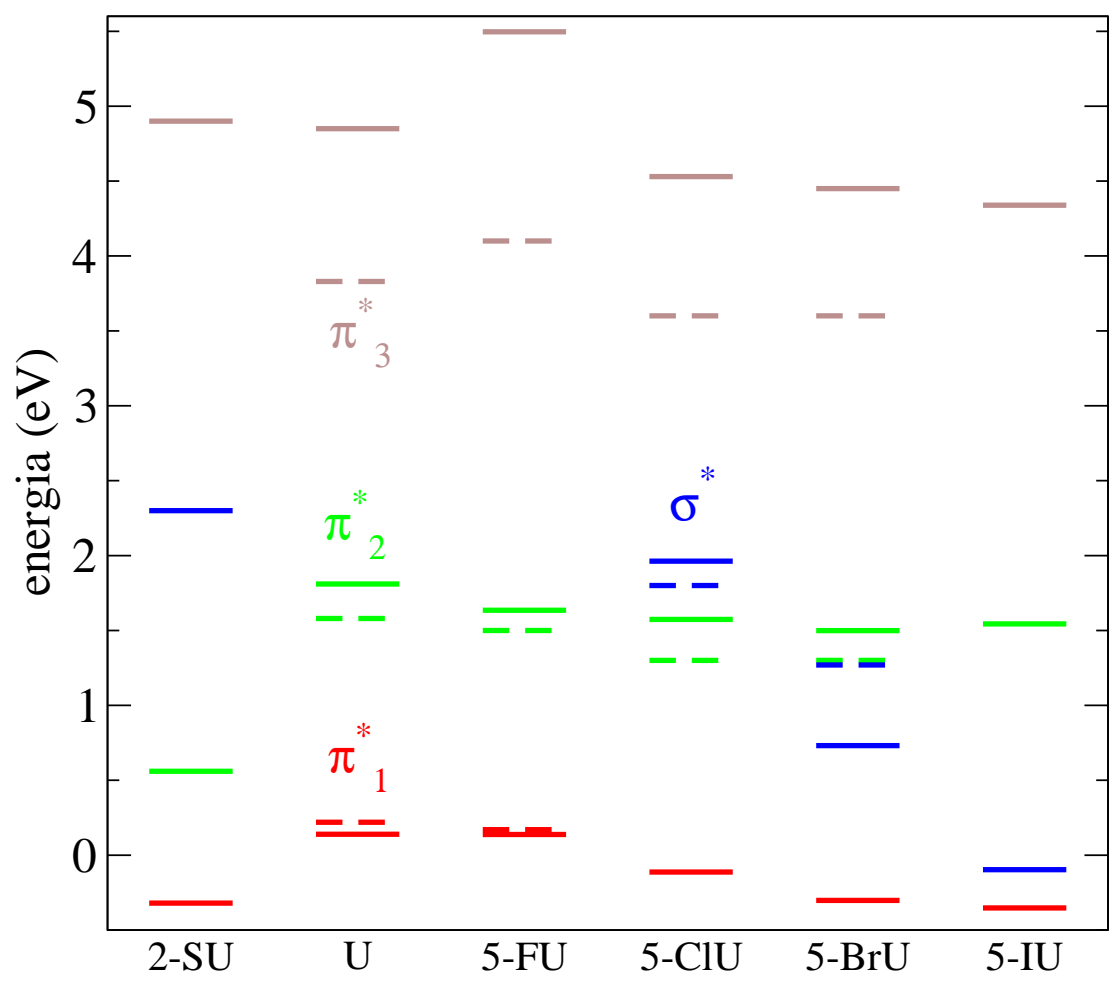

Figura 4.22: Posições dos estados do ânion da série de derivados de uracila, de acordo com os cálculos de espalhamento (linhas cheias) e segundo as medidas de Scheer et al. (linhas tracejadas) [43].

caráter misto de ressonância de forma e de ressonância de caroço-excitado [32, 130,131]. Uma descrição mais adequada requer cálculos multicanais que incluam estados excitados tripleto do alvo no espaço dos canais abertos, por meio do operador de projeção $P$. Os dois estados $\pi^{*}$ de mais baixa energia são ressonâncias de forma puras, e são bem descritos em cálculos que considerem apenas o canal elástico.

Já comparamos anteriormente os orbitais da 2-tiouracila e uracila e aqui a análise será sobre os derivados halogenados. Na figura 4.23 são apresentados para a 5bromouracila os orbitais virtuais $\pi_{1}^{*}, \pi_{2}^{*}, \pi_{3}^{*}, \sigma_{\mathrm{NH}}^{*}$ e $\sigma_{\mathrm{CBr}}^{*}$, bem como o SOMO do estado de dipolo. Os orbitais $\pi^{*}$ são bastante semelhantes entre a uracila e a série de halouracilas, sendo que a presença de um halogênio na posição 5 ou 6 pouco altera o perfil das densidades de probabilidade. De acordo com nossos cálculos de espalhamento, o estado 

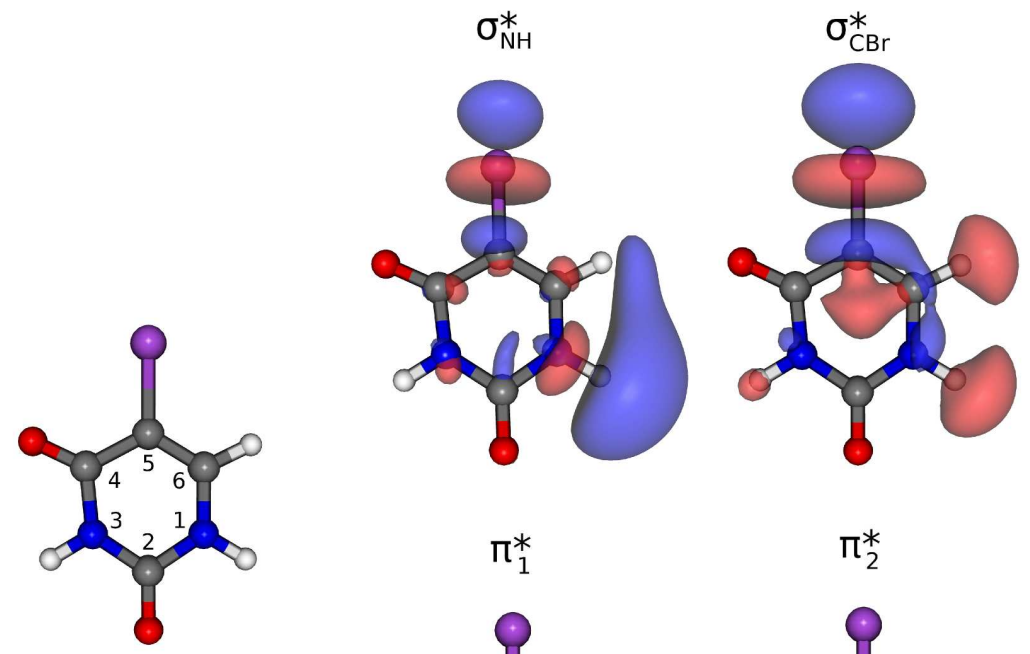

DBS
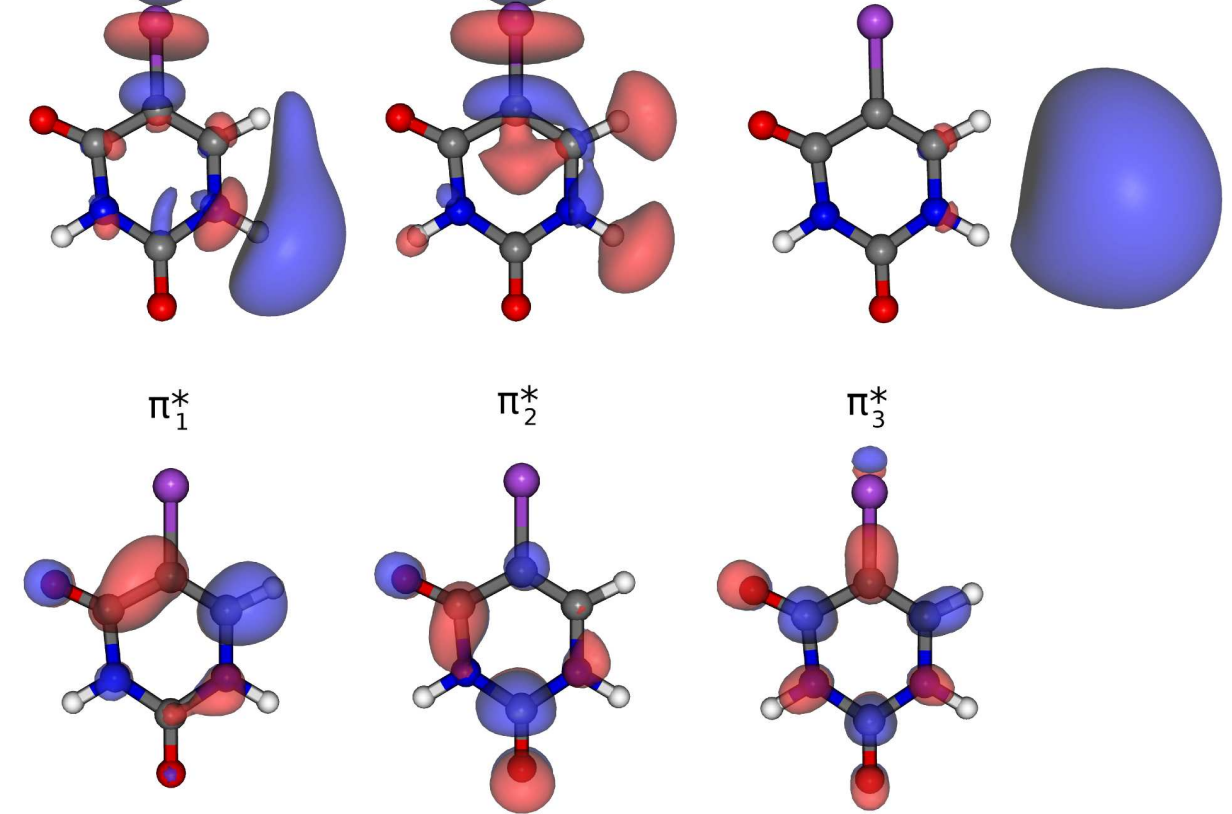

Figura 4.23: Estrutura da 5-bromouracila (à esquerda), onde as posições do anel são indicadas por números de 1 a 6 . São mostrados os orbitais virtuais $\pi^{*}$ (abaixo), $\sigma_{\mathrm{NH}}^{*}$ (acima, à esquerda) e $\sigma_{\mathrm{CBr}}^{*}$ (acima, no meio) e o SOMO do estado ligado por dipolo (acima, à direita). Os orbitais de valência e do estado de dipolo foram geradas para valores de isoprobabilidade de 0,04 e 0,01 unidades atômicas, respectivamente.

$\pi_{1}^{*}$ apresenta uma tendência de estabilização moderada diante do aumento do número atômico do halogênio. A partir da uracila, até a 5-iodouracila, o estado se localiza em $0,15,0,14,-0,11,-0,30$ e $-0,35 \mathrm{eV}$. Ao menos até a 5 -clorouracila esse efeito também é observado experimentalmente [43] e por cálculos de estado ligado [44,45], e nossos cálculos indicam a continuação dessa tendência para as demais halouracilas. Nas ressonâncias $\pi_{2}^{*}$ essa estabilização também está presente, embora de maneira mais suave, e com um leve desvio no caso da 5-iodouracila. Esses estados foram identificadas em 1,82, 1,64, 1,57, 1,50 e 1,54 eV ao longo da série. Na mesma progressão, a ressonância de caráter misto $\pi_{3}^{*}$ foi encontrada em 4,81, 5,50, 4,70, 4,45 e 4,34 eV, e o mesmo comportamento é verifi- 
cado. Embora a 5-fluorouracila destoe da série, a ordem relativa dos estados $\pi_{3}^{*}$ ao longo das 5-halouracilas concorda com observação experimental [43]. Conforme se aumenta o número atômico do halogênio, a combinação da maior afinidade eletrônica e polarizabilidade responde pelo aumento do caráter eletronegativo da molécula. Em outras palavras, o potencial efetivo que o elétron incidente sente será mais atrativo para as halouracilas mais pesadas e isso deve deslocar os estados do ânion para menores energias. E quanto mais próximo do halogênio estiver a densidade de probabilidade do orbital ressonante, maior será esse efeito estabilizante. Isso reflete numa estabilização acentuada para os estados localizados $\sigma_{\mathrm{CX}}^{*}$, mas moderada para os estados delocalizados $\pi^{*}$. Mesmo entre as ressonâncias $\pi^{*}$, é possível notar uma maior influência do átomo substituído nas energias dos estados $\pi_{1}^{*}$ e $\pi_{3}^{*}$ do que no caso das ressonância $\pi_{2}^{*}$.

O LUMO e o LUMO+1 (LUMO+4 no caso da 5-fluorouracila) da simetria $A^{\prime}$ da 5-fluorouracila, 5-clorouracila, 5-bromouracila e 6-clorouracila são apresentados na figura 4.24. Os orbitais da 5-iodouracila são semelhantes ao da 5-bromouracila e por isso não são mostrados. Na série de 5-halouracilas, esses orbitais virtuais são gerados pela combinação de uma parte com caráter anti-ligante na ligação N-H e outra parte com caráter anti-ligante na ligação C-X. A ocupação desses orbitais dá origem, portanto, às ressonâncias $\sigma_{\mathrm{CX}}^{*}$ e $\sigma_{\mathrm{NH}}^{*}$. A componente $\sigma_{\mathrm{CX}}^{*}$ fica mais evidente no orbital de mais baixa energia conforme se aumenta o número atômico do halogênio. Na 5-fluorouracila apenas o LUMO+4 se assemelha a um orbital anti-ligante na ligação, sendo que na 5clorouracila, LUMO e LUMO+1 apresentam esse perfil, enquanto na 5-bromouracila e na 5-iodouracila o caráter $\sigma_{\mathrm{CX}}^{*}$ já é contemplado apenas pelo LUMO. Essa tendência reflete na estabilização dos estados do ânion observada a partir dos cálculos de espalhamento, que apresentam energias de 1,96, 0,73 e -0,10 eV. Um orbital de caráter $\sigma_{\mathrm{NH}}^{*}$ também é comum na série de 5-halouracilas, sendo representado pelo LUMO na 5-fluorouracila, com contribuições do LUMO e do LUMO+1 no caso da 5-clorouracila, e passando para o LUMO+1 na 5-bromouracila e 5-iodouracila. A existência desse orbital em baixa energia sugere a existência de uma ressonância $\sigma_{\mathrm{NH}}^{*}$, mas como a seção de choque calculada não revela nenhuma estrutura que pode ser associada a essa ressonância, ela deve apresentar 

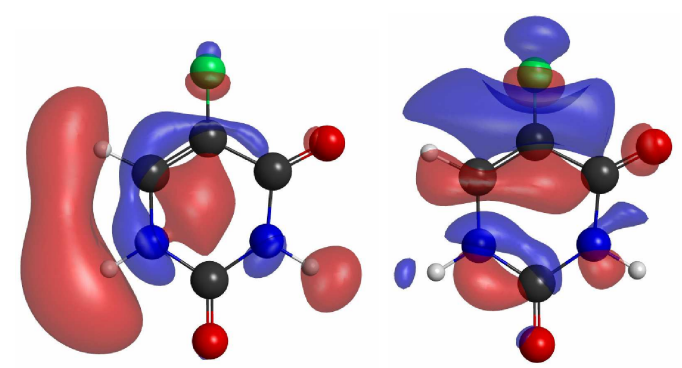

(a) LUMO e LUMO+4 $a^{\prime}$ da 5-fluorouracila

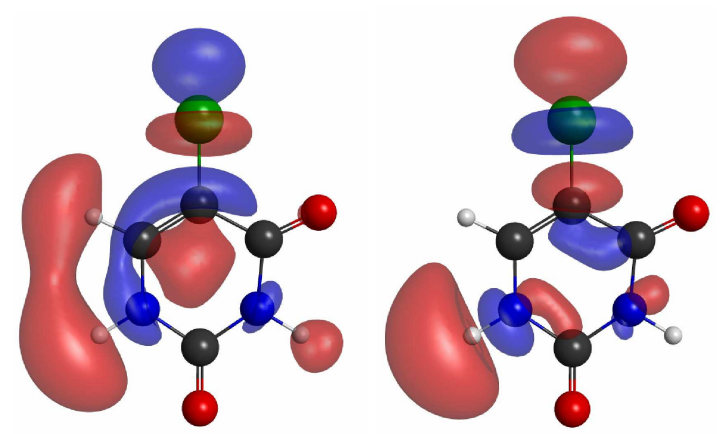

(b) LUMO e LUMO+1 $a^{\prime}$ da 5-clorouracila
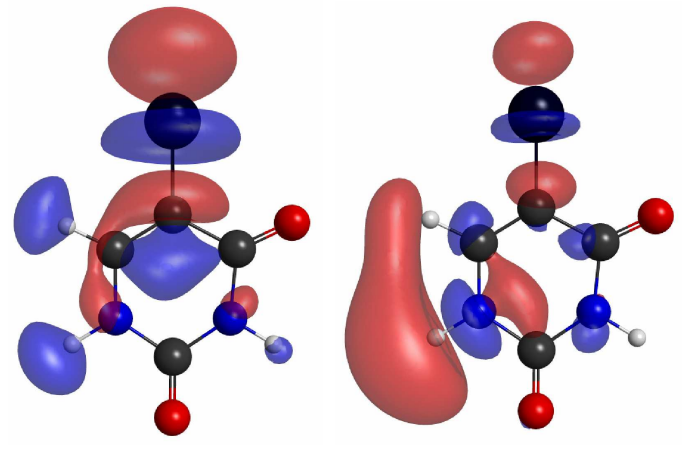

(c) LUMO e LUMO+1 $a^{\prime}$ da 5-bromouracila
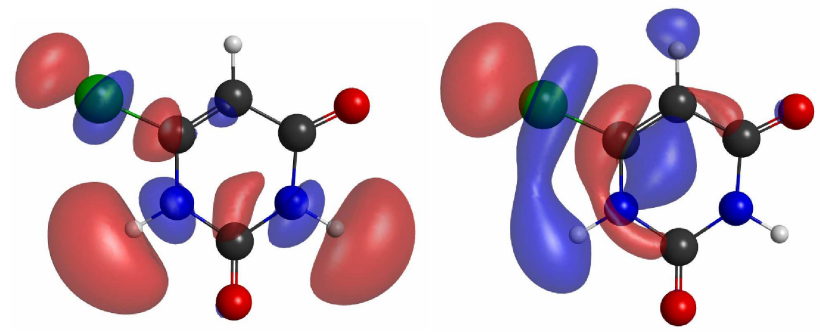

(d) LUMO e LUMO+1 $a^{\prime}$ da 6-clorouracila

Figura 4.24: Orbitais $\sigma^{*}$ da 5-fluorouracila, 5-clorouracila, 5-bromouracila e 6-clorouracila.

tempo de vida muito curto. Medidas do espectro de transmissão eletrônica também não detectaram esse estado [43].

Comparando os isômeros de clorouracila, os estados do ânion $\pi^{*}$ surgem em energias muito próximas. No entanto, a largura da ressonância $\pi_{3}^{*}$ é consideravelmente maior na 6-clorouracila $(0,80 \mathrm{eV})$ do que na 5-clorouracila $(0,45 \mathrm{eV})$, apesar de estar centrada em 4,70 eV em ambos os isômeros. Os maiores tempos de vida na segunda molécula permitem uma maior reorganização da geometria antes da ejeção do elétron, o que pode explicar porque apenas nesse isômero o fragmento $\mathrm{Cl}^{-}$é observado ao redor de $4 \mathrm{eV}$ [125]. A maior diferença no espectro de ressonâncias reside no estado $\sigma_{\mathrm{CCl}}^{*}$, que surge em 1,96 $\mathrm{eV}$ na 5-clorouracila, e estabiliza em $0,65 \mathrm{eV}$, aparecendo em 1,31 eV na 6-clorouracila. Também é notável a diferença nas larguras, de 1,03 eV na primeira e de 0,30 eV na segunda, e consequentemente nos tempos de vida, de 0,64 contra 2,21 fs. Em ambas as 
moléculas, o LUMO da simetria $A^{\prime}$ apresenta uma maior componente $\sigma_{\mathrm{NH}}^{*}$, enquanto no $\mathrm{LUMO}+1$ o caráter $\sigma_{\mathrm{CCl}}^{*}$ é mais predominante. $\mathrm{Na}$ 6-clorouracila as ligações $\mathrm{C}-\mathrm{Cl}$ e $\mathrm{N}-\mathrm{H}$ são vizinhas, e há certa sobreposição construtiva entre as componentes antiligantes das duas ligações, o que não ocorre na 5-clorouracila. Isso estabiliza o orbital da primeira molécula e portanto a ressonância $\sigma_{\mathrm{CCl}}^{*}$ apresenta menor energia e maior tempo de vida.

Além dos estados de valência descritos com cálculos de espalhamento, as 5halouracilas também são capazes de formar um ânion ligado por dipolo, uma vez que apresentam momentos de dipolo entre 4 e $5 \mathrm{D}$, acima do valor crítico de $\sim 2,4 \mathrm{D}$ [119]. Empregamos a base aug-cc-pVDZ+6s6p, onde o conjunto de funções difusas 6s6p foi centrado no hidrogênio da posição 1 do anel, que está próximo do polo positivo da molécula. Os cálculos foram realizados na geometria de equilíbrio da molécula neutra, otimizada no nível B3LYP/aug-cc-pVDZ. A energia do estado de dipolo foi obtida como a diferença entre os valores dos estados neutro e do ânion, ambos calculados com o método CCSD(T). A partir da uracila, aumentando o número atômico do halogênio, obtivemos o estado ligado por dipolo nas seguintes energias em relação ao neutro: $-65,-67,-70,-71,-75 \mathrm{meV}$. Há uma leve tendência de estabilização, embora os valores sejam todos muito próximos. Nosso cálculo para a uracila provê uma energia de $-65 \mathrm{meV}$, em relativo acordo com o valor medido a partir do espectro de fotoelétrons, de $-90 \mathrm{meV}[132,133]$. Esse resultado e a proximidade entre os valores obtidos para as espécies halogenadas sugere que nessas o ânion deva se apresentar entre -90 e $-100 \mathrm{meV}$. Inexistem resultados experimentais ou teóricos para as energias dos estados de dipolo das 5-halouracilas. Em todas as moléculas, o orbital ocupado pelo elétron adicional se situa num orbital difuso localizado entre as posições 1 e 6 do anel, conforme ilustrado na figura 4.23.

Uma informação importante obtida do espectro de dissociação é a energia a partir da qual um dado fragmento passa a ser observado. Esse valor deve estar necessariamente acima da energia necessária para que ocorra a reação de dissociação, a chamada energia de threshold da reação. Nas 5-halouracilas, fragmentos são observados já a partir de $0 \mathrm{eV}$, o que indica que as reações de dissociação correspondentes devem ser endotérmicas. Esse é um dos principais aspectos que carecem de uma melhor compre- 
ensão, uma vez que os cálculos existentes $[44,45,48,134]$ sugerem energias de threshold muito elevadas, incompatíveis com as observações. A eliminação dos fragmentos $\mathrm{Cl}^{-}, \mathrm{H}$ e $\mathrm{HCl}$ na 5-clorouracila, bem como $\mathrm{Br}^{-}$e $\mathrm{Br}$ na 5-bromouracila, todos já a partir de 0 eV, não deveria ser esperado com base nos cálculos existentes. São duas as explicações cogitadas para explicar a observação desses fragmentos em tão baixas energias. Eles poderiam surgir a partir da captura do elétron por fragmentos gerados da degradação térmica da molécula neutra, embora essa não deva ocorrer na faixa de temperaturas em que as mediadas foram realizadas [48]. A possibilidade usualmente mais creditada é a de captura eletrônica em bandas vibracionalmente quentes da molécula alvo, onde a energia térmica adicional daria conta de reduzir o threshold de dissociação [48].

Com o intuito de elucidar esse importante aspecto no perfil de dissociação das 5-halouracilas, foram realizados cálculos para os thresholds de dissociação para eliminação de H, X, X- e HX, conforme obtidos de cálculos G4(MP2) [135,136]. O método G4(MP2) é o mais recente da classe de métodos Gaussian-n, e é usualmente empregado para calcular grandezas termoquímicas com grande acurácia. A ideia central está fundamentada na observação de que diferentes aspectos dos cálculos de estrutura eletrônica, tais como correlação eletrônica e a influência de bases mais difusas ou com mais funções de polarização, são relativamente independentes entre si. Desse modo, métodos compostos como o G4(MP2) assumem a aditividade de tais efeitos, substituindo um cálculo sofisticado e dispendioso em que todas as contribuições são levadas em consideração por uma sucessão de cálculos muito mais baratos em que a influência de cada aspecto é avaliado individualmente. A tabela 4.5 contém os valores obtidos, com e sem a correção de energia de ponto zero, para a série de 5-halouracilas. A abstração do hidrogênio requer a menor energia de threshold a partir da posição 1, e nesse caso os valores obtidos estão em bom acordo com os resultados existentes $[48,134]$. A eliminação da posição 3 exige da ordem de $\sim 1,5 \mathrm{eV}$ para todos os sistemas e deve dar origem às estruturas observadas a partir dessa energia. Por outro lado, nossos cálculos fornecem thresholds para a quebra da ligação $\mathrm{C}-\mathrm{X} \sim 0,3$ eV abaixo de cálculos anteriores [44, 45, 48, 134], para todas as 5-halouracilas. Considerando que essa estabilização é superior ao desvio absoluto médio reportado para o método 
Tabela 4.5: Energias necessárias (em eV) para a eliminação de H (a partir da posição N1), $\mathrm{X}^{-}$, X e HX, onde X denota o halogênio. Os valores foram obtidos com cálculos G4(MP2), e são apresentados com a correção de energia vibracional de ponto zero. Entre parênteses estão os valores sem a correção.

\begin{tabular}{lcccc}
\hline \hline & $\mathrm{H}$ & $\mathrm{X}^{-}$ & $\mathrm{X}$ & $\mathrm{HX}$ \\
\hline Uracila & $0,85(1,22)$ & & & \\
5-fluorouracila & $0,65(1,02)$ & $1,71(1,84)$ & $2,91(3,08)$ & $-0,02(0,23)$ \\
5-clorouracila & $0,56(0,92)$ & $0,52(0,62)$ & $1,85(1,99)$ & $0,36(0,65)$ \\
5-bromouracila & $0,52(0,89)$ & $0,13(0,22)$ & $1,25(1,37)$ & $0,45(0,73)$ \\
6-clorouracila & $0,43(0,79)$ & $0,38(0,48)$ & $1,42(1,52)$ & $-0,12(0,14)$ \\
\hline \hline
\end{tabular}

G4(MP2), de $~ 0,05 \mathrm{eV}$ [136], nossos resultados devem fornecer energias de threshold que mais se aproximam dos valores reais.

Nossos resultados são compatíveis com a abstração de H e de HF para a 5-fluorouracila (limiares em $\sim 0,5 \mathrm{eV}$ e $\sim 0 \mathrm{eV}$, respectivamente), e com a formação de $\mathrm{Br}^{-}$para a 5-bromouracila (limiar em $\sim 0 \mathrm{eV}$ ) [46]. Quanto aos demais fragmentos, os thresholds calculados ainda ficam $\sim 0,3-1,2 \mathrm{eV}$ acima das energias em que eles passam a ser detectados. Calculamos então as energias térmicas vibracionais dentro da aproximação harmônica, somando a contribuição de cada modo vibracional através da distribuição de Boltzmann, para frequências vibracionais obtidas no nível B3LYP/aug-cc-pVTZ. Além da contribuição da energia de ponto zero, as 5-halouracilas apresentam energias vibracionais médias em torno de $0,3 \mathrm{eV}$, considerando uma temperatura de $450 \mathrm{~K}$, situação em que as medidas experimentais foram realizadas $[46,48,50]$. Desse modo, a inclusão de efeitos térmicos reduziria os thresholds de dissociação mostrados na tabela 4.5 em cerca de 0,3 $\mathrm{eV}$. Isso poderia explicar a ocorrência dos três fragmentos da 5-clorouracila $\left(\mathrm{H}, \mathrm{Cl}^{-}\right.$e $\mathrm{HCl}$ ) a partir de $\sim 0 \mathrm{eV}$, caso o cálculo G4(MP2) esteja superestimando o threshold em até $\sim 0,2 \mathrm{eV}$, bem acima de seu desvio médio, de $\sim 0,05 \mathrm{eV}$. Para testar essa possibilidade, realizamos cálculos na formulação G4 original [135], que leva os cálculos de teoria de 
perturbação até quarta ordem e é portanto ainda mais preciso que o método G4(MP2). Nesse caso, o threshold para eliminação de $\mathrm{Cl}^{-}$é de $0,60 \mathrm{eV}$, levemente superior ao resultado obtido com o cálculo G4(MP2), de 0,52 eV, sugerindo que a captura por moléculas vibracionalmente quentes é insuficiente para dar conta desse canal de dissociação. No caso da eliminação do radical neutro Br, a situação é ainda mais crítica, uma vez que o threshold calculado, de 1,25 eV, está muito acima do limiar observado já em $\sim 0 \mathrm{eV}$.

Passamos a investigar um mecanismo alternativo que possa explicar a formação de fragmentos em tão baixas energias. Considerando que a ligação $\mathrm{C}-\mathrm{H}$ é tipicamente mais forte do que a ligação $\mathrm{N}-\mathrm{H}$, a migração do hidrogênio da posição 1 para a posição 5 poderia estabilizar o ânion, o que facilitaria a eliminação do átomo de halogênio. Para testar essa hipótese, realizamos cálculos G4(MP2) para a configuração acima descrita, para 5-clorouracila e 5-bromouracila. Os thresholds de dissociação decrescem sistematicamente, e passam a ser compatíveis com os resultados experimentais. Embora esse mecanismo seja factível do ponto de vista termodinâmico, ele demandaria uma reorganização geométrica significativa. Portanto, seriam necessários cálculos que identifiquem as configurações de mínimo e de transição relevantes, o que permitiria avaliar se há uma rota de dissociação favorável cineticamente.

Um dos aspectos mais intrigantes sobre os dados de dissociação das 5-halouracilas é a ausência do sinal de eliminação de hidrogênio na 5-bromouracila e 5-iodouracila, em contraste aos casos da uracila, 5-fluorouracila e 5-clorouracila. Em mais baixas energias, os picos observados para a uracila devem surgir do acoplamento entre o estado ligado por dipolo e a ressonância dissociativa $\sigma_{\mathrm{NH}}^{*}[14,43]$. De acordo com esse mecanismo, o elétron é capturado no estado ligado por dipolo (parte interna da curva de energia potencial do estado do ânion ao longo da coordenada reativa $\mathrm{N} 1-\mathrm{H}$ ), dando origem a ressonâncias de Feshbach vibracionais. A dissociação se daria então pelo tunelamento do pacote de onda para a parte externa da curva de energia potencial, que apresenta caráter $\sigma_{\mathrm{NH}}^{*}$. Análises da energia de ligação do estado de dipolo, do threshold de dissociação e das frequências vibracionais do modo de estiramento $\nu_{\mathrm{NH}}$ apontam para picos de dissociação em torno de 0,7 e 1,0 eV na uracila, advindos dos níveis vibracionais $\nu_{\mathrm{NH}}=2,3$ [43]. Cálculos de 


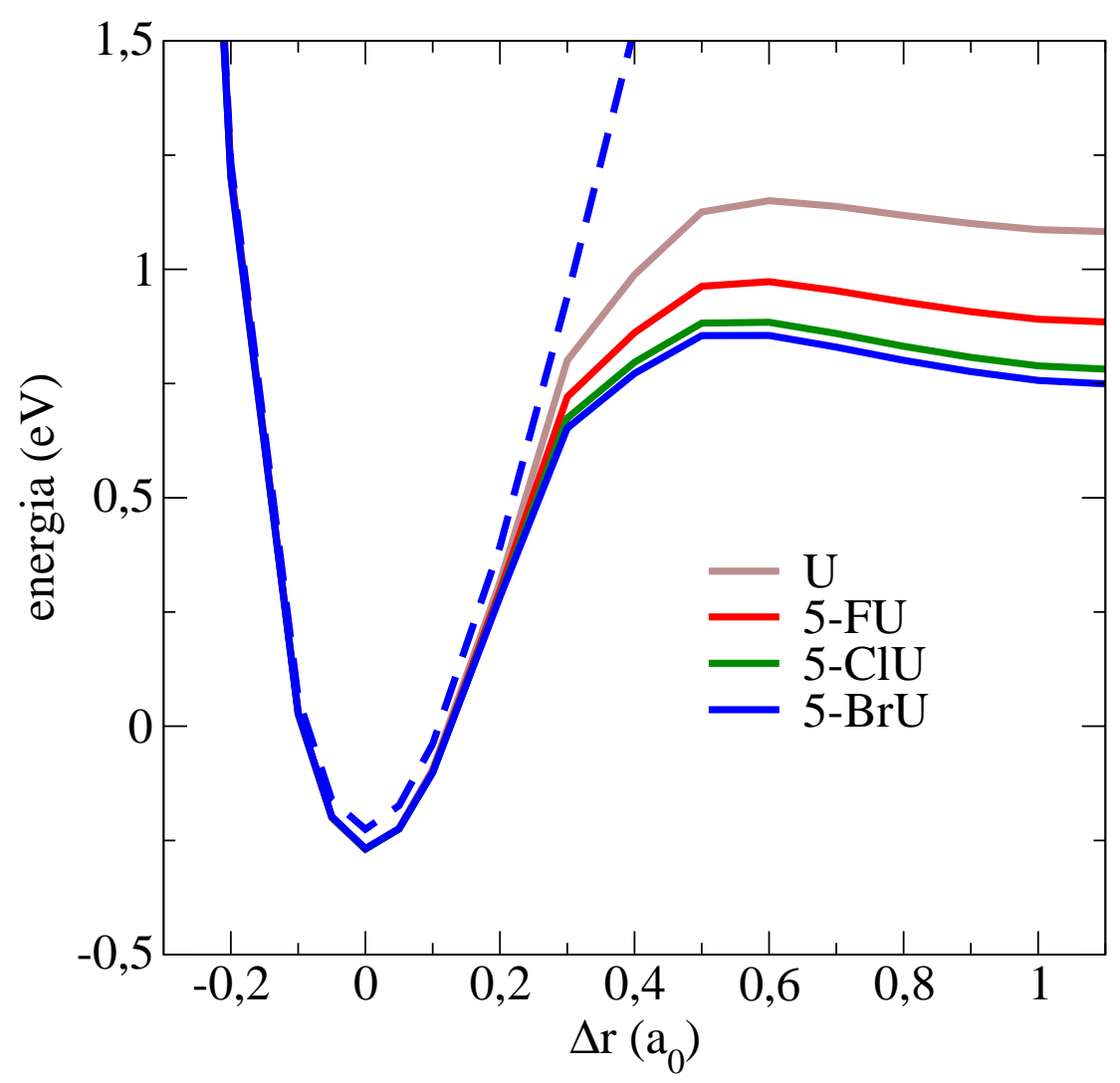

Figura 4.25: Curvas de energia potencial para o estado ligado por dipolo (à esquerda do estado de transição) e para o estado $\sigma_{\mathrm{NH}}^{*}$ (à direita) da série de 5-halouracilas, obtidas ao longo da coordenada de estiramento $\mathrm{N}-\mathrm{H}$. Também é mostrada a curva do estado neutro da 5-bromouracila.

dinâmica do pacote de onda confirmam esse mecanismo [14].

Como já apontado, o estado de dipolo da uracila e das 5-halouracilas apresentam energias de ligação semelhantes. Foram construídas curvas de energia potencial do estado de dipolo ao longo da coordenada N1-H, para as 5-halouracilas e uracila, e os resultados são mostrados na figura 4.25. As curvas para o estado neutro são muito semelhantes em todas as moléculas, e apenas a da 5-bromouracila é apresentada na figura 4.25. Os cálculos foram realizados no nível MP2/aug-cc-pVDZ+6s6p, mais barato computacionalmente do que o método $\operatorname{CCSD}(\mathrm{T})$, utilizado na obtenção das energias nas geometrias de equilíbrio. Para a 5-clorouracila, o estado de dipolo está em $-43 \mathrm{meV}$ 
segundo o cálculo MP2, comparável ao resultado de -73 meV do cálculo CCSD(T), o que sugere que as curvas de energia potencial estão bem descritas. As frequências do modo $\nu_{\mathrm{NH}}$ são essencialmente iguais ao longo da série, em torno de $\hbar \omega \approx 0,45 \mathrm{eV}$. As energias do estado de transição, quando há a mudança de caráter de estado ligado por dipolo para estado de valência $\sigma_{\mathrm{NH}}^{*}$, também são semelhantes, e apenas um tênue decréscimo desse valor com o aumento do número atômico é observado. Apesar da menor barreira e das menores energias de threshold para a eliminação de hidrogênio (ver tabela 4.5), as diferenças são muito pequenas em comparação à energia de excitação do modo $\nu_{\mathrm{NH}}$, de $\hbar \omega \approx 0,45 \mathrm{eV}$. Consequentemente, o perfil das curvas de energia potencial do ânion ao longo da coordenada de estiramento $\mathrm{N} 1-\mathrm{H}$ não justifica a ausência de $[\mathrm{XU}-\mathrm{H}]^{-}$em baixas energias na 5-bromouracila e 5-iodouracila.

No entanto, há três aspectos que podem explicar esse comportamento. Primeiro, os orbitais $\sigma^{*}$ de baixa energia (ver figura 4.24) sugerem acoplamentos $\sigma_{\mathrm{NH}}^{*} / \sigma_{\mathrm{CX}}^{*}$, com probabilidades crescentes na ligação $\mathrm{C}-\mathrm{X}$ a medida que se aumenta o número atômico do halogênio. Segundo, a tabela 4.5 indica thresholds apreciavelmente menores para a eliminação de $\mathrm{X}^{-}$, indo da 5-fluorouracila até a 5-bromouracila. Em particular, o threshold para a formação de $\mathrm{Br}^{-}$é bem menor que para a abstração do hidrogênio no caso da 5-bromouracila, ao contrário das halouracilas mais leves. E em terceiro lugar, a excitação térmica de modos que contemplem o estiramento $\mathrm{C}-\mathrm{X}$ deve ser facilitada com o aumento do número atômico do halogênio, em oposição ao modo de alta frequência $\nu_{\mathrm{NH}}$. Em relação a esse último ponto, o espectro vibracional calculado para 5-clorouracila e 5-bromouracila são bastante similares. O modo normal de menor energia com caráter $\mathrm{C}-\mathrm{X}$ mais significativo $\left(\nu_{5}\right)$ apresenta uma frequência vibracional maior na 5-clorouracila $(0,045 \mathrm{eV})$ do que na 5-bromouracila $(0,035 \mathrm{eV})$, além de contar com uma maior contribuição do estiramento $\mathrm{C}-\mathrm{X}$ no modo da segunda molécula. Na temperatura em que as medidas do espectro de dissociação foram realizadas, cerca de $450 K\left(k_{B} T=39 \mathrm{meV}\right)$ [40,46,48-50], a ocupação média calculada é de $\bar{\nu}_{5}=0,46$ (5-clorouracila) e $\bar{\nu}_{5}=0,68$ (5-bromouracila). Portanto, a dinâmica entre os estados acoplados $\sigma_{\mathrm{CX}}^{*}$ e $\sigma_{\mathrm{NH}}^{*}$ deve ocasionar uma competição entre a eliminação do halogênio e do hidrogênio, e os três aspectos acima discutidos devem favo- 
recer o segundo processo na 5-bromouracila e 5-iodouracila. Essa observação é consistente com os sinais medidos em mais baixas energias $(\lesssim 1 \mathrm{eV}):[\mathrm{FU}-\mathrm{H}]^{-}$e $[\mathrm{FU}-\mathrm{HF}]^{-}$para a 5-fluorouracila $[46] ;[\mathrm{ClU}-\mathrm{H}]^{-},[\mathrm{ClU}-\mathrm{HCl}]^{-}, \mathrm{e} \mathrm{Cl}^{-}$para a 5-clorouracila $[46,48]$; e apenas $\mathrm{X}^{-} /[\mathrm{XU}-\mathrm{X}]^{-}$para a 5-bromouracila e 5-iodouracila $[46,49,50]$.

O sinal correspondente à eliminação de hidrogênio, observado em $\sim 1,5 \mathrm{eV}$ na uracila e nas duas 5-halouracilas mais leves [46,48], também está completamente ausente na 5-bromouracila e 5-iodouracila $[46,49,50]$. Nessa energia, o átomo do hidrogênio eliminado é o da posição 3 , e o mecanismo de dissociação envolve o acoplamento do estado $\pi_{2}^{*}$ com uma ressonância $\sigma_{\mathrm{N} 3 \mathrm{H}}^{*}$, localizada no orbital anti-ligante da ligação N3-H [137]. A inspeção dos orbitais virtuais obtidos com cálculos de base compacta indica que os orbitais $\pi_{2}^{*}$ e $\sigma_{\mathrm{N} 3 \mathrm{H}}^{*}\left(\mathrm{LUMO}+2\right.$ da simetria $\left.A^{\prime}\right)$ são semelhantes ao longo da série de 5-halouracilas, o que sugere que o acoplamento $\pi_{2}^{*} / \sigma_{\mathrm{N} 3 \mathrm{H}}^{*}$ não deve se alterar substancialmente. Os aspectos discutidos acima para o regime de menores energias também devem se aplicar nesse caso e explicar a ausência desse canal de dissociação. Além disso, observamos uma considerável mistura no caráter dos orbitais virtuais $\sigma_{\mathrm{CX}}^{*}$ e $\sigma_{\mathrm{N} 3 \mathrm{H}}^{*}$ conforme a ligação N3-H é estirada, o que poderia favorecer a eliminação de $\mathrm{X}^{-}$em relação à do hidrogênio.

Avaliamos ainda o comportamento do estado adiabático do ânion das quatro 5-halouracilas, ao longo da ligação $\mathrm{C}-\mathrm{X}$, cujas curvas de energia potencial estão apresentadas na figura 4.26. Os cálculos foram realizados no nível B3LYP/aug-cc-pVTZ, e as curvas apresentados tem como zero da energia potencial a espécie neutra em sua geometria de equilíbrio. Nesse tipo de cálculo, otimiza-se a geometria do ânion, enquanto alguma coordenada reativa é mantida fixa, no caso o comprimento da ligação C-X. Esse procedimento indica o caminho de menor energia que o ânion adiabático deve seguir ao longo da coordenada reativa escolhida, sugerindo portanto possíveis mecanismos de dissociação, além de apontar para a existência de configurações estáveis (pontos de mínimo na curva) e de transição (pontos de máximo). Obtivemos ainda as afinidades eletrônicas verticais e adiabáticas, sendo que para a última calculamos a correção de energia de ponto zero. Os valores são comparadas aos resultados de Wetmore et al. [44] (B3LYP/6-311+G(2df,p), sem correção de ponto zero) e de Li et al. [45] (B3LYP/6-31+G(d), com e sem correção 


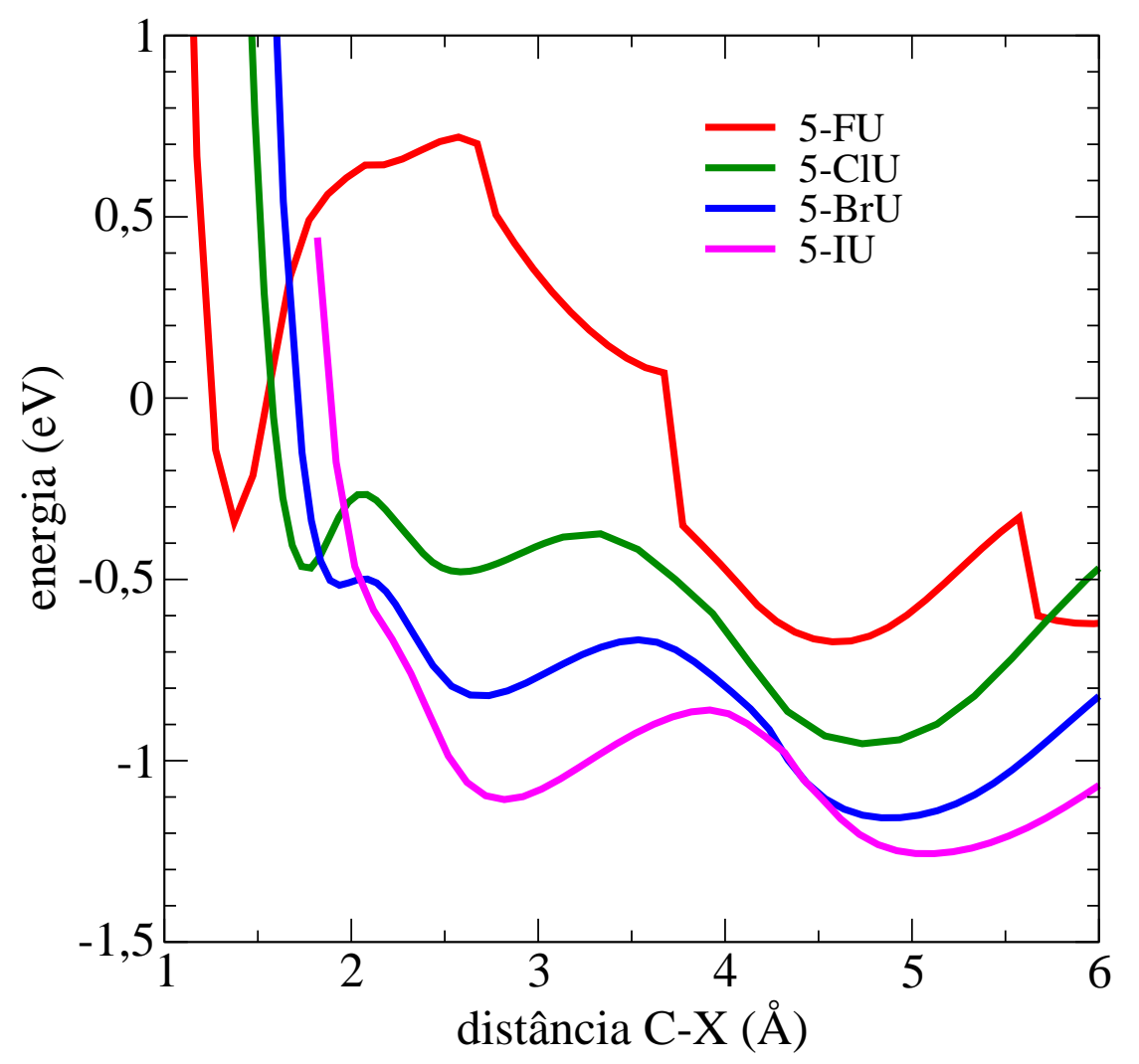

Figura 4.26: Curvas de energia potencial para o ânion adiabático das quatro 5halouracilas, em função da distância C-X, obtidas de cálculos B3LYP/aug-cc-pVTZ.

de ponto zero). Li et al. [45] também realizou cálculos para o ânion adiabático da uracila e 5-halouracilas, com exceção da 5-iodouracila, no nível B3LYP/6-31+G(d). Seus cálculos foram realizados até cerca de 3,0 A para a distância entre o carbono e o halogênio, enquanto os nossos foram estendidos até $6,5 \AA$, fornecendo mais informações sobre o comportamento do ânion adiabático, além de contar com uma base mais robusta. Na figura 4.27 ilustramos, para 5-clorouracila e 5-fluorouracila, algumas das estruturas ao longo da curva adiabática do ânion.

Para a 5-fluorouracila, obtivemos uma afinidade eletrônica adiabática de 0,34 eV, sem correção de energia de ponto zero, próxima dos valores existentes de 0,45 eV [44] e $0,37 \mathrm{eV}[45]$. Em todos os sistemas, a curvatura do potencial do ânion adiabático é menor do que a do neutro, na vizinhança do equilíbrio da espécie neutra, e por isso a 
correção de ponto zero aumenta a afinidade eletrônica adiabática. Com a correção obtemos o valor de 0,46 eV, muito próximo ao reportado por Li et al. [45], de 0,48 eV. Para a 5-clorouracila, nosso cálculo fornece 0,47 eV sem a correção de ponto zero, comparável aos valores obtidos por Wetmore et al. [44] (0,49 eV) e por Li et al. [45] (0,58 eV). Incluindo a correção o valor passa para $0,59 \mathrm{eV}$, também em ótimo acordo com o obtido por Li et al. [45], de 0,60 eV. A 5-bromouracila apresenta uma afinidade eletrônica adiabática de 0,52 eV segundo nossos cálculos, sem correção de ponto zero, valor similar aos obtidos anteriormente $(0,64 \mathrm{eV}$ [44] e $0,51 \mathrm{eV}$ [45]). Considerando o efeito de energia de ponto zero obtemos 0,64 eV, essencialmente o mesmo valor obtido por Wetmore et al. [44], de 0,63 eV. Para essas quatro 5-halouracilas, o ânion relaxado não possui mais uma simetria planar. A estrutura dobra de modo a acomodar a carga extra, acompanhando um pequeno estiramento da ligação carbono-halogênio e um deslocamento do hidrogênio ligado ao carbono da posição 6 para fora do plano do anel. No entanto, o estado ainda assume o caráter $\pi_{1}^{*}$, onde o orbital ocupado pelo elétron extra tem essencialmente o mesmo perfil do da figura 4.23. A 5-iodouracila, por outro lado, não apresenta um ânion estável em distâncias $\mathrm{C}-\mathrm{I}$ próximas da de equilíbrio da molécula neutra, como pode ser visto da figura 4.26. Nesse caso, o elétron adicional está mais fortemente localizado nessa ligação, e um estiramento mais pronunciado é necessário para relaxar o sistema. O ânion encontra sua estrutura de equilíbrio apenas a uma distância C-I de 2,82 A, configuração na qual o iodo forma um complexo ligado ao anel. A afinidade eletrônica adiabática é de 1,11 eV sem a correção de ponto zero e de 2,98 eV quando ela é levada em conta. A grande diferença nesse caso é reflexo do potencial muito raso do complexo ligado.

A medida que o halogênio é afastado de sua posição de equilíbrio, ocorrem uma sequência de mudanças estruturais (ver figura 4.27) e no caráter e energética do ânion adiabático. Na 5-clorouracila e 5-bromouracila, há inicialmente um estado de transição, onde o ânion apresenta um caráter misto $\pi^{*}$ e $\sigma_{\mathrm{CX}}^{*}$. À esquerda desse ponto o caráter $\pi^{*}$ é dominante, enquanto à direita o estado assume um perfil essencialmente $\sigma_{\mathrm{CX}}^{*}$. Essa transição também se dá na 5-iodouracila, mas sem a formação de uma barreira de energia potencial. A partir desse ponto as curvas das três 5-halouracilas mais pesadas tem 


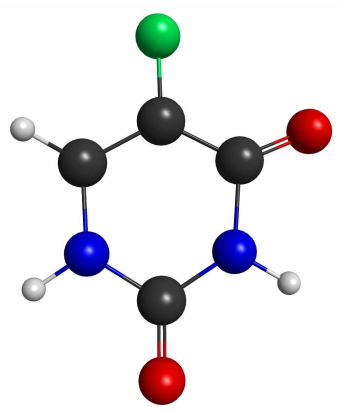

(a) $\mathrm{d}(\mathrm{C}-\mathrm{F}) \simeq 1.4 \AA$

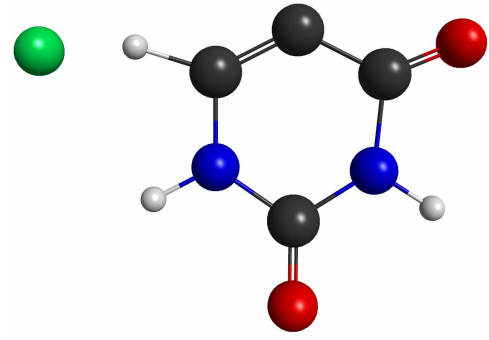

(d) $\mathrm{d}(\mathrm{C}-\mathrm{F}) \simeq 3.7 \AA$

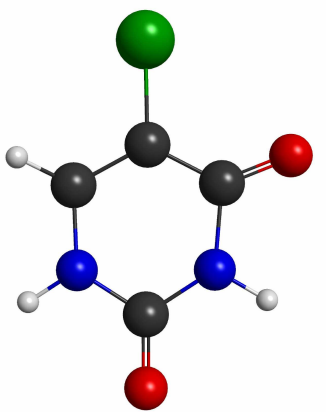

(g) $\mathrm{d}(\mathrm{C}-\mathrm{Cl}) \simeq 1.8 \AA$

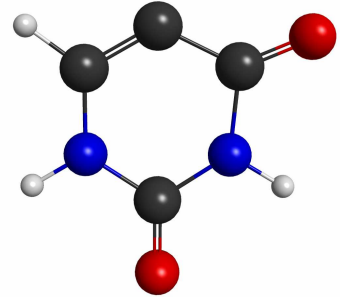

(b) $\mathrm{d}(\mathrm{C}-\mathrm{F}) \simeq 2.7 \AA$

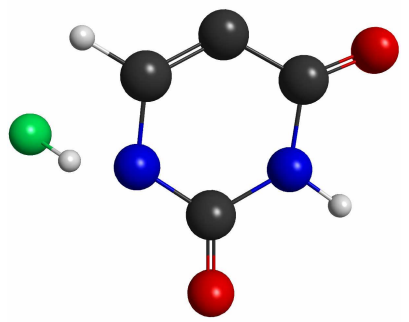

(e) $\mathrm{d}(\mathrm{C}-\mathrm{F}) \simeq 3.8 \AA$

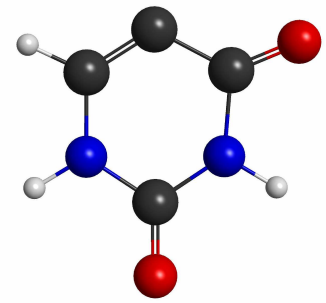

(h) $\mathrm{d}(\mathrm{C}-\mathrm{Cl}) \simeq 2.6 \AA$

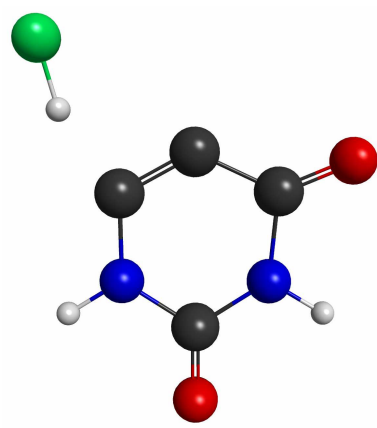

(c) $\mathrm{d}(\mathrm{C}-\mathrm{F}) \simeq 2.8 \AA$

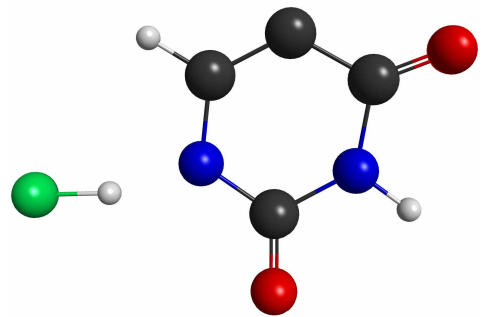

(f) $\mathrm{d}(\mathrm{C}-\mathrm{F}) \simeq 4.6 \AA$

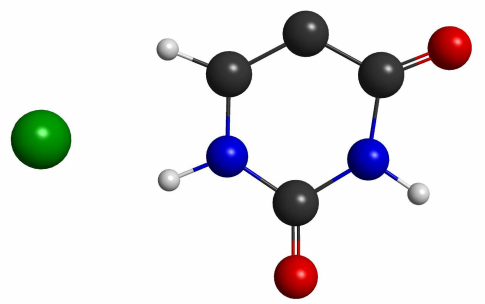

(i) $\mathrm{d}(\mathrm{C}-\mathrm{Cl}) \simeq 4.7 \AA$

Figura 4.27: Estruturas da 5-fluorouracila e 5-clorouracila referentes à curva do ânion adiabático da figura 4.26, em distintos comprimentos da ligação C-X.

o mesmo formato. Outro estado de transição se faz presente, que antecede a formação do complexo mais estável do ânion. Essa estabilização ocorre devido à aproximação do halogênio aos átomos de hidrogênio situados nas posições 1 e 6, ficando aproximadamente equidistante deles. Seguindo para maiores distâncias, o halogênio se afasta carregando consigo o elétron adicional, dissociando por fim como o ânion haleto. A 5-fluorouracila, 
por outro lado, apresenta uma curva para o ânion adiabático distinta. A mudança de caráter $\pi^{*}$ para $\sigma_{\mathrm{CF}}^{*}$ envolve uma barreira mais alta energeticamente, e que se estende para maiores comprimentos da ligação $\mathrm{C}-\mathrm{F}$. A estabilização que se dá após a transição ocorre porque o flúor captura o hidrogênio da posição 6 , formando assim o ácido fluorídrico, HF. Li et al. [45] já havia avaliado o comportamento do ânion adiabático realizando cálculos até distâncias de 2,8 A, e concluiu que a formação de HF envolveria a abstração do hidrogênio da posição 6. Além de endossar o comportamento descrito por Li et al. até essa distância, nosso cálculo foi estendido para maiores distâncias. Pouco após a formação do HF, o hidrogênio que estava ligado ao flúor retoma sua posição original. O ânion segue então em seu caminho de estabilização até o salto observado para a distância de $3,75 \AA$, onde o flúor captura o hidrogênio da posição 1, ligado ao nitrogênio. A energia potencial do ânion volta então a crescer e a molécula neutra HF se afasta do anel carregado. A descontinuidade em torno de 5,5 $\AA$ surge devido a uma reorientação do fragmento HF. A curva de energia potencial apresentada indica que seguindo na trajetória adiabática para a eliminação do flúor, esse abstrai o hidrogênio ligado ao nitrogênio e forma a molécula neutra HF, em contraste ao resultado de Li et al. [45], que indica que o hidrogênio adjacente ao flúor é capturado. Esse caminho de reação também é mais provável do ponto de vista energético, segundo nossos cálculos G4(MP2). A captura do hidrogênio da posição 1 seria inclusive endotérmica $(-0,02 \mathrm{eV})$, comparado à reação exotérmica $(0,86 \mathrm{eV})$ que envolveria o hidrogênio da posição 6. Vale mencionar a existência de um cálculo [138] para o ânion adiabático do complexo de 5-fluorouracila e adenina, realizado no nível B3LYP/6$31+\mathrm{G}(\mathrm{d})$, que aponta a formação do ácido HF a partir da abstração do hidrogênio ligado ao nitrogênio, em consistência com a nossa conclusão.

A curva de energia potencial do estado adiabático do ânion da 6-clorouracila está apresentado na figura 4.28, juntamente com a curva de seu isômero. Não há a formação de uma estrutura estável do ânion próximo da geometria de equilíbrio da molécula neutra, ao contrário do que ocorre na 5-clorouracila. O ânion encontra uma posição de equilíbrio somente para uma distância $\mathrm{C}-\mathrm{Cl}$ em torno de 2,6 A, com afinidade eletrônica adiabática de 1,11 eV, ou de 1,03 eV se ignorarmos a correção de energia de 


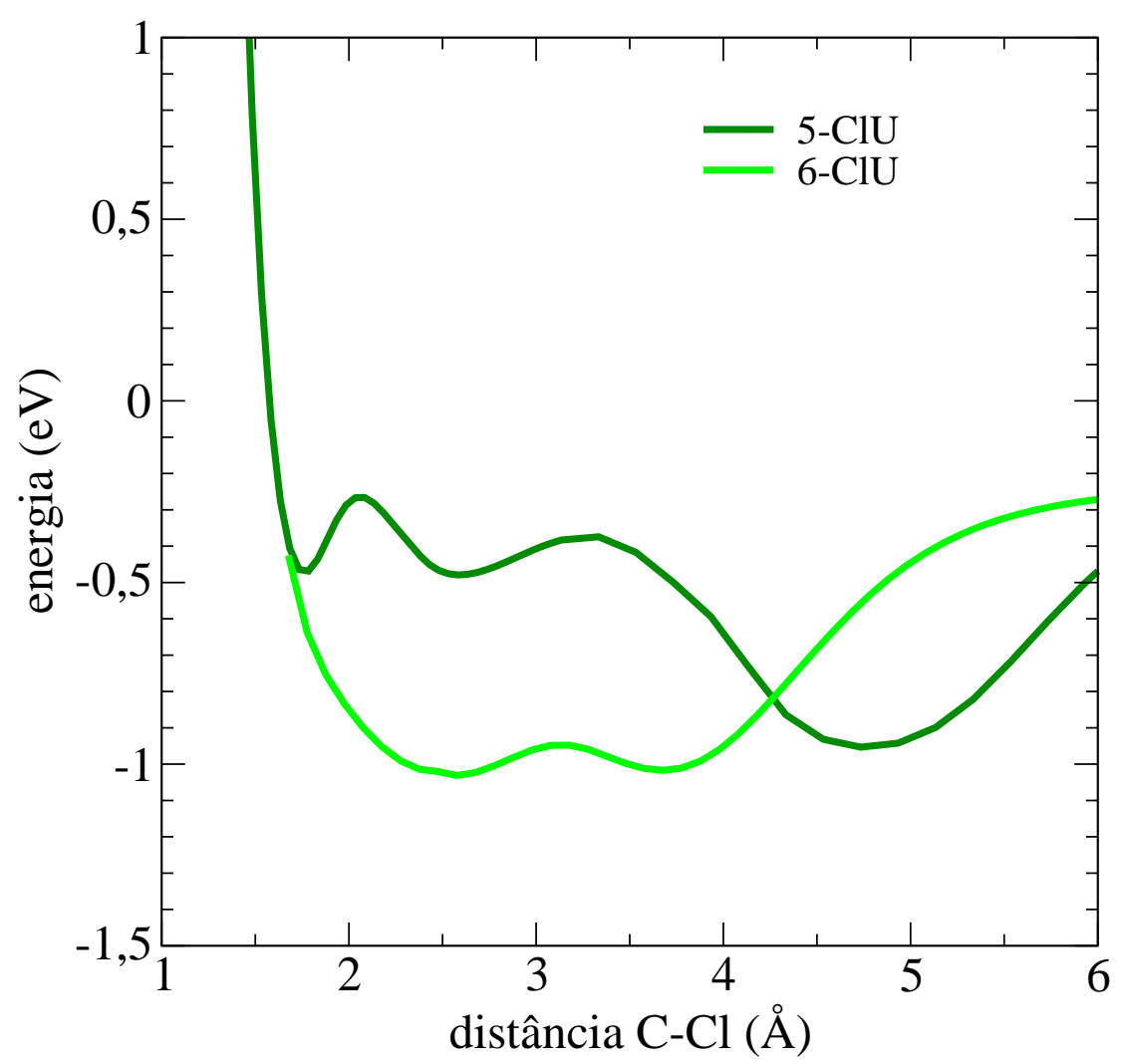

Figura 4.28: Curvas de energia potencial para o ânion adiabático de 6-clorouracila, em função da distância $\mathrm{C}-\mathrm{Cl}$.

ponto zero. Vale notar ainda que esse mínimo é mais estável em cerca de $\sim 0,5 \mathrm{eV}$ na 6-clorouracila do que na 5-clorouracila, tomando como referência a espécie neutra em sua respectiva geometria de equilíbrio. Estirando ainda mais a distância $\mathrm{C}-\mathrm{Cl}$, a situação é semelhante ao caso da 5-clorouracila. O cloro se move em direção aos dois hidrogênios adjacentes, há uma nova configuração de mínimo ao redor de $3,7 \AA$, e então ocorre a dissociação do $\mathrm{Cl}^{-}$. Embora o caminho de mínima energia não tenha mostrado a captura do hidrogênio em ambos os isômeros de clorouracila, as baixas energias de threshold (ver tabela 4.5) e a considerável estabilização do ânion com a aproximação entre cloro e hidrogênio suportam que esse é um canal provável. De fato, o experimento revela que a formação de $\mathrm{HCl}$ apresenta seções de choque superiores à de $\mathrm{Cl}^{-}$[125], em especial na 6clorouracila, onde o arranjo geométrico e os menores thresholds favorecem a captura [125]. 


\section{Capítulo 5}

\section{Cloroadeninas}

\subsection{Introdução}

Embora as halouracilas sejam as mais conhecidas e estudadas, há outras classes de moléculas halogenadas que são sensíveis à exposição de radiação ionizante, e por isso tem potencial aplicação em radioterapia. Como elétrons de baixa energia são muito eficientes em induzir reações de dissociação nessas moléculas, é fundamental compreender os mecanismos atuantes nesses processos. A maior parte dos estudos tem se concentrado em derivados das pirimidinas (uracila, timina e citosina), enquanto os derivados de purina (adenina e guanina) passaram a receber atenção mais recentemente. Estudos teóricos de purinas bromadas apontam para a rápida estabilização do ânion através da eliminação do brometo [53, 54, 139, 140]. Para os nucleotídeos de 8-bromoadenina [54] e 8-bromoguanina [139], os radicais formados pela eliminação do bromo podem desencadear reações que ocasionam a quebra da fita do DNA. Experimentos de colisão de elétrons por filmes de trímeros de nucleotídeos [140] confirmaram a habilidade dessas bromopurinas em provocar dano biológico. Foi sugerido inclusive que esse poderia ser ainda mais severo que nos análogos de pirimidina $[139,140]$. 


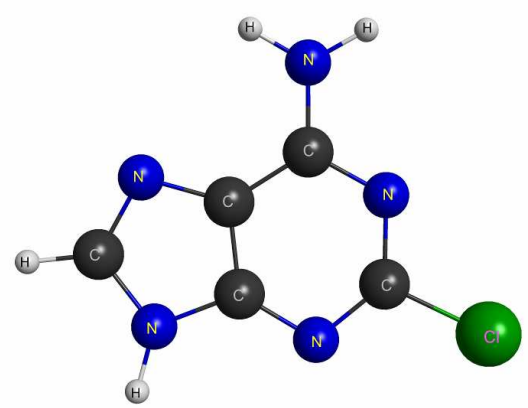

(a) 2-cloroadenina

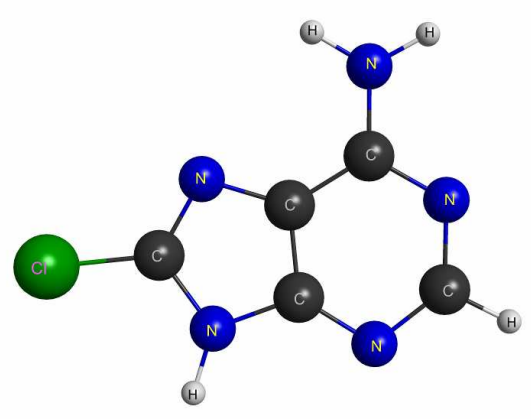

(b) 8-cloroadenina

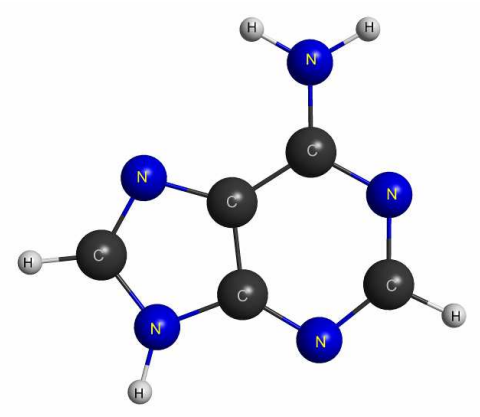

(c) Adenina

Figura 5.1: Estrutura geométrica da adenina, 2-cloroadenina, 8-cloroadenina.

Apesar do crescente interesse em novos compostos radiossensibilizadores e dos recentes resultados sobre purinas halogenadas, informações a respeito da interação de elétrons com essa classe de biomoléculas ainda é muito limitada. Em particular, não há qualquer trabalho sobre os estados ressonantes do ânion e sobre os mecanismos de dissociação. Em vista da relevância desses sistemas e da falta de trabalhos existentes sobre eles, incluímos a 2-cloroadenina e a 8-cloroadenina como moléculas alvo do nosso trabalho. Esses derivados halogenados são obtidos pela substituição de um hidrogênio da adenina por um átomo de cloro, podendo ocorrer nas posições 2 e 8 do anel. As estruturas geométricas da adenina, 2-cloroadenina e 8-cloroadenina estão apresentadas na figura 5.1.

Medidas do espectro de transmissão eletrônica para a adenina apontam a existência de três ressonâncias de forma $\pi^{*}$ [122]. Uma quarta ressonância $\pi^{*}$ foi obtida em cálculos de espalhamento [26,29,141], sendo de mais alta energia e fora da região em que a medida fora realizada. Embora os cálculos existentes descrevam corretamente a 
existência dos estados ressonantes, o acordo com as posições medidas é apenas razoável, superestimando especialmente a posição da terceira ressonância. Com o intuito de comparar com resultados anteriores [26,29,122,141], e de obter uma comparação equilibrada com os resultados das cloroadeninas, também realizamos cálculos para a adenina.

Nosso objetivo é caracterizar os estados aniônicos da adenina, 2-cloroadenina e 8-cloroadenina, avaliando como a halogenação e a posição da substituição alteram os estados das ressonâncias. Para isso, foram realizados cálculos de espalhamento elástico com o método multicanal de Schwinger implementado com pseudopotenciais, nas aproximações estático-troca e estático-troca mais polarização. A comparação com medidas do espectro de fragmentação da 2-cloroadenina [142] permite avaliar seus principais mecanismos de dissociação.

\subsection{Procedimentos computacionais}

A geometria da molécula no estado fundamental foi otimizada no nível B3LYP/6$311++\mathrm{G}(2 \mathrm{~d}, 1 \mathrm{p})$. Pseudopotenciais de BHS [66] foram utilizados para substituir os núcleos e os elétrons de caroço por um potencial efetivo, tanto no cálculo de estado ligado para descrever a molécula neutra quanto nos cálculos de espalhamento. A descrição do alvo é realizada na aproximação Hartree-Fock, com funções de base gaussianas-cartesianas geradas como descrito na referência [68]. Uma conjunto $5 s 5 p 2 d$ foi centrado nos átomos de carbono e nitrogênio (expoentes já apresentados anteriormente, na tabela 4.1) e um conjunto $6 s 5 p 2 d$ centrado no cloro (cujos expoentes estão na tabela 4.2). Por fim, a base $3 s$ da referência [96] foi centrada em cada hidrogênio. Obtivemos um total de 315 funções de base para a adenina e 346 para as cloroadeninas. A descrição do estado do alvo foi realizado com o pacote GAMESS [97], bem como as otimizações de geometria.

Os orbitais de partícula e de espalhamento foram representados por meio de MVOs [65]. Eles foram gerados no campo do cátion de carga +6 , para a adenina e a 
2-cloroadenina, e no campo do cátion de carga + 16 para a 8-cloroadenina. Embora a adenina e as cloroadeninas apresentem uma geometria de equilíbrio levemente não-planar, os cálculos de espalhamento foram realizados mantendo-se a restrição planar. Isso permite que as seções de choque sejam obtidas separadamente nas componentes $A^{\prime}$ e $A^{\prime \prime}$, facilitando a identificação das ressonâncias. Os cálculos existentes para a adenina [26, 29, 141] também fizeram uso dessa aproximação. Em ambas as simetrias adotamos o critério de energia $\varepsilon_{\text {espa }}+\varepsilon_{\text {part }}-\varepsilon_{\text {bura }}<\varepsilon_{\text {cut }}$ [37] para construir o espaço de configurações, onde $\varepsilon$ denota a energia do orbital em questão, de espalhamento, partícula e buraco. Tomamos $\varepsilon_{\text {cut }}=-1,09$ hartree para a adenina e 2-cloroadenina e $\varepsilon_{\text {cut }}=-5,10$ hartree para a 8cloroadenina, tomando acoplamentos de spin singleto e tripleto nas excitações virtuais simples. Obtivemos 25371 configurações para a adenina (12604 na simetria $A^{\prime}$ e 12767 na $\left.A^{\prime \prime}\right), 26223$ para a 2-cloroadenina (13052 na simetria $A^{\prime}$ e 13171 na $A^{\prime \prime}$ ) e 25109 para a 8-cloroadenina (12917 na simetria $A^{\prime}$ e 12192 na $A^{\prime \prime}$ ). Mais uma vez, não consideramos o efeito de longo alcance do momento de dipolo permanente sobre o processo de espalhamento. Tal efeito apenas causaria um aumento na magnitude da seção de choque, sem alterar de maneira significativa as posições e larguras das ressonâncias.

\subsection{Adenina}

A decomposição por simetrias da seção de choque integral elástica da adenina é mostrada na figura 5.2. Há quatro ressonâncias de forma $\pi^{*}$, identificadas a partir daqui como $\pi_{1}^{*}, \pi_{2}^{*}, \pi_{3}^{*}$ e $\pi_{4}^{*}$, em ordem crescente de energia. Na aproximação SE elas se encontram em 2,93, 3,77, 4,9 e 10,2 eV, e se assemelham aos dois resultados existentes obtidos no mesmo nível de aproximação. Dora et al. [29], através do método da matriz $\mathrm{R}$, reporta as energias das ressonâncias em 3,23, 4,02, 5,06 e 10,62 eV, enquanto Winstead e McKoy [141], com o método SMC, situam as três primeiras ressonâncias entre 2 e $5 \mathrm{eV}$ e a quarta logo acima de $10 \mathrm{eV}$, embora não apresente as energias exatas. Os pequenos desvios nesse nível de cálculo se devem a diferentes escolhas de bases e de geo- 


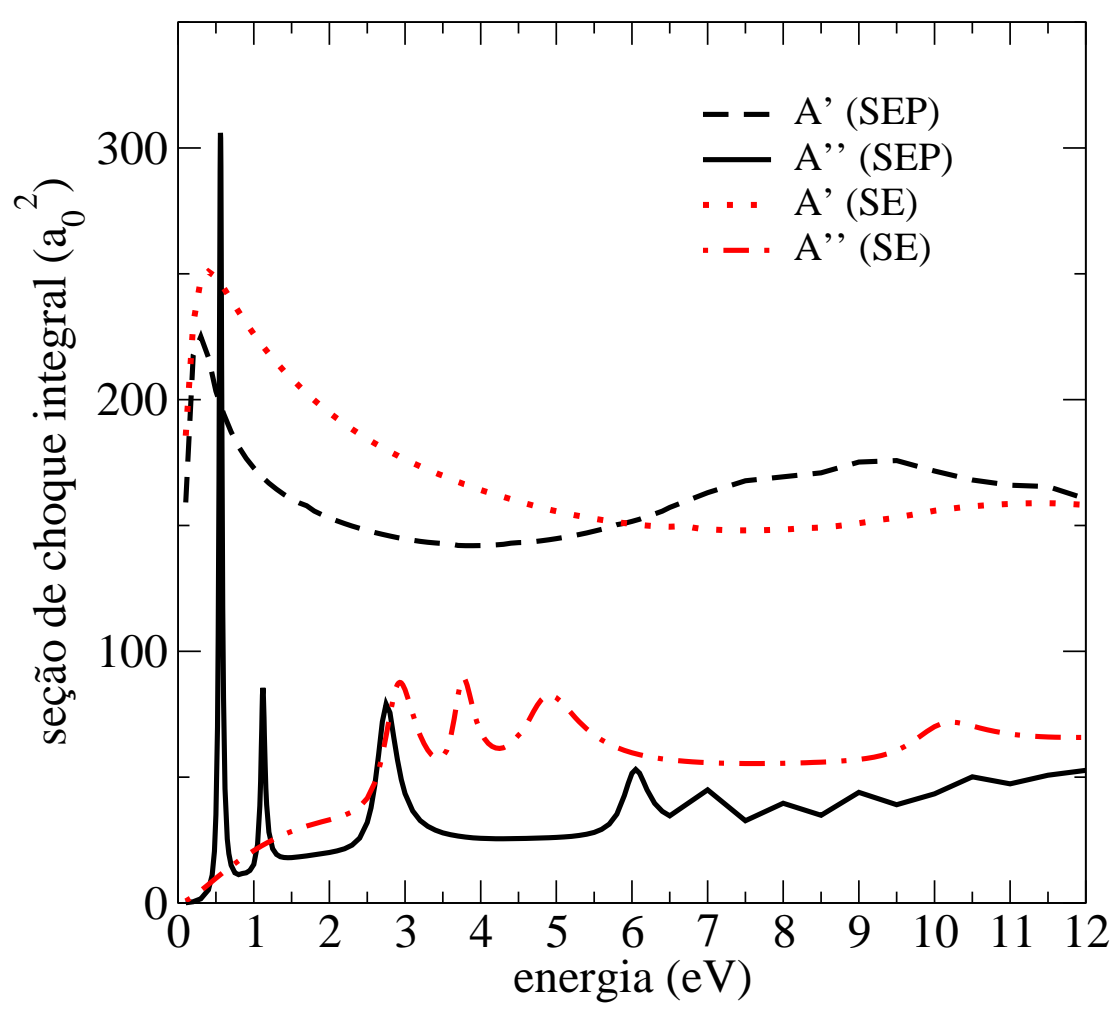

Figura 5.2: Seção de choque integral das simetrias $A^{\prime}$ e $A^{\prime \prime}$ da adenina, calculadas nas aproximações SE e SEP.

metrias. Winstead e McKoy [141] realizaram cálculos na aproximação SE para a molécula de guanina, para a geometria otimizada com a restrição de planaridade, e para a geometria totalmente otimizada, que assume um perfil quase planar onde os maiores desvios se dão nos hidrogênios do grupo amina. Eles observam um deslocamento para menores energias de 0,1-0,2 eV nas ressonâncias $\pi^{*}$ quando a configuração passa de planar para não-planar, e argumentam que tal deslocamento também deve ocorrer para os resultados obtidos dentro do cálculo SEP. Na adenina, as diferenças estruturais são semelhantes e uma estabilização da mesma ordem deve ser esperada.

Em nossos cálculos com polarização, as ressonâncias descem em energia e tornam-se mais finas, surgindo em 0,56, 1,12, 2,75 e 6,02 eV. Para Winstead e McKoy [141] as três primeiras ressonâncias ocorrem em 1,1, 1,8 e 4,1 eV, enquanto a ressonância de mais alta energia não teve sua energia determinada, dada a presença de pseudo-ressonâncias 
acima de $\sim 5 \mathrm{eV}$. O cálculo de Winstead e McKoy [141], também realizado com o método SMC, difere do nosso principalmente na construção do espaço CSF, e portanto na descrição dos efeitos de polarização. Enquanto em nossa abordagem as configurações são escolhidas individualmente, através de um critério energético [37], eles constroem espaços orbitais para buraco, partícula e espalhamento, que serão todos combinados. Portanto, a comparação dos resultados obtidos com os dois esquemas permite a avaliação da eficiência dos dois esquemas na descrição dos estados ressonantes. Na aproximação SEP, Dora et al. [29] encontra as ressonâncias em 1,30, 2,12, 3,12 e 7,07 eV, enquanto no nível mais sofisticado uncontracted close-coupling (u-CC) elas surgem em energias mais elevadas, em 1,58, 2,44, 4,38 e 7,94 eV. Há ainda o cálculo de Tonzani e Greene [26], que adota um modelo de espalhamento de uma partícula submetida a um potencial local obtido de cálculos DFT. Eles apresentam as ressonâncias em 2,4, 3,2, 4,4 e 9,0 eV, valores intermediários entre os cálculos SE e SEP obtidos por nós e pelos dois outros trabalhos mencionados. Finalmente, na medida do espectro de transmissão de elétrons de Aflatooni et al. [122] as três primeiras ressonâncias são observadas em 0,54, 1,36 e 2,17 eV, enquanto a quarta ressonância deve se encontrar acima $4 \mathrm{eV}$, energia até onde a medida foi realizada. Nossos resultados se comparam muito bem aos valores experimentais, apresentando o melhor acordo dentre os resultados teóricos existentes. Segundo nossos cálculos, a ressonância $\pi_{1}^{*}$ fica essencialmente em cima da posição medida, e as ressonâncias $\pi_{2}^{*}$ e $\pi_{3}^{*}$ se encontram respectivamente $0,24 \mathrm{eV}$ abaixo e $0,60 \mathrm{eV}$ acima das posições observadas. Uma vez relaxando a condição planar, devemos esperar um melhor acordo para as posições das duas ressonâncias $\pi^{*}$ de mais alta energia, enquanto as ressonâncias $\pi_{1}^{*}$ e $\pi_{2}^{*}$ ficariam localizadas abaixo do valor experimental. A energia de $6,02 \mathrm{eV}$ onde encontramos a ressonância $\pi_{4}^{*}$ deve ser um limite superior para sua real energia, tendo em vista que nosso cálculo ignora o acoplamento dessa ressonância com estados excitados tripleto da molécula neutra. Considerando que em outros sistemas que também manifestam esse caráter misto entre ressonância de forma e de caroço excitado o cálculo de espalhamento costuma superestimar sua energia em $0,5-1 \mathrm{eV}$, esperamos que a ressonância $\pi_{4}^{*}$ da adenina se encontre na região 5,0-5,5 eV. 
A simetria $A^{\prime}$ da seção de choque apresenta duas estruturas largas na aproximação SE, em torno de 11 e $15 \mathrm{eV}$. Apenas uma estrutura centrada ao redor de $8 \mathrm{eV}$ se mantém discernível quando efeitos de polarização são incluídos no cálculo. Tal estrutura deve corresponder a uma ou mais ressonâncias de forma $\sigma^{*}$, embora uma atribuição precisa não seja possível. Winstead e McKoy [141] também reportam uma estrutura semelhante no cálculo SE, embora a seção de choque para essa simetria no nível SEP não tenha sido apresentada. Dora et al. [29] apresentam o resultado mais completo para essa simetria. Eles observam ressonâncias de forma em 9,85 e 10,60 eV na aproximação SE, com larguras relativamente pequenas, da ordem daquelas obtidas para os estados $\pi^{*}$. Acreditamos que a superposição dessas duas estruturas corresponda à estrutura que observamos em $11 \mathrm{eV}$, embora em nosso cálculo a largura seja consideravelmente maior. No resultado SEP de Dora et al. apenas uma estrutura larga é visível em torno de $9,5 \mathrm{eV}$, se assemelhando mais à nossa curva de seção de choque. Eles encontraram ainda ressonâncias de Feshbach em 5,82 e 6,05 eV no nível u-CC, com larguras muito finas, não identificadas em nosso cálculo. Além disso, baseado na análise de orbitais virtuais e em resultados para pirrol [34], imidazol e pirazol [37] deve haver uma ressonância $\sigma_{\mathrm{NH}}^{*}$ em mais baixa energia, associada à ocupação de um orbital anti-ligante na ligação $\mathrm{N}-\mathrm{H}$ do grupo imidazol (ver figura 5.7). Entretanto, a grande largura e o espalhamento de background mais intenso em baixas energias devem mascarar a assinatura dessa ressonância na seção de choque [7,31].

\subsection{2-cloroadenina}

Os resultados para a seção de choque integral da 2-cloroadenina, nas aproximações SE e SEP, e simetrias $A^{\prime}$ e $A^{\prime \prime}$, estão apresentados na figura 5.3. Identificamos quatro ressonâncias de forma, que na aproximação SE se localizam em 2,61, 3,43, 4,6 e 9,8 eV . Dentro da aproximação SEP, as ressonâncias estão centradas em 0,29, 0,73, 2,55 e 5,69 eV. Inexistem medidas experimentais das energias das ressonâncias da 2-cloroadenina, 


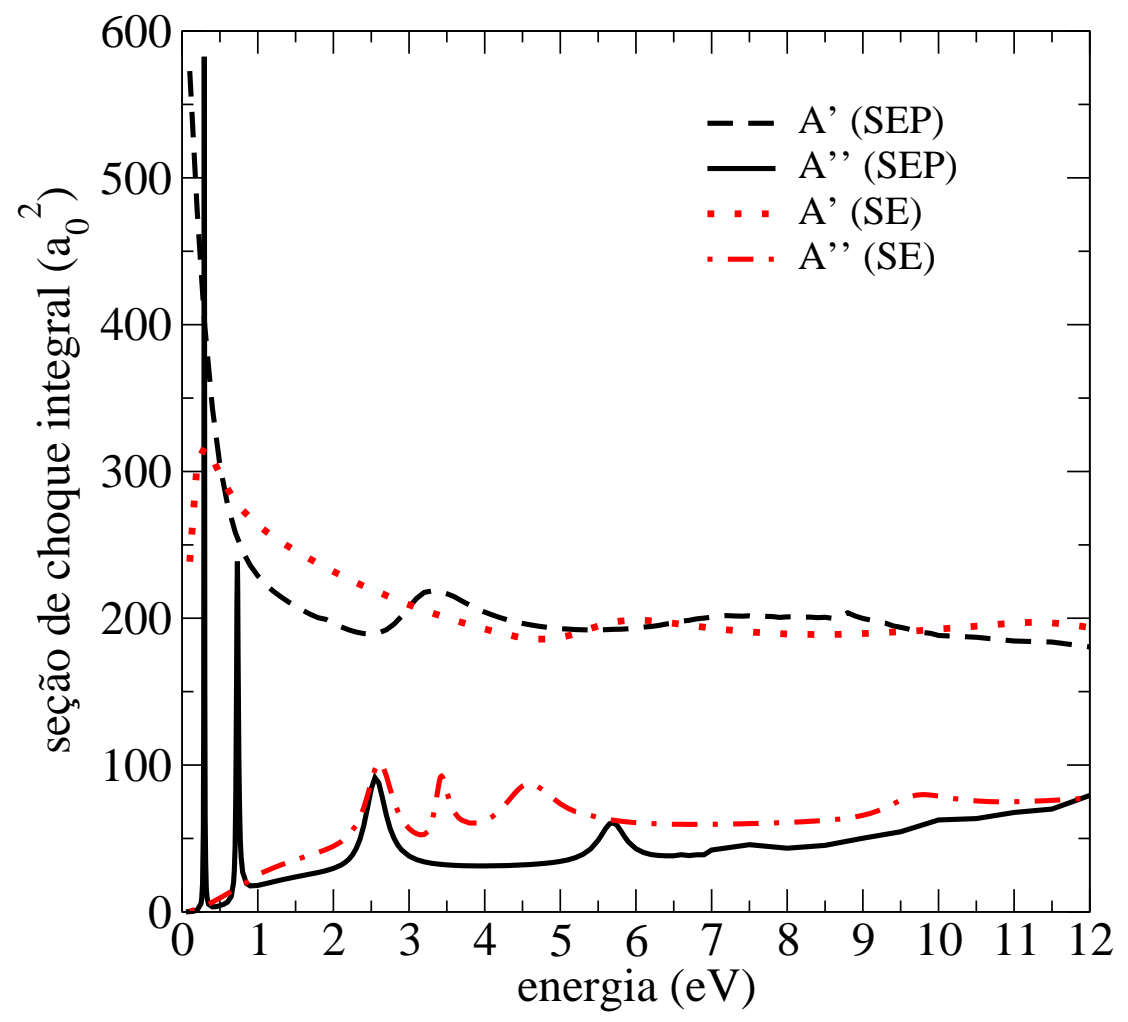

Figura 5.3: Seção de choque integral das simetrias $A^{\prime}$ e $A^{\prime \prime}$ da 2-cloroadenina, calculadas nas aproximações SE e SEP.

embora existam resultados do espectro de dissociação por captura eletrônica, que será discutido mais adiante. Na simetria $A^{\prime}$ a seção de choque apresenta uma estrutura em torno de $6 \mathrm{eV}$ na aproximação $\mathrm{SE}$, que se desloca para 3,3 eV quando efeitos de polarização são incorporados. Atribuímos esse pico a uma ressonância de forma $\sigma_{\mathrm{CCl}}^{*}$, que surge a partir da captura do elétron incidente no orbital anti-ligante localizado na ligação $\mathrm{C}-\mathrm{Cl}$ (ver figura 5.7). Em vista da contribuição significativa do background, o ajuste da autofase fornece uma energia da ressonância $(3,00 \mathrm{eV})$ um tanto deslocado da posição do máximo do pico $(3,3 \mathrm{eV})$. Como o modelo para a autofase adotado no ajuste incorpora adequadamente as componentes ressonantes e de background, esse procedimento é mais confiável do que a simples inspeção da posição do pico da seção de choque. Portanto, o valor de 3,00 eV deve ser tomado como nosso valor definitivo para a posição da ressonância $\sigma_{\mathrm{CCl}}^{*}$. Ainda encontramos uma estrutura razoavelmente pronunciada em torno de $11 \mathrm{eV}$ e uma 
bem mais suave em $16 \mathrm{eV}$, no resultado $\mathrm{SE}$, que devem surgir a partir de uma ou mais ressonâncias de forma $\sigma^{*}$. Na aproximação SEP, não é possível resolver as estruturas da simetria $\mathrm{A}^{\prime}$, devido à presença de pseudoressonâncias, e apenas uma única estrutura ao redor de $8 \mathrm{eV}$ permanece discernível. Finalmente, uma ressonância de forma $\sigma_{\mathrm{NH}}^{*}$ também deve existir na 2-cloroadenina, mas seu curto tempo de vida torna difícil a tarefa de identificá-la, teórica ou experimentalmente.

Os quatro orbitais $\pi^{*}$ estão ilustrados na figura 5.6, enquanto a figura 5.7 mostra os orbitais $\sigma_{\mathrm{CCl}}^{*}$ e $\sigma_{\mathrm{NH}}^{*}$, que são os dois de mais baixa energia da simetria $A^{\prime}$. O perfil dos orbitais será analisado em detalhes mais adiante, quando o espectro de ressonâncias da adenina e cloroadeninas for comparado. Segundo a relação de escala que vem sendo empregada para estimar as energias dos estados $\pi^{*}$ [116], esses deveriam surgir em 0,61, 1,12, 2,01 e 5,04 eV, em relativo bom acordo com os obtidos do cálculo de espalhamento $(0,29$, 0,73, 2,55 e 5,69 eV). Empregamos ainda a relação de escala própria para ressonâncias $\sigma_{\mathrm{CCl}}^{*}$ [83], e estimamos sua energia em 2,86 eV, em muito bom acordo com o resultado do cálculo de espalhamento de 3,00 eV. Esses valores foram obtidos ao se manter a molécula planar, enquanto na estrutura totalmente otimizada eles estabilizam levemente, em não mais do que 0,1 eV. Esperamos portanto que as energias das ressonâncias apresentem a mesma tendência, em linha com o discutido por Winstead e McKoy para a guanina e adenina [141]. Por fim, descrevemos o estado ligado por dipolo da 2-cloroadenina, fazendo uso da base aug-cc-pVDZ+6s6p. As energias de ligação obtidas dos cálculos MP2 e CCSD(T) são de $-11 \mathrm{meV}$ e $-31 \mathrm{meV}$, respectivamente. Nesse estado, o elétron adicional reside num orbital difuso, afastado da região da molécula, na direção das ligações $\mathrm{N}-\mathrm{H}$ e $\mathrm{C}-\mathrm{H}$ do grupo imidazol.

As curvas de eficiência dos fragmentos gerados por colisão de elétrons de baixa energia e a molécula de 2-cloroadenina estão apresentadas na figura 5.4, que foi adaptada da referência [142]. Há duas regiões em que a fragmentação do ânion se dá de maneira eficiente, abaixo de $3 \mathrm{eV}$ e entre 4,5 e $7 \mathrm{eV}$. Na comparação com o espectro da adenina, o padrão de decomposição não é tão rico, ao menos dentro do limite de detecção do arranjo experimental. A captura eletrônica dissociativa dá origem a cinco fragmentos, detectados 

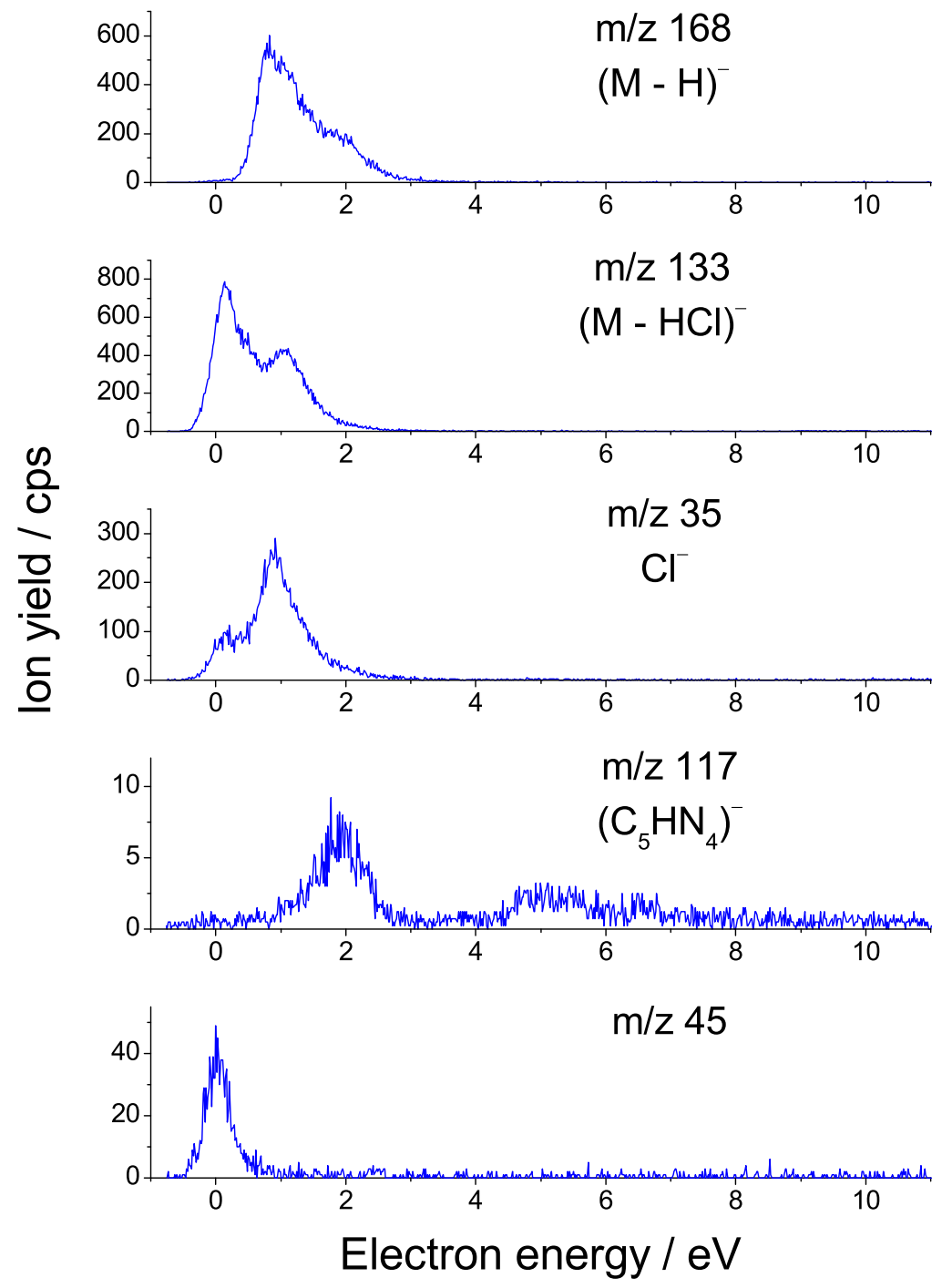

Figura 5.4: Curvas de eficiência para captura eletrônica dissociativa da 2-cloroadenina, resultando em fragmentos com razão carga/massa de $\mathrm{m} / \mathrm{z}=168(\mathrm{M}-\mathrm{H})^{-}, 133(\mathrm{M}-\mathrm{HCl})^{-}$, $35\left(\mathrm{Cl}^{-}\right), 117\left(\mathrm{C}_{5} \mathrm{HN}_{4}^{-}\right)$e 45. Figura adaptada da referência [142].

nas razões carga/massa de 168, 133, 117, 35 e 45. Os primeiros quatro foram atribuídos por estequiometria aos fragmentos $(\mathrm{M}-\mathrm{H})^{-},(\mathrm{M}-\mathrm{HCl})^{-},\left(\mathrm{C}_{5} \mathrm{HN}_{4}\right)^{-}$e $\mathrm{Cl}^{-}$, respectiva- 
Tabela 5.1: Energias necessárias (em eV) para a eliminação de $\mathrm{H}$ (a partir da posição N9), $\mathrm{Cl}^{-}$e $\mathrm{HCl}$. Os valores foram obtidos com cálculos G4(MP2), e são apresentados com a correção de energia vibracional de ponto zero. Entre parênteses estão os valores sem a correção.

\begin{tabular}{lcccc}
\hline \hline & $\mathrm{H}$ & $\mathrm{Cl}^{-}$ & $\mathrm{HCl}$ & $\mathrm{HCl}$ (amina) \\
\hline 2-cloroadenina & $0,67(1,01)$ & $0,27(0,35)$ & $0,18(0,42)$ & $0,87(1,13)$ \\
8-cloroadenina & $0,54(0,89)$ & $0,48(0,57)$ & $0,30(0,55)$ & $1,10(1,41)$ \\
Adenina & $0,90(1,24)$ & & & \\
\hline \hline
\end{tabular}

mente. A estrutura do ânion com razão $\mathrm{m} / \mathrm{z}=45$ não é óbvia para os experimentais.

O fragmento predominante, $(\mathrm{M}-\mathrm{HCl})^{-}$, tem picos em 0,2 e $1,0 \mathrm{eV}$ e é gerado a partir da perda simultânea dos radicais $\mathrm{H}$ e $\mathrm{Cl}$, que se recombinam para formar a molécula neutra $\mathrm{HCl}$, enquanto a carga reside no anel. O segundo ânion de maior intensidade, $(\mathrm{M}-\mathrm{H})^{-}$, é formado a partir da perda do átomo de hidrogênio da posição N9, em acordo com estudos de dissociação de purinas metiladas e deuteradas [143]. O formato das curvas é semelhante à obtida em estudos anteriores para a adenina [144,145], embora a posições dos picos estejam levemente deslocados para menores energias. Isso surge como uma consequência do efeito estabilizador do átomo de cloro que identificamos nos cálculos de espalhamento. Por fim, o fragmento $\mathrm{Cl}^{-}$é observado como uma sobreposição de duas estruturas, centradas em 0,2 e $0,9 \mathrm{eV}$.

Para auxiliar na análise dos mecanismos de dissociação, calculamos as energias requeridas para a eliminação do hidrogênio a partir do grupo imidazol (posição N9), e para a formação de $\mathrm{Cl}^{-}$e $\mathrm{HCl}$ nos isômeros de cloroadenina. Esses cálculos foram realizados no nível G4(MP2) e os resultados estão apresentados na tabela 5.1. O espectro de dissociação da 2-cloroadenina é dominado pela formação dos fragmentos $(\mathrm{M}-\mathrm{H})^{-}, \mathrm{Cl}^{-}$ e $(\mathrm{M}-\mathrm{HCl})^{-}$, e iniciamos a discussão sobre os mecanismos de dissociação responsáveis pelos dois últimos. Para que a ocorra a quebra da ligação $\mathrm{C}-\mathrm{Cl}$, o elétron adicional deve se localizar no orbital anti-ligante $\sigma_{\mathrm{CCl}}^{*}$. Dentro de uma dinâmica local, a largura vertical 
desse ânion $(1,16 \mathrm{eV})$ aponta para um tempo de vida muito curto $(\approx 0,6 f s)$, o que não permitiria uma relaxação vibracional apreciável. Desse modo, a formação direta desse estado não deve fornecer uma rota eficiente para a dissociação. Por outro lado, os estados do ânion $\pi^{*}$ poderiam permitir uma maior relaxação vibracional, dado seu maior tempo de vida. A partir de vibrações que quebrem a simetria da molécula, a ressonância $\sigma_{\mathrm{CCl}}^{*}$ poderia ser acessada numa geometria em que sua energia é mais baixa (e o tempo de vida é maior) do que na geometria de equilíbrio da molécula neutra. O bom acordo entre as posições obtidas do cálculo de espalhamento para as ressonâncias $\pi_{1}^{*}$ e $\pi_{2}^{*}$ e os picos associados à quebra da ligação $\mathrm{C}-\mathrm{Cl}$ sugerem que a dissociação ocorra a partir de um mecanismos indiretos $\pi^{*} / \sigma_{\mathrm{CCl}}^{*}$. A ressonância $\pi_{1}^{*}(0,29 \mathrm{eV})$ responderia pelas estruturas em torno de $0,2 \mathrm{eV}\left(\mathrm{Cl}^{-}\right.$e $\left.(\mathrm{M}-\mathrm{HCl})^{-}\right)$, enquanto que a ressonância $\pi_{2}^{*}(0,73 \mathrm{eV})$ daria origem aos picos situados em $0,9 \mathrm{eV}\left(\mathrm{Cl}^{-}\right)$e $1,0 \mathrm{eV}\left((\mathrm{M}-\mathrm{HCl})^{-}\right)$. Uma vez que esses canais de dissociação são observados apenas abaixo de $\sim 2 \mathrm{eV}$, não esperamos um envolvimento das ressonâncias $\pi_{3}^{*}$ e $\pi_{4}^{*}$, nem das ressonâncias de caroço-excitado que devem existir em maiores energias. A ausência de estruturas na região da ressonância $\pi_{3}^{*}$ pode ser justificada pelo menor grau de sobreposição entre os orbitais $\pi_{3}^{*}$ e $\sigma_{\mathrm{CCl}}^{*}$, o que desfavorece o acoplamento. O estado ligado por dipolo também não deve desempenhar um papel relevante na formação dos ânions $\mathrm{Cl}^{-}$e $(\mathrm{M}-\mathrm{HCl})^{-}$, já que o correspondente orbital ocupado é muito difuso e a sobreposição com o orbital $\sigma_{\mathrm{CCl}}^{*}$ é desprezível. Cálculos G4(MP2) apontam que o threshold para a formação de $\mathrm{Cl}^{-}$é de $0,27 \mathrm{eV}$, o que é compatível com o fato do fragmento ser observado já a partir de $0 \mathrm{eV}$. No canal competidor, o átomo de cloro captura um átomo de hidrogênio e forma a espécie neutra $\mathrm{HCl}$. Segundo os cálculos G4(MP2), tal reação seria endotérmica por apenas 0,18 eV caso o hidrogênio venha da posição N9, e por $0,87 \mathrm{eV}$ se a captura ocorrer no grupo amina. Portanto, a primeira reação deve dar origem ao pico mais intenso em $0,2 \mathrm{eV}$, enquanto a estrutura em 1,0 eV pode a princípio originar de ambas as reações.

Quanto ao canal de eliminação do hidrogênio, a similaridade entre as curvas da 2-cloroadenina e adenina [144-146] sugerem mecanismos de dissociação semelhantes nas duas moléculas. O mecanismo envolvendo o acoplamento do estado ligado por di- 
polo e a ressonância $\sigma_{\mathrm{NH}}^{*}[43,143,146]$ explica o sinal mais intenso da uracila [43] e da adenina [146], e tal mecanismo também deve operar para a 2-cloroadenina. Como já discutido, o elétron incidente é capturado numa ressonância de Feshbach vibracional do estado ligado por dipolo, que então acopla com a ressonância dissociativa $\sigma_{\mathrm{NH}}^{*}$. Podemos estimar suas energias a partir da energia de ligação do estado de dipolo $(-0,031 \mathrm{eV})$, obtida no nível CCSD(T), do threshold para a dissociação $(0,67 \mathrm{eV})$, e da frequência harmônica do estiramento $\mathrm{N}-\mathrm{H}(0,452 \mathrm{eV})$, que é assumida a mesma para o estado de dipolo e para a molécula neutra. A dissociação do nível vibracional $\nu=1(0,42 \mathrm{eV})$ seria proibida energeticamente, mas permitida para o nível $\nu=2(0,87 \mathrm{eV})$. Essa energia está em bom acordo com o pico observado em $0,8 \mathrm{eV}$, o que suporta que ele deva surgir a partir dessa ressonância de Feshbach vibracional. Níveis vibracionais mais altos também podem contribuir em certa medida acima de $\sim 1 \mathrm{eV}$, mas com menor intensidade. Além do acoplamento com ressonâncias $\sigma_{\mathrm{CCl}}^{*}$, os estados $\pi^{*}$ também podem acoplar com a ressonância $\sigma_{\mathrm{NH}}^{*}$ e induzir a quebra da ligação $\mathrm{N}-\mathrm{H}$, gerando assim as estruturas observadas acima de $\sim 1 \mathrm{eV}$. Considerando a estabilização das ressonâncias $\pi_{2}^{*}$ e $\pi_{3}^{*}$ na 2-cloroadenina, as estruturas análogas da curva de dissociação devem se mover de maneira correspondente. De fato, tal efeito é observado, pois os picos surgem em torno de 1 e 1,8 eV (comparados a 1,5 e 2,2 eV na adenina [144]), apesar da menor resolução em energia no experimento da 2-cloroadenina. O ombro em torno de 1,8 eV é claramente distinguível, e é atribuído à ressonância $\pi_{3}^{*}$, enquanto a ressonância $\pi_{2}^{*}$ deve contribuir para a eliminação do hidrogênio em $\sim 1 \mathrm{eV}$. No entanto, não é possível distinguir a relevância da ressonância de Feshbach vibracional $\nu=2$ e do mecanismo $\pi_{2}^{*} / \sigma_{\mathrm{NH}}^{*}$ para a estrutura observada em torno de 0,8 $\mathrm{eV}$.

A ressonância $\pi_{3}^{*}$ deve ser responsável pelo fragmento com $\mathrm{m} / \mathrm{z}=117$ observado em $2 \mathrm{eV}$, enquanto a estrutura em torno de $5 \mathrm{eV}$ deve ter como origem a ressonância $\pi_{4}^{*}$. Esse estado foi identificado em 5,69 eV nos cálculos de espalhamento, mas em vista da superestimativa usual, seu valor real deve se situar na região 4,7-5,2 eV. 


\subsection{8-cloroadenina}

A figura 5.5 mostra as componentes $A^{\prime}$ e $A^{\prime \prime}$ da seção de choque integral da 8-cloroadenina. Há quatro ressonâncias de forma $\pi^{*}$, que surgem na aproximação SE em 2,77, 3,49, 4,6 e 10,0 eV, deslocando-se para 0,35, 1,09, 2,06 e 6,1 eV no cálculo SEP. A simetria $A^{\prime}$ apresenta um pico pronunciado em 4,8 eV na aproximação SE, que se desloca para 2,8 eV no cálculo SEP. Atribuímos esse pico a uma ressonância de forma $\sigma_{\mathrm{CCl}}^{*}$, associada à ocupação pelo elétron incidente no orbital anti-ligante da ligação $\mathrm{C}-\mathrm{Cl}$. Na aproximação SE, essa simetria apresenta ainda um pico em 10 eV e uma estrutura larga na região de $15 \mathrm{eV}$. Apenas uma estrutura em torno de $8 \mathrm{eV}$ pode ser identificada no cálculo SEP, dada a presença de pseudoressonâncias. Não há resultados experimentais a respeito das ressonâncias da 8-cloroadenina. Realizamos ainda cálculos de estado ligado com base compacta, com o intuito de avaliar o caráter dos orbitais ressonantes e prover uma estimativa das posições das ressonâncias. Os quatro orbitais $\pi^{*}$ estão apresentados na figura 5.6, enquanto os dois orbitais de mais baixa energia da simetria $A^{\prime}$, de caráter $\sigma_{\mathrm{CCl}}^{*}$ e $\sigma_{\mathrm{NH}}^{*}$, estão apresentados na figura 5.7. Segundo a relação de escala [116], as ressonâncias $\pi^{*}$ da 8-cloroadenina se localizariam em 0,68, 1,19, 1,98 e 5,14 eV. A ressonância $\pi_{1}^{*}$ estaria 0,3 eV acima do valor obtido do cálculo de espalhamento, enquanto as ressonâncias $\pi_{2}^{*}$ e $\pi_{3}^{*}$ estariam 0,1 eV abaixo, de modo que há uma excelente concordância entre os valores. A maior diferença ocorre para a ressonância de mais alta energia $\pi_{4}^{*}$, onde estaríamos superestimando sua energia em $\sim 1 \mathrm{eV}$, como já seria esperado em vista do caráter desse estado. Quanto à ressonância $\sigma_{\mathrm{CCl}}^{*}$, a relação de escala para esses estados [117] oferece 2,17 eV para sua energia, comparável ao valor obtido do cálculo de espalhamento, de 2,8 $\mathrm{eV}$.

Embora não hajam medidas do espectro de fragmentação da 8-cloroadenina por elétrons de baixa energia, a discussão realizada para a 2-cloroadenina juntamente com a comparação entre os resultados dos cálculos de espalhamento para os dois isômeros podem apontar prováveis canais de dissociação. Uma primeira distinção importante reside no estado ligado por dipolo, que não deve existir na 8-cloroadenina, dado seu momento 


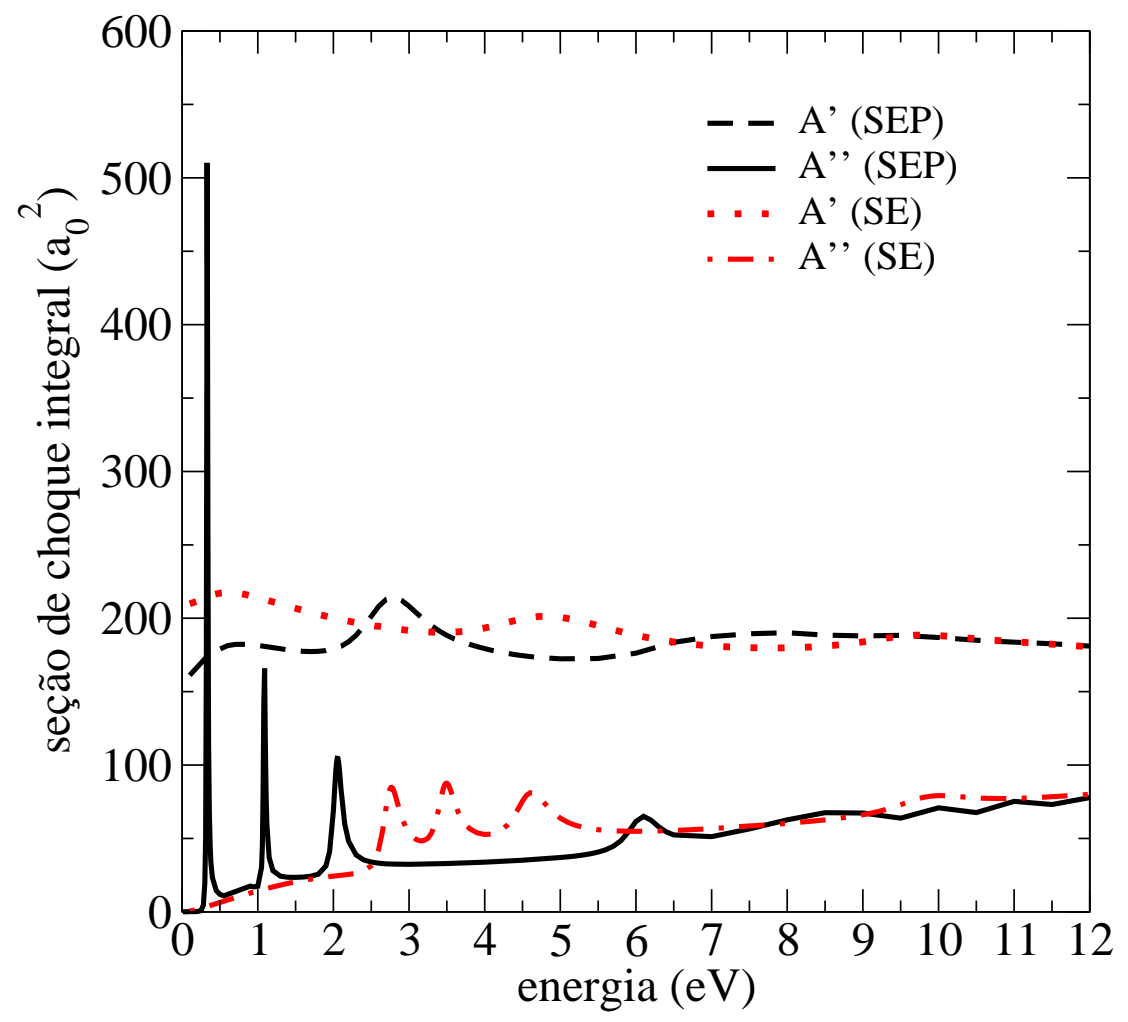

Figura 5.5: Seção de choque integral das simetrias $A^{\prime}$ e $A^{\prime \prime}$ da 8-cloroadenina, calculadas nas aproximações SE e SEP.

de dipolo consideravelmente inferior $(1,16 \mathrm{D})$ ao da 2-cloroadenina $(4,13 \mathrm{D})$, de acordo com o nível de cálculo empregado na otimização da geometria. A ausência de um estado ligado por dipolo deve suprimir o mecanismo de dissociação envolvendo o acoplamento da ressonância de Feshbach vibracional e a ressonância $\sigma_{\mathrm{NH}}^{*}$, e portanto não esperamos o pico mais intenso na eliminação de hidrogênio. Por outro lado, acoplamentos $\pi^{*} / \sigma_{\mathrm{NH}}^{*}$ ainda devem ocorrer e dar origem às estruturas na região $1-3 \mathrm{eV}$. Baseado na sobreposição entre os orbitais $\pi^{*}$ e o orbital $\sigma_{\mathrm{CCl}}^{*}$, a quebra da ligação $\mathrm{C}-\mathrm{Cl}$ deve envolver a formação das ressonâncias $\pi_{1}^{*}$ e $\pi_{3}^{*}$, com a ressonância $\pi_{2}^{*}$ possivelmente contribuindo em menor grau. Por fim, esperamos que o fragmento $\mathrm{HCl}$ seja ainda mais abundante na 8-cloroadenina do que na 2-cloroadenina. Na segunda molécula, a captura do hidrogênio exige um deslocamento razoável do cloro a partir de sua posição original, enquanto na primeira, cloro e hidrogênio já se encontram em posições adjacentes, o que deve facilitar 
a formação de $\mathrm{HCl}$. Esse comportamento já foi observado para os isômeros de clorouracila $[48,125]$, como já discutido. Embora os thresholds para a eliminação de $\mathrm{HCl}$ sejam maiores na 8-cloroadenina em cerca de $\sim 0,1 \mathrm{eV}$, o valor é muito pequeno para modificar as rotas de dissociação apontadas para a 2-cloroadenina. A formação da ressonância $\pi_{1}^{*}$ deve ocasionar a captura do hidrogênio adjacente ao cloro, enquanto que a partir da ressonância $\pi_{2}^{*}$ a captura do hidrogênio do grupo amina também passa a ser energeticamente permitido.

\subsection{Comparação entre adenina e derivados}

Os orbitais ressonantes $\pi^{*}$ da adenina, 2-cloroadenina e 8-cloroadenina estão ilustrados na figura 5.6, enquanto as posições das ressonâncias correspondentes estão apresentadas na tabela 5.2. A presença do cloro pouco altera o perfil dos orbitais, que são muito semelhantes nas três moléculas. O orbital $\pi_{1}^{*}$ é o mais delocalizado, com probabilidades apreciáveis nos dois anéis. O orbital $\pi_{2}^{*}$ se concentra predominantemente no anel de pirimidina, enquanto o $\pi_{3}^{*}$ está mais centrado no anel de imidazol. O grupo pirimidina concentra ainda o orbital de mais alta energia $\pi_{4}^{*}$, que muito se assemelha àquele observado na pirimidina [147].

As ressonâncias $\pi^{*}$ ocorrem sistematicamente em mais baixas energias nas cloroadeninas, em comparação à adenina. Como o cloro possui maior afinidade eletrônica que o hidrogênio substituído da adenina, ele tende a estabilizar os estados aniônicos das cloroadeninas. E quanto maior a densidade de probabilidade do orbital ressonante na vizinhança do cloro, maior será esse efeito estabilizador. Comparado à adenina, a ressonância $\pi_{1}^{*}$ da 2-cloroadenina estabiliza de $0,27 \mathrm{eV}$, enquanto na 8-cloroadenina o desvio é de $0,21 \mathrm{eV}$. O desvio observado da mesma ordem se dá porque em ambas as moléculas o orbital $\pi_{1}^{*}$ passa a contemplar o cloro. A ressonância $\pi_{2}^{*}$ estabiliza em 0,39 eV na 2cloroadenina e em apenas $0,03 \mathrm{eV}$ na 8-cloroadenina, refletindo a participação do cloro no orbital correspondente da primeira molécula e sua ausência na segunda. A situação 


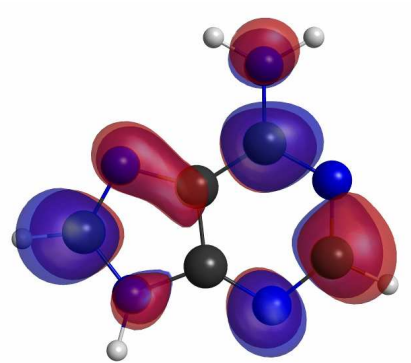

(a) $\pi_{1}^{*}$ da adenina

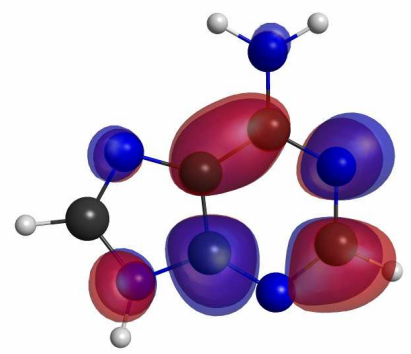

(d) $\pi_{2}^{*}$ da adenina

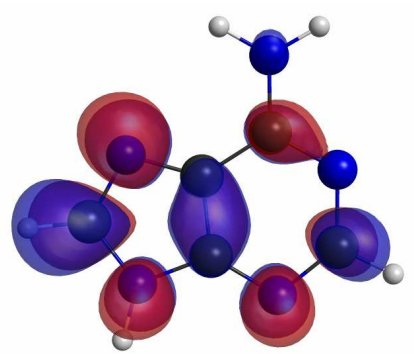

(g) $\pi_{3}^{*}$ da adenina

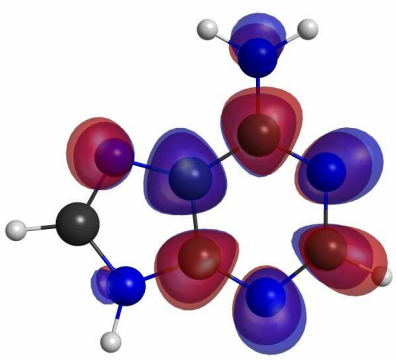

(j) $\pi_{4}^{*}$ da adenina

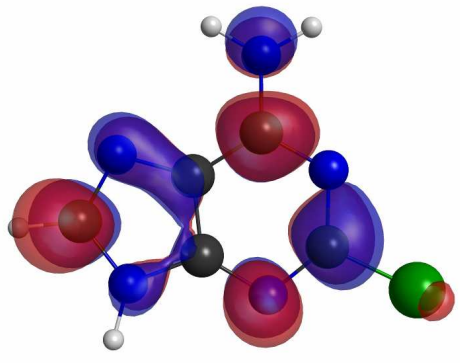

(b) $\pi_{1}^{*}$ da 2-cloroadenina

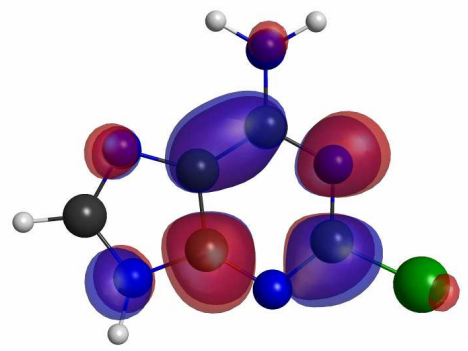

(e) $\pi_{2}^{*}$ da 2-cloroadenina

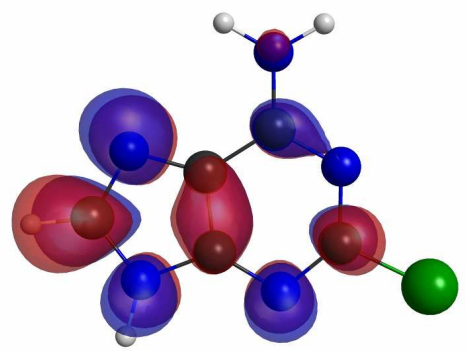

(h) $\pi_{3}^{*}$ da 2-cloroadenina

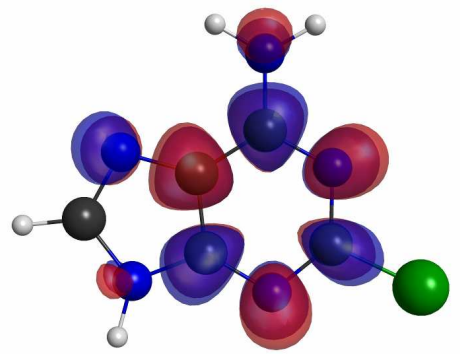

(k) $\pi_{4}^{*}$ da 2-cloroadenina

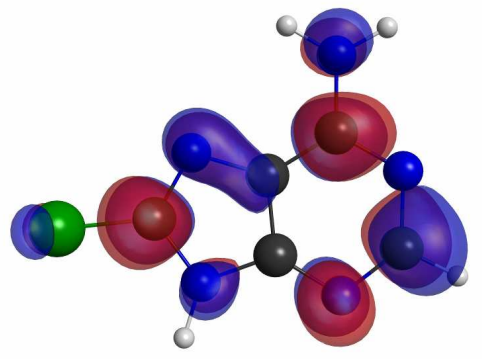

(c) $\pi_{1}^{*}$ da 8-cloroadenina

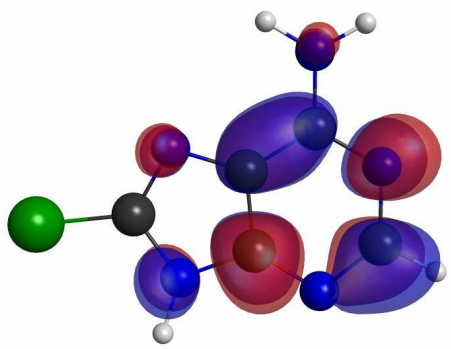

(f) $\pi_{2}^{*}$ da 8-cloroadenina

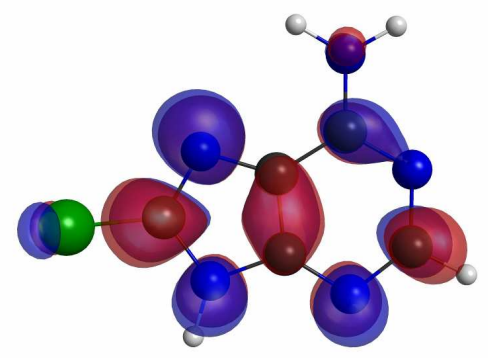

(i) $\pi_{3}^{*}$ da 8-cloroadenina

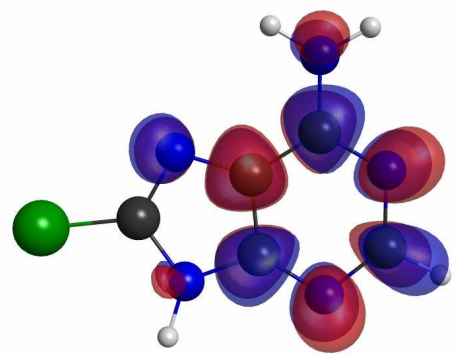

(l) $\pi_{4}^{*}$ da 8-cloroadenina

Figura 5.6: Orbitais $\pi^{*}$ da adenina, 2-cloroadenina e 8-cloroadenina. 
Tabela 5.2: Posições dos estados $\pi^{*}$ e $\sigma_{\mathrm{CCl}}^{*}$ da adenina, 2-cloroadenina e 8-cloroadenina (em unidades de eV).

\begin{tabular}{llllll}
\hline \hline Adenina & $\pi_{1}^{*}$ & $\pi_{2}^{*}$ & $\pi_{3}^{*}$ & $\pi_{4}^{*}$ \\
\hline Nosso resultado & $0,56(0,045)$ & $1,12(0,029)$ & $2,75(0,31)$ & $6,05(0,39)$ & \\
Aflatooni et al. $[122]$ & 0,54 & 1,36 & 2,17 & & \\
Winstead e McKoy [141] & 1,1 & 1,8 & 4,1 & & \\
Dora et al. (SEP) [29] & $1,30(0,14)$ & $2,12(0,09)$ & $3,12(0,28)$ & $7,07(0,24)$ & \\
Dora et al. (u-CC) [29] & $1,58(0,22)$ & $2,44(0,14)$ & $4,38(0,67)$ & $7,94(0,57)$ & \\
Tonzani [26] & $2,4(0,2)$ & $3,2(0,2)$ & $4,4(0,3)$ & $9,0(0,5)$ & $\sigma_{\mathrm{CCl}}^{*}$ \\
\hline \hline 2-cloroadenina & $\pi_{1}^{*}$ & $\pi_{2}^{*}$ & $\pi_{3}^{*}$ & $\pi_{4}^{*}$ & $2,00(1,16)$ \\
\hline Nosso resultado & $0,29(0,0084)$ & $0,73(0,030)$ & $2,55(0,32)$ & $5,69(0,43)$ & 3,86 \\
Relação de escala & 0,61 & 1,12 & 2,01 & 5,04 & $\sigma_{\mathrm{CCl}}^{*}$ \\
\hline \hline 8-cloroadenina & $\pi_{1}^{*}$ & $\pi_{2}^{*}$ & $\pi_{3}^{*}$ & $\pi_{4}^{*}$ & 2,8 \\
\hline Nosso resultado & 0,35 & 1,09 & 2,06 & 6,1 & 2,17 \\
Relação de escala & 0,68 & 1,19 & 1,98 & 5,14 & \\
\hline \hline
\end{tabular}

se inverte para a ressonância $\pi_{3}^{*}$, que desce em $0,20 \mathrm{eV}$ na 2-cloroadenina e em $0,69 \mathrm{eV}$ na 8-cloroadenina, quando comparado às posições da adenina. Por fim, a ressonância $\pi_{4}^{*}$ estabiliza em $0,35 \mathrm{eV}$ na 2-cloroadenina, porém surge $0,05 \mathrm{eV}$ em mais alta energia na 8-cloroadenina. Como tal estado também tem característica de ressonância de caroço excitado, orbitais $\pi^{*}$ de mais baixa energia possuem ocupação não desprezível, o que deve influenciar o comportamento da ressonância $\pi_{4}^{*}$ frente à halogenação da adenina.

O LUMO e o LUMO+1 de simetria $A^{\prime}$ da 2-cloroadenina e 8-cloroadenina estão ilustrados na figura 5.7. Na 2-cloroadenina, o LUMO+1 apresenta caráter $\sigma_{\mathrm{CCl}}^{*}$, e é associado à ressonância $\sigma_{\mathrm{CCl}}^{*}$ encontrada em 3,00 eV. A ressonância correspondente $\sigma_{\mathrm{CCl}}^{*}$ da 8-cloroadenina surge em 2,8 eV, estando associada à ocupação do LUMO da simetria $A^{\prime}$. As cloroadeninas compartilham ainda de um orbital localizado na ligação $\mathrm{N}-\mathrm{H}$, sendo 


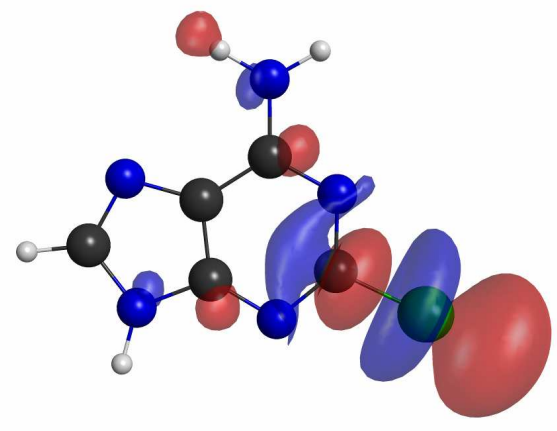

(a) LUMO a da 2-cloroadenina

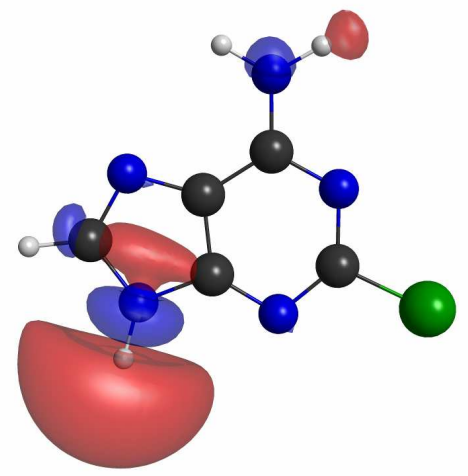

(c) LUMO+1 $a^{\prime}$ da 2-cloroadenina

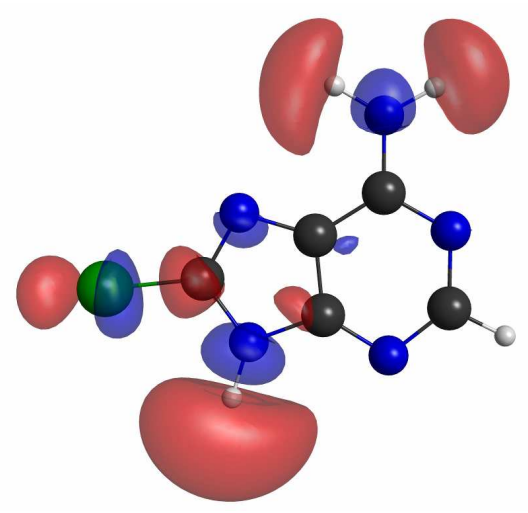

(b) LUMO a da 8-cloroadenina

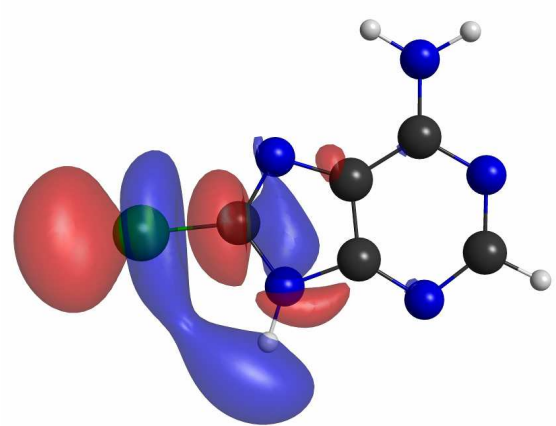

(d) LUMO+1 $a^{\prime}$ da 8-cloroadenina

Figura 5.7: Orbitais $\sigma^{*}$ de mais baixa energia da 2-cloroadenina e 8-cloroadenina.

esse o LUMO na 2-cloroadenina e o LUMO+1 na 8-cloroadenina. Em analogia a outros sistemas que apresentam ligação N-H, como as uracilas e halouracilas, aqui também deve haver uma ressonância $\sigma_{\mathrm{NH}}^{*}$ de baixa energia e de curto tempo de vida, não identificada nos cálculos de espalhamento. Assim como na comparação entre os isômeros de clorouracila, aqui a composição entre os caráteres anti-ligante das ligações $\mathrm{C}-\mathrm{Cl}$ e $\mathrm{N}-\mathrm{H}$ na 8-cloroadenina é responsável pela menor energia em que sua ressonância $\sigma_{\mathrm{CCl}}^{*}$ é encontrada. 


\section{Capítulo 6}

\section{Conclusões}

Foram realizados cálculos de espalhamento elástico de elétrons de baixa energia por uma série de moléculas halogenadas. Para tal empregamos o método multicanal de Schwinger implementado com pseudopotenciais, nas aproximações estático-troca e estático-troca mais polarização. Foram alvo de estudo três grupos de moléculas: pequenas moléculas halogenadas, derivados de uracila e cloroadeninas. No primeiro grupo entram clorometano e cloroeteno, o segundo é composto por uracila, 5-fluorouracila, 5clorouracila, 5-bromouracila, 5-iodouracila, 6-clorouracila e 2-tiouracila, enquanto o terceiro grupo inclui adenina, 2-cloroadenina e 8-cloroadenina. Por meio de uma série de cálculos de espalhamento curvas e superfícies de energias potenciais foram obtidas para alguns sistemas. Para os dois primeiros grupos construímos curvas de energia potencial ao longo da distância $\mathrm{C}-\mathrm{X}$, e para cloroeteno, 5-clorouracila e 5-bromouracila construímos ainda superfícies de energia potencial, considerando como segunda coordenada o ângulo formado quando o átomo de halogênio se movimenta para fora do plano definido pela geometria da molécula. Para o segundo grupo de moléculas, construímos curvas de energia potencial para o ânion adiabático, seguindo o estiramento da ligação $\mathrm{C}-\mathrm{X}$.

A seção de choque integral elástica do clorometano e a posição da ressonância $\sigma_{\mathrm{CCl}}^{*}$ apresentou bom acordo com os resultados experimentais. A formação desse estado 
dá origem à excitação vibracional do estiramento $\mathrm{C}-\mathrm{Cl}$, como pode ser comprovado pelos cálculos de dinâmica do pacote de onda. O pico para a excitação do primeiro nível vibracional concorda com a observação, embora a magnitude da seção de choque esteja um pouco superestimada. Considerando apenas a ativação da coordenada $\mathrm{C}-\mathrm{Cl}$, a proporção calculada entre as seções de choque de excitação dos três primeiros níveis vibracionais apresentou excelente concordância com a observação experimental. Esse resultado indica que o ânion prontamente relaxa por meio do estiramento dessa ligação, e que o acoplamento entre modos vibracionais devem desempenhar um papel pequeno para a excitação desse modo. No cloroeteno duas ressonâncias de forma foram encontradas, de caráter $\pi^{*}$ e $\sigma_{\mathrm{CCl}}^{*}$, em posições próximas das observadas experimentalmente. Cálculos de dinâmica realizados ao longo do estiramento $\mathrm{C}-\mathrm{Cl}$ forneceram seções de choque de dissociação duas ordens de magnitude inferiores aos dados experimentais, o que coloca o mecanismo direto como uma rota muito ineficiente para o processo dissociativo. Fazendo uso de modelos, foram obtidas superfícies de energia potencial diabáticas, bem como os acoplamentos diabáticos. A análise das superfícies aponta que a quebra da ligação $\mathrm{C}-\mathrm{Cl}$ inicia pela formação da ressonância $\pi^{*}$, que relaxa pela combinação do movimento do cloro para fora do plano e pela transferência de carga para o orbital $\sigma_{\mathrm{CCl}}^{*}$, que culmina na dissociação do fragmento $\mathrm{Cl}^{-}$. O modelo contempla ainda a existência de uma interseção cônica complexa nas superfícies adiabáticas.

Há três estados $\pi^{*}$ na uracila e derivados halogenados, que de maneira geral apresentaram posições em ótimo acordo com as medidas experimentais. Para a uracila, em particular, nosso cálculo apresenta a comparação mais favorável dentre os resultados teóricos existentes. O estado de mais baixa energia $\pi_{1}^{*}$ surge como uma ressonância na uracila e 5-fluorouracila e como um estado ligado nos demais sistemas, apresentando energias na faixa $-0,4-0,2 \mathrm{eV}$, enquanto os estados $\pi_{2}^{*}$ e $\pi_{3}^{*}$ são ressonâncias em todas as moléculas, surgindo nas regiões $1,5-1,8 \mathrm{eV}$ e 4,3-5,5 eV, respectivamente. Os dois estados de menor energia são ressonâncias de forma puras, enquanto o estado $\pi_{3}^{*}$ apresenta um caráter misto entre ressonância de forma e de caroço excitado. Identificamos ainda estados de caráter $\sigma_{\mathrm{CX}}^{*}$, onde o elétron é aprisionado num orbital anti-ligante na ligação 
C-X. O estado $\sigma_{\mathrm{CF}}^{*}$ não foi identificado a partir da seção de choque da 5-fluorouracila, devendo apresentar energia relativamente alta e curto tempo de vida. Na 5-clorouracila a ressonância $\sigma_{\mathrm{CCl}}^{*}$ é identificada como um pico bem pronunciado em 1,97 eV, em excelente acordo com a posição experimental de 1,8 eV. A ressonância $\sigma_{\mathrm{CBr}}^{*}$ da 5 -bromouracila está centrada em 0,73 eV, abaixo da posição inferida experimentalmente, de 1,3 eV. Os experimentais haviam sugerido que o sinal mais intenso da ressonância $\pi_{2}^{*}$ dificultaria a detecção desse estado, mas nossos resultados apontam que é a presença do momento de dipolo permanente da molécula que mascara sua assinatura na seção de choque. Por fim, na 5-iodouracila o estado $\sigma_{\mathrm{CI}}^{*}$ se mostra ligado, estando em $-0,1 \mathrm{eV}$ relativo ao estado do neutro. Os estados $\pi^{*}$ da 6-clorouracila tem energias muito próximas das do seu isômero. Por outro lado, o envolvimento da ligação $\mathrm{N}-\mathrm{H}$ para o orbital ressonante estabiliza a ressonância $\sigma_{\mathrm{CCl}}^{*}$, que surge em 1,31 eV. A substituição do oxigênio pelo enxofre introduz uma ressonância de forma $\sigma_{\mathrm{CS}}^{*}$ em $3,2 \mathrm{eV}$ na 2-tiouracila, enquanto os estados $\pi_{1}^{*}$ e especialmente o $\pi_{2}^{*}$ são estabilizados quando comparados aos estados análogos da uracila. As maiores polarizabilidades e comprimentos da ligação $\mathrm{C}-\mathrm{X}$ que acompanham o aumento no número atômico do halogênio provocam a progressiva estabilização dos estados do ânion. Esse efeito é tão mais pronunciado quanto maior a proximidade entre o halogênio e a densidade de probabilidade do elétron adicional. Desse modo, a tendência de estabilização com o aumento do número atômico do halogênio é moderada para os estados $\pi^{*}$ e significativa para os $\sigma_{\mathrm{CX}}^{*}$. Cálculos de estado ligado mostraram que as 5-halouracilas possuem um estado ligado por dipolo, que devem se situar em torno de $-0,1 \mathrm{eV}$.

5-clorouracila, 5-bromouracila e 5-iodouracila apresentaram curvas de energia potencial dos estados do ânion similares. As curvas dos estados $\pi_{1}^{*}$ e $\pi_{2}^{*}$ seguem paralelas àquela do estado neutro, enquanto o estado $\sigma_{\mathrm{CX}}^{*}$ é fortemente estabilizado mediante o estiramento da ligação $\mathrm{C}-\mathrm{X}$. A dinâmica do pacote de onda ao longo dessa coordenada reativa mostrou que as ressonâncias $\sigma_{\mathrm{CCl}}^{*}$ e $\sigma_{\mathrm{CBr}}^{*}$ estabilizam rapidamente através da ejeção do elétron. As seções de choque de dissociação calculadas muito inferiores às observações descartam o mecanismo direto como responsável pela ruptura da ligação. Por outro lado, as superfícies de energia potencial sugerem que a ressonância $\pi_{2}^{*}$ da 5-clorouracila relaxe 
por meio do deslocamento angular e radial do cloro e de uma migração do elétron, do anel para a ligação $\mathrm{C}-\mathrm{Cl}$. Esse mecanismo indireto $\pi_{2}^{*} / \sigma_{\mathrm{CX}}^{*}$ deve dar conta dos fragmentos gerados em $\sim 1,5 \mathrm{eV}$ na série de 5-halouracilas. Um mecanismo envolvendo o acoplamento $\pi_{1}^{*} / \sigma_{\mathrm{CX}}^{*}$ deve explicar os picos observados em $\sim 0 \mathrm{eV}$, embora esse deva ser ativado através de uma reorganização estrutural distinta. A formação do estado de dipolo num nível vibracionalmente excitado pode ocasionar a eliminação do hidrogênio nas duas 5-halouracilas mais leves, embora o mesmo não ocorra nas demais. Possíveis explicações para a supressão desse mecanismo incluem um maior acoplamento $\sigma_{\mathrm{NH}}^{*} / \sigma_{\mathrm{CX}}^{*}$, menores energias de threshold para a eliminação do halogênio e excitações térmicas do modo $\mathrm{C}-\mathrm{X}$ mais favoráveis. Os cálculos de estado ligado para o ânion adiabático revelaram que o halogênio eliminado se aproxima dos hidrogênios ajacente, e no caso da 5-fluorouracila há a formação de HF a partir da captura do hidrogênio ligado ao nitrogênio.

Quatro ressonâncias $\pi^{*}$ foram identificadas na adenina, 2-cloroadenina e 8cloroadenina, sendo as três primeiras caracterizadas como ressonâncias de forma puras, enquanto a de mais alta energia $\pi_{4}^{*}$ como uma ressonância de forma com caráter de ressonância de caroço excitado. Nas cloroadeninas as ressonâncias surgem sistematicamente abaixo do obtido para a adenina, e tal efeito é determinado pela contribuição do cloro para o orbital ressonante. Na 2-cloroadenina as ressonâncias mais afetadas são a $\pi_{1}^{*}$ e a $\pi_{2}^{*}$, enquanto na 8-cloroadenina a estabilização se sobressai nos estados $\pi_{1}^{*}$ e $\pi_{3}^{*}$. As cloroadeninas apresentaram ainda uma ressonância de forma $\sigma_{\mathrm{CCl}}^{*}$, localizada em 3,00 eV na 2-cloroadenina e em 2,8 eV na 8-cloroadenina. Não há resultados experimentais para a energética das ressonâncias das cloroadeninas, e no caso da adenina nossos cálculos apresentam o melhor acordo com as posições experimentais dentre os resultados teóricos existentes. A comparação entre nossos resultados e a medida do espectro de fragmentação da 2-cloroadenina permitiu avaliar os mecanismos de dissociação dominantes. As ressonâncias $\pi_{1}^{*}$ e $\pi_{2}^{*}$ iniciam o processo dissociativo que rompe a ligação $\mathrm{C}-\mathrm{Cl}$, podendo dar origem aos fragmentos $\mathrm{Cl}^{-}$e $\mathrm{HCl}$. O acoplamento da ressonância $\sigma_{\mathrm{NH}}^{*}$ com o estado de dipolo, e em menor grau com as ressonâncias $\pi_{2}^{*}$ e $\pi_{3}^{*}$ responde pela abstração do hidrogênio. 
De maneira geral, nossos resultados apontam que biomoléculas halogenadas são propensas em formar diferentes estados do ânion, que por sua vez relaxam através de variadas rotas de dissociação e respondem pelo rico espectro de fragmentação observado. Particularmente, a introdução do halogênio permite que estados $\pi^{*}$ estabilizem através de acoplamentos com o estado dissociativo $\sigma_{\mathrm{CX}}^{*}$. Além de corroborar a eficiência das 5halouracilas em dissociar mediante captura eletrônica, ainda propomos novos potenciais radiossensibilizadores, a 2-tiouracila e a 2-cloroadenina. A combinação de cálculos de espalhamento e de estado ligado, a construção de superfícies de energia potencial e cálculos de dinâmica vibracional do pacote de onda compõe uma poderosa estratégia na investigação de processos induzidos por captura eletrônica. Tal metodologia deve continuar a ser aplicada e deverá fornecer um entendimento ainda mais preciso da dinâmica desses ânions e de sua atuação em ambientes biológicos. 


\section{Bibliografia}

[1] W. Huo e Y.-K. Kim, IEEE Transactions on Plasma Science 27, 1225 (1999).

[2] M. Wertheimer, A. Fozza, e A. Holländer, Nuclear Instruments and Methods in Physics Research Section B: Beam Interactions with Materials and Atoms 151, 65 (1999).

[3] L. G. Christophorou e J. K. Olthoff, Applied Surface Science 192, 309 (2002).

[4] C. Winstead e V. McKoy, Electron-molecule collisions in low-temperature plasmas: The role of theory, in Fundamentals of Plasma Chemistry, edited by B. Bederson e H. Walther, , Advances In Atomic, Molecular, and Optical Physics Vol. 43, pp. 111 - 145, Academic Press, 2000.

[5] C. Oliveira, J. A. Souza Corrêa, M. P. Gomes, B. N. Sismanoglu, e J. Amorim, Applied Physics Letters 93, 041503 (2008).

[6] M. J. Taherzadeh e K. Karimi, International journal of molecular sciences 9, 1621 (2008).

[7] E. M. de Oliveira, S. d'A Sanchez, M. H. F. Bettega, A. P. P. Natalense, M. A. P. Lima, e M. T. d. N. Varella, Physical Review A 86, 20701 (2012).

[8] R. F. da Costa, M. H. F. Bettega, M. T. d. N. Varella, e M. A. P. Lima, The Journal of chemical physics 132, 124309 (2010). 
[9] E. M. de Oliveira, R. F. da Costa, S. d'A Sanchez, A. P. P. Natalense, M. H. F. Bettega, M. A. P. Lima, e M. T. d. N. Varella, Physical chemistry chemical physics : PCCP 15, 1682 (2013).

[10] B. Boudaïffa, P. Cloutier, D. Hunting, M. A. Huels, e L. Sanche, Science (New York, N.Y.) 287, 1658 (2000).

[11] D. M. Pearl, P. D. Burrow, I. I. Fabrikant, e G. A. Gallup, The Journal of Chemical Physics 102, 2737 (1995).

[12] R. S. Wilde, G. A. Gallup, e I. I. Fabrikant, Journal of Physics B: Atomic, Molecular and Optical Physics 32, 663 (1999).

[13] R. S. Wilde, G. A. Gallup, e I. I. Fabrikant, Journal of Physics B: Atomic, Molecular and Optical Physics 33, 5479 (2000).

[14] G. A. Gallup e I. I. Fabrikant, Physical Review A 83, 012706 (2011).

[15] S. Chourou e A. Orel, Physical Review A 77, 42709 (2008).

[16] M. Tarana, K. Houfek, J. Horáček, e I. I. Fabrikant, Physical Review A 84, 052717 (2011).

[17] D. J. Haxton, C. W. McCurdy, e T. N. Rescigno, Physical Review A 75, 012710 (2007).

[18] D. J. Haxton, T. N. Rescigno, e C. W. McCurdy, Physical Review A 75, 012711 (2007).

[19] T. Rescigno, W. Isaacs, A. Orel, H.-D. Meyer, e C. McCurdy, Physical Review A 65, $32716(2002)$.

[20] Y. Zheng, P. Cloutier, D. J. Hunting, J. R. Wagner, e L. Sanche, Journal of the American Chemical Society 126, 1002 (2004).

[21] H. Abdoul-Carime, S. Gohlke, E. Fischbach, J. Scheike, e E. Illenberger, Chemical Physics Letters 387, 267 (2004). 
[22] L. Sanche, The European Physical Journal D 35, 367 (2005).

[23] E. Alizadeh e L. Sanche, Chemical reviews 112, 5578 (2012).

[24] X. Pan, P. Cloutier, D. Hunting, e L. Sanche, Physical Review Letters 90, 208102 (2003).

[25] F. Martin, P. Burrow, Z. Cai, P. Cloutier, D. Hunting, e L. Sanche, Physical Review Letters 93, 068101 (2004).

[26] S. Tonzani e C. H. Greene, The Journal of chemical physics 124, 054312 (2006).

[27] C. Winstead e V. McKoy, The Journal of chemical physics 125, 074302 (2006).

[28] A. Dora, J. Tennyson, L. Bryjko, e T. van Mourik, The Journal of chemical physics 130, 164307 (2009).

[29] A. Dora, L. Bryjko, T. van Mourik, e J. Tennyson, The Journal of chemical physics 136, 024324 (2012).

[30] I. Baccarelli, F. Sebastianelli, F. A. Gianturco, e N. Sanna, The European Physical Journal D 51, 131 (2008).

[31] J. S. dos Santos, R. F. da Costa, e M. T. d. N. Varella, The Journal of chemical physics 136, 084307 (2012).

[32] C. Winstead, V. McKoy, e S. d'Almeida Sanchez, The Journal of chemical physics 127, 085105 (2007).

[33] C. Winstead e V. McKoy, Physical Review Letters 98, 113201 (2007).

[34] E. M. de Oliveira, M. A. P. Lima, M. H. F. Bettega, S. d'A Sanchez, R. F. da Costa, e M. T. d. N. Varella, The Journal of chemical physics 132, 204301 (2010).

[35] T. C. Freitas, S. d'A. Sanchez, M. T. d. N. Varella, e M. H. F. Bettega, Physical Review A 84, 062714 (2011). 
[36] T. C. Freitas, K. Coutinho, M. T. d. N. Varella, M. A. P. Lima, S. Canuto, e M. H. F. Bettega, The Journal of chemical physics 138, 174307 (2013).

[37] F. Kossoski e M. H. F. Bettega, The Journal of Chemical Physics 138, 234311 (2013).

[38] S. Zamenhof, R. De Giovanni, e S. Greer, Nature 181, 827 (1958).

[39] J. Kopyra, C. Koenig-Lehmann, I. Bald, e E. Illenberger, Angewandte Chemie (International ed. in English) 48, 7904 (2009).

[40] H. Abdoul-Carime, M. A. Huels, E. Illenberger, e L. Sanche, Journal of the American Chemical Society 123, 5354 (2001).

[41] C.-R. Wang e Q.-B. Lu, Journal of the American Chemical Society 132, 14710 (2010).

[42] Z. Li, P. Cloutier, L. Sanche, e J. R. Wagner, The journal of physical chemistry. B 115, 13668 (2011).

[43] A. Scheer, K. Aflatooni, G. Gallup, e P. Burrow, Physical Review Letters 92, 068102 (2004).

[44] S. D. Wetmore, R. J. Boyd, e L. A. Eriksson, Chemical Physics Letters 343, 151 (2001).

[45] X. Li, L. Sanche, e M. D. Sevilla, The Journal of Physical Chemistry A 106, 11248 (2002).

[46] R. Abouaf e H. Dunet, The European Physical Journal D 35, 405 (2005).

[47] H. Abdoul-Carime, M. A. Huels, F. Brüning, E. Illenberger, e L. Sanche, The Journal of Chemical Physics 113, 2517 (2000).

[48] S. Denifl, S. Matejcik, B. Gstir, G. Hanel, M. Probst, P. Scheier, e T. D. Märk, The Journal of Chemical Physics 118, 4107 (2003). 
[49] R. Abouaf, J. Pommier, e H. Dunet, International Journal of Mass Spectrometry 226, 397 (2003).

[50] H. Abdoul-Carime, M. A. Huels, E. Illenberger, e L. Sanche, International Journal of Mass Spectrometry 228, 703 (2003).

[51] S. Denifl, S. Ptasinska, G. Hanel, B. Gstir, M. Probst, P. Scheier, e T. D. Märk, The Journal of chemical physics 120, 6557 (2004).

[52] G. Elion, Science 244, 41 (1989).

[53] L. Chomicz, J. Rak, e P. Storoniak, The journal of physical chemistry. B 116, 5612 (2012).

[54] L. Chomicz, J. Leszczynski, e J. Rak, The journal of physical chemistry. B 117, 8681 (2013).

[55] A. Szabó e N. S. Ostlund, Modern quantum chemistry : introduction to advanced electronic structure theory (Dover Publications, Mineola (N.Y.), 1996), Première édition Macmillan 1982. Edition revue chez McGraw-Hill 1989.

[56] P. Hohenberg e W. Kohn, Phys. Rev. 136, B864 (1964).

[57] W. Kohn e L. J. Sham, Phys. Rev. 140, A1133 (1965).

[58] K. Takatsuka e V. McKoy, Physical Review A 24 (1981).

[59] K. Takatsuka e V. McKoy, Physical Review A 30 (1984).

[60] R. F. da Costa, M. T. d. N. Varella, M. H. F. Bettega, e M. A. P. Lima, The European Physical Journal D 69, 159 (2015).

[61] B. Lippmann e J. Schwinger, Physical Review 79, 469 (1950).

[62] M. Lima e V. McKoy, Physical Review A 38, 501 (1988).

[63] M. Lima, L. Brescansin, e A. da Silva, Physical Review A 41, 327 (1990). 
[64] s. J. Hunt e W. A. Goddard, Chemical Physics Letters 3, 414 (1969).

[65] C. W. Bauschlicher, The Journal of Chemical Physics 72, 880 (1980).

[66] G. B. Bachelet, D. R. Hamann, e M. Schluter, Physical Review B 26, 4199 (1982).

[67] M. Bettega, L. Ferreira, e M. Lima, Physical Review A 47 (1993).

[68] M. H. F. Bettega, A. P. P. Natalense, M. A. P. Lima, e L. G. Ferreira, International Journal of Quantum Chemistry 60, 821 (1996).

[69] K. Takatsuka e V. Mckoy, Physical Review A 30 (1984).

[70] H. Feshbach, Annals of Physics 19, 287 (1962).

[71] A. Hazi, T. Rescigno, e M. Kurilla, Physical Review A 23 (1981).

[72] W. Domcke, Physics Reports 208, 97 (1991).

[73] H. Estrada e W. Domcke, Physical Review A 40, 1262 (1989).

[74] M. Varella e M. Lima, Physical Review A 76, 052701 (2007).

[75] C. W. McCurdy, The Journal of Chemical Physics 78, 6773 (1983).

[76] L. S. Cederbaum e W. Domcke, Journal of Physics B: Atomic and Molecular Physics 14, 4665 (1981).

[77] E. Wigner, Physical Review 73, 1002 (1948).

[78] W. Domcke, M. Berman, H. Estrada, e L. S. Cederbaum, Physical Review A 28 (1983).

[79] D. Kosloff e R. Kosloff, Journal of Computational Physics 52, 35 (1983).

[80] K. Takatsuka e N. Hashimoto, The Journal of Chemical Physics 103, 6057 (1995).

[81] M. Feit, J. Fleck, e A. Steiger, Journal of Computational Physics 47, 412 (1982). 
[82] S. Mahapatra e N. Sathyamurthy, Journal of the Chemical Society, Faraday Transactions 93, 773 (1997).

[83] K. Aflatooni, G. A. Gallup, e P. D. Burrow, The Journal of Physical Chemistry A 104, 7359 (2000).

[84] K. Aflatooni, B. Hitt, G. A. Gallup, e P. D. Burrow, The Journal of Chemical Physics 115, 6489 (2001).

[85] P. D. Burrow, The Journal of Chemical Physics 77, 2699 (1982).

[86] M. Guerra, D. Jones, G. Distefano, F. Scagnolari, e A. Modelli, The Journal of Chemical Physics 94, 484 (1991).

[87] X. Shi, T. M. Stephen, e P. D. Burrow, The Journal of Chemical Physics 96, 4037 (1992).

[88] J. K. Olthoff, J. A. Tossell, e J. H. Moore, The Journal of Chemical Physics 83, 5627 (1985).

[89] K. Stricklett, S. Chu, e P. Burrow, Chemical Physics Letters 131, 279 (1986).

[90] I. I. Fabrikant, Journal of Physics B: Atomic, Molecular and Optical Physics 27, 4325 (1994).

[91] A. M. Krzysztofowicz e C. Szmytkowski, Journal of Physics B: Atomic, Molecular and Optical Physics 28, 1593 (1995).

[92] M. Kimura, O. Sueoka, C. Makochekanwa, H. Kawate, e M. Kawada, The Journal of Chemical Physics 115, 7442 (2001).

[93] X. Shi, V. K. Chan, G. A. Gallup, e P. D. Burrow, The Journal of Chemical Physics 104, 1855 (1996).

[94] M. J. Frisch et al., Gaussian-09 Revision D.01, Gaussian Inc. Wallingford CT 2009. 
[95] P. J. Stephens, F. J. Devlin, C. F. Chabalowski, e M. J. Frisch, The Journal of Physical Chemistry 98, 11623 (1994).

[96] T. H. Dunning, The Journal of Chemical Physics 53, 2823 (1970).

[97] M. S. Gordon e M. W. Schmidt, Advances in electronic structure theory: GAMESS a decade later (Elsevier, Amsterdam, 2005), pp. 1167-1189.

[98] P. Mach, J. Urban, e V. Staemmler, Chemical Physics 356, 164 (2009).

[99] R. F. da Costa, M. H. F. Bettega, M. A. P. Lima, M. C. A. Lopes, L. R. Hargreaves, G. Serna, e M. A. Khakoo, Physical Review A 85, 062706 (2012).

[100] R. F. da Costa, M. H. F. Bettega, M. T. d. N. Varella, E. M. de Oliveira, e M. A. P. Lima, Physical Review A 90, 052707 (2014).

[101] G. Gallup, Journal of Physics B: Atomic, Molecular and Optical Physics 26, 759 (1993).

[102] S. Feuerbacher, T. Sommerfeld, e L. S. Cederbaum, The Journal of Chemical Physics 120, 3201 (2004).

[103] G. A. Worth e L. S. Cederbaum, Annual review of physical chemistry 55, 127 (2004).

[104] A. W. Jasper, C. Zhu, S. Nangia, e D. G. Truhlar, Faraday Discussions 127, 1 (2004).

[105] H. Estrada, L. S. Cederbaum, e W. Domcke, The Journal of Chemical Physics 84, $152(1986)$.

[106] V. Vallet, Z. Lan, S. Mahapatra, A. L. Sobolewski, e W. Domcke, The Journal of chemical physics 123, 144307 (2005).

[107] D. Haxton, T. Rescigno, e C. McCurdy, Physical Review A 72, 022705 (2005). 
[108] F. A. Gianturco e R. R. Lucchese, The Journal of chemical physics 120, 7446 (2004).

[109] S. Yalunin e S. B. Leble, The European Physical Journal Special Topics 144, 115 (2007).

[110] F. Kossoski, M. H. F. Bettega, e M. T. d. N. Varella, The Journal of chemical physics 140, 024317 (2014).

[111] T. Sommerfeld, Chemphyschem: a European journal of chemical physics and physical chemistry 2, 677 (2001).

[112] R. Krishnan, J. S. Binkley, R. Seeger, e J. A. Pople, The Journal of Chemical Physics 72, 650 (1980).

[113] M. N. Glukhovtsev, A. Pross, M. P. McGrath, e L. Radom, The Journal of Chemical Physics 103, 1878 (1995).

[114] F. Kossoski e M. T. d. N. Varella, Phys. Chem. Chem. Phys. 17, 17271 (2015).

[115] J. Kopyra, H. Abdoul-Carime, F. Kossoski, e M. T. d. N. Varella, Physical chemistry chemical physics : PCCP 16, 25054 (2014).

[116] S. W. Staley e J. T. Strnad, The Journal of Chemical Physics 98, 116 (1994).

[117] K. Aflatooni, G. A. Gallup, e P. D. Burrow, The Journal of Physical Chemistry A 104, 7359 (2000).

[118] S. A. Pshenichnyuk, G. A. Gallup, e P. D. Burrow, The journal of physical chemistry. A 111, 11837 (2007).

[119] K. D. Jordan e F. Wang, Annual review of physical chemistry 54, 367 (2003).

[120] P. Skurski, M. Gutowski, e J. Simons, International Journal of Quantum Chemistry 80, 1024 (2000).

[121] C. Winstead e V. McKoy, The Journal of chemical physics 125, 174304 (2006). 
[122] K. Aflatooni, G. Gallup, e P. Burrow, The Journal of Physical Chemistry A 102, 6205 (1998).

[123] F. A. Gianturco, F. Sebastianelli, R. R. Lucchese, I. Baccarelli, e N. Sanna, The Journal of chemical physics 128, 174302 (2008).

[124] C. Winstead e V. McKoy, The Journal of chemical physics 129, 077101 (2008).

[125] S. Denifl, S. Matejcik, S. Ptasinska, B. Gstir, M. Probst, P. Scheier, E. Illenberger, e T. D. Mark, The Journal of chemical physics 120, 704 (2004).

[126] A. Modelli e P. Burrow, The Journal of Physical Chemistry A 108, 5721 (2004).

[127] R. F. da Costa, M. T. d. N. Varella, M. A. P. Lima, e M. H. F. Bettega, The Journal of chemical physics 138, 194306 (2013).

[128] O. Dolgounitcheva, V. G. Zakrzewski, e J. V. Ortiz, The Journal of chemical physics 134, 074305 (2011).

[129] J. Kopyra, S. Freza, H. Abdoul-Carime, M. Marchaj, e P. Skurski, Physical chemistry chemical physics : PCCP 16, 5342 (2014).

[130] I. Nenner, The Journal of Chemical Physics 62, 1747 (1975).

[131] A. S. Barbosa, D. F. Pastega, e M. H. F. Bettega, Physical Review A 88, 022705 (2013).

[132] J. H. Hendricks, The Journal of Chemical Physics 104, 7788 (1996).

[133] J. Schiedt, R. Weinkauf, D. Neumark, e E. Schlag, Chemical Physics 239, 511 (1998).

[134] X. Li, L. Sanche, e M. D. Sevilla, The Journal of Physical Chemistry B 108, 5472 (2004).

[135] L. A. Curtiss, P. C. Redfern, e K. Raghavachari, The Journal of chemical physics 126, 084108 (2007). 
[136] L. A. Curtiss, P. C. Redfern, e K. Raghavachari, The Journal of chemical physics 127, 124105 (2007).

[137] P. D. Burrow e G. A. Gallup, The Journal of chemical physics 125, 154309 (2006).

[138] X. Li, M. D. Sevilla, e L. Sanche, Journal of the American Chemical Society 125, 8916 (2003).

[139] L. Chomicz, A. Furmanchuk, J. Leszczynski, e J. Rak, Physical chemistry chemical physics : PCCP 16, 6568 (2014).

[140] M. Wieczór, P. Wityk, J. Czub, L. Chomicz, e J. Rak, Chemical Physics Letters 595-596, 133 (2014).

[141] C. Winstead e V. McKoy, The Journal of chemical physics 125, 244302 (2006).

[142] F. Kossoski, J. Kopyra, e M. T. d. N. Varella, Physical chemistry chemical physics : PCCP 17, 28958 (2015).

[143] S. Denifl, P. Sulzer, D. Huber, F. Zappa, M. Probst, T. D. Märk, P. Scheier, N. Injan, J. Limtrakul, R. Abouaf, e H. Dunet, Angewandte Chemie (International ed. in English) 46, 5238 (2007).

[144] D. Huber, M. Beikircher, S. Denifl, F. Zappa, S. Matejcik, A. Bacher, V. Grill, T. D. Märk, e P. Scheier, The Journal of chemical physics 125, 084304 (2006).

[145] S. Gohlke, H. Abdoul-Carime, e E. Illenberger, Chemical Physics Letters 380, 595 (2003).

[146] K. Aflatooni, A. M. Scheer, e P. D. Burrow, The Journal of chemical physics 125, 054301 (2006).

[147] A. Modelli e P. D. Burrow, The journal of physical chemistry. A 115, 1100 (2011). 